University of South Florida

DIGITAL COMMONS

Digital Commons @ University of

@ UNIVERSITY OF SOUTH FLORIDA

South Florida

3-2-2012

\title{
Evaluation of Urinary Pesticide Biomarkers Among a Sample of the Population in the United States
}

\author{
Alex Lance Lebeau \\ University of South Florida, alebeau@health.usf.edu
}

Follow this and additional works at: https://digitalcommons.usf.edu/etd

Part of the American Studies Commons, Public Health Commons, and the Toxicology Commons

\section{Scholar Commons Citation}

Lebeau, Alex Lance, "Evaluation of Urinary Pesticide Biomarkers Among a Sample of the Population in the United States" (2012). USF Tampa Graduate Theses and Dissertations.

https://digitalcommons.usf.edu/etd/4123

This Dissertation is brought to you for free and open access by the USF Graduate Theses and Dissertations at Digital Commons @ University of South Florida. It has been accepted for inclusion in USF Tampa Graduate Theses and Dissertations by an authorized administrator of Digital Commons @ University of South Florida. For more information, please contact digitalcommons@usf.edu. 
Evaluation of Urinary Pesticide Biomarkers Among a Sample of the Population in the United States

By

\author{
Alex Lance LeBeau \\ A dissertation submitted in partial fulfillment \\ of the requirements for the degree of \\ Doctor of Philosophy \\ Department of Environmental and Occupational Health \\ College of Public Health \\ University of South Florida \\ Major Professor: Raymond D. Harbison, M.S., Ph.D. \\ James McCluskey, M.D., Ph.D. \\ Steve Morris, M.D., R.N. \\ Debra Price, Ph.D., MSPH \\ Date of Approval: \\ March 02, 2012
}

Keywords: organophosphate, residential, children, background, pyrethroid

Copyright ( 2012, Alex Lance LeBeau 


\section{Acknowledgements}

Support for this project came from the Center for Environmental/Occupational Risk Analysis and Management. All exposure data associated with this study were available from the Centers for Disease Control and Prevention.

Special thanks should be offered to Dr. Raymond Harbison. His wisdom and guidance was instrumental in my academic and professional career. This dissertation would not have been possible without his assistance.

I would like to acknowledgement my doctoral committee members for their help and feedback: Dr. James McCluskey, Dr. Steve Morris and Dr. Debra Price. Additional thanks goes to Dr. Michael Fant for acting as chairperson during the dissertation defense. 


\section{Table of Contents}

List of Tables $\quad$ iv

List of Figures $\quad$ vii

List of Abbreviations and Acronyms $\quad$ ix

$\begin{array}{ll}\text { Abstract } & \text { xiv }\end{array}$

Chapter 1: Introduction 1

Chapter 2: Literature Review $\quad 4$

2.1 Pesticide Use 4

2.2 Regulations

2.3 Exposure Assessment $\quad 7$

2.4 Biomonitoring $\quad 7$

2.5 Pesticide Exposure $\quad 9$

2.5.1 Occupational Exposure 9

2.5.2 Residential Exposure 12

$\begin{array}{ll}2.6 \text { Pesticides } & 14\end{array}$

2.6.1 Organophosphate Insecticide $\quad 14$

2.6.1.1 Organophosphate Health Effects $\quad 15$

2.6.1.1.1 Acute $\quad 15$

2.6.1.1.2 Chronic 18

2.6.1.2 Chlorpyrifos 19

2.6.1.2.1 Toxicokinetics 20

2.6.1.2.1.1 Absorption 20

2.6.1.2.1.2 Distribution 20

2.6.1.2.1.3 Metabolism 21

2.6.1.2.1.4 Elimination $\quad 21$

2.6.1.2.2 Mechanism of Toxicity 22

2.6.1.2.3 Toxicity Assessment 23

2.6.1.2.3.1 Body Weight 23

2.6.1.2.3.2 Neurological 23

2.6.1.2.3.3 Developmental Effects $\quad 25$

2.6.1.3 Methyl Parathion $\quad 26$

2.6.1.3.1 Toxicokinetics $\quad 27$

2.6.1.3.1.1 Absorption 27

2.6.1.3.1.2 Distribution $\quad 27$ 
2.6.1.3.1.3 Metabolism 28

2.6.1.3.1.4 Elimination 28

2.6.1.3.2 Mechanism of Toxicity 28

2.6.1.3.3 Toxicity Assessment 29

2.6.1.3.3.1 Body Weight $\quad 30$

2.6.1.3.3.2 Neurological 30

2.6.1.3.3.3 Developmental Effects 31

2.6.2 Pyrethroids

2.6.2.1 Health Effects 34

2.6.2.1.1 Acute $\quad 34$

2.6.2.1.2 Chronic 34

2.6.2.2 Toxicokinetics $\quad 35$

2.6.2.2.1 Absorption $\quad 35$

2.6.2.2.2 Distribution 36

2.6.2.2.3 Metabolism $\quad 36$

2.6.2.2.4 Elimination $\quad 37$

2.6.2.3 Mechanism of Toxicity 37

2.6.3.3 Toxicity Assessment 38

2.6.3.3.1 Body Weight 38

2.6.3.3.2 Neurological 39

2.6.3.3.3 Developmental Effects $\quad 39$

Chapter 3: Methods $\quad 41$

3.1 Data Source $\quad 41$

3.2 Data Analysis 43

Chapter 4: Results $\quad 47$

4.1 Overall Detection Frequency $\quad 48$

4.2 Correlation of Exposures $\quad 50$

4.3 Organophosphate 52

4.3.1 Chlorpyrifos Biomarker: 3,5,6-Trichlorpyridinol (TCPy) 52

4.3.1.1 Descriptive Statistics 52

4.3.1.2 Comparative Statistics $\quad 55$

4.3.1.3 Logistic Regression 68

4.3.2 Methyl Parathion Biomarker: Paranitrophenol (PNP) 69

4.3.2.1 Descriptive Statistics 69

4.3.2.2 Comparative Statistics 72

4.3.2.3 Logistic Regression $\quad 85$

4.4 Pyrethroid 86

4.4.1 Pyrethroid Biomarker: 3-Phenoxybenzoic Acid (3-PBA) 86

4.4.1.1 Descriptive Statistics 86

4.4.1.2 Comparative Statistics $\quad 89$

4.4.1.3 Logistic Regression 102

4.5 Summary of Mean Biomarker Concentrations 103

$\begin{array}{ll}\text { 4.6 Biochemical Summary } & 105\end{array}$ 
Chapter 5: Discussion

5.1 Evaluation of Research Hypotheses

5.2 Evaluation of Results

113

5.3 Biomarker of Exposure Research

115

5.4 Evaluation of Risk

119

5.5 Limitations of the Research

Chapter 6: Conclusion

References

About the Author

End Page 


\section{List of Tables}

Table 1: $\quad$ Pesticides Included In This Research. $\quad 4$

Table 2: Occupational Exposure Limits. 11

Table 3: Occupational Biological Monitoring Exposure Limits. 12

Table 4: Oral MRLs from the ATSDR. 13

Table 5: Partial List of Pyrethrins and Pyrethroids. 33

Table 6: Detections Among Individuals in the Dataset. 49

Table 7: Evaluation of Multiple Exposures Among Individuals in the Sample. 50

Table 8: Pearson Correlation Matrix. 51

Table 9: Spearman Correlation Matrix. 51

Table 10: Descriptive Statistics for 3,5,6-Trichlorpyridinol. 53

Table 11: Descriptive statistics for Detectable Levels of 3,5,6-Trichlorpyridinol. 54

Table 12: Student's t-test Comparing Geometric Means of Males Versus Females for 3,5,6-Trichlorpyridinol. 56

Table 13: One-Way ANOVA and Tukey Analysis Comparing Geometric Means of Ethnic Groups for 3,5,6-Trichlorpyridinol.

Table 14: One-Way ANOVA and Tukey Analysis Comparing Geometric Means of Age Groups for 3,5,6-Trichlorpyridinol.

Table 15: Student's t-test Comparing Detects Versus Non-Detects for Arithmetic Mean of Height for 3,5,6-Trichlorpyridinol.

Table 16: Student's t-test Comparing Detects Versus Non-Detects for Arithmetic Mean of Weight for 3,5,6-Trichlorpyridinol.

Table 17: 3,5,6-Trichlorpyridinol Female Biochemical t-test Comparisons. 
Table 18: 3,5,6-Trichlorpyridinol Male Biochemical t-test Comparisons. 66

Table 19: 3,5,6-Trichlorpyridinol Overall Biochemical t-test Comparisons. 67

Table 20: Logistic Regression for 3,5,6-Trichlorpyridinol. 68

Table 21: Descriptive Statistics for Paranitrophenol. $\quad 70$

Table 22: Descriptive Statistics for Detectable Levels of Paranitrophenol. 71

Table 23: Student's t-test Comparing Geometric Means of Males Versus Females for Paranitrophenol.

Table 24: One-Way ANOVA and Tukey Analysis Comparing Geometric Means of Ethnic Groups for Paranitrophenol.

Table 25: One-Way ANOVA and Tukey Analysis Comparing Geometric Means of Age Groups for Paranitrophenol.

Table 26: Student's t-test Comparing Detects Versus Non-Detects for Arithmetic Mean of Height for Paranitrophenol.

Table 27: Student's t-test Comparing Detects Versus Non-Detects for Arithmetic Mean of Weight for Paranitrophenol.

Table 28: Paranitrophenol Female Biochemical t-test Comparisons.

Table 29: Paranitrophenol Male Biochemical t-test Comparisons.

Table 30: Paranitrophenol Overall Biochemical t-test Comparisons.

Table 31: Logistic Regression for Paranitrophenol.

Table 32: Descriptive Statistics for 3-Phenoxybenzoic Acid.

Table 33: Descriptive statistics for detectable levels of 3-Phenoxybenzoic Acid.

Table 34: Student's t-test Comparing Geometric Means of Males Versus Females for 3-Phenoxybenzoic Acid.

Table 35: One-Way ANOVA and Tukey Analysis Comparing Geometric Means of Ethnic Groups for 3-Phenoxybenzoic Acid.

Table 36: One-Way ANOVA and Tukey Analysis Comparing Geometric Means of Age Groups for 3-Phenoxybenzoic Acid. 
Table 37: Student's t-test Comparing Detects Versus Non-Detects for Arithmetic Mean of Height for 3-Phenoxybenzoic Acid.

Table 38: Student's t-test Comparing Detects Versus Non-Detects for Arithmetic Mean of Weight for 3-Phenoxybenzoic Acid.

Table 39: 3-Phenoxybenzoic Acid Female Biochemical t-test Comparisons.

Table 40: 3-Phenoxybenzoic Acid Male Biochemical t-test Comparisons.

Table 41: 3-Phenoxybenzoic Acid Overall Biochemical t-test Comparisons.

Table 42: Logistic Regression for 3-Phenoxybenzoic Acid.

Table 43: Summery of Means for All Three Biomarkers.

Table 44: Summary of Results from Epidemiological Biomarker Studies. 


\section{List of Figures}

Figure 1: Pesticide Type By Sector. $\quad 5$

Figure 2: Organophosphate Insecticides Versus Other Insecticides. 15

Figure 3: Chlorpyrifos Metabolism. 22

Figure 4: Methyl Parathion Metabolism. 29

$\begin{array}{ll}\text { Figure 5: } & \text { Permethrin Metabolism. } \\ & 38\end{array}$

Figure 6: Detection Frequency of Urinary Pesticide Biomarkers. 48

Figure 7: Number of Detections Among Individuals. 49

Figure 8: Detection Frequency of Biomarkers Among Individuals. 50

Figure 9: Pearson Correlation of Log-Transformed Biomarker Concentrations in Urine.

Figure 10: Comparison of Means for 3,5,6-Trichlorpyridinol.

Figure 11: Comparison of Detectible Geometric Mean Concentrations for 3,5,6Trichlorpyridinol.

Figure 12: Comparison of Geometric Mean Values of Males Versus Females for 3,5,6-Trichlorpyridinol.

Figure 13: Comparison of Geometric Mean Values of Ethnic Groups for 3,5,6Trichlorpyridinol.

Figure 14: Comparison of Geometric Mean Values of Age Groups for 3,5,6Trichlorpyridinol.

Figure 15: Graph of Arithmetic Mean Height for Detects Versus Non-Detects for 3,5,6-Trichlorpyridinol, Ages 6-11.

Figure 16: Graph of Arithmetic Mean Weight for Detects Versus Non-Detects for 3,5,6-Trichlorpyridinol, Ages 6-11. 
Figure 17: Comparison of Means for Paranitrophenol.

Figure 18: Comparison of Detectible Geometric Mean Concentrations for Paranitrophenol.

Figure 19: Comparison of Geometric Mean Values of Males Versus Females for Paranitrophenol.

Figure 20: Comparison of Geometric Mean Values of Ethnic Groups for Paranitrophenol.

Figure 21: Comparison of Geometric Mean Values of Age Groups for Paranitrophenol.

Figure 22: Graph of Arithmetic Mean Height for Detects Versus Non-Detects for Paranitrophenol, Ages 6-11.

Figure 23: Graph of Arithmetic Mean Weight for Detects Versus Non-Detects for Paranitrophenol, Ages 6-11.

Figure 24: Comparison of Means for 3-Phenoxybenzoic Acid.

Figure 25: Comparison of Detectible Geometric Mean Concentrations for 3Phenoxybenzoic Acid.

Figure 26: Comparison of Geometric Mean Values of Males Versus Females for 3-Phenoxybenzoic Acid.

Figure 27: Comparison of Geometric Mean Values of Ethnic Groups for 3Phenoxybenzoic Acid.

Figure 28: Comparison of Geometric Mean Values of Age Groups for 3Phenoxybenzoic Acid.

Figure 29: Graph of Arithmetic Mean Height for Detects Versus Non-Detects for 3-Phenoxybenzoic Acid, Ages 6-11.

Figure 30: Graph of Arithmetic Mean Height for Detects Versus Non-Detects for 3-Phenoxybenzoic Acid, Ages 6-11.

Figure 31: Overall Cholesterol Levels Across All Three Biomarkers.

Figure 32: Overall Sodium Levels Across All Three Biomarkers.

Figure 33: Female Cholesterol Levels Across All Three Biomarkers. 


\section{List of Abbreviations and Acronyms}

3,5,6-Trichloropyridinol

TCPy

3-Phenoxybenzoic Acid

3-PBA

Acetylcholinesterase

AChE

Agency for Toxic Substances and Disease Registry

ATSDR

Alanine Aminotransferase

ALT

Alkaline Phosphatase

Alk Phos

American Conference of Governmental Industrial Hygienists

ACGIH

Arithmetic Mean

$\mathrm{AM}$

Aspartate Aminotransferase

AST

ATSDR Minimal Risk Level

MRL

Attention Deficit Hyperactivity Disorder

ADHD

Benchmark Dose

BMD

Biological Exposure Indices

BEI

Biomarker of Exposure

BOE

Blood Urea Nitrogen

BUN

Butylcholinesterase

BuChE

Center for the Health Assessment of Mothers and Children of Salinas

CHAMACOS 
Centers for Disease Control and Prevention

Centimeter

$\mathrm{cm}$

Central nervous System

CNS

Chemical Abstract Service

CAS

Creatinine-Adjusted Arithmetic Mean

CAAM

Creatinine-Adjusted Geometric Mean

CAGM

Creatinine-Adjusted Mean

CAM

Cumulative Risk Assessment

CRA

Cytochrome P-450

CYP

Diethylphosphate

DEP

Diethylthiophosphate

DETP

Environmental Protection Agency

EPA

Federal Environmental Pesticide Control Act

FEPCA

Federal Food, Drug and Cosmetic Act

FFDCA

Federal Insecticide, Fungicide and Rodenticide Act

FIFRA

Food Additives Amendment

FAA

Food and Drug Administration

FDA

Food Quality Protection Act

FQPA

Gamma-Glutamyl Transferase

GGT

Geometric Mean

GM

Gram per Deciliter

$\mathrm{g} / \mathrm{dL}$ 
Gram per Liter

$\mathrm{g} / \mathrm{L}$

Integrated Pest Management

IPM

Integrated Risk Information System

IRIS

Intermediate Syndrome

IS

Kilogram

$\mathrm{kg}$

Lactate Dehydrogenase

$\mathrm{LDH}$

Limit of Detection

LOD

Lower Confidence Limit

LCL

Margin of Exposure

MOE

Methyl Parathion

MP

Microgram per Gram

$\mu \mathrm{g} / \mathrm{g}$

Microgram per Liter

$\mu \mathrm{g} / \mathrm{L}$

Microgram per Kilogram

$\mu \mathrm{g} / \mathrm{kg}$

Microgram per Kilogram per Day

$\mu g / \mathrm{kg} /$ day

Milligram per Deciliter

$\mathrm{mg} / \mathrm{dL}$

Milligram per Kilogram per Day

$\mathrm{mg} / \mathrm{kg} /$ day

Milligram per Cubic Meter

$\mathrm{mg} / \mathrm{m}^{3}$

Millimole per Kilogram

$\mathrm{mmol} / \mathrm{Kg}$

Millimole per Liter

$\mathrm{mmol} / \mathrm{L}$

Minimal Risk Level

MRL 
Mobile Examination Center

National Health and Nutritional Examination Survey

NHANES

National Institute for Occupational Safety and Health

NIOSH

National Research Council

NRC

Neuropathy Target Enzyme

NTE

Not Available

NA

Number

$\mathrm{n}$

Occupational Exposure Limit

OEL

Occupational Safety and Health Administration

OSHA

Odds Ratio

OR

One-Way Analysis of Variance

ANOVA

Organophosphate

OP

Organophosphate-Induced Delayed Neuropathy

OPIDN

Paranitrophenol

PNP

Paraoxonase

PON1

Part per Million

PPM

Peripheral Nervous System

PNS

Permissible Exposure Limit

PEL

Point of Departure

POD

Primary Sampling Unit

PSU

Recommended Exposure Limit

REL 
Unit Per Liter

$\mathrm{U} / \mathrm{L}$

Upper Confidence Limit

UCL 


\begin{abstract}
Pesticide use in the United States continues to attract negative public attention. In recent years, this attention has focused on the effects that chronic, low-level pesticides may have, especially on children and various sub-populations. Over the past decade, studies have attempted to correlate negative health effects with detections of pesticide biomarkers in biological media. The current research investigates biomarker of exposure levels in a sample of the United States population. Data from the 2001-2002 NHANES dataset $(n=11,039)$ was evaluated. The detection frequency of urinary biomarkers of exposure and the geometric mean from the NHANES pesticide dataset $(n=3,152)$ were determined. Of the 18 specific pesticide biomarkers, three were detected in more than $50 \%$ of the sample: $79 \%$ had a detectable level of 3,5,6-trichloropyridinol, a biomarker of chlorpyrifos, with a geometric mean of $2.07 \mu \mathrm{g} / \mathrm{L}$ (C.I: $1.98-2.17)$; 53\% had a detectable level of paranitrophenol, a biomarker of methyl parathion, with a geometric mean of $0.367 \mu \mathrm{g} / \mathrm{L}$ (C.I.: 0.346-0.389); and 77\% had a detectable level of 3-phenoxybenzoic acid, a biomarker of permethrin, with a geometric mean of $0.336 \mu$ g/L (C.I.: 0.3200.352). These levels fall within the range of other epidemiological and biomonitoring studies investigating background levels of biomarkers in the general population. The association between the detection of a biomarker and variations in mean height and weight of children aged 6-11 was evaluated. No significant results were found when evaluating these differences for 3,5,6-trichloropyridinol exposure. Paranitrophenol
\end{abstract}


associated with shorter children at age 8 [Non-Detect=134.3 cm and Detect: $130.9 \mathrm{~cm}$ $(\mathrm{p}=0.046)]$ and taller children at age 11 [Detect=153.7 $\mathrm{cm}$ and Non-Detect=149.9 cm $(\mathrm{p}=0.022)]$. Heavier children associated with 3-Phenoxybenzoic Acid at age 7: [Detect $=28.61 \mathrm{~kg}$ and Non-Detect $=25.26 \mathrm{~kg}(\mathrm{p}=0.009)]$. Clinical chemistry biochemical concentration comparisons were made between individuals that had a detectable level of the biomarker in urine and those that did not. Two biochemicals had a significant difference across all three biomarkers: cholesterol and sodium. The biochemical levels with significant difference between detects and non-detects for the biomarkers were not elevated above clinical reference values. Overall, there is insufficient evidence to suggest a relationship between background pesticide exposures in this sample and negative health effects. 


\section{Chapter 1}

\section{Introduction}

Public health concerns surrounding the use of pesticides have been a major focus of the United States Environmental Protection Agency (EPA) and the United States Food and Drug Administration (FDA) for decades. Research conducted around World War II led to the refinement and discovery of new, inexpensive and effective pesticide products $[1,2]$. These new discoveries began to replace the inorganic substances (copper acetoarsenite, sodium chlorate, sulfur) that had been used previously [1, 2]. Consumers in the 1950's did not appear to be concerned with any potential hazards these new pesticides may pose, and consumers in the 1960's were more concerned with the impact that pesticide use had on wildlife than the impact that pesticides had on farmers [2, 3]. This emerging concern originated from the publication of Rachel Carson's Silent Spring in 1962 which highlighted the potential environmental dangers of pesticides [1, 2, 3]. Public concern now became focused on the possible detrimental effects pesticide use was having on the environment. While the quality of the research and the conclusions reached in Silent Spring have been called into question, the work has been credited with the initiation of the modern environmental movement $[4,5]$.

Public concern over pesticide use was, in part, responsible for the focus on regulating the use and application of pesticides in the United States. The potential 
deleterious effects that pesticides may have on the environment, and on members of the population, spawned a new effort to regulate their use [6-12].

Regulatory agencies began to conduct research into potential exposures to pesticides and determine what might be considered safe exposure levels (i.e., no appreciable increased risk of a deleterious effect). While decades of research have established putative mechanisms for deleterious effects associated with acute, high-level exposures, very little evidence exists to support effects from chronic, low-level exposures. Studies in recent years have attempted to characterize the contribution of chronic, low-level pesticide exposures to birth defects, most notably neurological, behavioral and birth outcomes. The research conducted in the current study will utilize urinary biomarker data gathered during a National Health and Nutrition Examination Survey (NHANES) national sampling event to determine if chronic, low-level exposure to pesticides can be associated with an increased risk of adverse health outcomes. 
The objectives of the current study are as follows:

- Characterize low-level exposures in a sample of the general population of the United States.

- Determine mean concentrations of biomarkers of exposure levels in the sample and compare those levels to determine if any subgroup is at an increased risk of a toxicological outcome.

- Examine the feasibility of establishing a biomarker of exposure threshold level based on the concentration of urinary biomarkers of exposure.

This study will attempt to test the following hypotheses:

1. Biomonitoring data obtained from NHANES indicate the presence of background biomarkers of exposure in individuals from a sample of the general population.

2. Mean concentrations of biomarkers of exposure are homogeneous across the various subgroups of the sample, indicating that no one subgroup is at an increased risk of an adverse health outcome.

3. Urine sample data from NHANES reveal that biomarker of exposure levels in the sample are not correlated with an increased risk of a negative health outcome. 


\section{Chapter 2}

\section{Literature Review}

Pesticides encompass a large group of chemicals that are used for preventing, destroying, repelling or mitigating pests [13]. This category includes, but is not limited to, insecticides, fungicides, herbicides and rodenticides [14]. A variety of products are available for eliminating or mitigating pests in both residential and agricultural settings. For the purposes of this dissertation, the pesticides being evaluated are listed in Table 1.

Table 1: Pesticides Included In This Research.

\begin{tabular}{|c|c|}
\hline Parent Compound & Pesticide Type \\
\hline Chlorpyrifos & Organophosphate Insecticide \\
\hline Methyl Parathion & Organophosphate Insecticide \\
\hline Permethrin & Pyrethroid Insecticide \\
\hline
\end{tabular}

\subsection{Pesticide Use}

On a global scale, approximately \$39 billion dollars were spent on pesticides in 2007, with $\$ 12.5$ billion dollars spent in the Unites States (US) alone [15]. This equates to the use of 5.2 billion pounds of pesticide's active ingredients globally, with 1.1 billion

pounds used in the US (Figure 1) [15]. These active ingredients are used to create the more than 20,000 EPA registered pesticides currently available in the US [16]. 


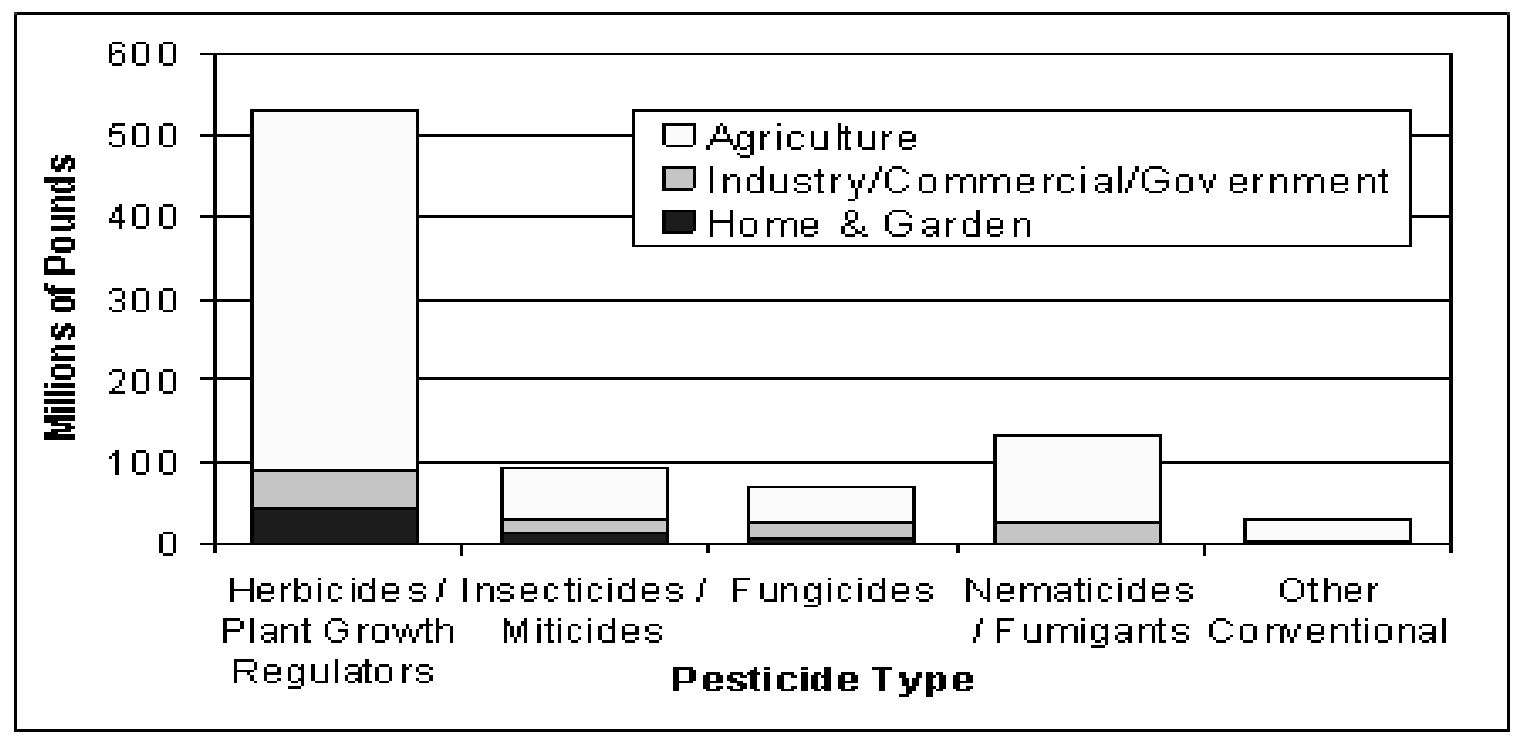

Figure 1: Pesticide Type By Sector. This breakdown from the EPA 2007 market estimate indicates that agricultural applications of herbicides dominate the market. Figure from the EPA [14].

\subsection{Regulations}

Federal regulations have been established by the federal government in an attempt to make the use and application of pesticide products safe for the end user. The first federal pesticide legislation in the US was the Insecticide Act of 1910 [13]. This Act set standards to protect consumers from misbranded or impure pesticides $[17,18,19]$. The Federal Food, Drug and Cosmetic Act (FFDCA) of 1938 allowed for the establishment of regulatory limits for pesticide residues in food [19]. The Federal Insecticide, Fungicide and Rodenticide Act (FIFRA) of 1947 required all pesticides being sold interstate or to foreign entities to be registered with the US Department of Agriculture [18]. It also required the identification labels on containers to carry information about the manufacturer of the pesticide, the ingredients, directions for use and a protective warning statement [18]. FIFRA was amended in 1959 and 1964 to include additional pesticides. In addition, the 1964 amendment gave authority to the Secretary of Agriculture to refuse 
registration of a new pesticide or cancel an existing registration if the pesticide was thought to pose a hazard $[17,18]$.

The 1954 Miller Amendment to the FFDCA established pesticide residue tolerances and required the seizure of raw agricultural commodities if they contained residues above established tolerance levels [18, 19]. The Delaney Clause, part of the Food Additives Amendment (FAA) of 1958, prohibited the use of a food additive if it was shown to be carcinogenic in humans or laboratory animals $[18,19,20]$. The responsibility of the amended FIFRA was transferred to the EPA at the agency's inception in 1970 [21]. This transfer of power was a paradigm shift from creating safe user conditions in agricultural settings to reducing risk from pesticides in the general population and the environment [22]. FIFRA was amended in 1972 with the passage of the Federal Environmental Pesticide Control Act (FEPCA) [21-23].

The FEPCA required all pesticides to be registered with the EPA and required the pesticide to be classified as general use or restricted use [22]. Under this Act, certification was now necessary for those applying restricted use pesticides and pesticides would now only be registered if they could be demonstrated to not cause unreasonable harm to the environment [22]. In 1996, the FFDCA was amended with the Food Quality Protection Act (FQPA). The FQPA called for the review of all current maximum residue levels of pesticides on food and added the requirement that infants and children must now receive additional protection and focus [24]. The Act also called for an aggregate and cumulative risk assessment for non-occupational exposures to pesticides [24]. 


\subsection{Exposure Assessment}

Exposure is the opportunity to contact a substance and absorb a dose [14]. Exposure assessment determines the chemical encountered, the route of exposure, and the magnitude, frequency and duration of the exposure [24]. Assessment methods vary based upon the type of exposure. Occupational exposure evaluations consist of sampling the air surrounding the breathing zone, skin wipe samples or ambient air monitoring to determine an exposure level [25]. In occupational settings, a more sensitive and specific metric for establishing an exposure is to conduct biomonitoring as part of a workplace medical surveillance program [26].

\subsection{Biomonitoring}

Biomonitoring is the sampling of biological media (blood, urine, tissue, breast milk) for any chemical that may have been absorbed into the body during an exposure [27-32]. History points to the use of biomonitoring for the evaluation of workplace exposures in the 1920's and 1940's with the examination of blood for the presence of lead as well as examining mercury levels in urine [32]. In 1987, the National Research Council (NRC) established three distinct categories for biological markers to be used for the evaluation of an exposure: biomarkers of exposure, biomarkers of effect and biomarkers of susceptibility [28, 31, 32]. Biomarkers of exposure are detectable levels of a parent chemical compound, intermediate biomarker or conjugate in body tissue or biological fluids [29, 32, 33]. Biomarkers of effect are changes in clinical chemistry levels or other biochemical levels that can quantitatively or qualitatively predict an adverse health outcome or an impairment from an exposure [28]. Biomarkers of effect 
are used to determine early biological or physiological alterations caused by an exposure to a chemical or substance [32]. Alteration in biochemical enzymes or formation of deoxyribonucleic acid (DNA) adducts due to an exposure would be considered biomarkers of effect. Lastly, biomarkers of susceptibility indicate how an exposure might have an effect based on certain metabolic characteristics of an individual or a population [28, 31].

Biomonitoring provides a measurement of exposure from all routes [30, 32]. Detection of biomarkers in biological media can be influenced by the half-life of a chemical in vivo, physical characteristics of the chemical itself and the detection limit of the biomarker in body tissues and fluids by the laboratory conducting the analysis [26, 30, 34]. In order to properly evaluate biomonitoring data, the toxicokinetics of the chemical must be understood [35].

Biomonitoring can be used in the workplace. Occupational biomonitoring is commonly a step in an overall health surveillance program [36]. The program begins with a base-line evaluation that is followed by periodic monitoring to determine if there are any exceedances of established threshold limits [36]. While biomonitoring programs in occupational settings have become more commonplace in recent years, and more accurate due to advances in detection, biomonitoring can also be utilized for establishing exposure in the general population [29]. 
Population-based studies utilizing biomarker levels in biological samples have attempted to evaluate exposure and to identify any public health trends in order to determine if public health control measures have been effective [32]. Large population based studies evaluating pesticide exposures include: The German Environmental Study (GerES); The Center for the Health Assessment of Mothers and Children of Salinas (CHAMACOS); The National Health and Nutrition Examination Survey (NHANES); the Netherlands Generation R study; and the Children’s Pesticide Exposure Survey (CPES) of Washington State and Georgia [37-41]. Smaller, localized studies on pesticide exposures have also been conducted.

\subsection{Pesticide Exposures}

\subsubsection{Occupational Exposure}

Agricultural workers, exterminators and pesticide manufacturing employees encounter high exposures to pesticides due to their trade and, thus, are at the highest risk for a biologically significant pesticide overexposure in the workplace [42-44]. It is estimated that approximately 2-2.5 million workers come in contact with pesticides annually as a result of their employment $[45,46]$. Dermal contact and inhalation are the primary routes of exposure in occupational settings [47]. The National Institute for Occupational Safety and Health (NIOSH) Sentinel Event Notification System for Occupational Risk (SENSOR) program monitors occupational illnesses and injury in participating states [44, 48]. SENSOR data analyzed by Calvert (2008) indicated that, between 1998 and 2005, approximately 3,200 acute occupationally exposed pesticide related illnesses were reported in 10 states [42]. Other identified estimates vary on the 
actual number of annual occupational exposures to pesticides. Geer et al. (2004) reported EPA estimates in 1992 that suggested 10,000-20,000 acute occupational excessive exposures occur annually [49]. Occupational excessive exposures may vary depending on a number of factors: The type of pesticide used, the amount used, the route of exposure and the frequency and duration of the exposure to the pesticide $[42,43,50]$. Additional factors when evaluating an occupational exposure to pesticides include: the proper use of personal protective equipment (PPE), proper application of the product, proper training for use, accidental spillage, soiled clothing and the concentration of the pesticide in solution, among others [43, 50, 51].

Occupational exposure threshold limits have been established to protect the health of workers [52]. These limits attempt to protect the worker in exposure situations. Regulatory occupational exposure limits (OELs) are enforceable by law whereas authoritative OELs are suggestions by credible organizations [52]. It is important to note that these regulations are intended to protect worker health. They do not, however, predict whether or not an adverse health outcome will occur if an exposure exceeds the threshold value [14]. Additionally, occupational pesticide exposures are augmented by the EPA Worker Protection Standard, which adds additional margins of safety for employees from occupational exposures to agricultural pesticides [45].

The Occupational Safety and Health Administration (OSHA) publishes regulatory, enforceable Permissible Exposure Limits (PELs) in order to protect worker's health [53]. NIOSH is responsible for the non-regulatory Recommended Exposure 
Limits (RELs) [54]. The American Conference of Governmental Industrial Hygienists (ACGIH) publishes both the non-regulatory Threshold Limit Values (TLVs) and Biological Exposure Indices (BEIs), which can be used in conjunction with each other [55]. Not all chemicals have an established BEI. Exposures below the TLV are not expected to result in exceedances of established BEIs. The regulatory and authoritative OELs for the pesticides covered in this research are listed in Tables 2 and 3.

Table 2: Occupational Exposure Limits.

\begin{tabular}{|c|c|c|c|c|c|}
\hline \multirow{2}{*}{ Pesticide } & \multicolumn{2}{|c|}{ PEL $^{\mathrm{a}}\left(\mathrm{mg} / \mathrm{m}^{3}\right)^{\mathrm{b}}$} & \multicolumn{2}{c|}{$\mathrm{REL}^{\mathrm{c}}\left(\mathrm{mg} / \mathrm{m}^{3}\right)$} & $\begin{array}{c}\mathrm{TLV}^{\mathrm{d}} \\
\left(\mathrm{mg} / \mathrm{m}^{3}\right)\end{array}$ \\
\cline { 2 - 6 } & TWA $^{\mathrm{e}}$ & STEL $^{\mathrm{f}}$ & TWA & STEL & TWA \\
\hline Chlorpyrifos & None & None & 0.2 & $\begin{array}{c}0.6 \\
\text { (skin) }\end{array}$ & 0.1 \\
\hline Methyl Parathion & None & None & 0.2 (skin) & None & 0.02 \\
\hline Permethrin & $\begin{array}{c}5.0 \\
\text { (pyrethrum) }\end{array}$ & None & $\begin{array}{c}5.0 \\
\text { (pyrethrum) }\end{array}$ & None & $\begin{array}{c}5.0 \\
\text { (pyrethrum) }\end{array}$ \\
\hline
\end{tabular}

${ }^{a}\left(\right.$ PEL) $=$ Permissible Exposure Limit, enforceable by OSHA; ${ }^{b}\left(\mathrm{mg} / \mathrm{m}^{3}\right)$ Milligrams per Cubic Meter; ${ }^{\mathrm{C}}(\mathrm{REL})=$ Recommended Exposure Limit, published by NIOSH; ${ }^{\mathrm{d}}(\mathrm{TLV})=$ Threshold Limit Value, published by ACGIH; ${ }^{\mathrm{e}}$ (TWA) = Time Weighted Average, Based on an 8-Hour Work Day, 40 Hours a Week; ${ }^{\mathrm{f}}(\mathrm{STEL})=$ Short-Term Exposure Limit, Based on a maximum 15 Minute Exposure Average. [53-55]

To establish exposure status, occupational exposure assessments can use either direct sampling methods or modeling [52]. As part of a medical surveillance program, biomonitoring can aid in determining an exposure and identifying trends. This includes establishment of a baseline biomarker of exposure (BOE) level and annual or periodic monitoring of biomarkers in conjunction with a physical examination [36]. 
Table 3: Occupational Biological Monitoring Exposure Limits.

\begin{tabular}{|c|c|}
\hline Parent & Biological Exposure Indices (BEI) \\
\hline Chlorpyrifos & $70 \% \mathrm{AChE}^{\mathrm{a}}$ of Baseline \\
\hline \multirow{2}{*}{ Methyl Parathion } & $70 \% \mathrm{AChE}$ of Baseline; \\
& $0.5 \mathrm{mg} / \mathrm{g}^{\mathrm{b}}$ for Parathion \\
\hline Permethrin & None \\
\hline
\end{tabular}

${ }^{a}(\mathrm{AChE})=$ Acetylcholinesterase; ${ }^{\mathrm{b}}(\mathrm{mg} / \mathrm{g})$ Milligrams per Gram. ACGIH BEI [55].

\subsubsection{Residential Exposure}

Individuals that are exposed to pesticides outside of an occupational setting are considered general population exposures. Exposures in the general population can be secondary and are generally orders of magnitude lower than occupational exposures [56]. In 2007, domestic use of pesticides accounted for 8 percent of the total conventional pesticides used in the United States [15]. Widespread pesticide use in the United States has equated to 94,000 reported pesticide exposures in 2008, according to the American Association of Poison Control Centers' National Poison Data System's $26^{\text {th }}$ annual report [57]. This value indicates the number of individuals in the population with suspected pesticide exposures. Public concern has, in part, driven the interest relating to regulation and mitigation of public and environmental contact with these substances [6, 7, 11].

Residential exposures occur through a variety of sources: handling and application of pesticides in home and garden settings; residues remaining on surfaces in the home following residential application of pesticide products; food and drinking water that contain pesticide residues; and aerosol drift and take-home exposure from either pesticide applications in close proximity to the home or from family members transporting residues home on soiled or contaminated clothing [50, 56, 58-63]. It has 
been suggested that ingestion of food products containing pesticides is the primary route of exposure for the general population [64-67].

The FQPA of 1996 called for the safety evaluation of pesticides based on all routes of exposure from non-occupational sources [68, 69]. Additionally, the EPA is required to address the risks pesticides may pose to infants and children. This act also required the re-assessment of pesticide tolerance levels in food products. Based on the FQPA and the National Academy of Science, the EPA established maximum residue levels on food products that vary by commodity [70]. As an additional evaluation of risk, the Agency for Toxic Substances and Disease Registry (ATSDR) has established Minimal Risk Levels (MRL). The MRL (Table 4) is an estimate of the acceptable daily exposure that is likely to be without an increased appreciable, non-cancer risk [71]. The ATSDR MRL was established to evaluate exposures and potential health effects at hazardous waste sites, but can also be used as an evaluation/screening tool for exposures in the general population [71].

Table 4: Oral MRLs from the ATSDR.

\begin{tabular}{|c|c|c|c|}
\hline Parent & Acute & Intermediate & Chronic \\
\hline Chlorpyrifos & $0.003 \mathrm{mg} / \mathrm{kg} / \mathrm{day}^{\mathrm{a}}$ & $0.003 \mathrm{mg} / \mathrm{kg} /$ day & $0.001 \mathrm{mg} / \mathrm{kg} / \mathrm{day}$ \\
\hline Methyl Parathion & $\mathrm{NA}$ & $0.0007 \mathrm{mg} / \mathrm{kg} / \mathrm{day}$ & $0.0003 \mathrm{mg} / \mathrm{kg} / \mathrm{day}$ \\
\hline Permethrin & $0.3 \mathrm{mg} / \mathrm{kg} / \mathrm{day}$ & $0.2 \mathrm{mg} / \mathrm{kg} / \mathrm{day}$ & $\mathrm{NA}$ \\
\hline
\end{tabular}

a $(\mathrm{mg} / \mathrm{kg} /$ day) Milligrams per Kilogram per Day. These thresholds are based on a milligram per kilogram per day (mg/kg/day) ingestion rate [71] 


\subsection{Pesticides}

As previously noted, pesticides encompass a large group of chemicals aimed at mitigating or destroying pests. Pesticide use has been receding since reaching a plateau in the 1980's, as can be viewed in Figure 2 [13]. This reduction has been, in part, attributed to the manufacture of more efficacious compounds and the establishment of Integrated Pest Management (IPM) systems in developed countries [13]. Mechanisms of toxicity for the pesticides investigated in this study are similar for both pests and mammals [13, 22]. Precautions must be taken to reduce the chance for an overexposure to pesticide products. The two main categories of pesticides that will be covered by this research, organophosphates and pyrethroids, will be detailed in the following sections.

\subsubsection{Organophosphate Insecticide}

In 2007, organophosphates (OP) accounted for 35\% of all insecticides used in the US (33 Million Pounds) [15]. OP were originally synthesized in the 1800's, but their refinement for pest mitigation did not occur until the late 1930's and early 1940's [13, 72]. OP are readily degraded in the environment by way of hydrolysis, photolysis or biodegradation [73, 74]. There is little evidence to suggest that OP bioaccumulate in body tissue or the environment, since metabolism of the parent appears rapid [75]. The research conducted in this study included two organophosphate pesticides: Chlorpyrifos and Methyl Parathion. 


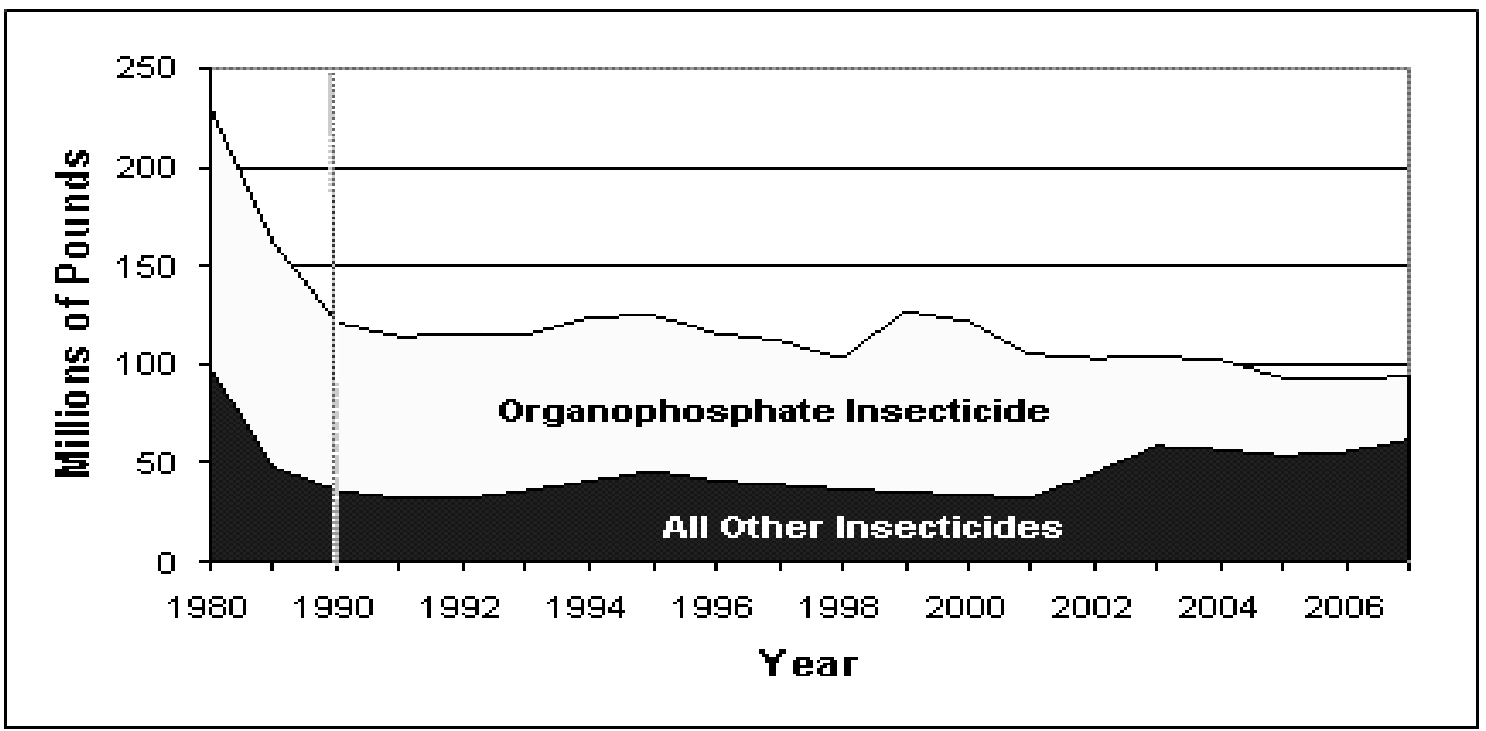

Figure 2: Organophosphate Insecticides Versus Other Insecticides. This EPA graph indicates the application, in pounds, of organophosphates versus all other insecticides since 1980. Figure from the EPA [14]. The dotted line (at year 1990) signifies a change in the scale for time.

\subsubsection{Organophosphate Health Effects}

\subsection{Acute}

Effects following acute OP exposure are documented and well understood [30]. The toxidrome commonly associated with acute OP overexposure is the inhibition of acetylcholinesterase (AChE) in the Central Nervous System (CNS) and the Peripheral Nervous System (PNS), as AChE is the primary target of OP pesticides [72, 76]. Once a dose of OP has been absorbed, it must undergo biotransformation to produce AChEinhibitory effects [13]. The majority of the biotransformation takes place in the liver via cytochrome P-450 (CYP) mediated oxidative desulfuration to remove the sulfur that is bound to the phosphorus, replacing it with an oxygen molecule [72]. This forms the reactive oxon form of the parent $\mathrm{OP}$ [72]. The oxon analog is responsible for AChE inhibition [77]. Hydrolysis and paroxonase (PON1) activity detoxify the oxon and 
reduce it to byproducts [77]. OP can also bypass the desulfuration pathway and can be reduced by CYP-mediated dearylation into excretable metabolites without being transformed into the toxic intermediate [77].

The nervous system is the target for OP AChE inhibition [77]. Acetylcholine is a neurohumoral transmitter that relays nerve impulses across synapses and neuroeffector junctions [73]. Hydrolysis of acetylcholine by AChE at cholinergic nerve terminals terminates the electrical conduction [72, 77]. The inhibition of AChE by the OP oxon results in accumulation of acetylcholine in the CNS and PNS and cholinergic synapses, resulting in the overstimulation of the muscarinic and nicotinic receptors [78]. Overstimulation of these receptors can result in a cholinergic syndrome with symptom presentation based on the receptor type being targeted [76, 79].

Accumulation of acetylcholine in the CNS can result in confusion, hypothermia, tremors, paralysis and coma [76]. PNS muscarinic receptor depression can manifest as bradycardia, hypotension, miosis, gastrointestinal distress and lacrimation [76]. Stimulation of nicotinic PNS receptors present as tachycardia, fasciculation, ataxia, convulsions, and paralysis [76]. Death from acute AChE inhibition is theorized to follow respiratory failure due to bronchoconstriction, increased bronchial secretions, intercostal and diaphragmatic muscle paralysis and inhibition of respiratory centers in the brain stem [13]. While AChE is the most understood cholinesterase when it comes to inhibition, a second type of cholinesterase, butylcholinesterase (also known as plasma pseudocholinesterase; BuChE), also undergoes inhibition, though its function is not well 
understood [13]. It is believed that BuChE may be a sensitive biomarker of exposure when acute overexposure is suspected, but inhibition of BuChE alone cannot be considered a biomarker of effect when evaluating exposure to OP [13].

A second manifestation of acute OP excessive exposure is Intermediate Syndrome (IS). This syndrome was first described in 1987 by Sri Lankan physicians observing hospitalizations of attempted suicide patients following ingestion of OP pesticides [13]. Onset of this syndrome is anywhere from 24-96 hours following acute overexposure to OP [81]. The effects observed during this crisis do not appear to originate from AChE inhibition [77]. While the exact disease etiology is unknown, the symptoms are serious and include slowed respiration due to muscle weakness and weak neck muscles, in addition to proximal limb and cranial nerve palsies [13, 77]. IS could lead to death due to paralysis and respiratory failure [13].

A third sequela from excessive op exposure is Organophosphate-Induced Delayed Neuropathy (OPIDN) [13, 14, 82]. Also referred to as a neurotoxicity or a polyneuropathy in the literature, this syndrome manifests itself anywhere from 7-21 days following an acute cholinergic crisis (sources vary on the actual time for the signs to present) $[14,82]$. Physiologically, sensory and motor axon degradation occurs in the distal regions of the peripheral nervous system and in the spinal cord [14]. A single exposure to an OPIDN-causing OP can lead to the inhibition of Neuropathy Target Enzyme (NTE) via phosphorylation [83]. Phosphorylation, along with 'aging' of at least $70 \%$ of the NTE, is required for the signs of OPIDN to be observed [72]. Aging is a loss 
of an alkyl group bound to NTE [80]. Studies have shown that inhibition of NTE is independent of AChE inhibition; however, age of the individual exposed does seem to be a factor on susceptibility, as young animals are at less of a risk to OPIDN following exposure due to the higher percentage of NTE inhibition required for young animals as compared to adult animals (90\% versus $70 \%$, respectively) [72]. Symptoms of this toxidrome include paresthesia, sensory loss, muscle weakness in extremities and limb muscles [84]. Not all OP pesticides are capable of causing OPIDN [14]. Only OP that are capable of aging NTE can cause OPIDN [13].

\subsection{Chronic}

While the effects from acute overexposures to OP pesticides have been well researched, there appears to be no consensus on the potential health effects from chronic, low-level exposures [72]. Recently, it has been proposed that chronic exposures to pesticides are contributing to neuropsychiatric disorders [85]. However, reviews of the research have found no conclusive evidence that low-level exposures to OP contribute to clinically significant neuropsychological effects or peripheral nerve dysfunction, though research in this area continues [72, 86-88]. Beyond neurological outcomes, public health concern has focused on the effects of pesticide exposures on the young. The FQPA of 1996 called for an evaluation of aggregate pesticide exposures on the general population, with special attention to infants and children [68]. With this increased focus on the young, new concerns arose questioning whether exposures to pesticides could result in teratogenic effects. It has been observed that physiological differences in young animals 
(low detoxication rate by CYP and PON1) may make them more sensitive to a cholinergic crisis than adult animals [77].

Epidemiological studies of OP suggest that exposure to the fetus during development may result in biochemical and behavioral abnormalities. These recent studies have begun to evaluate the association of exposures of pregnant mothers to pesticides and negative birth outcomes. Outcomes evaluated in these studies include: decreased head circumference, decreased birth weight, decreased body length, decreased time of gestation, increased incidence of ADHD and memory impairment in children [77].

\subsubsection{Chlorpyrifos}

Chlorpyrifos (O,O-diethyl-O-(3,5,6-trichloro-2-pyridyl) phosphororthioate; CAS 2921-88-2), a colorless to white solid organophosphate insecticide, has been used for the mitigation of cockroaches, termites, fleas and ticks $[73,77]$. It is also used on vegetable, fruit, cotton, tobacco, corn crops and golf course turf to reduce damage from insects [77, 89]. Chlorpyrifos for pesticide applications was first used in 1965 [77, 90]. While chlorpyrifos is still used in the control of pests in agricultural operations, its use in residential settings was phased out in 2001 [77]. The removal from residential settings was based on the findings of the EPA's preliminary human health risk assessment [91]. Current exposures to chlorpyrifos are primarily limited to agricultural settings [77]. 


\subsection{Toxicokinetics}

\subsection{Absorption}

Chlorpyrifos is absorbed through ingestion, dermal and inhalation routes [74]. Nolan et al. (1984) reported recovery of urinary biomarkers at 70\% following an oral exposure to $0.5 \mathrm{mg} / \mathrm{kg}$ of chlorpyrifos and urinary biomarker recovery at $1.3 \%$ from a dermal exposure to $5.0 \mathrm{mg} / \mathrm{kg}$ from post-dosing samples [92]. A small amount is eliminated in the bile from phase II glutathione conjugations [77]. Timchalk et al. (2002) administered oral doses of $0.5-2.0 \mathrm{mg} / \mathrm{kg}$ to human volunteers [93]. Only $20-35 \%$ of the oral dose was recovered as 3,5,6-trichloro-2-pyridinol (a primary biomarker detected following exposure to chlorpyrifos; also known as 3,5,6-trichloropyridinol and TCPy) [93]. Chlorpyrifos exposures in the general population are thought to occur via ingestion of residues remaining on food products, though reductions of use in agriculture may reduce exposures from this route [51, 62, 77]. Dermal exposure to chlorpyrifos is not thought to be a major route of exposure in the general population following the restriction of its application, and inhalation exposures from agricultural applications are thought to be low, in relation to the diet [77]. While prior studies have suggested that concentration in ambient air and residues on surfaces may be a potential source of exposure for children, inhalation of ambient air in homes is no longer thought to be a source of exposure following the moratorium of chlorpyrifos use in residential scenarios [73].

\subsection{Distribution}

Animal studies indicate that chlorpyrifos is distributed to all organs of the body following dosing [73]. Bioassay experiments suggest that chlorpyrifos is found in high 
concentrations in adipose and fatty tissues [77]. Smith et al. (1967) suggested that the half-life in adipose tissue is 62 hours, while the half-life is reduced to $10-16$ hours in the liver, kidney and the heart [94]. Abdel Rhaman et al. (2002) indicated that TCPy was observed in all tissues within 5 minutes following dosing with ${ }^{14} \mathrm{C}$ radiolabeled chlorpyrifos (5mg/kg) [95].

\subsection{Metabolism}

Chlorpyrifos is metabolized to form any of three final biomarkers: 3,5,6trichloropyridinol, diethylthiophosphate (DETP) or diethylphosphate (DEP) [77]. Chlorpyrifos must be bioactivated/desulfurated and transformed into the chlorpyrifosoxon analog to inhibit AChE activity in the CNS and PNS [77]. The majority of the transformation occurs in the liver via cytochrome P-450 dependent monooxygenase desulfuration [72]. Detoxication of the oxon takes place through hydrolysis using paroxonase (PON1) as the catalyst to form DEP and TCPy [77]. Chlorpyrifos itself can be directly reduced to DETP and TCPy via cytochrome P-450-mediated dearylation [77]. Animal studies have suggested that TCPy undergoes further metabolism through conjugation with glucuronic acid and sulfate [77].

\subsection{Elimination}

Half-life of elimination in humans has been estimated at 27 hours following an oral or dermal exposure [92]. Timchalk et al. (2007) recovered most of the administered dose in the urine 72 hours after dosing rats with $~ 50 \mathrm{mg} / \mathrm{kg}$ chlorpyrifos [96]. 


\subsection{Mechanism of Toxicity}

Chlorpyrifos, by itself, is an inefficient inhibitor of AChE; however, the chlorpyrifos oxon, created by oxidative desulfuration, is an excellent inhibitor of the enzyme [77]. Metabolism of the parent and oxon metabolite is rapid, as can be seen in Figure 3.<smiles>CCOP(=S)(OCC)Oc1nc(Cl)c(Cl)cc1Cl</smiles>

Chlorpyrifos

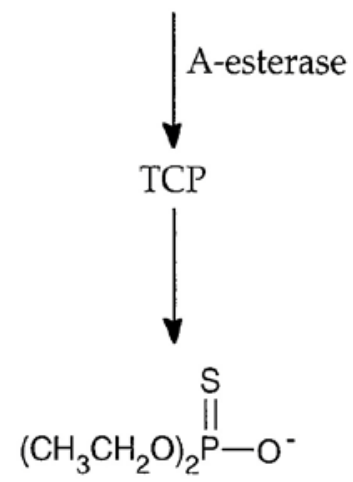

Diethyl thiophosphate (DETP)<smiles>CCOP(=O)(OCC)Oc1nc(Cl)c(Cl)cc1Cl</smiles>

Chlorpyrifos Oxon

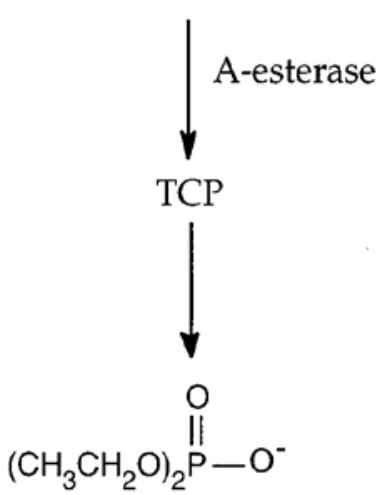

Diethyl phosphate (DEP)

Figure 3: Chlorpyrifos Metabolism. Chlorpyrifos can be either metabolized directly to TCP(y) and DETP or it can undergo further metabolism via Cytochrome P-450 to form chlorpyrifos oxon. The oxon analog is detoxified via Paroxonase 1 to form TCP(y) and DEP. Figure from ATSDR [73]. P-450= Cytochrome P-450; A-esterase $=$ Paroxonase 1; $\mathrm{TCP}=3,5,6$ - trichloropyridinol; $\mathrm{DETP}=$ diethylthiophosphate; $\mathrm{DEP}=$ diethylphosphate 


\subsection{Toxicity Assessment}

The assessment for chlorpyrifos will be limited to select outcomes. This assessment is focused on the more important public health risks. Studies addressing human data are presented when available.

\subsection{Body Weight}

Male and female rats with whole body exposure to $5,300 \mathrm{mg} / \mathrm{m}^{3}$ of a solution of Pyrenone Dursban for 4 hour lost a mean $10 \%$ body weight, however no weight variations were observed in rats dosed with $2,500 \mathrm{mg} / \mathrm{m}^{3}$ of Pyrenone Dursban pressurized spray [73]. Corley et al. (1989) dosed Fischer 344 rats with a maximum concentration of $287 \mu \mathrm{g} / \mathrm{m}^{3}$ for 6 hours a day, 5 days a week for 13 weeks [97]. No body weight differences were noted for any dosing group [97]. Rodents with acute oral exposure to chlorpyrifos at high doses have recorded decreases in mean body weight [73]. Moser (1995) orally dosed rats with a one-time $100 \mathrm{mg} / \mathrm{kg}$ of technical grade chlorpyrifos in corn oil had a 13.3\% decrease in body weight 24 hours post dosing [98]. No alterations in body weight have been observed from intermediate exposures in rodents [73].

\subsection{Neurological}

Much of the literature pertaining to neurological effects following exposure to chlorpyrifos centers around the inhibition of cholinesterase activity. An animal study by Breslin et al. (1996) evaluated pregnant Fischer 344 rats orally dosed with 15 mg/kg/day of technical grade Dursban F via gavage on gestation days 6-15 [99]. Erythrocyte AChE 
activity was reduced $\sim 80 \%$ as compared to controls [99]. An evaluation of OPIDN in hens by Capodicasa et al. (1991) resulted in maximum inhibition of NTE 5-7 days following a one time dosing of 60-150 $\mathrm{mg} / \mathrm{kg}$ chlorpyrifos [100].

A study by Albers et al. (2004) evaluated the effects of chlorpyrifos on the central nervous system of occupationally exposed individuals [101]. The study evaluated employees at Dow Chemical Company where pesticides were manufactured. Cases and controls were identified from the facility. A baseline examination was conducted as well as a follow-up examination approximately one year later. Average creatinine-adjusted TCPy in the exposed group was $251(\mu) \mathrm{g} / \mathrm{L}$ (urine) and $192.2 \mu \mathrm{g} / \mathrm{g}$ (creatinine-adjusted) [101]. The study concluded that chronic, low-level occupational chlorpyrifos exposures were not associated with clinically evident or subclinical peripheral neuropathy when compared to controls [101].

Steenland et al. (2000) conducted a cross-sectional study with 191 termiticide applicators (both current and former) [102]. Recently exposed applicators had a mean urinary concentration of TCPy at $629.5 \mu \mathrm{g} / \mathrm{L}$ [102]. When the termiticide applicators were compared with a control group, few exposure-related effects were significant. Many were homogenous for effects on clinical examination. However, significant differences were found when comparing the performance of the exposed on the length of sway and pegboard test to controls [102]. 


\subsection{Developmental Effects}

Deacon et al. (1980) evaluated physical abnormalities in a group of pregnant CF-1 mice orally dosed with up to $25 \mathrm{mg} / \mathrm{kg} /$ day chlorpyrifos on gestation days 6-15; the study concluded that chlorpyrifos was not teratogenic [103].

Whyatt et al. (2004), along with Perera, used data obtained from the Columbia Center for Children’s Environmental Health in New York to determine the association of exposure of African American or Dominican pregnant women to pesticides [104]. Women in this study participated in biomonitoring at the time of birth. Blood samples were collected from the umbilical cord at birth and from the mother within two days after giving birth [104]. Plasma TCPy levels were determined and a negative association was found between detection of TCPy and birth weight and length [104]. These data were further analyzed to determine the impact of chlorpyrifos exposure on neurodevelopment. Rauh et al. (2006) determined that "highly exposed" (chlorpyrifos >6.17 pg/g plasma) children 3 years of age scored lower on the Bayley Psychomotor Developmental Index and the Bayley Mental Development Index when compared to those exposed to a lower level $(<6.17 \mathrm{pg} / \mathrm{g})$ [105]. These levels are based on the chlorpyrifos detected in the umbilical cord plasma collected at the time of birth. A follow-up study by Rauh et al. in 2011 re-assessed these children at age 7 [106]. This study, using the original biomarker level at birth, reported that children exposed to chlorpyrifos in utero show deficits in the working memory index and the full scale IQ test [106]. 
Eskenazi et al. (2004) investigated chlorpyrifos exposure and negative birth outcomes in the Center for the Health Assessment of Mothers and Children of Salinas Study (CHAMACOS) [107]. After sampling and analyzing maternal urine for chlorpyrifos biomarkers, no significant association was found between TCPy detection in urine and negative birth outcomes (birth weight, length, head circumference and length of gestation) [107].

Berkowitz et al. (2004) investigated the relationship between pesticide exposure and negative birth outcomes in the Children's Environmental cohort study at Mount Sinai Hospital, New York [108]. Races were mixed in this study with approximately 50\% of the participants identified as Hispanic [108]. Evaluation of urinary TCPy concentration was not found to have a significant association with reductions in birth weight and length; however, this study did find a slight decrease in head circumference when TCPy and PON1 activity were considered jointly [108].

\subsubsection{Methyl Parathion}

Methyl parathion (O,O-dimethyl-O-(p-nitrophenyl)-phosphororthioate; CAS 29800-0), first manufactured in the USA in 1954, is an insecticide used on crops, such as cotton and soybeans [74, 109]. It is a white crystalline solid or brownish liquid containing $80 \%$ methyl parathion as the active ingredient $[74,109]$. Exposures to the general population are thought to be low [74]. Inhalation exposures are thought to be the route of exposure to individuals living near agricultural application of methyl parathion (MP) [74]. Dermal may be the most relevant exposure route based on the fact that the 
EPA has accepted voluntary cancelation of the use of MP on a variety of food products and residential application is prohibited [74, 110]. The EPA determined that MP posed an unacceptable dietary risk to children aged 1-6 [110].

\subsection{Toxicokinetics}

\subsection{Absorption}

Humans appear to readily absorb MP via ingestion, inhalation and dermal exposures [74]. Oral absorption is limited by first pass metabolism in the small intestine [109]. Human exposures to methyl parathion have shown that AChE inhibition takes place following dermal absorption [74]. The ATSDR indicated that exposure can occur through inhalation, though no human studies identified absorption via inhalation [74].

\subsection{Distribution}

Distribution studies involving human exposures are limited. A human dosing study by Morgan et al. (1977) indicated that ingestion of either $2 \mathrm{mg}$ or $4 \mathrm{mg}$ of MP in food resulted in urinary excretion of biomarkers, with the highest concentrations 4 and 8 hours after ingestion [111]. Garcia-Repetto et al. (1997) reported that MP distributed to various body compartments of the rat following gavage and results indicated that, depending on the tissue, the half-life of elimination is anywhere from 8 to 16 days [112]. Bioassay studies have suggested that MP distributed to the blood, brain, liver and adipose tissue [109]. 


\subsection{Metabolism}

Like other OP pesticides, MP can be either detoxified or bioactivated after absorption. Detoxication takes place via dearylation by oxidatively cleaving the compound to form paranitrophenol (PNP) and dimethyl thiophosphate [109]. Oxidative desulfuration via Cytochrome P-450 transforms MP to the more toxic analog, Methyl Paraoxon [109]. The oxon is detoxified by paraoxonase (PON1) to form either paranitrophenol or dimethylphosphate and can be further reduced to form conjugates with glucuronic acid and sulfate $[74,109]$. Methyl parathion itself is not effective at inhibiting AChE [74]. Studies have indicated that oral absorption of MP limits its toxicity due to first pass metabolism [74].

\subsection{Elimination}

Abu-Qare et al. (2000) used pregnant rats to apply a dermal dose of a radiolabeled MP solution. Urinary recovery of was 91\% within 96 hours [113]. Excretion from an oral exposure occurs mainly through urine and appears to be rapid. A human volunteer study by Morgan et al. (1977) suggested that $86 \%$ of 4-nitrophenol had been eliminated 8 hours following dosing, with the highest recovery during the first 4 hours [111].

\subsection{Mechanism of Toxicity}

Like other organophosphate pesticides, MP must be bioactivated to form methyl paraoxon in order to elicit AChE inhibitory effects, as seen in Figure 4 [112]. 


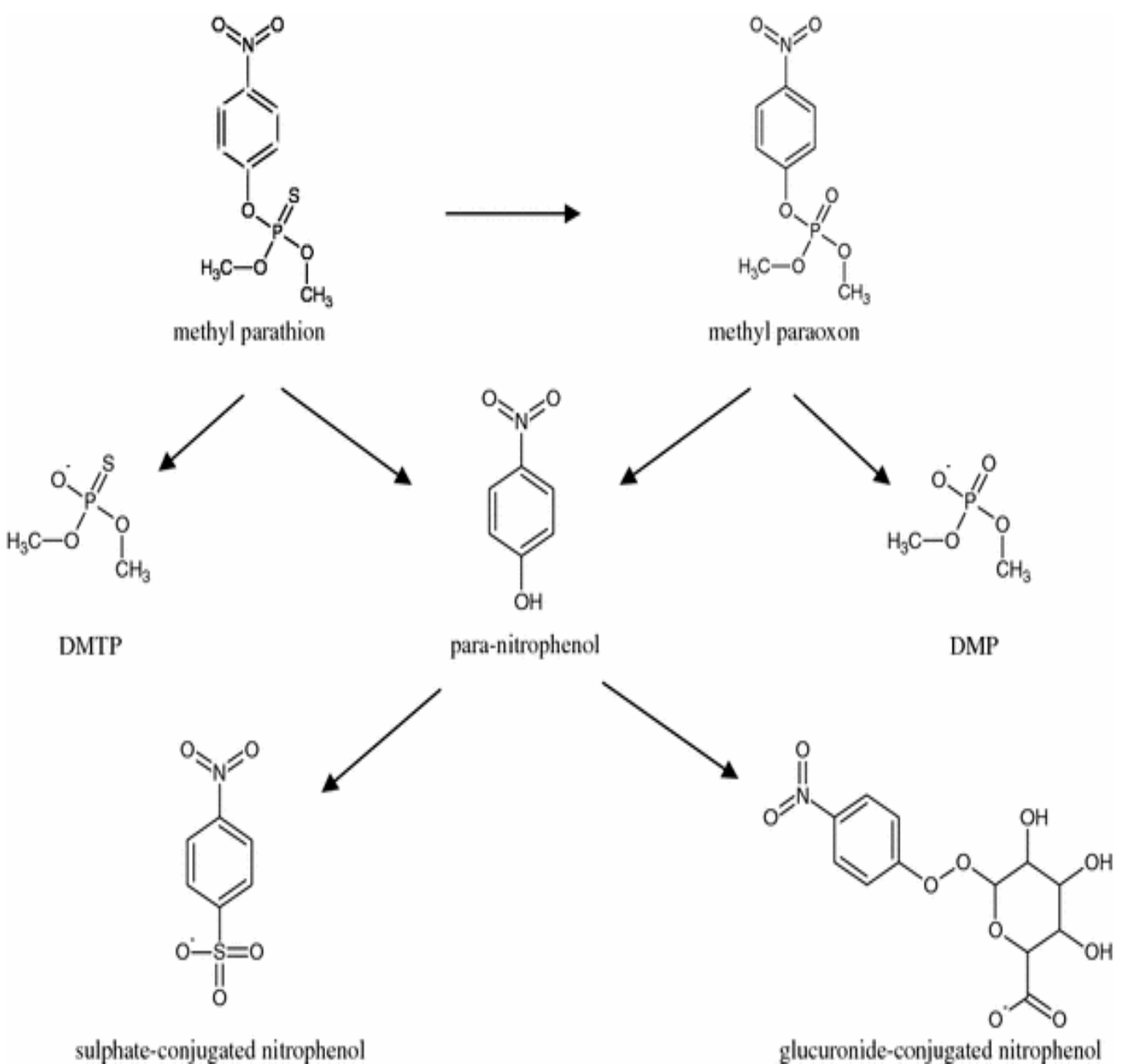

Figure 4: Methyl Parathion Metabolism. Methyl Parathion can be reduced directly to form PNP and DMTP or it can undergo activation via cytochrome P-450 to form methyl paraoxon. The oxon analog is detoxified via PON1 to form PNP and DMP. Figure from Panuwet et al. (2009) [114]. DMTP= dimethyl thiophosphate; DMP= dimethylphosphate. Reprinted with permission.

\subsection{Toxicity Assessment}

The assessment for methyl parathion will be limited to select outcomes. This assessment focuses on relevant public health outcomes. Studies addressing human data are presented when available. 


\subsection{Body Weight}

Studies have evaluated variations in body weight following acute, intermediate and chronic oral exposures. Tian et al. (1997) did not observe any significant body weight variations in mice dosed with $5 \mathrm{mg} / \mathrm{kg} /$ day for 15 days [115]. Two of eight dogs dosed with $3.0 \mathrm{mg} / \mathrm{kg} /$ day for 13 weeks were reported to be emaciated and dehydrated; these effects were not noted in dogs dosed with concentrations that were orders of magnitude lower [74]. Rats orally dosed with methyl parathion at concentrations of 2.5 $\mathrm{mg} / \mathrm{kg} /$ day for 2 years showed significant reductions in body weight in comparison to controls [74]. However, this variation was not consistent during the study duration and variations were not observed in animals dosed with concentrations that were orders of magnitude lower [74].

\subsection{Neurological}

The neurotoxic effects of MP center around the inhibition of AChE [112]. Rodnitzky et al. (1978) orally dosed two male volunteers with $2 \mathrm{mg} / \mathrm{day}$ of MP for 5 days, and, 8 weeks later, were orally exposed to $4 \mathrm{mg} /$ day of MP for 5 days. No significant reductions in AChE-activity were observed for either dosing [116]. Male rats orally dosed with $5 \mathrm{mg} / \mathrm{kg}$ via gavage displayed cholinergic signs seven minutes post dosing, resulting in an approximately 44\% reduction in plasma cholinesterase when compared to controls [74]. Crittenden et al. (1998) dosed mice with MP at 1, 3 and 6 $\mathrm{mg} / \mathrm{kg} /$ day recorded decreased brain AChE activity at various points over the 28-day study in the groups dosed with $3 \mathrm{mg} / \mathrm{kg}$ and $6 \mathrm{mg} / \mathrm{kg}$ [117]. 
In the 1990's, MP was illegally applied in residences in at least nine Midwestern and Southern states [118]. The target population of one of the studies investigating MP exposure was children who were 6 years of age or younger at the time of MP application. Exposure was established based on either wipe samples from the home (in Ohio and Mississippi) or the detection of paranitrophenol (PNP) in a urine sample (Ohio only). The study evaluated whether exposed children had an adverse neurological outcome. Based on the results of tests used to evaluate neurobehavior and general intelligence, the exposures were not associated with negative outcomes on most neurobehavioral tests [118]. The findings do suggest that those children exposed may have alterations in shortterm memory, but the authors note that the findings are not conclusive because the effects are not consistent across both study sites [118]. The delay in time between the application of MP and neurobehavioral testing (2.5 years in Mississippi and 4.5 years in Ohio) and the age of the children at the time of the neurobehavioral assessment may have affected the findings [118].

\subsection{Developmental Effects}

Numerous studies have used rodents to identify the effects of methyl parathion on pregnant dams during gestation. A mouse study by Gupta et al. (1985) identified increased observed visible signs of toxicity in dams and fetuses exposed to $1.5 \mathrm{mg} / \mathrm{kg} / \mathrm{day}$ of MP [119].

The Eskenazi et al. (2004) study referenced in the chlorpyrifos section (Page 26) also evaluated the association of urinary concentrations of PNP to negative birth 
outcomes [107]. When comparing women with detects of the biomarker to those that did not have a detect for PNP, women with levels of PNP above the median (median $=0.05 \mu \mathrm{g} / \mathrm{L}$ ) had children with increased head circumference when compared with women without a detect $(\beta=0.29 \mathrm{~cm}, \mathrm{p}=0.06)$ [108]. Additionally women with PNP levels below the median had children with increased length as compared to women with no detects $(\beta=0.60 \mathrm{~cm} ; \mathrm{p}=0.03)[107]$.

\subsubsection{Pyrethroids}

Pyrethrum, a natural extract used as an insecticide, is obtained from the chrysanthemum cinerariaefolium and chrysanthemum cineum flowers [120]. Use of these extracts for insect mitigation can be traced back at least 2,000 years to China and Persia $[13,121]$. While effective at controlling insects, degradation of pyrethrum occurs quickly in sunlight and the environment [120]. Pyrethroids are synthetic analogs of pyrethrums $[13,120]$. The synthetic pyrethroids are similar in structure to pyrethrum but are more resistant to rapid degradation [120].

Pyrethroids are insecticides used in agricultural settings and household applications for the control of scabies, lice and mosquitoes and, in addition, are among the most frequently used pesticides $[13,122]$. Pyrethrum, as a group, contains six active compounds referred to as pyrethrins [123]. In comparison, there are over 1,000 synthetic pyrethroids, though only a few of those are commonly used in the US [120]. Several examples of these compounds can be seen in Table 5. The mechanism of action for pyrethroids is similar for insects and mammals; however, because of a faster metabolism 
and lower sensitivity at the target site, mammals are relatively resistant to the actions of pyrethroids [121].

Pyrethroids are classified as either Type I or Type II, depending on their physical properties and toxicological outcomes in rats, though other rodents have also been used to classify the effects of an overexposure [64, 124]. Type I compounds elicit aggressive behavior, increased sensitivity to external stimulation, startle response, fine and whole body tremors as well as prostration in rats [124]. These sequalae are referred to as Tsyndrome [124]. Type II pyrethroids are characterized by burrowing, salivation, coarse tremors, choreoatetosis and clonic seizures in rats [124]. In addition, Type II pyrethroids are chemically differentiated from Type I compounds by the presence of a cyano (CN) group on the alpha carbon [124]. Outcomes from exposure to Type II compounds are referred to as CS-syndrome [124]. Pyrethroids contain two chiral carbons and, in some cases, an additional carbon on the alcohol moiety to total three $[13,120]$. In addition to existing in cis- and trans- conformations, pyrethroids can result in up to eight different isomers $[13,120]$. The conformation of the compound can have an effect on toxicity [13].

Table 5: Partial List of Pyrethrins and Pyrethroids.

\begin{tabular}{|c|c|c|}
\hline Pyrethrins & Type I Pyrethroids & Type II Pyrethroids \\
\hline Pyrethrin I & Allethrin & Cyfluthrin \\
\hline Pyrethrin II & Bifenthrin & Cyhalothrin \\
\hline Cinerin I & Permethrin & Deltamethrin \\
\hline Cinerin II & Resmethrin & Fenvalerate \\
\hline Jasmolin I & Tefluthrin & Flumetrhin \\
\hline Jasmolin II & Tetramethrin & Tralomethrin \\
\hline
\end{tabular}

Adapted from ATSDR Toxicological Profile [120]. 
Pyrethrins and pyrethroids are degraded by sunlight and typically do not persist in the environment, though permethrin and cyhalothrin persist longer due to structural characteristics [120]. Environmental half-life ranges from days to a few weeks [120]. The compounds are typically immobile in soil and are biodegradable in the environment, though it has been shown that this insecticide does bioaccumulate in aquatic organisms [120]. Permethrin is the most frequently used pyrethroid in the US and is the pyrethroid that will be focused on in this study $[64,120]$.

\subsubsection{Health Effects}

\subsection{Acute}

While their use as an insecticide is effective and potent, they pose little hazard to humans due to their low mammalian toxicity (three orders of magnitude lower than that of insects) [125]. The adverse health effect of pyrethroids depends on their classification, though their primary target is disruption of the voltage-gated sodium channels of the nervous system [121, 24, 126]. Type I pyrethroids function by prolonging the opening of the sodium ion channel to cause repetitive firing of the action potential [13]. Type II compounds also work on the sodium channel; however, instead of rapid fire, the sodium channel remains open which results in depolarization of the channel and does not allow for the generation of an action potential [13].

\subsection{Chronic}

The reported effects of chronic, low-level exposure to pyrethroids, if any, are limited in the literature. However, because of the rapid metabolism of the compounds, 
pyrethroids are not believed to result in neurological signs from chronic, low-level exposures [120]. In 1999, the Cancer Assessment Review Committee (EPA) classified pyrethrins as "likely to be a human carcinogen by the oral route" based on a study finding increases in thyroid follicular cell tumors in male rats and increased incidence of hepatocellular adenomas and carcinomas in female rats fed high doses of pyrethroids (1,000 ppm and 3,000 ppm) [120]. However, other animal studies using high dosings have not come to the same conclusions [120]. There has also been an attempt to correlate pyrethroids exposure to reduction in semen and hormone levels in adult men [65, 127].

\subsubsection{Toxicokinetics}

\subsection{Absorption}

Studies have indicated that pyrethroids are readily absorbed through inhalation exposure and moderately through oral exposure, while less than $2 \%$ of the applied dose following dermal exposure is absorbed [120, 128]. Oral absorption takes place in the intestinal tract, though first pass metabolism may underestimate the true absorbed dose [120]. An inhalation study in humans by Leng et al. (1997) indicated that urinary biomarkers were $93 \%$ recovered within 24 hours, with peak rates between 30 minutes and 3 hours, indicating rapid metabolism [129]. Human and animal information on dermal absorption is limited [120]. In occupational settings, exposures to pyrethroids are thought to occur from inhalation and dermal exposure, though studies have indicated that the skin is an effective barrier to absorption [120]. General population exposure is suggested to be through the ingestion of agricultural products that have been treated with pyrethroids $[120,125]$. It is suggested that general population exposure also originates from 
household treatments with pyrethroids [128]. Because of their lower vapor pressure, pyrethroids can form particulates at room temperature and partition into household dusts [128]. Because young children tend to have higher hand-to-mouth activity, this may also be a relevant source of exposure [130].

\subsection{Distribution}

In humans, once absorbed into the blood stream, pyrethroids are rapidly distributed [128]. Pyrethroids are theorized to distribute to most tissues, especially those high in lipid content [120]. They are also thought to concentrate in the central and peripheral nervous systems [120]. Distribution studies for dermal and inhalation exposures in humans and animals was lacking.

\subsection{Metabolism}

Many of the studies on the metabolism of pyrethroids are based on mammalian animal models [120]. The parent compound of pyrethroids is the active, toxic form, as metabolism forms byproducts that are thought to have little or no toxicity $[13,120]$. Metabolism occurs through two major pathways: hydrolysis of the ester bond and oxidation of the alcohol moiety [13]. One pathway may be the major path of biotransformation, depending on the type of pyrethroids encountered [120]. The biomarker 3-Phenoxybenzoic Acid (3-PBA) will be evaluated in this research. It is a biomarker for 10 out of the 18 common pyrethroids registered in the US [128]. 


\subsection{Elimination}

Depending on the specific pyrethroid encountered and the rate of exposure, elimination half-life ranges from 6.4-16.5 hours [128]. Animal studies indicate that Type I and II pyrethroids are eliminated within 4-12 days following oral dosing and the majority is eliminated within 12-48 hours [120].

\subsubsection{Mechanism of Toxicity}

The parent form of the pyrethroid is responsible for interruption in the sodium channel action potential. Metabolism detoxifies the parent pyrethroid, inactivating the Type I and II effects, and forms excretable metabolites, as can be seen in Figure 5. 

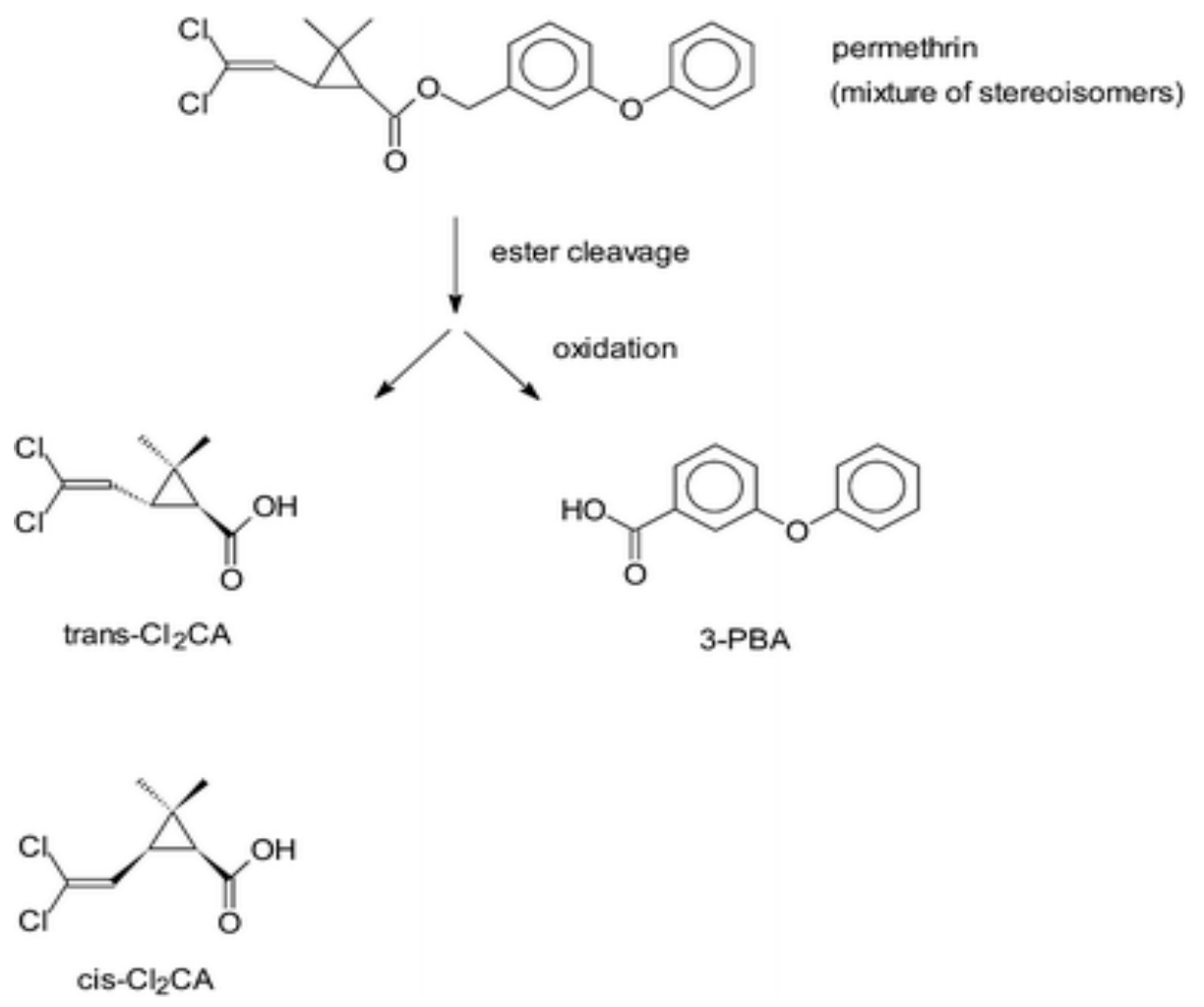

Figure 5: Permethrin Metabolism. Permethrin undergoes detoxication to form 3Phenoxybenzoic Acid, the metabolite of interest in this research. Figure from Hardt et al. (2003) [131]. Cis/Trans- $\mathrm{Cl}_{2} \mathrm{CA}=$ 2,2- Dimethylcyclopropane Carboxlic Acid; 3-PBA= 3Phenoxybenzoic Acid. Reprinted with permission.

\subsubsection{Toxicity Assessment}

Because there are a variety of synthetic mixtures and conformations of pyrethroids available, the information in this section will not be limited to one specific pyrethrin or pyrethroid. This assessment is limited to relevant public health risks.

\subsection{Body Weight}

Various animal studies evaluated and associated pyrethroid and pyrethrin exposure to reductions in body weight and food consumption. Parker et al. (1984) orally dosed female dogs with fenvalerate at 1,000 ppm in the diet for 6 months; dosed dogs had 
significant decreased body weight and food consumption when compared to controls [132].

\subsection{Neurological}

In occupational exposure scenarios, paresthesia is reported following dermal contact to pyrethroids [121]. Other acute signs include muscular fasciculations, headache and convulsions [120]. Signs of neurotoxicity seem to dependent on whether the exposure was to Type I or Type II pyrethroids. Neurological signs in laboratory animals from an exposure include aggressive behavior, increased sensitivity to external stimulation, startle response, tremors and prostration for Type I compounds and burrowing, salivation, coarse tremors, choreoatetosis and clonic seizures for Type II compounds [124]. Oral dosing with permethrin in rats resulted in a significant decrease in motor activity at $200 \mathrm{mg} / \mathrm{kg}$ [133]. Hypersensitivity to sound has been reported in other bioassay experiments [120].

\subsection{Developmental Effects}

Pregnant rats exposed to a maximum of $600 \mathrm{mg} / \mathrm{kg} / \mathrm{day}$ of total pyrethrins (extract) on gestation days 6-15 did not result in developmental toxicity, though maternal toxicity was observed in rats dosed with $75 \mathrm{mg} / \mathrm{kg} /$ day [134]. The type of pyrethroids may have an effect on the toxicity outcomes following oral exposure. Pregnant dams dosed with a maximum of $8 \mathrm{mg} / \mathrm{kg} /$ day of cypermethrin on gestation days 6-15 did not have any significant differences between control animals [135]. 
Berkowitz et al. (2004) evaluated the association of phenoxybenzoic acid in urine and decreases in birth weight, length and head circumference in the Mount Sinai study (referenced on page 26). No significant associations were found between the exposure and birth outcomes [108]. 


\section{Chapter 3}

\section{Methods}

\subsection{Data Source}

The data evaluated in this research originated from the 2001-2002 NHANES sampling event. National health monitoring dates back to the National Health Survey Act of 1956 that gave authorization for the creation of a continuing survey that would give statistical data on the amount, distribution and types of illness and disability in the US [136]. The National Health Examination Survey's of the 1960's (NHES I-III) were multi-year studies that evaluated either select chronic diseases, or growth and development, in a variety of age groups [136]. The impact of nutrition and its relationship to health status was added to the study design in the 1970, thus creating the National Health and Nutrition Examination Survey and resulted in multi-year studies (NHANES I-III and HHANES), with a different focus for each study event [136]. Beginning in 1999, NHANES became a continuous, annual survey event in the US [136].

Sampling for the 2001-2002 NHANES collected data from 11,039 participants aged 6-85+ in 30 Primary Sampling Units (PSU) across the US. A PSU is defined as a county or a group of contiguous counties [137]. The PSU can be further divided into blocks or groups of blocks within one of those counties and households on the blocks. The PSUs were visited over a 12-month period [137]. Examinations, interviews and 
specimen collections took place at Mobile Examination Centers (MEC) set-up in the PSU for easy data collection [137]. The Centers for Disease Control and Prevention (CDC) does not supply specific information on the locations of PSU in order to protect the confidentiality of participants [138]. Demographic information gathered from the examination was entered into a database file by NHANES researchers. The information found in this file included participant's age, gender, ethnicity, education level, marital status and household income. This information was imported into a Microsoft Access (2003) database for matching to other data files from the NHANES database.

Priority non-persistent pesticides and their biomarkers as well as organophosphate pesticide data were supplied in a separate data file within the 2001-2002 NHANES Laboratory subsection of the NHANES website. This dataset included information from a subset of 3,152 individuals from the main sampling event and included information for 18 biomarkers. Analysis of spot urine (random) samples to evaluate for the presence of pesticide biomarkers was conducted for a randomly selected sample from the overall NHANES sample population [139].

After collection of the samples at each MEC, specimens were shipped to the Division of Environmental Health Laboratory Sciences for analysis using the appropriate shipping and storage methods [139]. The urinary levels of the biomarkers were measured using one of two mass spectrometric methods [139]. Detailed laboratory analytical information is available in the NHANES pesticide documentation and NHANES laboratory procedures manual. For each specific biomarker, the dataset indicated 
whether or not the biomarker was detected and, if detected, the urinary level in micrograms/liter $(\mu \mathrm{g} / \mathrm{L})$. If the biomarker was not detected in the sample, a value of the detection limit (DL) divided by the square root of two (DL/ $\sqrt{2})$ was reported [139]. Also included in this data file was the urinary concentration of creatinine in the sampled individual, reported in $\mathrm{mg} / \mathrm{dL}$. Information from this subset was matched using a common numerical identifier to the information in the demographic data file. This allows all samples collected from one individual to be matched across multiple, individual data files.

\subsection{Data Analysis}

The pesticide subfile was imported into SAS (Version 9.2) to undergo basic statistical analysis. The frequency of detection was determined for each biomarker in the pesticide dataset. Biomarkers selected for inclusion in this research were those that were detected in more than $50 \%$ of the samples. This criterion has been used in other population biomarker analysis [140]. Three biomarkers met the requirement for inclusion in this research: 3,5,6-trichloropyridinol, paranitrophenol and 3-phenoxybenzoic acid. The analysis was limited to biomarkers that could be related to a parent compound. The non-specific biomarkers for OP compounds were not analyzed in this study.

After using Access to match the pesticide biomarker concentrations to demographic information (age, ethnicity, and gender) from NHANES using a common identifier, data was stratified into individual Access queries for each biomarker. The queries also contained information on each child's and adolescent's height (in 
centimeters, cm) and weight (in kilograms, kg) that were also matched in the Access database using the NHANES common identifier. Biomarkers of clinical chemistry (biochemical concentrations) were related to individuals included in the pesticide data file. From the Access database, individual files were created in Microsoft Excel (2003) for import into SAS for analysis. The creation of Excel files also allowed for the data to be examined. There were numerous instances where values were missing across all of the NHANES databases used in this research. The number of missing individual values is observable when examining the number of individuals involved in each analysis across the data.

Results for biomarker concentrations were log-transformed to determine the geometric mean. This transformation corrects for the non-normal distribution found in the sample due to the large amount of concentrations below or close to the Limit of Detection (LOD) [141-142]. The overall geometric and arithmetic means for each biomarker were determined and the confidence intervals and quartiles were calculated. The geometric mean for each participant that had a detectable level of the biomarker in their urine was also calculated. Once the data was imported into SAS, a Students t-test was performed and the geometric mean determined for overall biomarker concentrations and for the gender subgroup. An Analysis of Variance (ANOVA) was performed and the geometric mean was determined for the age and ethnicity subfiles for each biomarker; the Tukey post-hoc analysis was used to determine which means were significantly different. To account for dilution of urine in the sample, the creatinine-adjusted geometric mean values (in microgram/g creatinine, $\mu \mathrm{g} / \mathrm{g}$ ) were determined and supplied along side the 
biomarker concentration $(\mu \mathrm{g} / \mathrm{L})$ for comparison. Additionally, the correlation of biomarker detects was conducted using Systat 13 in an attempt to determine if the exposures were associated with each other across the overall exposure group. Level of significance was reported based on the variance findings from the SAS analysis (either pooled or satterthwaite).

Logistic regression was performed on the data from the pesticide subsample. This regression used multiple independent variables to model the relationship between the predictive independent variables and the dichotomous, dependent outcome (a yes or no detection of the biomarker in the urine sample). Logistic regression predicted the change in the coefficient $(\beta)$ in relation to a change in the reference group based on the independent variables in the model: gender (dichotomous data), age (continuous data) and ethnicity (categorical data). The group with the largest amount of individuals was used as the reference group for gender and ethnicity. In these regression models, females and Non-Hispanic Whites were the largest groups. Additionally, the model supplied odds ratios to indicate which independent variable had a higher odds of having a detect for the biomarker in the urine sample in relation to the reference group.

A Students t-test was conducted and the arithmetic mean was determined for the height and weight of each of the biomarker detect and non-detect groups for children aged 6-11. This analysis determined if children with a recorded detect had a statistically significant difference in either height or weight when compared to those children that did 
not have a recorded exposure to the biomarker. Level of significance was reported based on the variance findings from the SAS analysis (either pooled or satterthwaite).

An additional data file supplied by the NHANES contained biochemical concentrations for participants aged 12-85+. Included in this file were the concentrations of liver and kidney enzymes, as well as electrolyte concentrations, among others. The biochemical concentrations were imported into an Access database. This information was used to create Excel files for overall male and female concentrations and overall participant concentrations. Student's t-tests were conducted on each break-down group and the arithmetic means were determined. These divisions would determine if age or gender differences show variations in the comparison of individuals that had a coded detect for the biomarker versus those with a non-detect. As with the other analyses, the level of significance was reported based on the variance findings from the SAS analysis (either pooled or satterthwaite).

The NHANES demographic database file, as well as the pesticide subsample file, contained values for interview weight, MEC exam weight and a value for maskedvariance pseudo-PSU [137]. These values were not incorporated into this data analysis. 


\section{Chapter 4}

\section{Results}

Results are grouped by pesticide and biomarker. Analysis for each biomarker was conducted to determine:

1. The overall and creatinine-adjusted geometric and arithmetic mean for all individuals in the sample.

2. Geometric mean for individuals coded as a detect for the biomarker.

3. Geometric mean comparison for males versus females.

4. Geometric mean comparison between ethnic groups.

5. Geometric mean comparisons for age groupings.

6. Height and weight comparisons for children based on detects versus non-detects.

7. Biochemical arithmetic mean comparisons for males, females and the biomarker overall.

8. Logistic regression comparison for all groups involved in the research. 


\subsection{Overall Detection Frequency}

TCPy and 3-PBA were detected in more than $75 \%$ of the sample. PNP met inclusion criteria by a small margin (53\%). The remaining specific biomarkers were detected in much lower amounts in the sample.

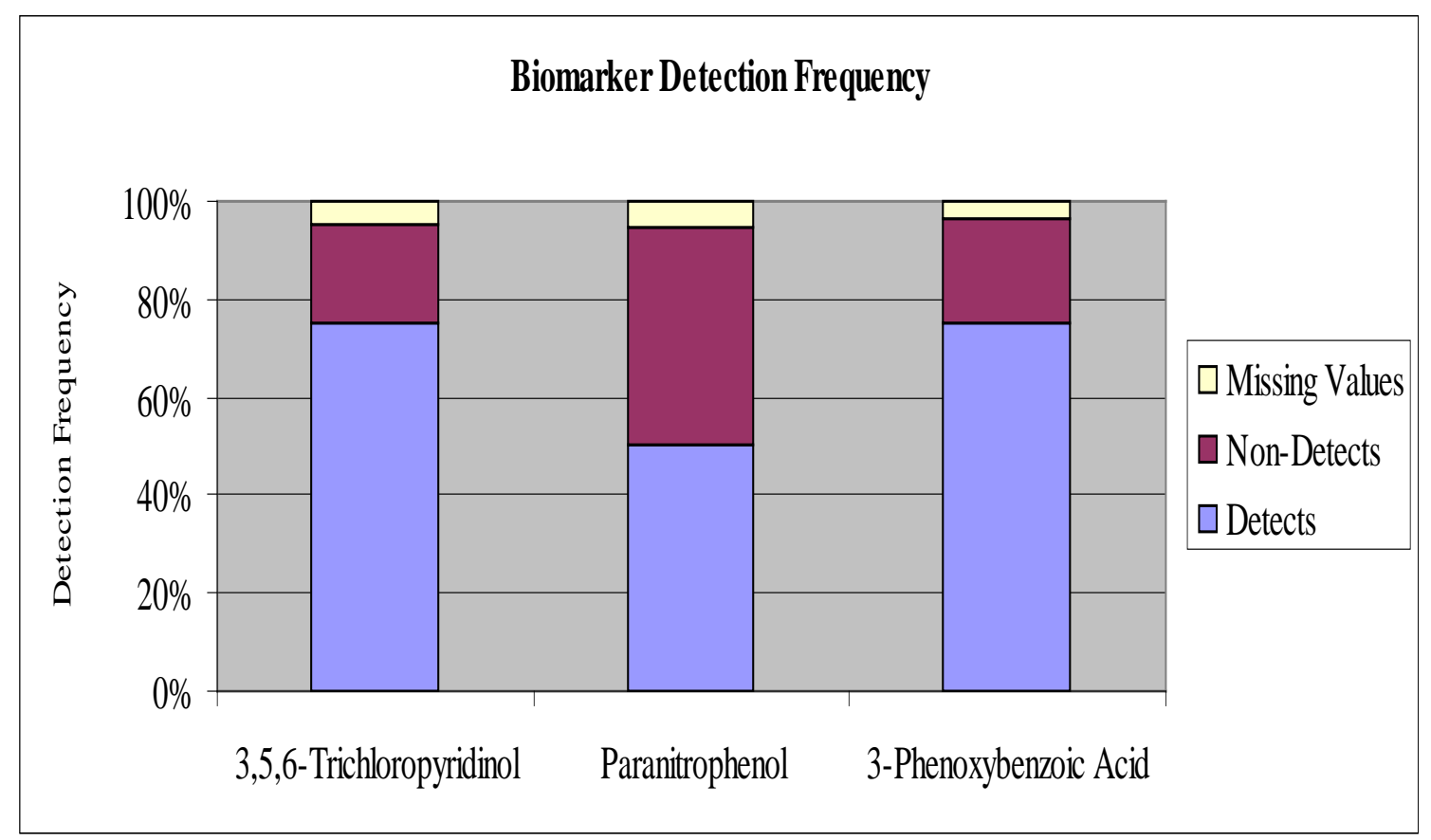

Figure 6: Detection Frequency of Urinary Pesticide Biomarkers. Detection frequencies for specific pesticide biomarkers can be viewed in Table 6 . 


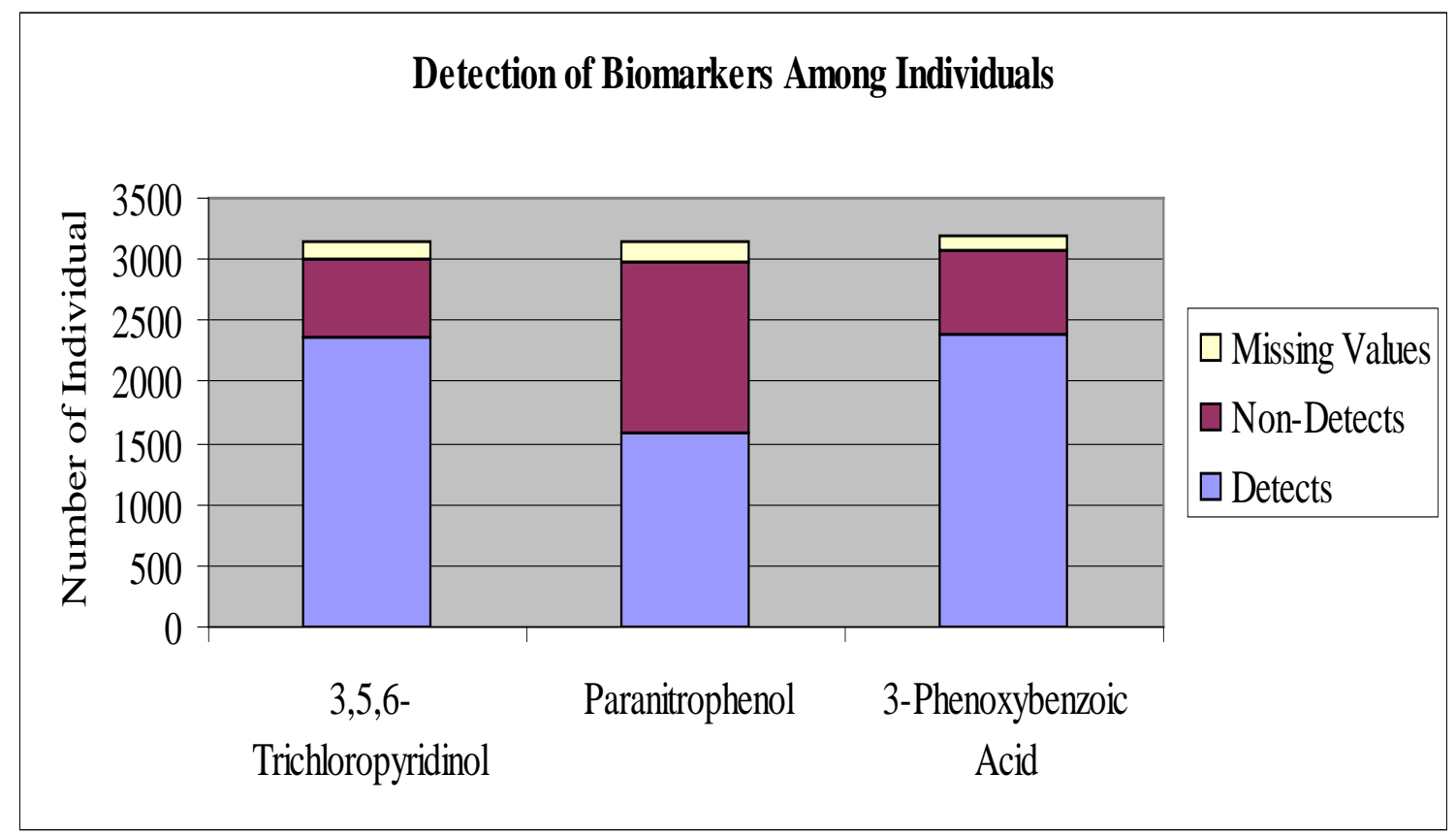

Figure 7: Number of Detections Among Individuals.

Table 6: Detections Among Individuals in the Dataset.

\begin{tabular}{|c|c|c|c|c|c|}
\hline & Detects & $\begin{array}{c}\text { Non- } \\
\text { Detects }\end{array}$ & $\begin{array}{c}\text { Missing } \\
\text { Values }\end{array}$ & $\begin{array}{c}\text { Total } \\
\text { Analyzed }\end{array}$ & $\begin{array}{c}\text { Detection } \\
\text { Frequency }\end{array}$ \\
\hline 3,5,6-Trichloropyridinol & 2368 & 643 & 141 & 3011 & $78.6 \%$ \\
\hline Paranitrophenol & 1580 & 1395 & 177 & 2975 & $53.1 \%$ \\
\hline 3-Phenoxybenzoic Acid & 2395 & 689 & 104 & 3048 & $77.4 \%$ \\
\hline
\end{tabular}




\subsection{Correlation of Exposures}

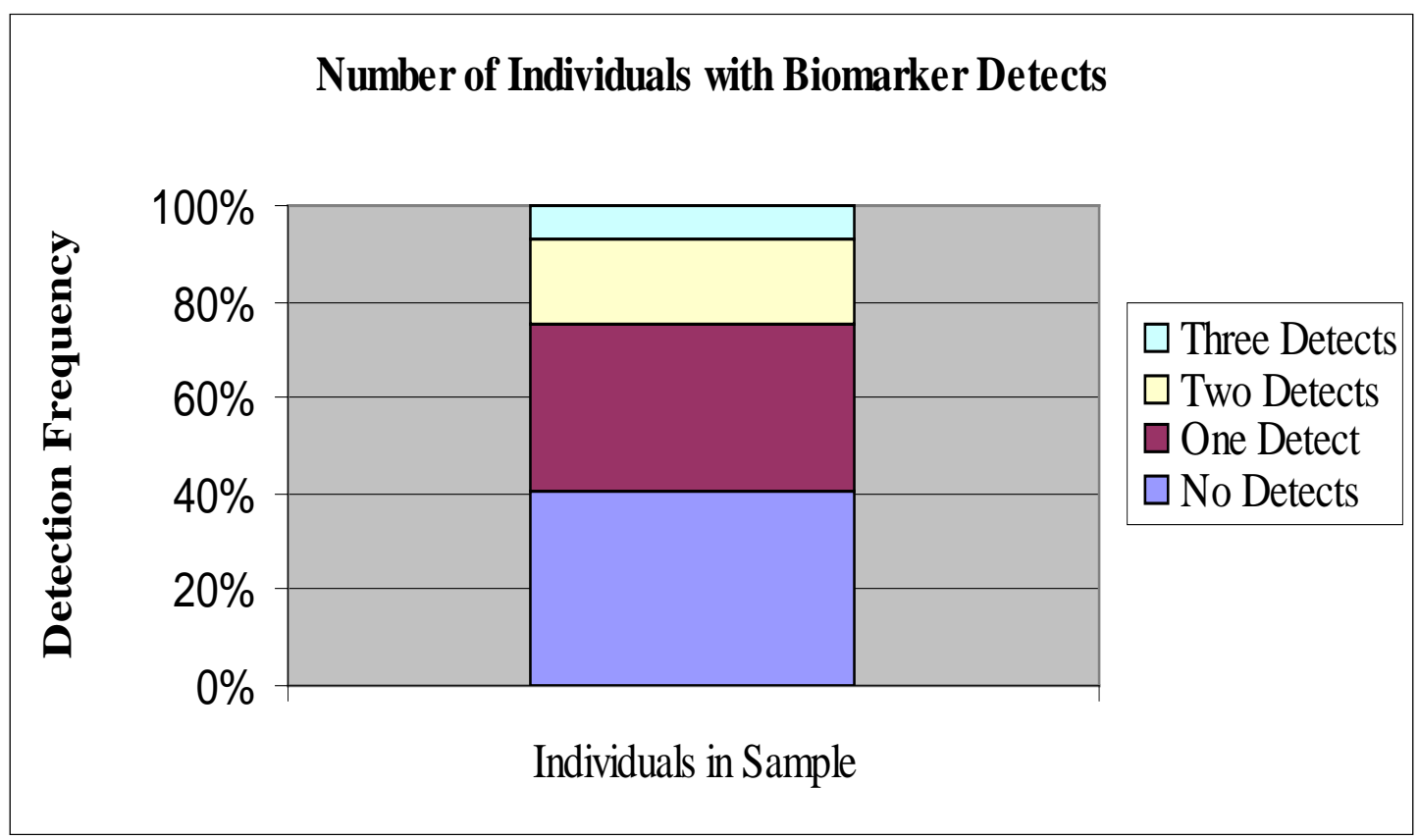

Figure 8: Detection Frequency of Biomarkers Among Individuals.

Table 7: Evaluation of Multiple Exposures Among Individuals in the Sample.

\begin{tabular}{|c|c|c|c|c|c|}
\hline & $\begin{array}{c}\text { No } \\
\text { Detects }\end{array}$ & $\begin{array}{c}\text { One } \\
\text { Detect }\end{array}$ & $\begin{array}{c}\text { Two } \\
\text { Detects }\end{array}$ & $\begin{array}{c}\text { Three } \\
\text { Detects }\end{array}$ & Total \\
\hline Number of Individuals & 1205 & 1030 & 536 & 204 & 2975 \\
\hline Percentage of Individuals & $40.50 \%$ & $34.60 \%$ & $18 \%$ & $6.90 \%$ & $100 \%$ \\
\hline
\end{tabular}

When evaluating individuals with detectable levels of the biomarker in their urine, 536 individuals had recorded detects for two biomarkers, while only 204 individuals were exposed to all three biomarkers. 


\section{Scatterplot Matrix}

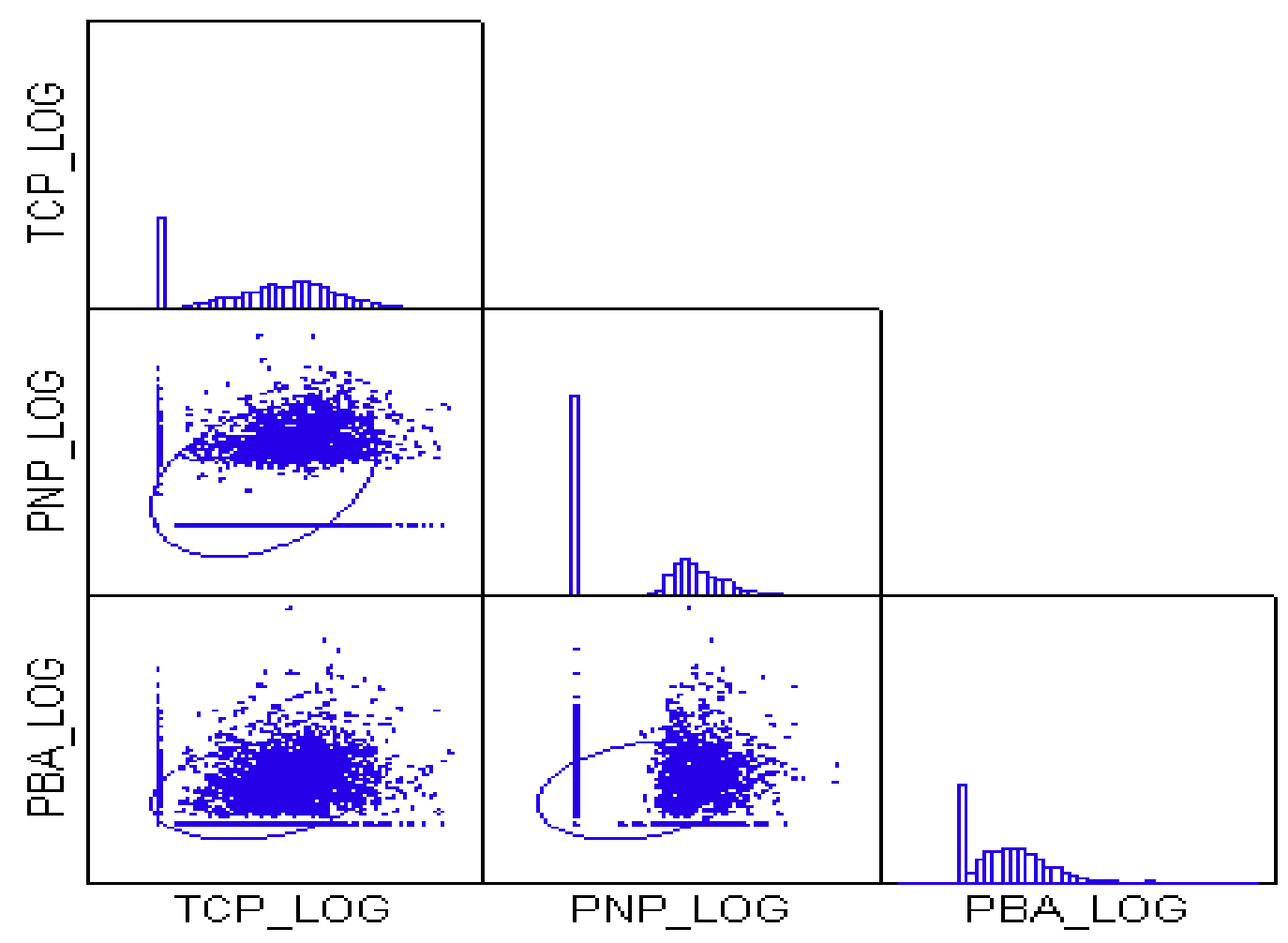

Figure 9: Pearson Correlation of Log-Transformed Biomarker Concentrations in Urine.

Table 8: Pearson Correlation Matrix.

\begin{tabular}{|c|c|c|c|}
\hline & TCP_LOG & PNP_LOG & PBA_LOG \\
\hline TCP_LOG & 1 & \multicolumn{2}{|c|}{} \\
\hline PNP_LOG & $\mathrm{r}=0.357$ & 1 & 1 \\
\hline PBA_LOG & $\mathrm{r}=0.267$ & $\mathrm{r}=0.28$ & \\
\hline
\end{tabular}

All values listed in Table 8 reflect the linear correlation between the biomarkers (r), as seen in Figure 9.

Table 9: Spearman Correlation Matrix.

\begin{tabular}{|c|c|c|c|}
\hline & TCP_LOG & PNP_LOG & PBA_LOG \\
\hline TCP_LOG & 1 & \multicolumn{2}{|c|}{} \\
\hline PNP_LOG & $\mathrm{r}_{\mathrm{s}}=0.37$ & 1 & 1 \\
\hline PBA_LOG & $\mathrm{r}_{\mathrm{s}}=0.299$ & $\mathrm{r}_{\mathrm{s}}=0.291$ & \\
\hline
\end{tabular}

This correlation examines the nonparametric correlation between the biomarkers $\left(\mathrm{r}_{\mathrm{s}}\right)$. 
Correlation analysis conducted on the log transformed data does not indicate that the levels are highly correlated. Both the Spearman and Pearson correlation was conducted to determine if the results varied. The results appear to be relatively close.

\subsection{Organophosphate}

\subsubsection{Chlorpyrifos Biomarker: 3,5,6-Trichloropyridinol (TCPy)}

\subsubsection{Descriptive Statistics}

The information covered in the following figures and tables characterizes the exposures to chlorpyrifos in the overall sample and in various subgroups.

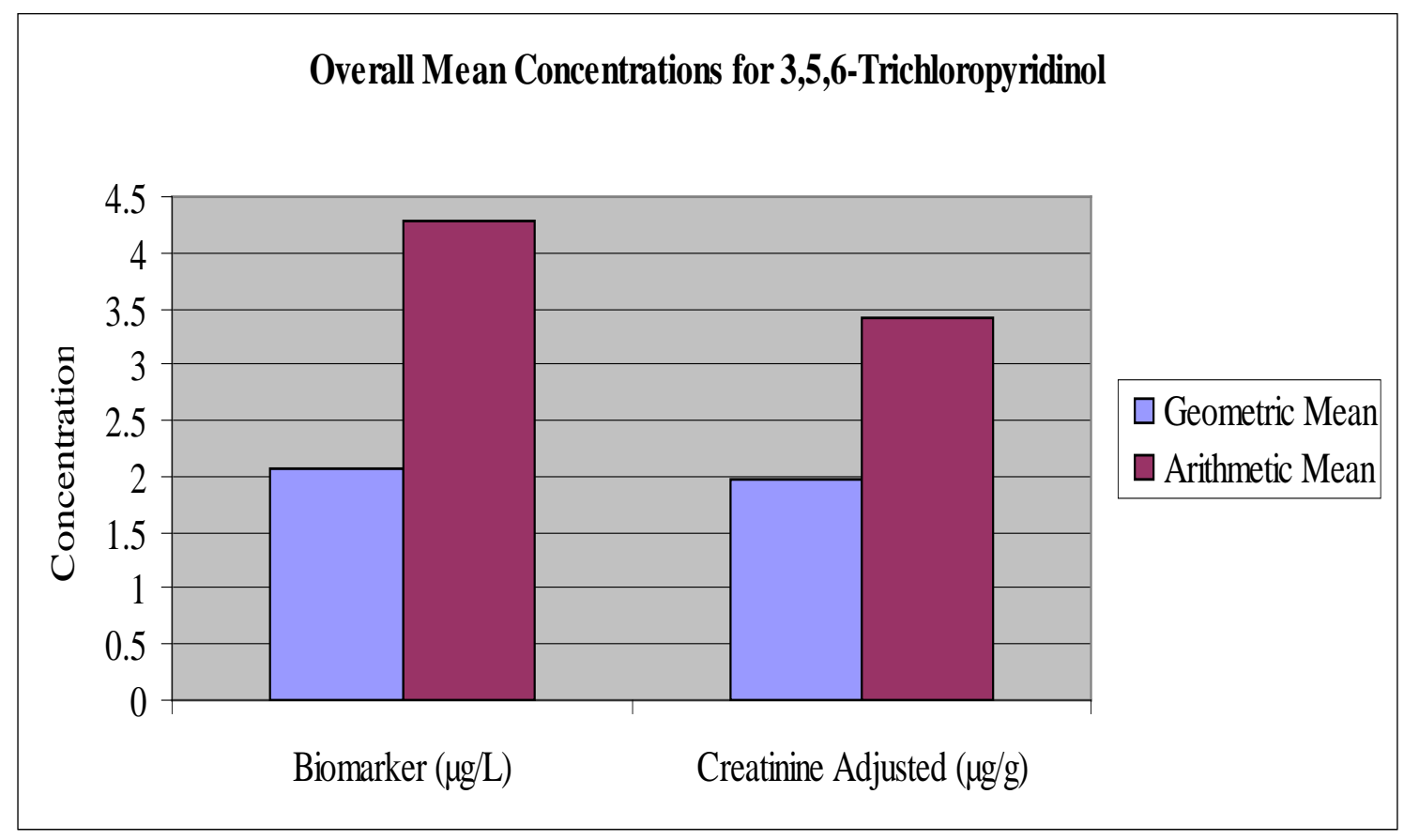

Figure 10: Comparison of Means for 3,5,6-Trichloropyridinol. $\mu \mathrm{g} / \mathrm{l}=$ Micrograms per Liter; $\mu \mathrm{g} / \mathrm{g}=$ Micrograms per Gram. Adjusting for creatinine results in means (both geometric and arithmetic) that are lower than if using the concentration of the TCPy biomarker in urine $(\mu \mathrm{g} / \mathrm{L})$ alone. Limit of Detection (LOD) for TCPy in sample was 0.4 $\mu \mathrm{g} / \mathrm{L}$. 
Table 10: Descriptive Statistics for 3,5,6-Trichloropyridinol.

\begin{tabular}{|c|c|c|}
\hline \multicolumn{3}{|c|}{ Biomarker $(\mu \mathrm{g} / \mathrm{L})^{\mathrm{a}}$} \\
\hline & $\begin{array}{c}\text { Geometric } \\
\text { Mean }\end{array}$ & $\begin{array}{c}\text { Arithmetic } \\
\text { Mean }\end{array}$ \\
\hline $\mathrm{n}^{\mathrm{c}}$ & 3011 & 3011 \\
\hline Mean & 2.07 & 4.28 \\
\hline $\mathrm{LCL}^{\mathrm{d}}$ & 1.98 & 4.06 \\
\hline $\mathrm{UCL}^{\mathrm{e}}$ & 2.17 & 4.50 \\
\hline $\mathrm{SD}^{\mathrm{f}}$ & 3.69 & 6.06 \\
\hline $\mathrm{P} 25^{\mathrm{g}}$ & 0.77 & 0.77 \\
\hline $\mathrm{P} 50^{\mathrm{h}}$ & 2.61 & 2.61 \\
\hline $\mathrm{P}^{2}{ }^{\mathrm{I}}$ & 5.33 & 5.33 \\
\hline P90 ${ }^{j}$ & 9.34 & 9.34 \\
\hline P95 $5^{\mathrm{K}}$ & 13.87 & 13.87 \\
\hline $\operatorname{Min}^{1}$ & 0.28 & 0.28 \\
\hline $\operatorname{Max}^{\mathrm{m}}$ & 79.59 & 79.59 \\
\hline
\end{tabular}

\begin{tabular}{|c|c|c|}
\hline \multicolumn{3}{|c|}{ Creatinine Adjusted $(\mu \mathrm{g} / \mathrm{g})^{\mathrm{b}}$} \\
\hline & $\begin{array}{c}\text { Geometric } \\
\text { Mean }\end{array}$ & $\begin{array}{c}\text { Arithmetic } \\
\text { Mean }\end{array}$ \\
\hline $\mathrm{n}$ & 3009 & 3009 \\
\hline Mean & 1.98 & 3.42 \\
\hline LCL & 1.91 & 3.25 \\
\hline UCL & 2.06 & 3.58 \\
\hline SD & 2.98 & 4.75 \\
\hline P25 & 1.08 & 1.08 \\
\hline P50 & 2.23 & 2.23 \\
\hline P75 & 4.08 & 4.08 \\
\hline P90 & 6.89 & 6.89 \\
\hline P95 & 10.27 & 10.27 \\
\hline Min & 0.0362 & 0.0362 \\
\hline Max & 97.29 & 97.29 \\
\hline
\end{tabular}

${ }^{a}(\mu \mathrm{g} / \mathrm{L})=$ Micrograms per Liter; ${ }^{\mathrm{b}}(\mu \mathrm{g} / \mathrm{g})=$ Micrograms per Gram; ${ }^{\mathrm{c}}(\mathrm{n})=$ Number in Sample; ${ }^{\mathrm{d}}(\mathrm{LCL})=$ Lower Confidence Limit; ${ }^{\mathrm{e}}(\mathrm{UCL})=$ Upper Confidence Limit; ${ }^{\mathrm{f}}(\mathrm{SD})=$ Standard Deviation; ${ }^{\mathrm{g}}(\mathrm{P} 25)=$ Lower Quartile; ${ }^{\mathrm{h}}(\mathrm{P} 50)=$ Median; ${ }^{\mathrm{i}}(\mathrm{P} 75)=$ Upper Quartile; ${ }^{\mathrm{j}}(\mathrm{P} 90)=90^{\text {th }}$ Percentile; ${ }^{\mathrm{k}}(\mathrm{P} 95)=95^{\text {th }}$ Percentile; ${ }^{\mathrm{l}}(\mathrm{Min})=$ Minimum ${ }^{\mathrm{m}}($ Max $)=$ Maximum 


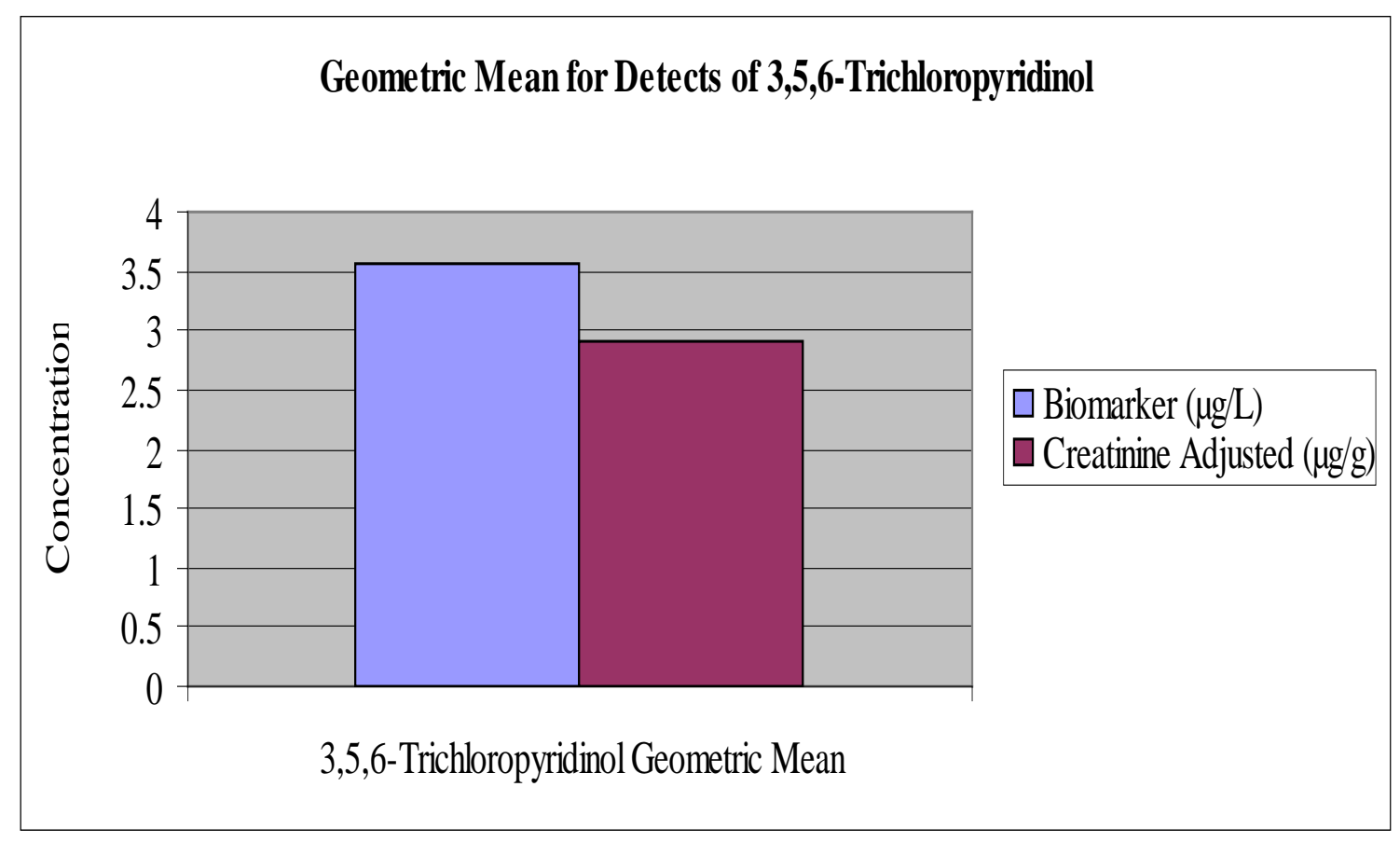

Figure 11: Comparison of Detectable Geometric Mean Concentrations for 3,5,6-Trichloropyridinol. $\mu \mathrm{g} / \mathrm{l}=$ Micrograms per Liter; $\mu \mathrm{g} / \mathrm{g}=$ Micrograms per Gram.

Table 11: Descriptive Statistics for Detectable Levels of 3,5,6-Trichloropyridinol.

\begin{tabular}{|l|c|c|c|c|c|c|}
\hline & $\mathrm{GM}^{\mathrm{c}}$ & $\mathrm{LCL}^{\mathrm{d}}$ & $\mathrm{UCL}^{\mathrm{e}}$ & $\mathrm{SD}^{\mathrm{f}}$ & Median & $\mathrm{n}^{\mathrm{g}}$ \\
\hline Biomarker $(\mu \mathrm{g} / \mathrm{L})^{\mathrm{a}}$ & 3.56 & 3.44 & 3.69 & 2.43 & 3.68 & 2368 \\
\hline Creatinine Adjusted $(\mu \mathrm{g} / \mathrm{g})^{\mathrm{b}}$ & 2.91 & 2.82 & 3.01 & 2.23 & 2.87 & 2366 \\
\hline
\end{tabular}

a $(\mu \mathrm{g} / \mathrm{L})=$ Micrograms per Liter; ${ }^{\mathrm{b}}(\mu \mathrm{g} / \mathrm{g})=$ Micrograms per Gram; ${ }^{\mathrm{c}}(\mathrm{GM})=$ Geometric Mean; ${ }^{\mathrm{d}}(\mathrm{LCL})=$ Lower Confidence Limit; ${ }^{\mathrm{e}}(\mathrm{UCL})=$ Upper Confidence Limit; ${ }^{\mathrm{f}}(\mathrm{SD})=$ Standard Deviation; ${ }^{\mathrm{g}}(\mathrm{n})=$ Number in Sample

The geometric mean was determined for $78.6 \%$ of the individuals that had a detectable level of biomarker in their urine sample. Based on this analysis, the geometric mean for only detectable levels of the biomarker was $1.49 \mu \mathrm{g} / \mathrm{L}$ higher that the overall geometric mean. 


\subsubsection{Comparative Statistics}

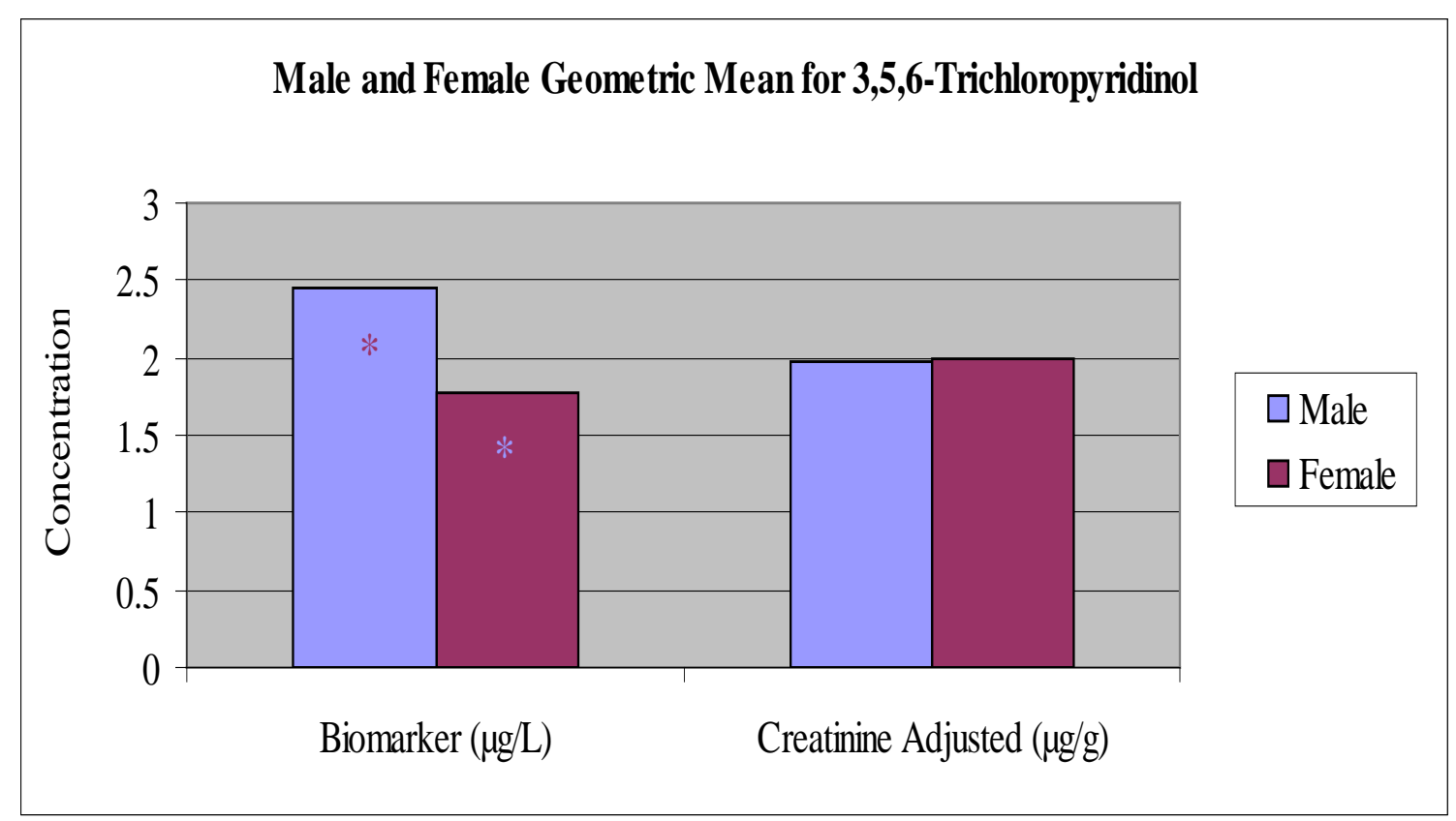

Figure 12: Comparison of Geometric Mean Values of Males Versus Females for 3,5,6-Trichloropyridinol. $\mu \mathrm{g} / \mathrm{l}=$ Micrograms per Liter; $\mu \mathrm{g} / \mathrm{g}=$ Micrograms per Gram. Color-coded “*” indicates males are significantly different from females. 
Table 12: Student's t-test Comparing Geometric Means of Males Versus Females for 3,5,6-Trichloropyridinol.

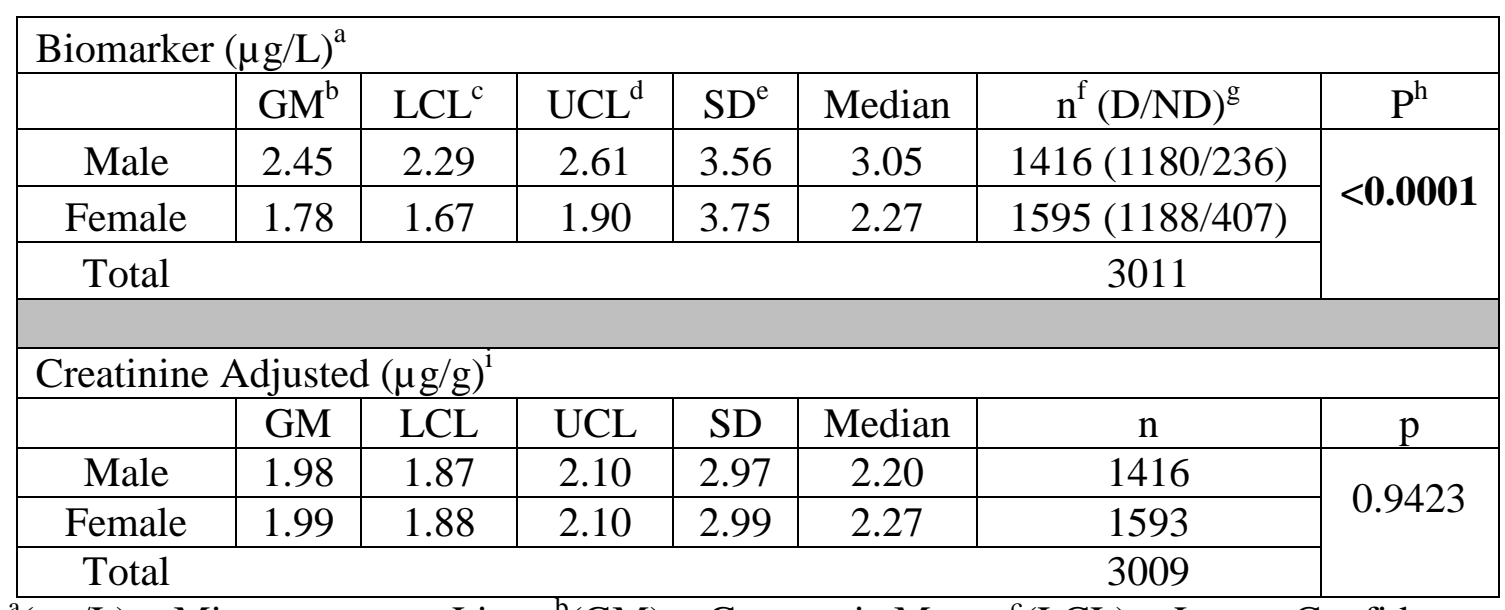

${ }^{\mathrm{a}}(\mu \mathrm{g} / \mathrm{L})=$ Micrograms per Liter; ${ }^{\mathrm{b}}(\mathrm{GM})=$ Geometric Mean; ${ }^{\mathrm{C}}(\mathrm{LCL})=$ Lower Confidence Limit; ${ }^{\mathrm{d}}(\mathrm{UCL})=$ Upper Confidence Limit; ${ }^{\mathrm{e}}(\mathrm{SD})=$ Standard Deviation; ${ }^{\mathrm{f}}(\mathrm{n})=$ Number in Sample; ${ }^{g}(\mathrm{D} / \mathrm{ND})=$ Number of Detects/Number of Non-Detects; ${ }^{\mathrm{h}}(\mathrm{p})=$ Level of Significance at $\mathrm{p}=0.05$ Level (Highlighted in Bold); ${ }^{\mathrm{i}}(\mu \mathrm{g} / \mathrm{g})=$ Micrograms per Gram

Males have a statistically significant higher geometric mean (GM) when compared to females, but only when using the unadjusted biomarker concentration in urine $(\mu \mathrm{g} / \mathrm{L})$. Adjusting for creatinine negates any significant difference. 


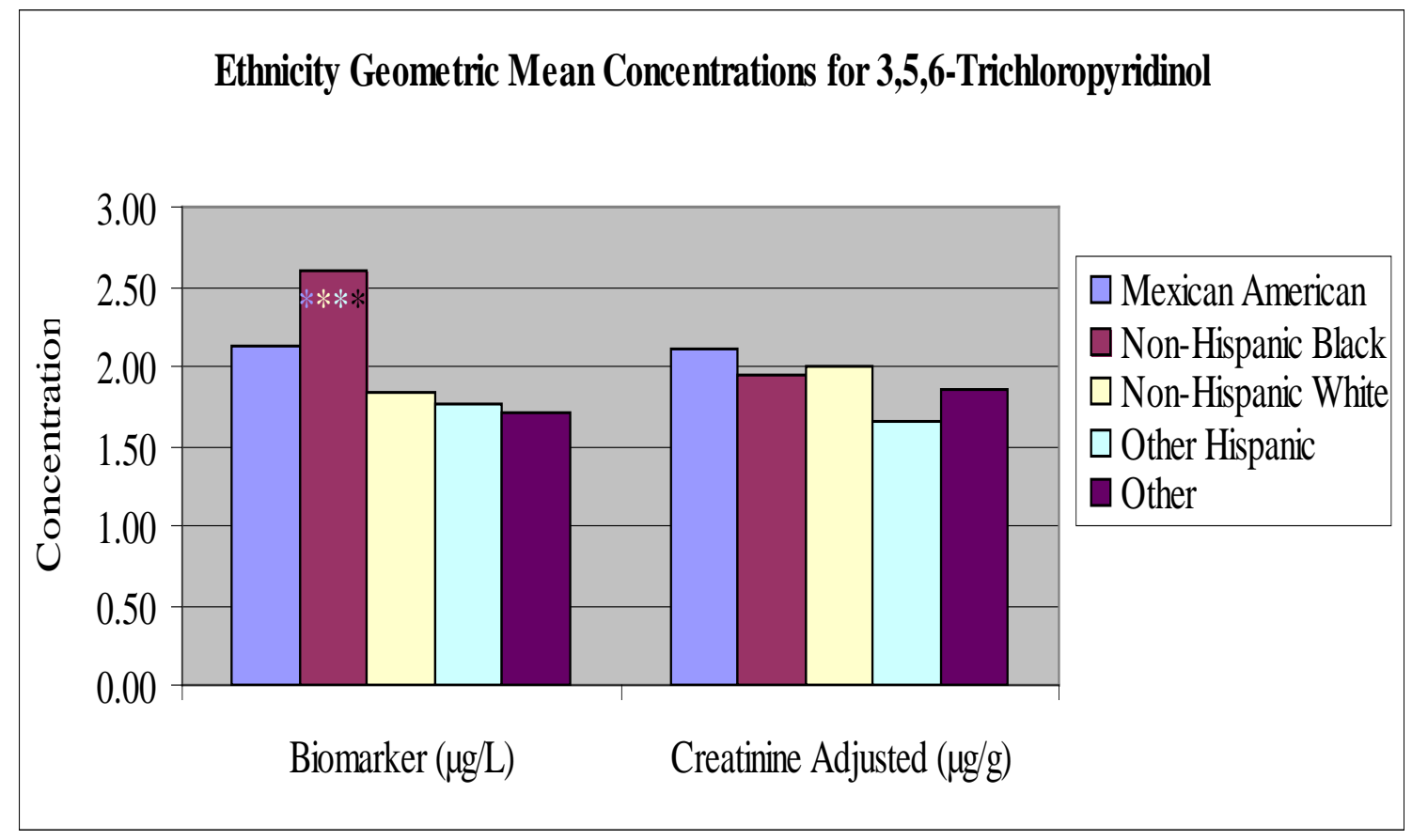

Figure 13: Comparison of Geometric Mean Values of Ethnic Groups for 3,5,6-Trichloropyridinol. $\mu \mathrm{g} / \mathrm{l}=$ Micrograms per Liter; $\mu \mathrm{g} / \mathrm{g}=$ Micrograms per Gram. Color-coded “****” indicates this groups is significantly different from all other groups. 
Table 13: One-Way ANOVA and Tukey Analysis Comparing Geometric Means of Ethnic Groups for 3,5,6-Trichloropyridinol.

\begin{tabular}{|c|c|c|c|c|c|c|}
\hline \multicolumn{7}{|l|}{ Biomarker $(\mu \mathrm{g} / \mathrm{L})^{\mathrm{a}}$} \\
\hline & $\mathrm{GM}^{\mathrm{b}}$ & $\mathrm{LCL}^{\mathrm{C}}$ & $\mathrm{UCL}^{\mathrm{d}}$ & $\mathrm{SD}^{\mathrm{e}}$ & $n^{f}(D / N D)^{g}$ & $\mathrm{P}^{\mathrm{h}}$ \\
\hline Mexican American & 2.12 & 1.88 & 2.37 & 3.36 & $744(611 / 133)$ & \multirow{6}{*}{$<0.0001$} \\
\hline Non-Hispanic Black *all & 2.60 & 2.35 & 2.85 & 3.52 & $762(635 / 127)$ & \\
\hline Non-Hispanic White & 1.84 & 1.62 & 2.05 & 3.88 & $1255(936 / 319)$ & \\
\hline Other Hispanic & 1.77 & 1.09 & 2.45 & 3.96 & $129(94 / 35)$ & \\
\hline Other & 1.70 & 0.99 & 2.41 & 3.97 & $121(92 / 29)$ & \\
\hline \multicolumn{5}{|l|}{ Total } & 3011 & \\
\hline \multicolumn{7}{|c|}{ Creatinine Adjusted $(\mu \mathrm{g} / \mathrm{g})^{\mathrm{i}}$} \\
\hline & GM & LCL & UCL & SD & $\mathrm{n}$ & $\mathrm{p}$ \\
\hline Mexican American & 2.10 & 1.91 & 2.30 & 2.74 & 744 & \multirow{6}{*}{0.1847} \\
\hline Non-Hispanic Black & 1.94 & 1.73 & 2.15 & 2.94 & 761 & \\
\hline Non-Hispanic White & 1.99 & 1.82 & 2.16 & 3.10 & 1254 & \\
\hline Other Hispanic & 1.66 & 1.09 & 2.23 & 3.30 & 129 & \\
\hline Other & 1.86 & 1.32 & 2.41 & 3.06 & 121 & \\
\hline \multicolumn{5}{|l|}{ Total } & 3009 & \\
\hline
\end{tabular}

${ }^{\mathrm{a}}(\mu \mathrm{g} / \mathrm{L})=$ Micrograms per Liter; ${ }^{\mathrm{b}}(\mathrm{GM})=$ Geometric Mean; ${ }^{\mathrm{C}}(\mathrm{LCL})=$ Lower Confidence Limit; ${ }^{\mathrm{d}}(\mathrm{UCL})=$ Upper Confidence Limit; ${ }^{\mathrm{e}}(\mathrm{SD})=$ Standard Deviation; ${ }^{\mathrm{f}}(\mathrm{n})=$ Number in Sample; ${ }^{\mathrm{g}}(\mathrm{D} / \mathrm{ND})=$ Number of Detects/Number of Non-Detects; ${ }^{\mathrm{h}}(\mathrm{p})=$ Level of Significance at $\mathrm{p}=0.05$ Level (Highlighted in Bold); ${ }^{\mathrm{i}}(\mu \mathrm{g} / \mathrm{g})=$ Micrograms per Gram. *all indicates that this group is significantly different than all other ethnic groups.

The unadjusted biomarker concentration in urine $(\mu \mathrm{g} / \mathrm{L})$ for non-Hispanic Blacks had a significantly elevated GM as compared with the other ethic groups. However, when adjusting for creatinine, there were no significant findings. 


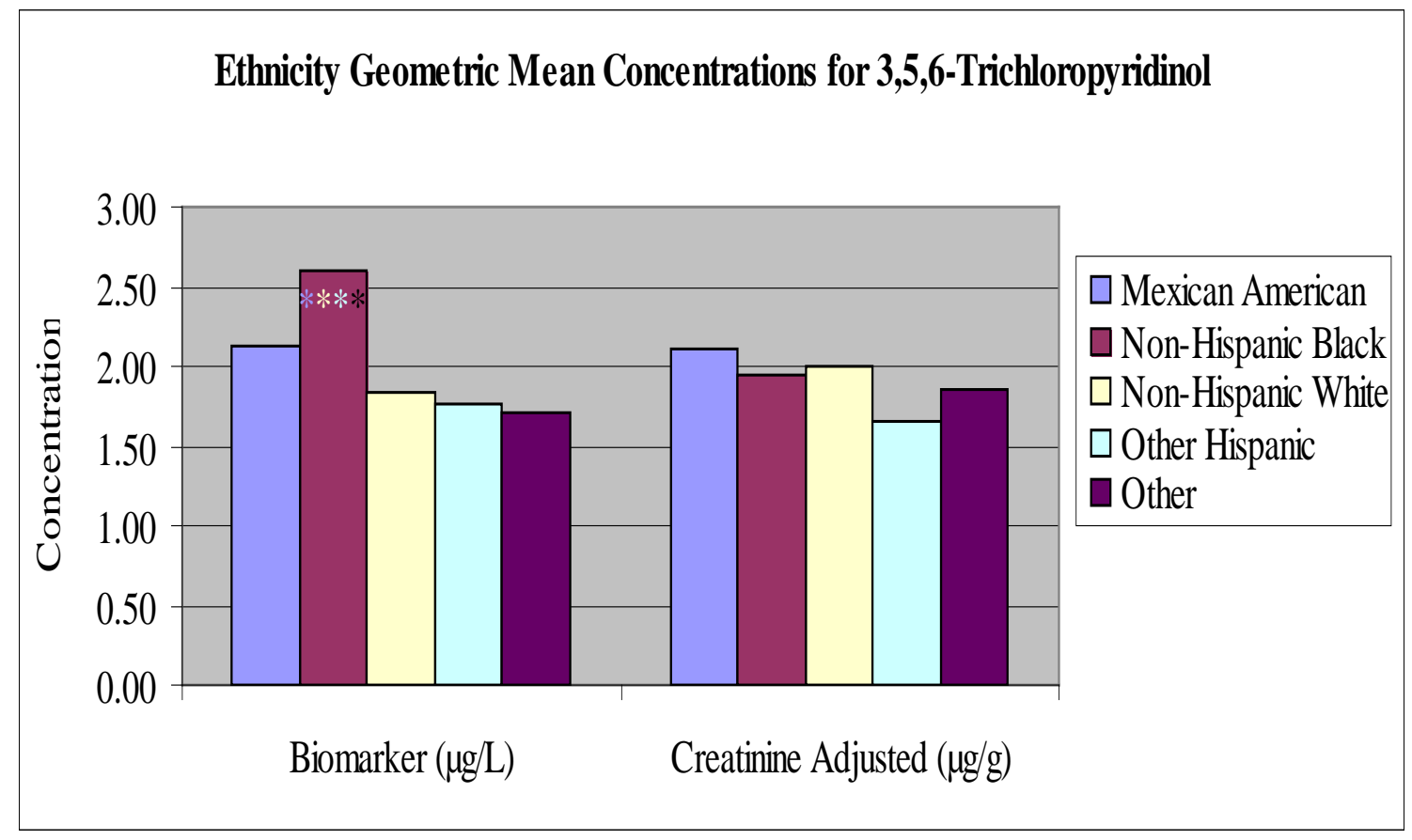

Figure 14: Comparison of Geometric Mean Values of Age Groups for 3,5,6-Trichloropyridinol. $\mu \mathrm{g} / \mathrm{l}=$ Micrograms per Liter; $\mu \mathrm{g} / \mathrm{g}=$ Micrograms per Gram. Color-coded “****” indicates which groups are significantly different from each other. 
Table 14: One-Way ANOVA and Tukey Analysis Comparing Geometric Means of Age Groups for 3,5,6-Trichloropyridinol.

\begin{tabular}{|c|c|c|c|c|c|c|}
\hline \multicolumn{7}{|c|}{ Biomarker $(\mu \mathrm{g} / \mathrm{L})^{\mathrm{a}}$} \\
\hline & $\mathrm{GM}^{\mathrm{b}}$ & $\mathrm{LCL}^{\mathrm{C}}$ & $\mathrm{UCL}^{\mathrm{d}}$ & $\mathrm{SD}^{\mathrm{e}}$ & $\mathrm{n}^{\mathrm{f}}(\mathrm{D} / \mathrm{ND})^{\mathrm{g}}$ & $\mathrm{P}^{\mathrm{h}}$ \\
\hline Children* & 2.72 & 2.44 & 2.99 & 3.39 & $573(491 / 82)$ & \multirow{4}{*}{$<0.0001$} \\
\hline Adolescent* & 2.84 & 2.59 & 3.08 & 3.38 & $741(643 / 98)$ & \\
\hline Adult** & 1.65 & 1.47 & 1.83 & 3.77 & $1697(1234 / 463)$ & \\
\hline \multicolumn{6}{|l|}{ Total } & \\
\hline \multicolumn{7}{|c|}{ Creatinine Adjusted $(\mu \mathrm{g} / \mathrm{g})^{\mathrm{i}}$} \\
\hline & GM & LCL & UCL & $\mathrm{SD}$ & $\mathrm{n}$ & $\mathrm{p}$ \\
\hline Children*** & 3.26 & 3.03 & 3.49 & 2.78 & 573 & \multirow{4}{*}{$<0.0001$} \\
\hline Adolescent*** & 2.09 & 1.90 & 2.28 & 2.66 & 740 & \\
\hline Adult*** & 1.76 & 1.61 & 1.90 & 3.02 & 1696 & \\
\hline Total & & & & & 3009 & \\
\hline
\end{tabular}

${ }^{\mathrm{a}}(\mu \mathrm{g} / \mathrm{L})=$ Micrograms per Liter; ${ }^{\mathrm{b}}(\mathrm{GM})=$ Geometric Mean; ${ }^{\mathrm{C}}(\mathrm{LCL})=$ Lower Confidence Limit; ${ }^{\mathrm{d}}(\mathrm{UCL})=$ Upper Confidence Limit; ${ }^{\mathrm{e}}(\mathrm{SD})=$ Standard Deviation; ${ }^{\mathrm{f}}(\mathrm{n})=$ Number in Sample; ${ }^{g}(\mathrm{D} / \mathrm{ND})=$ Number of Detects/Number of Non-Detects; ${ }^{\mathrm{h}}(\mathrm{p})=$ Level of Significance at $\mathrm{p}=0.05$ Level (Highlighted in Bold); $(\mu \mathrm{g} / \mathrm{g})=$ Micrograms per Gram.

* Indicates group is significantly different from Adults.

** Indicates that group is significantly different from Adolescents and Children.

*** Indicates that all groups are significantly different from each other.

Significant differences are present for both the biomarker concentration in urine ( $\mu \mathrm{g} / \mathrm{L})$ and when adjusting for creatinine $(\mu \mathrm{g} / \mathrm{g})$. For the unadjusted urinary biomarker concentration, children and adolescents are significantly elevated when compared to adults; however, there is no significant difference between children and adolescents within the same group. All three groups had a significant difference when adjusting for creatinine. 


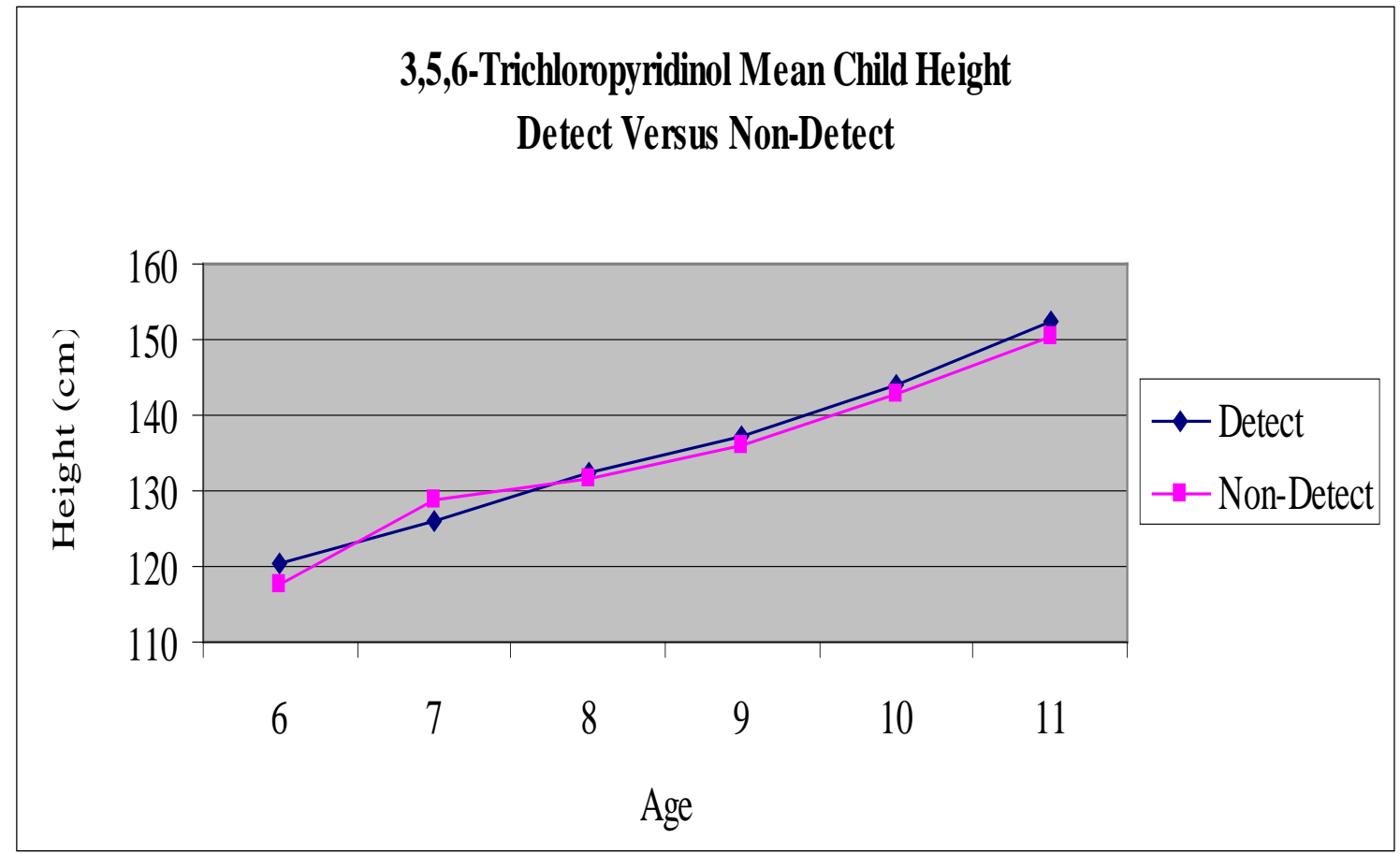

Figure 15: Graph of Arithmetic Mean Height for Detects Versus Non-Detects for 3,5,6-Trichloropyridinol, Ages 6-11. cm= Centimeter. 
Table 15: Student's t-test Comparing Detects Versus Non-Detects for Arithmetic Mean of Height for 3,5,6-Trichloropyridinol.

\begin{tabular}{|c|c|c|c|c|c|c|c|}
\hline Age & Detect $^{\mathrm{a}}$ & Mean $\left(\mathrm{cm}^{\mathrm{b}}\right)$ & $\mathrm{LCL}^{\mathrm{C}}$ & $\mathrm{UCL}^{\mathrm{d}}$ & $\mathrm{SD}^{\mathrm{e}}$ & $n^{f}$ & $\mathrm{p}^{\mathrm{g}}$ \\
\hline \multirow{2}{*}{6} & Yes & 120.4 & 119 & 121.7 & 5.90 & 74 & \multirow{2}{*}{0.096} \\
\hline & No & 117.5 & 114.6 & 120.4 & 5.05 & 14 & \\
\hline \multirow{2}{*}{7} & Yes & 125.9 & 124.7 & 127.1 & 5.54 & 86 & \multirow{2}{*}{0.165} \\
\hline & No & 128.8 & 124.7 & 132.8 & 7.90 & 17 & \\
\hline \multirow{2}{*}{8} & Yes & 132.5 & 130.7 & 134.3 & 8.02 & 77 & \multirow{2}{*}{0.682} \\
\hline & No & 131.4 & 126.9 & 135.9 & 6.30 & 10 & \\
\hline \multirow{2}{*}{9} & Yes & 137.2 & 135.7 & 138.7 & 7.45 & 98 & \multirow{2}{*}{0.492} \\
\hline & No & 135.8 & 132.7 & 138.9 & 5.28 & 14 & \\
\hline \multirow{2}{*}{10} & Yes & 144 & 141.9 & 146 & 8.24 & 67 & \multirow{2}{*}{0.685} \\
\hline & No & 142.9 & 138.8 & 147 & 6.04 & 11 & \\
\hline \multirow{2}{*}{11} & Yes & 152.6 & 150.9 & 154.3 & 8.14 & 88 & \multirow{2}{*}{0.360} \\
\hline & No & 150.6 & 146.6 & 154.5 & 7.14 & 15 & \\
\hline
\end{tabular}

(Detect) $=$ Detectable Level of Biomarker in the Urine Sample; ${ }^{b}(\mathrm{~cm})=$ Centimeters;

${ }^{c}($ LCL $)=$ Lower Confidence Limit; ${ }^{\mathrm{d}}(\mathrm{UCL})=$ Upper Confidence Limit; ${ }^{\mathrm{e}}(\mathrm{SD})=$ Standard Deviation; ${ }^{\mathrm{f}}(\mathrm{n})=$ Number in Sample; ${ }^{\mathrm{g}}(\mathrm{p})=$ Level of Significance at $\mathrm{p}=0.05$ Level

There are no significant differences at the $\mathrm{p}<0.05$ level between detect and nondetect urinary concentrations of 3,5,6-trichloropyridinol when evaluating variations in children's height. 


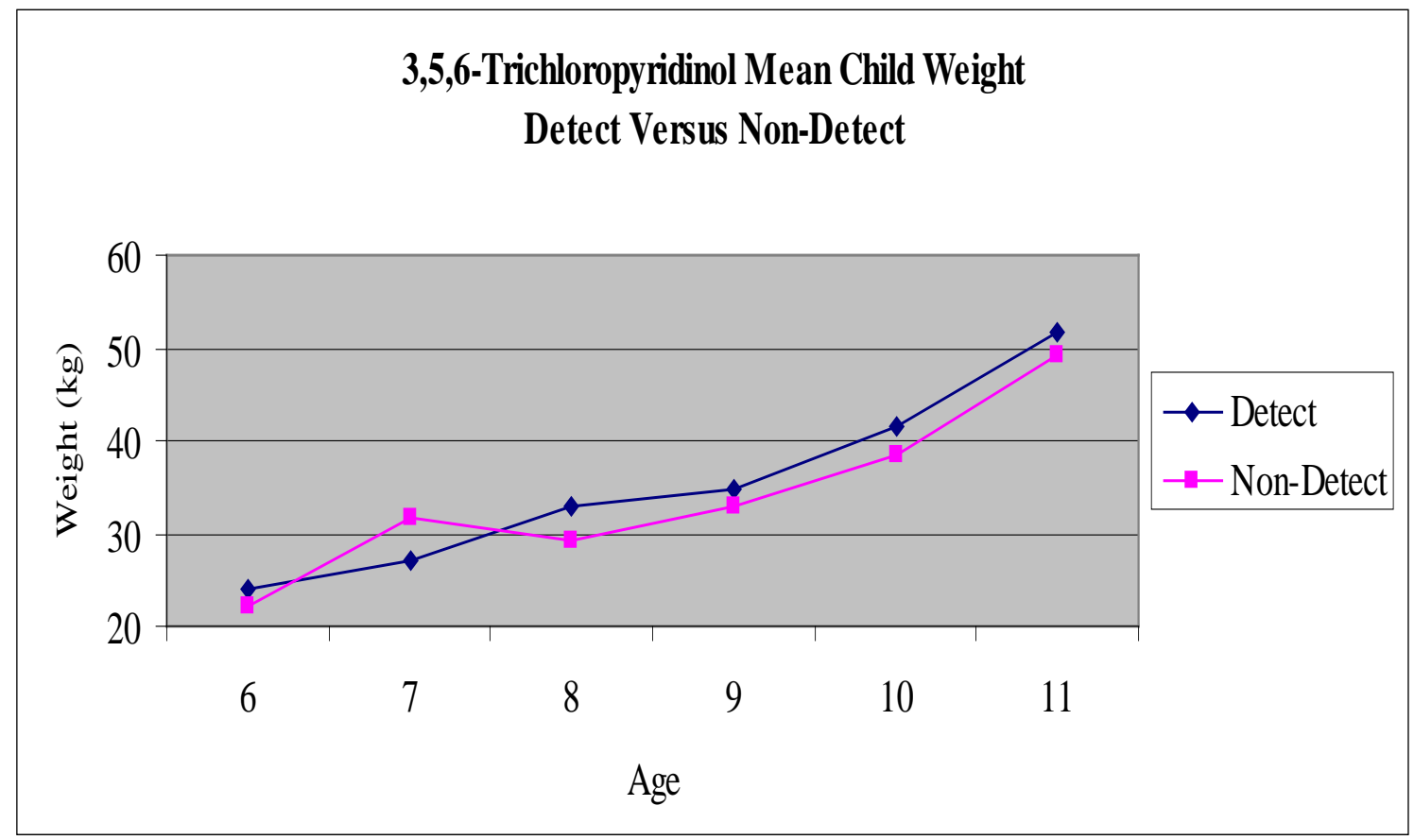

Figure 16: Graph of Arithmetic Mean Weight for Detects Versus Non-Detects for 3,5,6Trichloropyridinol, Ages 6-11. Kg= Kilograms 
Table 16: Student's t-test Comparing Detects Versus Non-Detects for Arithmetic Mean of Weight for 3,5,6-Trichloropyridinol.

\begin{tabular}{|c|c|c|c|c|c|c|c|}
\hline Age & Detect $^{\mathrm{a}}$ & Mean $\left(\mathrm{Kg}^{\mathrm{b}}\right)$ & $\mathrm{LCL}^{\mathrm{C}}$ & $\mathrm{UCL}^{\mathrm{d}}$ & $\mathrm{SD}^{\mathrm{e}}$ & $n^{f}$ & $\mathrm{p}^{\mathrm{g}}$ \\
\hline \multirow{2}{*}{6} & Yes & 23.86 & 22.91 & 24.81 & 4.09 & 74 & \multirow{2}{*}{0.201} \\
\hline & No & 22.29 & 19.59 & 24.98 & 4.66 & 14 & \\
\hline \multirow{2}{*}{7} & Yes & 27.07 & 25.91 & 28.23 & 5.37 & 85 & \multirow{2}{*}{0.080} \\
\hline & No & 31.56 & 26.58 & 36.55 & 9.69 & 17 & \\
\hline \multirow{2}{*}{8} & Yes & 33.07 & 30.69 & 35.45 & 10.34 & 75 & \multirow{2}{*}{0.258} \\
\hline & No & 29.23 & 24.37 & 34.09 & 6.79 & 10 & \\
\hline \multirow{2}{*}{9} & Yes & 34.83 & 32.78 & 36.87 & 10.10 & 96 & \multirow{2}{*}{0.532} \\
\hline & No & 33.06 & 28.50 & 37.61 & 7.89 & 14 & \\
\hline \multirow{2}{*}{10} & Yes & 41.49 & 38.22 & 44.77 & 13.42 & 67 & \multirow{2}{*}{0.453} \\
\hline & No & 38.34 & 32.74 & 43.93 & 8.32 & 11 & \\
\hline \multirow{2}{*}{11} & Yes & 51.65 & 47.52 & 55.77 & 19.11 & 85 & \multirow{2}{*}{0.640} \\
\hline & No & 49.20 & 40.58 & 57.82 & 15.56 & 15 & \\
\hline
\end{tabular}

${ }^{a}($ Detect $)=$ Detectable Level of Biomarker in the Urine Sample; ${ }^{b}(\mathrm{Kg})=$ Kilograms;

${ }^{\mathrm{c}}(\mathrm{LCL})=$ Lower Confidence Limit; ${ }^{\mathrm{d}}(\mathrm{UCL})=$ Upper Confidence Limit; ${ }^{\mathrm{e}}(\mathrm{SD})$ = Standard Deviation; ${ }^{\mathrm{f}}(\mathrm{n})=$ Number in Sample; ${ }^{\mathrm{g}}(\mathrm{p})=$ Level of Significance at $\mathrm{p}=0.05$ Level

There are no significant differences at the $\mathrm{p}<0.05$ level between detect and nondetect urinary concentrations of 3,5,6-trichloropyridinol when evaluating variations in children's weight. 
Table 17: 3,5,6-Trichloropyridinol Female Biochemical t-test Comparisons.

\begin{tabular}{|c|c|c|c|c|c|c|c|c|c|}
\hline Biochemical & Detect $^{\mathrm{a}}$ & Mean & $\mathrm{LCL}^{\mathrm{b}}$ & $\mathrm{UCL}^{\mathrm{c}}$ & $\mathrm{SD}^{\mathrm{d}}$ & $\mathrm{n}^{\mathrm{e}}$ & $\operatorname{Min}^{f}$ & $\operatorname{Max}^{\mathrm{g}}$ & $\mathrm{p}^{\mathrm{h}}$ \\
\hline \multirow{2}{*}{ Alanine Transaminase $(\mathrm{U} / \mathrm{L})^{\mathrm{i}}$} & Yes & 18.76 & 18.15 & 19.38 & 9.29 & 874 & 5 & 102 & \multirow{2}{*}{0.177} \\
\hline & No & 19.58 & 18.52 & 20.64 & 9.90 & 340 & 5 & 102 & \\
\hline \multirow{2}{*}{ Albumin $(g / d L)^{j}$} & Yes & 4.17 & 4.14 & 4.19 & 0.34 & 874 & 2.6 & 5 & \multirow{2}{*}{0.661} \\
\hline & No & 4.16 & 4.12 & 4.20 & 0.36 & 340 & 2.6 & 5 & \\
\hline \multirow{2}{*}{ Alkaline Phosphatase (U/L) } & Yes & 83.76 & 80.85 & 86.67 & 43.90 & 874 & 30 & 424 & \multirow{2}{*}{0.002} \\
\hline & No & 76.11 & 72.35 & 79.87 & 35.25 & 340 & 24 & 269 & \\
\hline \multirow{2}{*}{ Aspartate Transaminase (U/L) } & Yes & 21.56 & 21.07 & 22.04 & 7.34 & 874 & 9 & 114 & \multirow{2}{*}{0.296} \\
\hline & No & 22.05 & 21.26 & 22.83 & 7.35 & 340 & 7 & 84 & \\
\hline \multirow{2}{*}{ Bicarbonate $(\mathrm{mmol} / \mathrm{L})^{\mathrm{k}}$} & Yes & 22.76 & 22.61 & 22.90 & 2.22 & 874 & 16 & 29 & \multirow{2}{*}{0.001} \\
\hline & No & 23.24 & 23.01 & 23.47 & 2.18 & 340 & 18 & 29 & \\
\hline \multirow{2}{*}{ Bilirubin $(\mathrm{mg} / \mathrm{dL})^{\mathrm{l}}$} & Yes & 0.66 & 0.64 & 0.67 & 0.22 & 874 & 0.2 & 2.1 & \multirow{2}{*}{0.876} \\
\hline & No & 0.66 & 0.64 & 0.68 & 0.20 & 340 & 0.2 & 1.6 & \\
\hline \multirow{2}{*}{ Blood Urea Nitrogen (mg/dL) } & Yes & 11.99 & 11.58 & 12.41 & 6.23 & 874 & 2 & 122 & \multirow{2}{*}{0.912} \\
\hline & No & 11.95 & 11.37 & 12.53 & 5.45 & 340 & 3 & 53 & \\
\hline \multirow{2}{*}{ Total Calcium (mg/dL) } & Yes & 9.43 & 9.40 & 9.45 & 0.39 & 874 & 8.1 & 11 & \multirow{2}{*}{0.095} \\
\hline & No & 9.47 & 9.43 & 9.51 & 0.39 & 340 & 8.3 & 10.7 & \\
\hline \multirow{2}{*}{ Chloride (mmol/L) } & Yes & 103.20 & 103.00 & 103.40 & 2.61 & 874 & 89 & 111 & \multirow{2}{*}{0.034} \\
\hline & No & 102.80 & 102.50 & 103.10 & 2.87 & 339 & 89 & 113 & \\
\hline \multirow{2}{*}{ Cholesterol (mg/dL) } & Yes & 186.90 & 184.10 & 189.70 & 42.13 & 874 & 91 & 460 & \multirow{2}{*}{$<.0001$} \\
\hline & No & 202.50 & 197.50 & 207.60 & 47.30 & 340 & 90 & 476 & \\
\hline \multirow{2}{*}{ Creatinine (mg/dL) } & Yes & 0.72 & 0.71 & 0.74 & 0.22 & 874 & 0.3 & 4.4 & 0.019 \\
\hline & No & 0.76 & 0.73 & 0.78 & 0.23 & 340 & 0.3 & 3.1 & 0.019 \\
\hline$\gamma$ Glutamvl Transferase (U/L) & Yes & 19.54 & 18.28 & 20.80 & 18.96 & 874 & 4 & 266 & \\
\hline$\gamma$ Glutamyı I ransterase (U/L) & No & 22.27 & 19.41 & 25.14 & 26.88 & 340 & 6 & 369 & $0.08 /$ \\
\hline & Yes & 3.18 & 3.15 & 3.21 & 0.40 & 874 & 2.3 & 5.4 & 0062 \\
\hline GIODUIn (mg/aL) & No & 3.13 & 3.09 & 3.17 & 0.39 & 340 & 2.2 & 4.6 & 0.002 \\
\hline & Yes & 89.21 & 87.47 & 90.95 & 26.25 & 874 & 34 & 453 & 0171 \\
\hline Glucose (mg/dL) & No & 92.16 & 88.30 & 96.03 & 36.20 & 340 & 30 & 521 & $0.1 / 1$ \\
\hline & Yes & 82.01 & 79.56 & 84.47 & 37.03 & 874 & 7 & 240 & \\
\hline Iron (mg/dL) & No & 83.14 & 79.11 & 87.16 & 37.75 & 340 & 12 & 268 & 0.638 \\
\hline Lactate Debydrooenase (U/L) & Yes & 130.80 & 129.00 & 132.70 & 28.33 & 874 & 58 & 470 & 0745 \\
\hline Lactate Denyarogenase (U/L) & No & 130.20 & 127.20 & 133.30 & 28.62 & 339 & 51 & 329 & 0.745 \\
\hline Ocmolality $(\mathrm{mmol} / \mathrm{Ko})^{\mathrm{m}}$ & Yes & 275.50 & 275.10 & 275.90 & 5.53 & 874 & 248 & 310 & 0989 \\
\hline Usmorallty (1111101/Rg) & No & 275.50 & 274.90 & 276.10 & 5.55 & 340 & 252 & 294 & \\
\hline & Yes & 4.00 & 3.96 & 4.04 & 0.58 & 874 & 2.3 & 6.1 & 0019 \\
\hline Phosphorus (mg/dL) & No & 3.92 & 3.87 & 3.98 & 0.53 & 340 & 2.3 & 5.8 & 0.019 \\
\hline Potassium (mmol/L) & Yes & 3.98 & 3.96 & 4.00 & 0.33 & 874 & 2.6 & 6 & \\
\hline Potassium (mmol/L) & No & 4.01 & 3.97 & 4.05 & 0.36 & 340 & 2.9 & 5.3 & $0.1 / 9$ \\
\hline Total Protein ( $\mathrm{g} / \mathrm{dL})$ & Yes & 7.35 & 7.31 & 7.38 & 0.48 & 874 & 5.5 & 9.5 & \\
\hline rotal Proteln (g/aL) & No & 7.29 & 7.24 & 7.34 & 0.50 & 340 & 5.9 & 9.1 & 0.068 \\
\hline & Yes & 138.30 & 138.20 & 138.50 & 2.51 & 874 & 124 & 147 & \\
\hline soaium (mmol/L) & No & 138.30 & 138.00 & 138.50 & 2.53 & 340 & 125 & 145 & 0.551 \\
\hline & Yes & 116.00 & 110.80 & 121.30 & 78.40 & 874 & 23 & 742 & \\
\hline Triglycerides (mg/dL) & No & 131.60 & 120.60 & 142.70 & 103.70 & 340 & 28 & 1077 & 0.013 \\
\hline & Yes & 4.50 & 4.42 & 4.58 & 1.19 & 874 & 0.4 & 10.9 & \\
\hline Uric Acia (mg/aL) & No & 4.70 & 4.55 & 4.85 & 1.39 & 340 & 2.4 & 13.9 & 0.018 \\
\hline
\end{tabular}

${ }^{\mathrm{a}}$ (Detect) $=$ Detectable Level of Biomarker in the Urine Sample; ${ }^{\mathrm{b}}(\mathrm{LCL})=$ Lower Confidence Limit; ' $($ UCL $)=$ Upper Confidence Limit; ${ }^{\mathrm{d}}(\mathrm{SD})=$ Standard Deviation; ${ }^{\mathrm{e}}(\mathrm{n})=$ Number in Sample; ${ }^{\mathrm{f}}(\mathrm{Min})=$ Minimum; ${ }^{\mathrm{g}}(\mathrm{Max})=$ Maximum; ${ }^{\mathrm{h}}(\mathrm{p})=$ Level of Significance at $\mathrm{p}=0.05$ Level (highlighted in Bold); ${ }^{\mathrm{i}}(\mathrm{U} / \mathrm{L})=$ Units per Liter; ${ }^{\mathrm{j}}(\mathrm{g} / \mathrm{dL})=$ Grams per Deciliter; ${ }^{\mathrm{k}}(\mathrm{mmol} / \mathrm{L})=$ Millimole per Liter; ${ }^{\mathrm{l}}(\mathrm{mg} / \mathrm{dL})=$ Milligram per Deciliter; ${ }^{\mathrm{m}}(\mathrm{mmol} / \mathrm{Kg})=$ Millimole per Kilogram 
Table 18: 3,5,6-Trichloropyridinol Male Biochemical t-test Comparisons.

\begin{tabular}{|c|c|c|c|c|c|c|c|c|c|}
\hline Biochemical & Detect $^{\mathrm{a}}$ & Mean & $\mathrm{LCL}^{\mathrm{b}}$ & $\mathrm{UCL}^{\mathrm{c}}$ & $\mathrm{SD}^{\mathrm{d}}$ & $\mathrm{n}^{\mathrm{e}}$ & $\operatorname{Min}^{f}$ & $\operatorname{Max}^{\mathrm{g}}$ & $\mathrm{p}^{\mathrm{h}}$ \\
\hline \multirow{2}{*}{ Alanine Transaminase $(\mathrm{U} / \mathrm{L})^{\mathrm{i}}$} & Yes & 26.67 & 25.42 & 27.93 & 19.08 & 892 & 7 & 243 & \multirow{2}{*}{0.861} \\
\hline & No & 26.46 & 24.42 & 28.50 & 13.93 & 181 & 9 & 109 & \\
\hline \multirow{2}{*}{ Albumin $(\mathrm{g} / \mathrm{dL})^{\mathrm{j}}$} & Yes & 4.39 & 4.37 & 4.41 & 0.31 & 892 & 2.1 & 5.3 & \multirow{2}{*}{0.750} \\
\hline & No & 4.38 & 4.34 & 4.42 & 0.29 & 181 & 3.2 & 5.3 & \\
\hline \multirow{2}{*}{ Alkaline Phosphatase (U/L) } & Yes & 104.70 & 99.81 & 109.50 & 73.70 & 892 & 19 & 589 & \multirow{2}{*}{0.112} \\
\hline & No & 94.94 & 83.22 & 106.70 & 79.95 & 181 & 37 & 617 & \\
\hline \multirow{2}{*}{ Aspartate Transaminase (U/L) } & Yes & 26.41 & 25.57 & 27.24 & 12.68 & 892 & 9 & 187 & \multirow{2}{*}{0.426} \\
\hline & No & 27.23 & 25.34 & 29.12 & 12.89 & 181 & 13 & 118 & \\
\hline \multirow{2}{*}{ Bicarbonate $(\mathrm{mmol} / \mathrm{L})^{\mathrm{k}}$} & Yes & 23.97 & 23.83 & 24.11 & 2.14 & 892 & 15 & 29 & \multirow{2}{*}{0.084} \\
\hline & No & 24.27 & 23.97 & 24.58 & 2.08 & 181 & 18 & 30 & \\
\hline \multirow{2}{*}{ Bilirubin (mg/dL) $)^{1}$} & Yes & 0.82 & 0.80 & 0.84 & 0.32 & 892 & 0.3 & 3.5 & \multirow{2}{*}{0.349} \\
\hline & No & 0.80 & 0.76 & 0.84 & 0.27 & 181 & 0.3 & 2.4 & \\
\hline \multirow{2}{*}{ Blood Urea Nitrogen (mg/dL) } & Yes & 14.16 & 13.81 & 14.50 & 5.26 & 892 & 3 & 48 & \multirow{2}{*}{0.204} \\
\hline & No & 13.61 & 12.80 & 14.42 & 5.52 & 181 & 4 & 42 & \\
\hline \multirow{2}{*}{ Total Calcium (mg/dL) } & Yes & 9.55 & 9.53 & 9.58 & 0.40 & 892 & 7.2 & 11.3 & \multirow{2}{*}{0.664} \\
\hline & No & 9.54 & 9.48 & 9.60 & 0.40 & 181 & 7.6 & 10.6 & \\
\hline \multirow{2}{*}{ Chloride (mmol/L) } & Yes & 102.50 & 102.30 & 102.70 & 2.57 & 892 & 83 & 112 & \multirow{2}{*}{0.235} \\
\hline & No & 102.20 & 101.80 & 102.60 & 2.69 & 181 & 93 & 108 & \\
\hline \multirow{2}{*}{ Cholesterol (mg/dL) } & Yes & 184.90 & 182.10 & 187.80 & 43.86 & 892 & 71 & 566 & \multirow{2}{*}{0.308} \\
\hline & No & 188.60 & 182.30 & 194.90 & 42.80 & 181 & 86 & 407 & \\
\hline \multirow{2}{*}{ Creatinine (mg/dL) } & Yes & 0.96 & 0.95 & 0.98 & 0.26 & 892 & 0.4 & 4.4 & \\
\hline & No & 0.99 & 0.95 & 1.02 & 0.25 & 181 & 0.4 & 2.6 & 0.303 \\
\hline$\gamma$ Glutamvl Transferase (U/L) & Yes & 30.12 & 28.04 & 32.19 & 31.59 & 892 & 6 & 482 & \\
\hline$\gamma$ Glutamyl I ransterase (U/L) & No & 32.39 & 27.24 & 37.54 & 35.10 & 181 & 6 & 394 & $0.38 /$ \\
\hline & Yes & 3.08 & 3.05 & 3.11 & 0.43 & 891 & 1.6 & 5.6 & \\
\hline GIODumn (mg/aL) & No & 3.04 & 2.97 & 3.11 & 0.48 & 181 & 2 & 5.9 & $0.3 / 7$ \\
\hline Clucoce $(\mathrm{ma} / \mathrm{dI})$ & Yes & 95.24 & 93.19 & 97.29 & 31.18 & 892 & 58 & 707 & 0669 \\
\hline Glucose (mg/dL) & No & 96.33 & 91.75 & 100.90 & 31.25 & 181 & 69 & 382 & 0.009 \\
\hline & Yes & 96.50 & 93.94 & 99.05 & 38.84 & 892 & 12 & 333 & \\
\hline Iron (mg/dL) & No & 99.81 & 93.96 & 105.70 & 39.89 & 181 & 18 & 223 & 0.298 \\
\hline Lactate Dehydrogenase (U/L) & Yes & 138.50 & 136.30 & 140.80 & 34.58 & 892 & 52 & 399 & 0.037 \\
\hline Lactate Denyarogenase $(U / L)$ & No & 133.70 & 129.80 & 137.60 & 26.88 & 181 & 72 & 247 & 0.031 \\
\hline Ocmolality $(\mathrm{mmol} / \mathrm{Ko})^{\mathrm{m}}$ & Yes & 278.00 & 277.60 & 278.30 & 5.30 & 892 & 218 & 299 & 0.061 \\
\hline Usmorallty (1111101/Rg) & No & 277.20 & 276.40 & 277.90 & 5.40 & 181 & 261 & 298 & 0.001 \\
\hline Phosnhorus (mo/dI) & Yes & 3.92 & 3.88 & 3.97 & 0.71 & 892 & 2.4 & 6.6 & 0332 \\
\hline Phosphorus (mg/dL) & No & 3.87 & 3.77 & 3.96 & 0.64 & 181 & 2.4 & 6.6 & 0.332 \\
\hline & Yes & 4.12 & 4.10 & 4.14 & 0.35 & 892 & 3.1 & 5.5 & \\
\hline Potassium (mmol/L) & No & 4.14 & 4.09 & 4.19 & 0.34 & 181 & 3.2 & 5.4 & 0.523 \\
\hline Total Protein ( $\mathrm{g} / \mathrm{dL}$ ) & Yes & 7.47 & 7.44 & 7.50 & 0.46 & 891 & 5.3 & 9.4 & \\
\hline 1 otal Proteln (g/aL) & No & 7.42 & 7.35 & 7.50 & 0.49 & 181 & 6.2 & 9.8 & 0.209 \\
\hline & Yes & 139.10 & 138.90 & 139.20 & 2.58 & 892 & 108 & 147 & 0.077 \\
\hline sodium (mmol/L) & No & 138.70 & 138.40 & 139.00 & 2.34 & 181 & 131 & 144 & 0.077 \\
\hline Triglvcerides (mo/dL) & Yes & 145.00 & 132.30 & 157.70 & 193.60 & 892 & 21 & 3854 & 0.617 \\
\hline irigiycerides (mg/aL) & No & 137.20 & 110.10 & 164.20 & 184.50 & 181 & 28 & 2337 & $0.01 /$ \\
\hline & Yes & 6.00 & 5.91 & 6.09 & 1.32 & 892 & 1.5 & 13.4 & \\
\hline Uric Acid (mg/aL) & No & 5.99 & 5.79 & 6.19 & 1.37 & 181 & 2.6 & 11 & 0.905 \\
\hline
\end{tabular}

${ }^{\mathrm{a}}$ (Detect) $=$ Detectable Level of Biomarker in the Urine Sample; ${ }^{\mathrm{b}}(\mathrm{LCL})=$ Lower Confidence Limit; ' $($ UCL $)=$ Upper Confidence Limit; ${ }^{\mathrm{d}}(\mathrm{SD})=$ Standard Deviation; ${ }^{\mathrm{e}}(\mathrm{n})=$ Number in Sample; ${ }^{\mathrm{f}}(\mathrm{Min})=$ Minimum; ${ }^{\mathrm{g}}(\mathrm{Max})=$ Maximum; ${ }^{\mathrm{h}}(\mathrm{p})=$ Level of Significance at $\mathrm{p}=0.05$ Level (highlighted in Bold); ${ }^{\mathrm{i}}(\mathrm{U} / \mathrm{L})=$ Units per Liter; ${ }^{\mathrm{j}}(\mathrm{g} / \mathrm{dL})=$ Grams per Deciliter; ${ }^{\mathrm{k}}(\mathrm{mmol} / \mathrm{L})=$ Millimole per Liter; ${ }^{\mathrm{l}}(\mathrm{mg} / \mathrm{dL})=$ Milligram per Deciliter; ${ }^{\mathrm{m}}(\mathrm{mmol} / \mathrm{Kg})=$ Millimole per Kilogram 
Table 19: 3,5,6-Trichloropyridinol Overall Biochemical t-test Comparisons.

\begin{tabular}{|c|c|c|c|c|c|c|c|c|c|}
\hline Biochemical & Detect $^{\mathrm{a}}$ & Mean & $\mathrm{LCL}^{\mathrm{b}}$ & $\mathrm{UCL}^{\mathrm{c}}$ & $\mathrm{SD}^{\mathrm{d}}$ & $\mathrm{n}^{\mathrm{e}}$ & $\operatorname{Min}^{f}$ & $\operatorname{Max}^{\mathrm{g}}$ & $\mathrm{p}^{\mathrm{h}}$ \\
\hline \multirow{2}{*}{ Alanine Transaminase $(\mathrm{U} / \mathrm{L})^{\mathrm{i}}$} & Yes & 22.76 & 22.03 & 23.48 & 15.56 & 1766 & 5 & 243 & \multirow{2}{*}{0.218} \\
\hline & No & 21.97 & 20.94 & 22.99 & 11.91 & 521 & 5 & 109 & \\
\hline \multirow{2}{*}{ Albumin $(g / d L)^{j}$} & Yes & 4.28 & 4.26 & 4.29 & 0.34 & 1766 & 2.1 & 5.3 & \multirow{2}{*}{0.011} \\
\hline & No & 4.23 & 4.20 & 4.26 & 0.36 & 521 & 2.6 & 5.3 & \\
\hline \multirow{2}{*}{ Alkaline Phosphatase (U/L) } & Yes & 94.31 & 91.43 & 97.19 & 61.68 & 1766 & 19 & 589 & \multirow{2}{*}{$<.0001$} \\
\hline & No & 82.65 & 77.86 & 87.45 & 55.71 & 521 & 24 & 617 & \\
\hline \multirow{2}{*}{ Aspartate Transaminase (U/L) } & Yes & 24.01 & 23.51 & 24.50 & 10.66 & 1766 & 9 & 187 & \multirow{2}{*}{0.755} \\
\hline & No & 23.85 & 22.99 & 24.70 & 9.94 & 521 & 7 & 118 & \\
\hline \multirow{2}{*}{ Bicarbonate $(\mathrm{mmol} / \mathrm{L})^{\mathrm{k}}$} & Yes & 23.37 & 23.26 & 23.47 & 2.26 & 1766 & 15 & 29 & \multirow{2}{*}{0.041} \\
\hline & No & 23.60 & 23.41 & 23.79 & 2.20 & 521 & 18 & 30 & \\
\hline \multirow{2}{*}{ Bilirubin (mg/dL) ${ }^{1}$} & Yes & 0.74 & 0.73 & 0.76 & 0.28 & 1766 & 0.2 & 3.5 & \multirow{2}{*}{0.010} \\
\hline & No & 0.71 & 0.69 & 0.73 & 0.24 & 521 & 0.2 & 2.4 & \\
\hline \multirow{2}{*}{ Blood Urea Nitrogen (mg/dL) } & Yes & 13.09 & 12.81 & 13.36 & 5.86 & 1766 & 2 & 122 & \multirow{2}{*}{0.053} \\
\hline & No & 12.53 & 12.05 & 13.00 & 5.53 & 521 & 3 & 53 & \\
\hline \multirow{2}{*}{ Total Calcium (mg/dL) } & Yes & 9.49 & 9.47 & 9.51 & 0.40 & 1766 & 7.2 & 11.3 & \multirow{2}{*}{0.910} \\
\hline & No & 9.49 & 9.46 & 9.53 & 0.39 & 521 & 7.6 & 10.7 & \\
\hline \multirow{2}{*}{ Chloride (mmol/L) } & Yes & 102.80 & 102.70 & 103.00 & 2.61 & 1766 & 83 & 112 & \multirow{2}{*}{0.103} \\
\hline & No & 102.60 & 102.40 & 102.80 & 2.82 & 520 & 89 & 113 & \\
\hline \multirow{2}{*}{ Cholesterol (mg/dL) } & Yes & 185.90 & 183.90 & 187.90 & 43.01 & 1766 & 71 & 566 & \multirow{2}{*}{$<.0001$} \\
\hline & No & 197.70 & 193.70 & 201.70 & 46.22 & 521 & 86 & 476 & \\
\hline \multirow{2}{*}{ Creatinine (mg/dL) } & Yes & 0.84 & 0.83 & 0.86 & 0.27 & 1766 & 0.3 & 4.4 & \\
\hline & No & 0.84 & 0.81 & 0.86 & 0.26 & 521 & 0.3 & 3.1 & 0.529 \\
\hline Glutamyl Trancferace (L/L) & Yes & 24.88 & 23.64 & 26.13 & 26.64 & 1766 & 4 & 482 & 0539 \\
\hline$\gamma$ Glutamyl I ransterase (U/L) & No & 25.79 & 23.18 & 28.40 & 30.34 & 521 & 6 & 394 & 0.539 \\
\hline Clobulin (moldI & Yes & 3.13 & 3.11 & 3.15 & 0.42 & 1765 & 1.6 & 5.6 & \\
\hline Globulin (mg/dL) & No & 3.10 & 3.07 & 3.14 & 0.42 & 521 & 2 & 5.9 & 0.203 \\
\hline & Yes & 92.26 & 90.90 & 93.61 & 29.00 & 1766 & 34 & 707 & \\
\hline Glucose (mg/dL) & No & 93.61 & 90.64 & 96.59 & 34.59 & 521 & 30 & 521 & 0.416 \\
\hline & Yes & 89.33 & 87.53 & 91.13 & 38.63 & 1766 & 7 & 333 & 0.925 \\
\hline Iron (mg/dL) & No & 88.93 & 85.55 & 92.31 & 39.28 & 521 & 12 & 268 & 0.835 \\
\hline 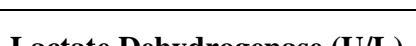 & Yes & 134.70 & 133.20 & 136.20 & 31.86 & 1766 & 52 & 470 & 0024 \\
\hline Lactate Dehydrogenase (U/L) & No & 131.40 & 129.00 & 133.90 & 28.05 & 520 & 51 & 329 & 0.024 \\
\hline Ocmolalitw (mmol/(x)m & Yes & 276.70 & 276.50 & 277.00 & 5.56 & 1766 & 218 & 310 & 0.015 \\
\hline Usmolality (mmol/Kg) & No & 276.10 & 275.60 & 276.50 & 5.55 & 521 & 252 & 298 & 0.015 \\
\hline & Yes & 3.96 & 3.93 & 3.99 & 0.65 & 1766 & 2.3 & 6.6 & \\
\hline Phosphorus (mg/dL) & No & 3.90 & 3.85 & 3.95 & 0.57 & 521 & 2.3 & 6.6 & 0.042 \\
\hline & Yes & 4.05 & 4.03 & 4.07 & 0.35 & 1766 & 2.6 & 6 & \\
\hline Potassium (mmol/L) & No & 4.05 & 4.02 & 4.09 & 0.36 & 521 & 2.9 & 5.4 & 0.826 \\
\hline Total Drotain (a/dT ) & Yes & 7.41 & 7.38 & 7.43 & 0.47 & 1765 & 5.3 & 9.5 & 0002 \\
\hline Total Protem (g/dL) & No & 7.34 & 7.29 & 7.38 & 0.50 & 521 & 5.9 & 9.8 & \\
\hline & Yes & 138.70 & 138.60 & 138.80 & 2.57 & 1766 & 108 & 147 & \\
\hline Sodium (mmol/L) & No & 138.40 & 138.20 & 138.60 & 2.47 & 521 & 125 & 145 & 0.017 \\
\hline Trialycerides (mo/dI) & Yes & 130.70 & 123.70 & 137.60 & 148.90 & 1766 & 21 & 3854 & 0680 \\
\hline Triglycerides (mg/dL) & No & 133.50 & 121.70 & 145.30 & 137.10 & 521 & 28 & 2337 & 0.680 \\
\hline & Yes & 5.26 & 5.19 & 5.32 & 1.47 & 1766 & 0.4 & 13.4 & \\
\hline Uric Acid (mg/dL) & No & 5.15 & 5.02 & 5.28 & 1.51 & 521 & 2.4 & 13.9 & 0.137 \\
\hline
\end{tabular}

${ }^{\mathrm{a}}$ (Detect) $=$ Detectable Level of Biomarker in the Urine Sample; ${ }^{\mathrm{b}}(\mathrm{LCL})=$ Lower Confidence Limit; ${ }^{\mathrm{C}}(\mathrm{UCL})=$ Upper Confidence Limit; ${ }^{\mathrm{d}}(\mathrm{SD})=$ Standard Deviation; ${ }^{\mathrm{e}}(\mathrm{n})=$ Number in Sample; ${ }^{\mathrm{f}}(\mathrm{Min})=$ Minimum; ${ }^{\mathrm{g}}(\mathrm{Max})=$ Maximum; ${ }^{\mathrm{h}}(\mathrm{p})=$ Level of Significance at $\mathrm{p}=0.05$ Level (highlighted in Bold); ${ }^{\mathrm{i}}(\mathrm{U} / \mathrm{L})=$ Units per Liter; ${ }^{\mathrm{j}}(\mathrm{g} / \mathrm{dL})=$ Grams per Deciliter; ${ }^{\mathrm{k}}(\mathrm{mmol} / \mathrm{L})=$ Millimole per Liter; ${ }^{\mathrm{l}}(\mathrm{mg} / \mathrm{dL})=$ Milligram per Deciliter; ${ }^{\mathrm{m}}(\mathrm{mmol} / \mathrm{Kg})=$ Millimole per Kilogram 


\subsubsection{Logistic Regression}

Table 20: Logistic Regression for 3,5,6-Trichloropyridinol.

\begin{tabular}{|c|c|c|c|}
\hline & $\begin{array}{c}\text { Detect }^{\mathrm{a}} \\
\left(\mathrm{DF}^{\mathrm{b}}=1\right)\end{array}$ & $\begin{array}{l}\text { Detect, Non-Hispanic White } \\
(\mathrm{DF}=1)\end{array}$ & $\begin{array}{l}\text { Detect, Female } \\
(\mathrm{DF}=1)\end{array}$ \\
\hline Age & $\begin{array}{c}\beta=-0.0145 \\
\text { Wald } \chi^{2}=53.74 \\
p<0.0001 \\
\text { OR=0.986 }\end{array}$ & & \\
\hline Mexican American & & $\begin{array}{c}\beta=0.221 \\
\text { Wald } \chi 2=4.86 \\
p=0.028 \\
\text { OR=1.31 }\end{array}$ & \\
\hline $\begin{array}{l}\text { Non-Hispanic } \\
\text { Black }\end{array}$ & & $\begin{array}{c}\beta=-0.317 \\
\text { Wald } \chi 2=3.50 \\
p=0.062 \\
O R=0.765\end{array}$ & \\
\hline Other Hispanic & & $\begin{array}{c}\beta=0.272 \\
\text { Wald } \chi 2=7.20 \\
p=0.007 \\
\text { OR }=1.38\end{array}$ & \\
\hline Other & & $\begin{array}{c}\beta=-0.128 \\
\text { Wald } \chi 2=0.500 \\
p=0.479 \\
\text { OR }=0.924\end{array}$ & \\
\hline Male & & & $\begin{array}{c}\beta=0.28 \\
\text { Wald } \chi 2=36.28 \\
p<0.0001 \\
O R=1.75\end{array}$ \\
\hline
\end{tabular}

${ }^{\mathrm{a}}($ Detect $)=$ Detectable Level of Biomarker in the Urine Sample, used as a reference category in the Model; ${ }^{\mathrm{b}}(\mathrm{DF})=$ Degree of Freedom. Significant differences are highlight in Bold.

The overall model fit was significant, with the Likelihood $\chi 2=119.4$, $\mathrm{p}<0.0001$ and the $\mathrm{R}_{\text {Max }}^{2}=0.0602$. The Hosmer and Lemeshow goodness-of-fit test resulted in a $\chi 2=12.2, p=0.144$, indicating that the data from the independent variables fit the model moderately well. The listed detects at the row headers are the reference groups for each sub-category. When stratifying for individual groups, age does not seem to have an effect on the detection of a biomarker $(\beta=-0.0145$ and $\mathrm{OR}=0.986, \mathrm{p}<0.0001)$. Mexican Americans $(\beta=0.221$ and $\mathrm{OR}=1.31, \mathrm{p}=0.028)$ and Other Hispanics $(\beta=0.272$ and $\mathrm{OR}=$ 1.38, $\mathrm{p}=0.007$ ) had a slightly higher change in the regression coefficient and higher odds 
of having a detectable level of the biomarker than Non-Hispanic Whites (reference group). Males had a higher change in the regression coefficient and higher odds of having a detectable level of biomarker than females $(\beta=0.28$ and $\mathrm{OR}=1.75, \mathrm{p}<0.0001)$.

\subsubsection{Methyl Parathion Biomarker: Paranitrophenol (PNP)}

\subsubsection{Descriptive Statistics}

The information covered in the following figures and tables characterizes the exposures to methyl parathion in the overall sample and in various subgroups.

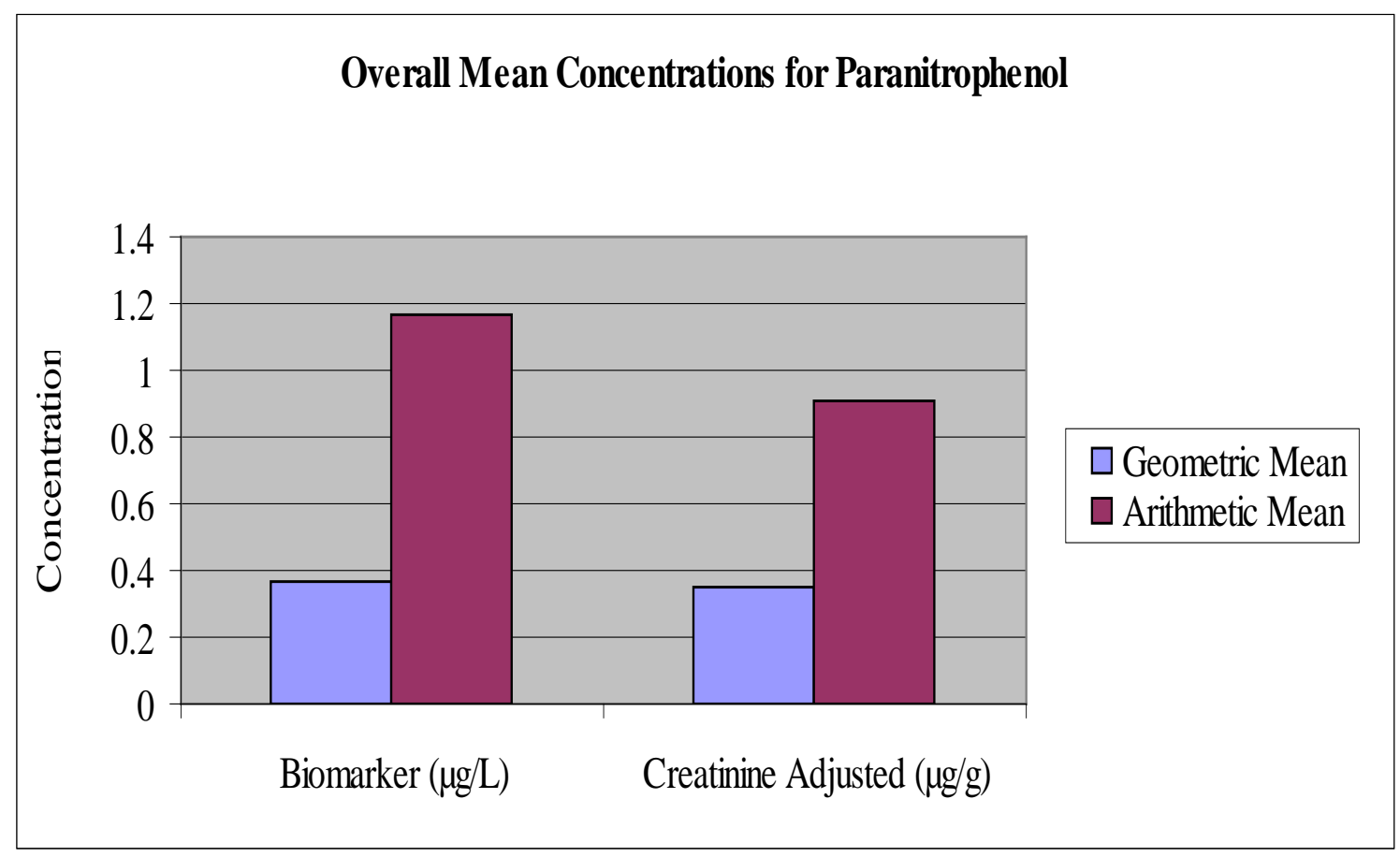

Figure 17: Comparison of Means for Paranitrophenol. $\mu \mathrm{g} / \mathrm{l}=$ Micrograms per Liter; $\mu \mathrm{g} / \mathrm{g}=$ Micrograms per Gram. Adjusting for creatinine results in means (both geometric and arithmetic) that are lower than if using the concentration of the PNP biomarker in urine $(\mu \mathrm{g} / \mathrm{L}$ ) alone. Limit of Detection (LOD) for PNP in sample was $0.1 \mu \mathrm{g} / \mathrm{L}$. 
Table 21: Descriptive Statistics for Paranitrophenol.

\begin{tabular}{|c|c|c|}
\hline \multicolumn{3}{|c|}{ Biomarker $(\mu \mathrm{g} / \mathrm{L})^{\mathrm{a}}$} \\
\hline & $\begin{array}{c}\text { Geometric } \\
\text { Mean }\end{array}$ & $\begin{array}{l}\text { Arithmetic } \\
\text { Mean }\end{array}$ \\
\hline $\mathrm{n}^{\mathrm{c}}$ & 2975 & 2975 \\
\hline Mean & 0.367 & 1.16 \\
\hline $\mathrm{LCL}^{\mathrm{d}}$ & 0.346 & 1.08 \\
\hline $\mathrm{UCL}^{\mathrm{e}}$ & 0.389 & 1.25 \\
\hline $\mathrm{SD}^{\mathrm{f}}$ & 5.11 & 2.35 \\
\hline $\mathrm{P} 25^{\mathrm{g}}$ & $<\mathrm{LOD}^{\mathrm{h}}$ & $<\mathrm{LOD}$ \\
\hline $\mathrm{P} 50^{\mathrm{i}}$ & 0.7 & 0.7 \\
\hline$P 75^{j}$ & 1.46 & 1.46 \\
\hline $\mathrm{P}^{\mathrm{K}}{ }^{\mathrm{K}}$ & 2.82 & 2.82 \\
\hline${\mathrm{P} 95^{\mathrm{I}}}^{2}$ & 3.92 & 3.92 \\
\hline $\operatorname{Min}^{\mathrm{m}}$ & 0.07 & 0.07 \\
\hline $\operatorname{Max}^{\mathrm{n}}$ & 59.89 & 59.89 \\
\hline
\end{tabular}

\begin{tabular}{|c|c|c|}
\hline \multicolumn{3}{|c|}{ Creatinine Adjusted $(\mu \mathrm{g} / \mathrm{g})^{\mathrm{b}}$} \\
\hline & $\begin{array}{c}\text { Geometric } \\
\text { Mean }\end{array}$ & $\begin{array}{c}\text { Arithmetic } \\
\text { Mean }\end{array}$ \\
\hline $\mathrm{N}$ & 2973 & 2973 \\
\hline Mean & 0.352 & 0.905 \\
\hline LCL & 0.335 & 0.839 \\
\hline UCL & 0.371 & 0.970 \\
\hline SD & 4.18 & 1.83 \\
\hline P25 & 0.096 & 0.096 \\
\hline P50 & 0.427 & 0.427 \\
\hline P75 & 1.08 & 1.08 \\
\hline P90 & 2.10 & 2.10 \\
\hline P95 & 3.20 & 3.20 \\
\hline Min & 0.0124 & 0.0124 \\
\hline Max & 51.26 & 51.26 \\
\hline
\end{tabular}

${ }^{a}(\mu \mathrm{g} / \mathrm{L})=$ Micrograms per Liter; ${ }^{\mathrm{b}}(\mu \mathrm{g} / \mathrm{g})=$ Micrograms per Gram; ${ }^{\mathrm{c}}(\mathrm{n})=$ Number in Sample; ${ }^{\mathrm{d}}(\mathrm{LCL})=$ Lower Confidence Limit; ${ }^{\mathrm{e}}(\mathrm{UCL})=$ Upper Confidence Limit; ${ }^{\mathrm{f}}(\mathrm{SD})=$ Standard Deviation; ${ }^{\mathrm{g}}(\mathrm{P} 25)=$ Lower Quartile; ${ }^{\mathrm{h}}(\mathrm{LOD})=$ Limit of Detection, at $0.1 \mu \mathrm{g} / \mathrm{L}$.; ${ }^{\mathrm{i}}(\mathrm{P} 50)=$ Median; ${ }^{\mathrm{j}}(\mathrm{P} 75)=$ Upper Quartile; ${ }^{\mathrm{k}}(\mathrm{P} 90)=90^{\text {th }}$ Percentile; ${ }^{\mathrm{l}}(\mathrm{P} 95)=95^{\text {th }}$

Percentile; ${ }^{\mathrm{m}}(\mathrm{Min})=$ Minimum $^{\mathrm{n}}(\mathrm{Max})=$ Maximum

Adjusting for creatinine results in means (both geometric and arithmetic) that are lower than if using the concentration of the biomarker in urine $(\mu \mathrm{g} / \mathrm{L})$ alone, but not by a large margin. 


\section{Geometric Mean for Detects of Paranitrophenol}

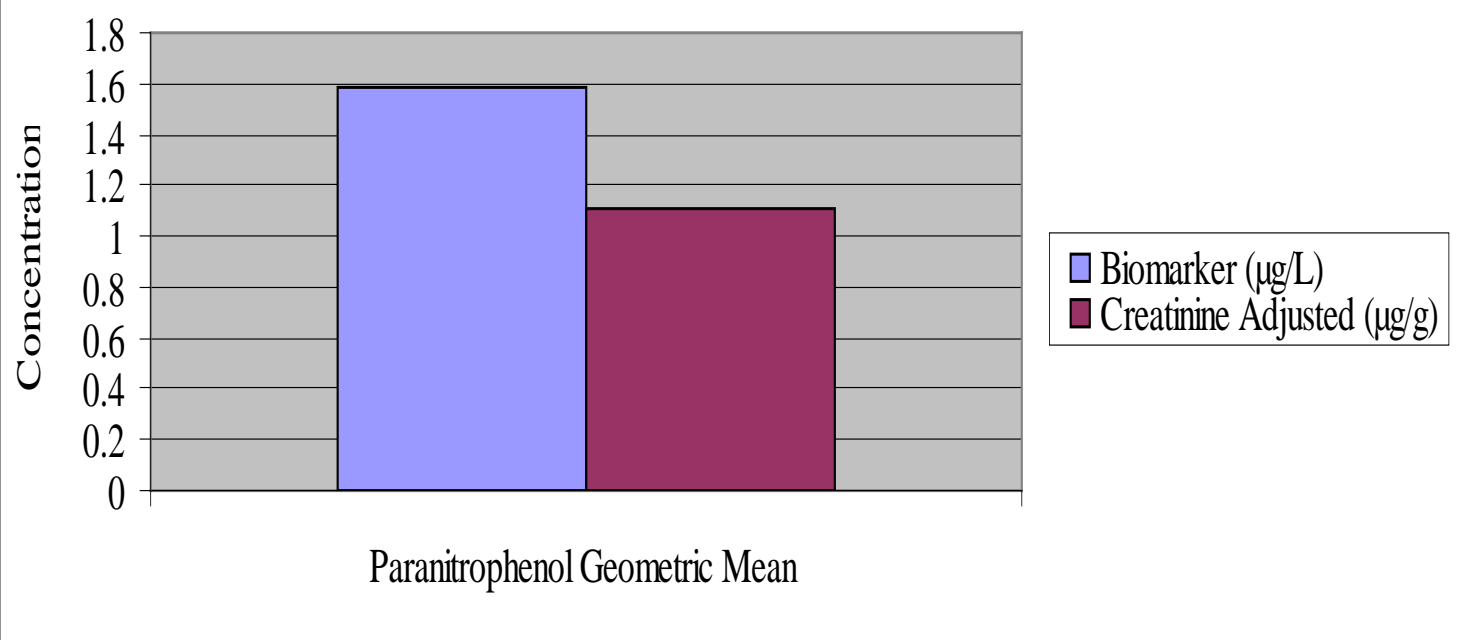

Figure 18: Comparison of Detectable Geometric Mean Concentrations for Paranitrophenol. $\mu \mathrm{g} / \mathrm{l}=$ Micrograms per Liter; $\mu \mathrm{g} / \mathrm{g}=$ Micrograms per Gram.

Table 22: Descriptive Statistics for Detectable Levels of Paranitrophenol.

\begin{tabular}{|l|c|c|c|c|c|c|}
\hline & $\mathrm{GM}^{\mathrm{c}}$ & $\mathrm{LCL}^{\mathrm{d}}$ & $\mathrm{UCL}^{\mathrm{e}}$ & $\mathrm{SD}^{\mathrm{f}}$ & Median & $\mathrm{n}^{\mathrm{g}}$ \\
\hline Biomarker $(\mu \mathrm{g} / \mathrm{L})^{\mathrm{a}}$ & 1.58 & 1.53 & 1.64 & 1.97 & 1.39 & 1580 \\
\hline${\text { Creatinine Adjusted }(\mu \mathrm{g} / \mathrm{g})^{\mathrm{b}}}^{2}$ & 1.11 & 1.06 & 1.15 & 2.16 & 1.02 & 1578 \\
\hline
\end{tabular}

${ }^{\mathrm{a}}(\mu \mathrm{g} / \mathrm{L})=$ Micrograms per Liter; ${ }^{\mathrm{b}}(\mu \mathrm{g} / \mathrm{g})=$ Micrograms per Gram; ${ }^{\mathrm{c}}(\mathrm{GM})=$ Geometric Mean; ${ }^{\mathrm{d}}(\mathrm{LCL})=$ Lower Confidence Limit; ${ }^{\mathrm{e}}(\mathrm{UCL})=$ Upper Confidence Limit; ${ }^{\mathrm{f}}(\mathrm{SD})=$ Standard Deviation; ${ }^{\mathrm{g}}(\mathrm{n})=$ Number in Sample

The geometric mean was determined for the $53.1 \%$ of the individuals that had a detectable level of biomarker in their urine sample. Based on this analysis, the geometric mean for only detectable levels of the biomarker was $1.2 \mu \mathrm{g} / \mathrm{L}$ higher that the overall geometric mean. 


\subsubsection{Comparative Statistics}

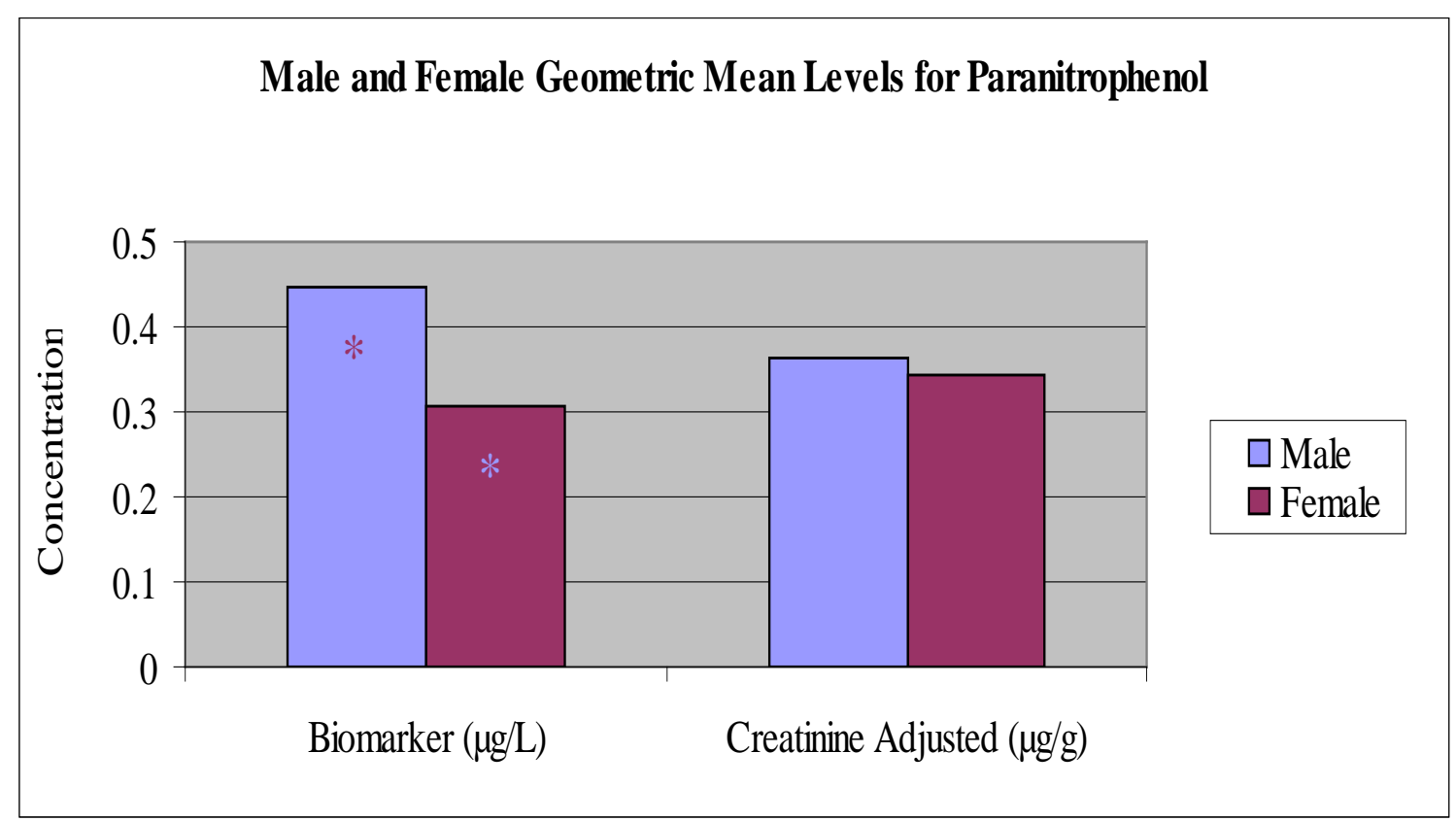

Figure 19: Comparison of Geometric Mean Values of Males versus Females for Paranitrophenol. $\mu \mathrm{g} / \mathrm{l}=$ Micrograms per Liter; $\mu \mathrm{g} / \mathrm{g}=$ Micrograms per Gram. Colorcoded “*” indicates males are significantly different from females. 
Table 23: Student's t-test Comparing Geometric Means of Males Versus Females for Paranitrophenol.

\begin{tabular}{|c|c|c|c|c|c|c|c|}
\hline \multicolumn{8}{|c|}{ Biomarker $(\mu \mathrm{g} / \mathrm{L})^{\mathrm{a}}$} \\
\hline & $\mathrm{GM}^{\mathrm{b}}$ & $\mathrm{LCL}^{\mathrm{C}}$ & $\mathrm{UCL}^{\mathrm{d}}$ & $\mathrm{SD}^{\mathrm{e}}$ & Median & $n^{f}(D / N D)^{g}$ & $\mathrm{P}^{\mathrm{h}}$ \\
\hline Male & 0.447 & 0.410 & 0.487 & 5.14 & 0.830 & $1395(823 / 572)$ & \multirow{3}{*}{$<0.0001$} \\
\hline Female & 0.308 & 0.284 & 0.333 & 4.99 & $<\mathrm{LOD}^{\mathrm{i}}$ & $1580(757 / 823)$ & \\
\hline \multicolumn{6}{|l|}{ Total } & 2975 & \\
\hline \multicolumn{8}{|c|}{ Creatinine Adjusted $(\mu g / g)^{j}$} \\
\hline & GM & LCL & UCL & SD & Median & $\mathrm{n}$ & $\mathrm{p}$ \\
\hline Male & 0.363 & 0.336 & 0.392 & 4.27 & 0.519 & 1395 & \multirow{3}{*}{0.276} \\
\hline Female & 0.343 & 0.320 & 0.368 & 4.35 & 0.333 & 1578 & \\
\hline \multicolumn{6}{|l|}{ Total } & 2973 & \\
\hline
\end{tabular}

${ }^{\mathrm{a}}(\mu \mathrm{g} / \mathrm{L})=$ Micrograms per Liter; ${ }^{\mathrm{b}}(\mathrm{GM})=$ Geometric Mean; ${ }^{\mathrm{C}}(\mathrm{LCL})=$ Lower Confidence Limit; ${ }^{d}(\mathrm{UCL})=$ Upper Confidence Limit; ${ }^{\mathrm{e}}(\mathrm{SD})=$ Standard Deviation; ${ }^{\mathrm{f}}(\mathrm{n})=$ Number in Sample; ${ }^{g}(\mathrm{D} / \mathrm{ND})=$ Number of Detects/Number of Non-Detects; ${ }^{\text {h}}(\mathrm{p})$ Level of Significance at $\mathrm{p}=0.05$ Level (Highlighted in Bold); ${ }^{\mathrm{i}}(\mathrm{LOD})=$ Limit of Detection, at 0.1 $\mu \mathrm{g} / \mathrm{L} ;{ }^{\mathrm{j}}(\mu \mathrm{g} / \mathrm{g})=$ Micrograms per Gram

Males have a statistically significant higher GM when compared to females, but only when using the unadjusted biomarker concentration in urine $(\mu \mathrm{g} / \mathrm{L})$. Adjusting for dilution negates any significant difference. 


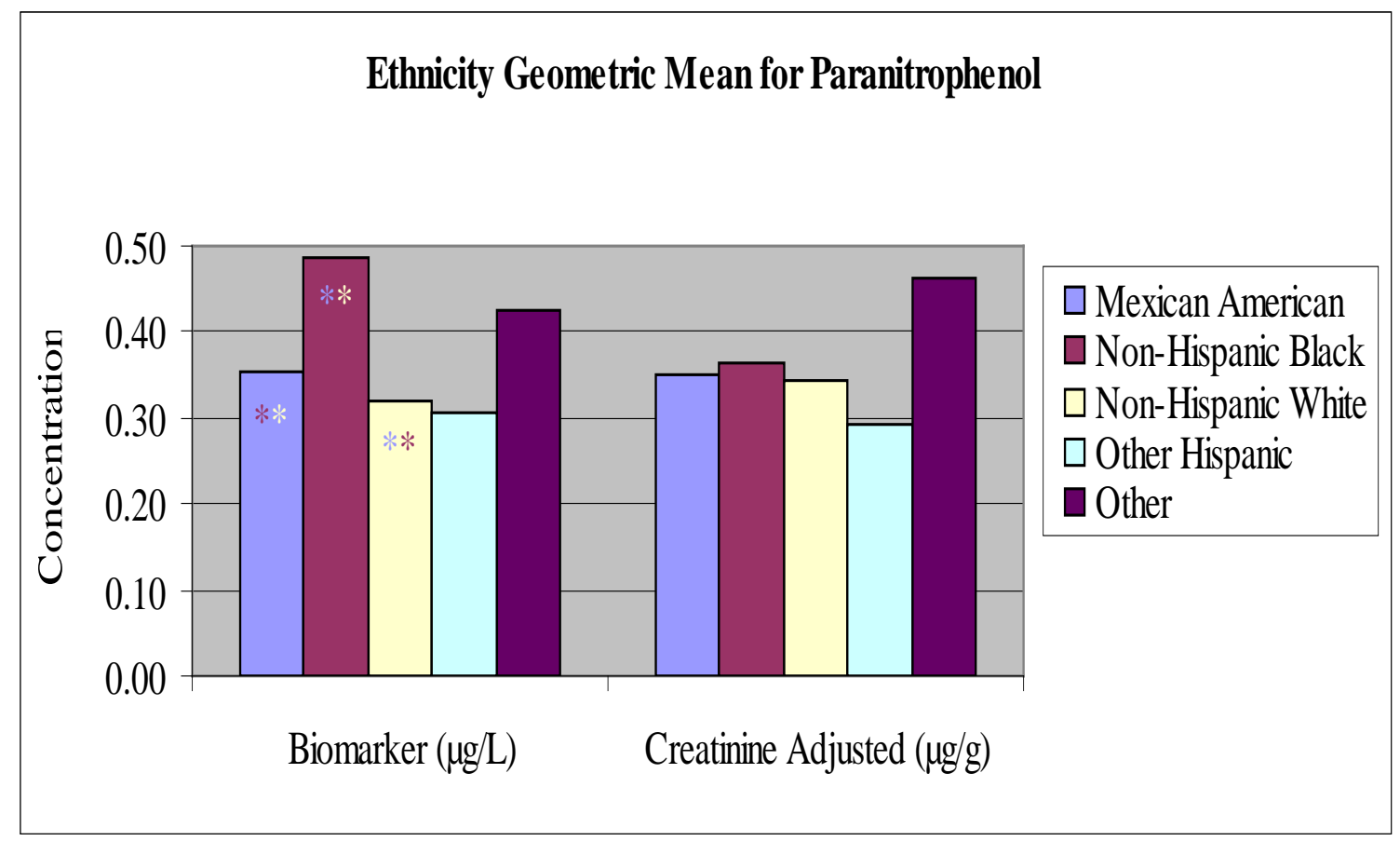

Figure 20: Comparison of Geometric Mean Values of Ethnic Groups for Paranitrophenol. $\mu \mathrm{g} / \mathrm{l}=$ Micrograms per Liter; $\mu \mathrm{g} / \mathrm{g}=$ Micrograms per Gram. Color-coded “**” indicates which groups are significantly different from each other. 
Table 24: One-Way ANOVA and Tukey Analysis Comparing Geometric Means of Ethnic Groups for Paranitrophenol.

\begin{tabular}{|c|c|c|c|c|c|c|}
\hline \multicolumn{7}{|l|}{ Biomarker $(\mu \mathrm{g} / \mathrm{L})^{\mathrm{a}}$} \\
\hline & $\mathrm{GM}^{\mathrm{b}}$ & $\mathrm{LCL}^{\mathrm{c}}$ & $\mathrm{UCL}^{\mathrm{d}}$ & $\mathrm{SD}^{\mathrm{e}}$ & $\mathrm{n}^{\mathrm{f}}(\mathrm{D} / \mathrm{ND})^{\mathrm{g}}$ & $\mathrm{P}^{\mathrm{h}}$ \\
\hline Mexican American* & 0.353 & 0.012 & 0.695 & 4.75 & $744(402 / 342)$ & \multirow{6}{*}{$<0.0001$} \\
\hline Non-Hispanic Black* & 0.486 & 0.095 & 0.877 & 5.42 & $738(439 / 299)$ & \\
\hline Non-Hispanic White* & 0.319 & 0.034 & 0.603 & 5.12 & $1247(605 / 642)$ & \\
\hline Other Hispanic & 0.306 & -0.537 & 1.15 & 4.83 & $126(62 / 64)$ & \\
\hline Other & 0.424 & -0.418 & 1.27 & 4.71 & $120(72 / 48)$ & \\
\hline \multicolumn{6}{|l|}{ Total } & \\
\hline \multicolumn{7}{|c|}{ Creatinine Adjusted $(\mu g / g)^{i}$} \\
\hline & GM & LCL & UCL & SD & $\mathrm{n}$ & p \\
\hline Mexican American & 0.350 & 0.066 & 0.634 & 3.95 & 744 & \multirow{6}{*}{0.131} \\
\hline Non-Hispanic Black & 0.364 & 0.036 & 0.692 & 4.54 & 737 & \\
\hline Non-Hispanic White & 0.344 & 0.113 & 0.576 & 4.16 & 1246 & \\
\hline Other Hispanic & 0.292 & -0.443 & 1.03 & 4.21 & 126 & \\
\hline Other & 0.461 & -0.161 & 1.08 & 3.48 & 120 & \\
\hline \multicolumn{5}{|l|}{ Total } & 2973 & \\
\hline
\end{tabular}

${ }^{\mathrm{a}}(\mu \mathrm{g} / \mathrm{L})=$ Micrograms per Liter; ${ }^{\mathrm{b}}(\mathrm{GM})=$ Geometric Mean; ${ }^{\mathrm{C}}(\mathrm{LCL})=$ Lower Confidence Limit; ${ }^{\mathrm{d}}(\mathrm{UCL})=$ Upper Confidence Limit; ${ }^{\mathrm{e}}(\mathrm{SD})=$ Standard Deviation; ${ }^{\mathrm{f}}(\mathrm{n})=$ Number in Sample; ${ }^{g}(\mathrm{D} / \mathrm{ND})=$ Number of Detects/Number of Non-Detects; ${ }^{\mathrm{h}}(\mathrm{p})=$ Level of Significance at $\mathrm{p}=0.05$ Level (Highlighted in Bold); ${ }^{\mathrm{i}}(\mu \mathrm{g} / \mathrm{g})=$ Micrograms per Gram.

* Indicates groups that are significantly different from each other.

Mexican Americans, Non-Hispanic Blacks and Non-Hispanic Whites are significantly different compared to each other when using the unadjusted biomarker concentration $(\mu \mathrm{g} / \mathrm{L})$. No difference was observed when adjusting for creatinine. 


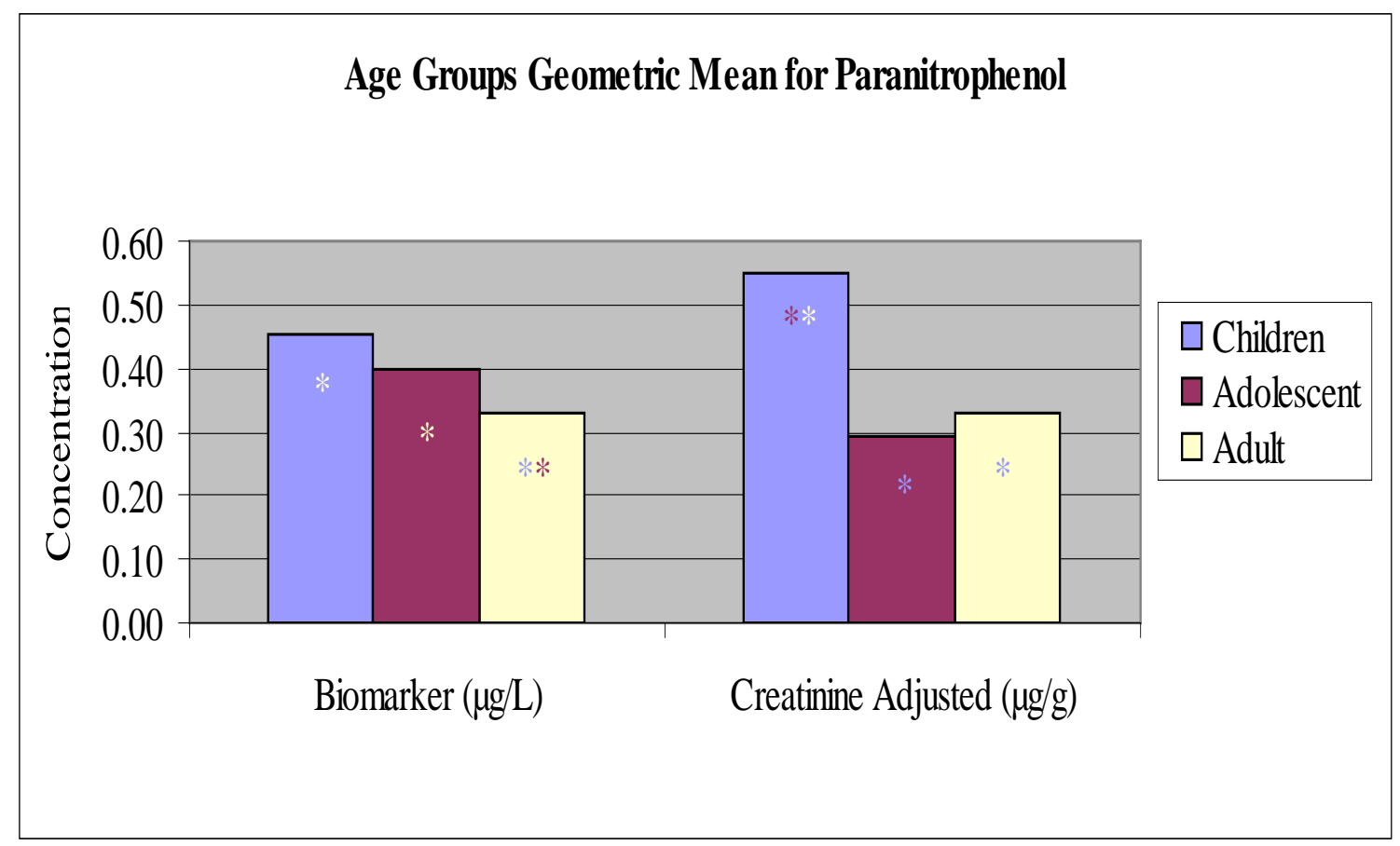

Figure 21: Comparison of Geometric Mean Values of Age Groups for Paranitrophenol. $\mu \mathrm{g} / \mathrm{l}=$ Micrograms per Liter; $\mu \mathrm{g} / \mathrm{g}=$ Micrograms per Gram. Color-coded “*”” indicates which groups are significantly different from each other. 
Table 25: One-Way ANOVA and Tukey Analysis Comparing Geometric Means of Age Groups for Paranitrophenol.

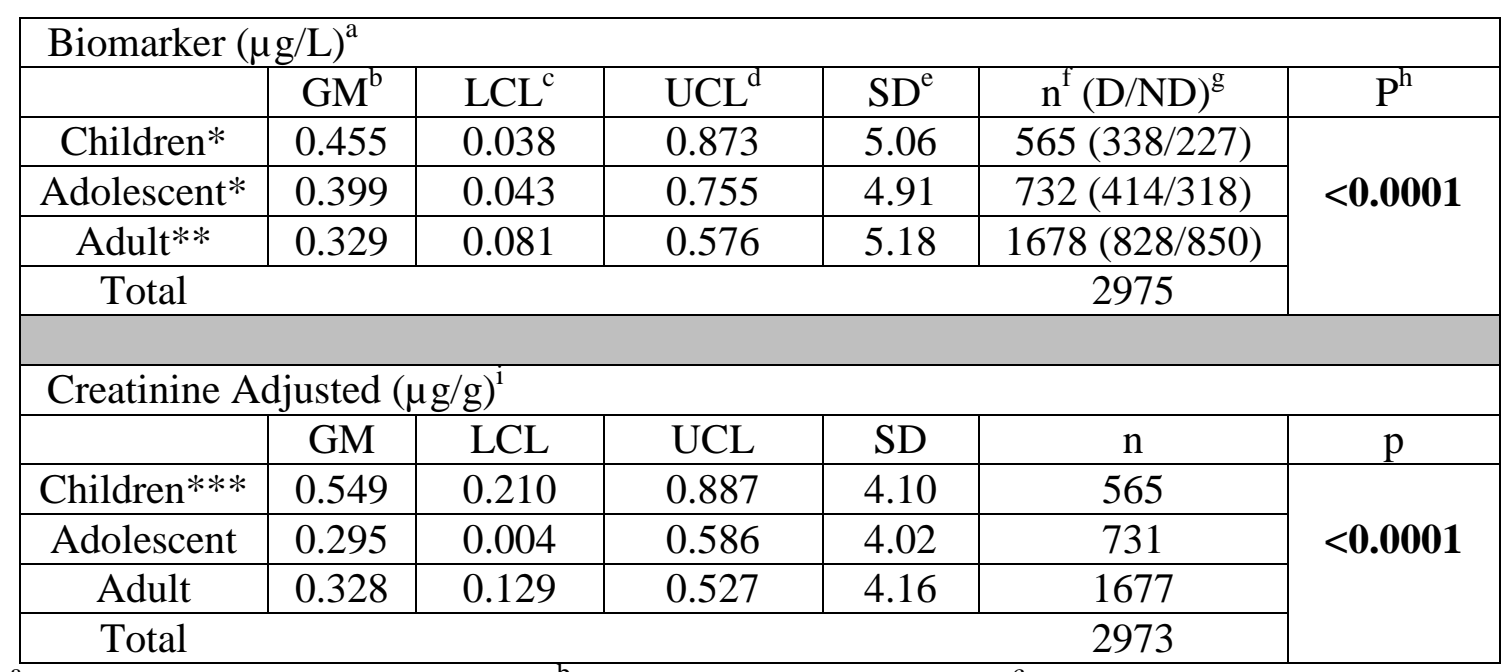

${ }^{\mathrm{a}}(\mu \mathrm{g} / \mathrm{L})=$ Micrograms per Liter; ${ }^{\mathrm{b}}(\mathrm{GM})=$ Geometric Mean; ${ }^{\mathrm{c}}(\mathrm{LCL})=$ Lower Confidence Limit; ${ }^{\mathrm{d}}(\mathrm{UCL})=$ Upper Confidence Limit; ${ }^{\mathrm{e}}(\mathrm{SD})=$ Standard Deviation; ${ }^{\mathrm{f}}(\mathrm{n})=$ Number in Sample; ${ }^{g}(\mathrm{D} / \mathrm{ND})=$ Number of Detects/Number of Non-Detects; ${ }^{\mathrm{h}}(\mathrm{p})=$ Level of Significance at $\mathrm{p}=0.05$ Level (Highlighted in Bold); ${ }^{\mathrm{i}}(\mu \mathrm{g} / \mathrm{g})=$ Micrograms per Gram.

* Indicates group is significantly different from Adults.

** Indicates that group is significantly different from Adolescents and Children.

*** Indicates that Children were significantly different from Adolescents and Adults.

Significant differences exist for both the urinary concentration of the biomarker and when adjusting for creatinine. For the unadjusted biomarker in urine, children and adolescents were significantly different from the adult group, but were not significantly different from each other. Children in the creatinine-adjusted analysis were significantly different from adolescents and adults, but adolescents not significantly different from adults. 


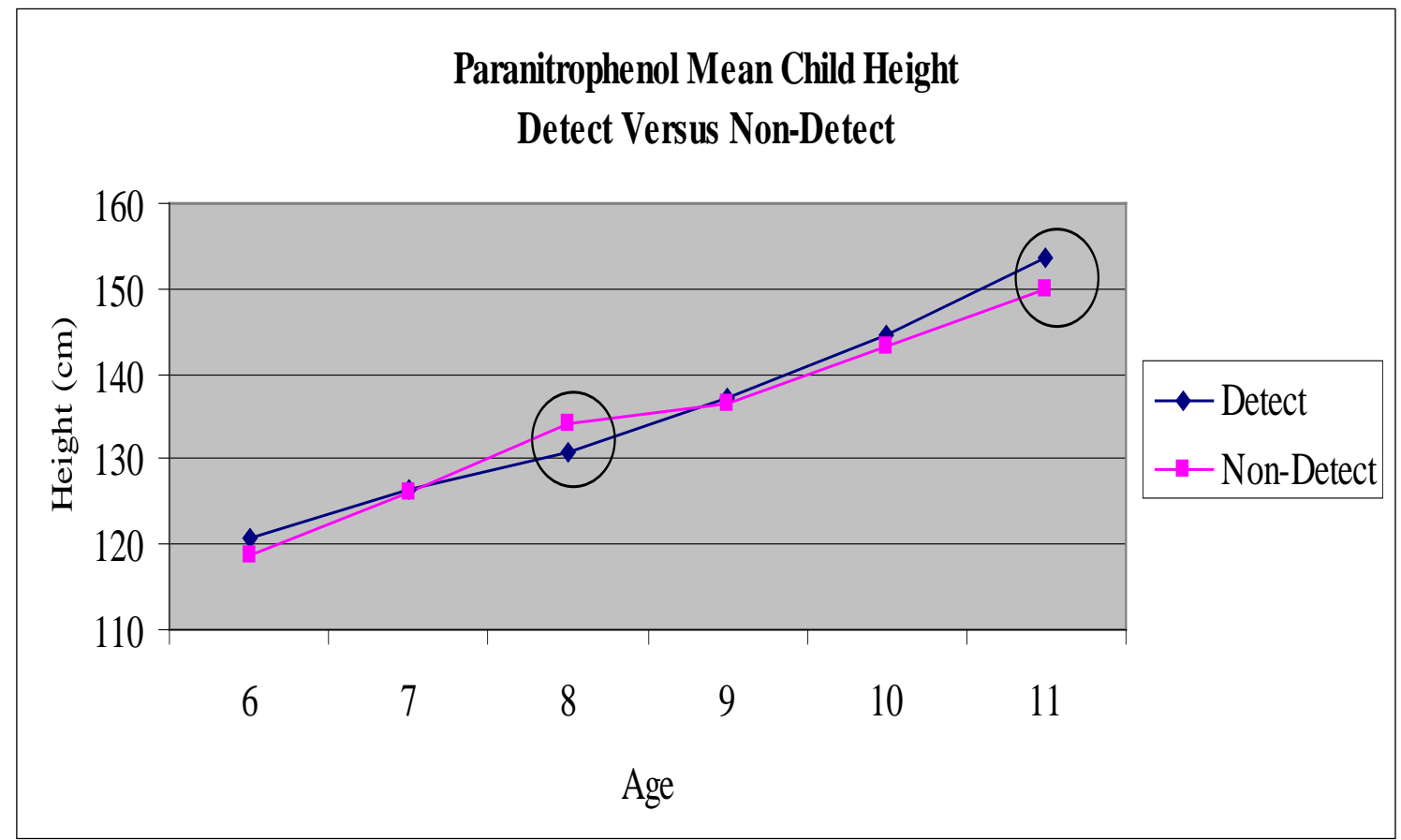

Figure 22: Graph of Arithmetic Mean Height for Detects Versus Non-Detects for Paranitrophenol, Ages 6-11. cm= Centimeter. $\bigcirc=$ Significantly different means . 
Table 26: Student's t-test Comparing Detects Versus Non-Detects for Arithmetic Mean of Height for Paranitrophenol.

\begin{tabular}{|c|c|c|c|c|c|c|c|}
\hline Age & Detect $^{\mathrm{a}}$ & Mean $\left(\mathrm{cm}^{\mathrm{b}}\right)$ & $\mathrm{LCL}^{\mathrm{C}}$ & $\mathrm{UCL}^{\mathrm{d}}$ & $\mathrm{SD}^{\mathrm{e}}$ & $n^{f}$ & $p^{g}$ \\
\hline \multirow{2}{*}{6} & Yes & 120.7 & 118.9 & 122.4 & 6.43 & 54 & \multirow{2}{*}{0.100} \\
\hline & No & 118.7 & 117.1 & 120.3 & 4.60 & 34 & \\
\hline \multirow{2}{*}{7} & Yes & 126.5 & 125 & 128 & 5.90 & 62 & \multirow{2}{*}{0.759} \\
\hline & No & 126.1 & 124 & 128.1 & 6.37 & 40 & \\
\hline \multirow{2}{*}{8} & Yes & 130.9 & 128.7 & 133.2 & 7.83 & 49 & \multirow{2}{*}{0.046} \\
\hline & No & 134.3 & 131.8 & 136.7 & 7.48 & 38 & \\
\hline \multirow{2}{*}{9} & Yes & 137.3 & 135.4 & 139.3 & 7.63 & 62 & \multirow{2}{*}{0.619} \\
\hline & No & 136.6 & 134.7 & 138.6 & 6.67 & 48 & \\
\hline \multirow{2}{*}{10} & Yes & 144.4 & 141.9 & 146.9 & 8.56 & 47 & \multirow{2}{*}{0.512} \\
\hline & No & 143.2 & 140.5 & 145.8 & 7.04 & 29 & \\
\hline \multirow{2}{*}{11} & Yes & 153.7 & 151.6 & 155.8 & 8.34 & 63 & \multirow{2}{*}{0.022} \\
\hline & No & 149.9 & 147.6 & 152.3 & 7.04 & 37 & \\
\hline
\end{tabular}

a (Detect) = Detectable Level of Biomarker in the Urine Sample; ${ }^{b}(\mathrm{~cm})=$ Centimeters;

${ }^{c}($ LCL $)=$ Lower Confidence Limit; ${ }^{\mathrm{d}}(\mathrm{UCL})=$ Upper Confidence Limit; ${ }^{\mathrm{e}}(\mathrm{SD})=$ Standard Deviation; ${ }^{\mathrm{f}}(\mathrm{n})=$ Number in Sample; ${ }^{\mathrm{g}}(\mathrm{p})=$ Level of Significance at $\mathrm{p}=0.05$ Level (highlighted in Bold)

There is a significantly higher mean height for age 8 non-detects as compared to those with a detect for the biomarker. Children with a recorded detect age 11 had a significantly higher mean height than those children in the same age group that did not have a detect. 


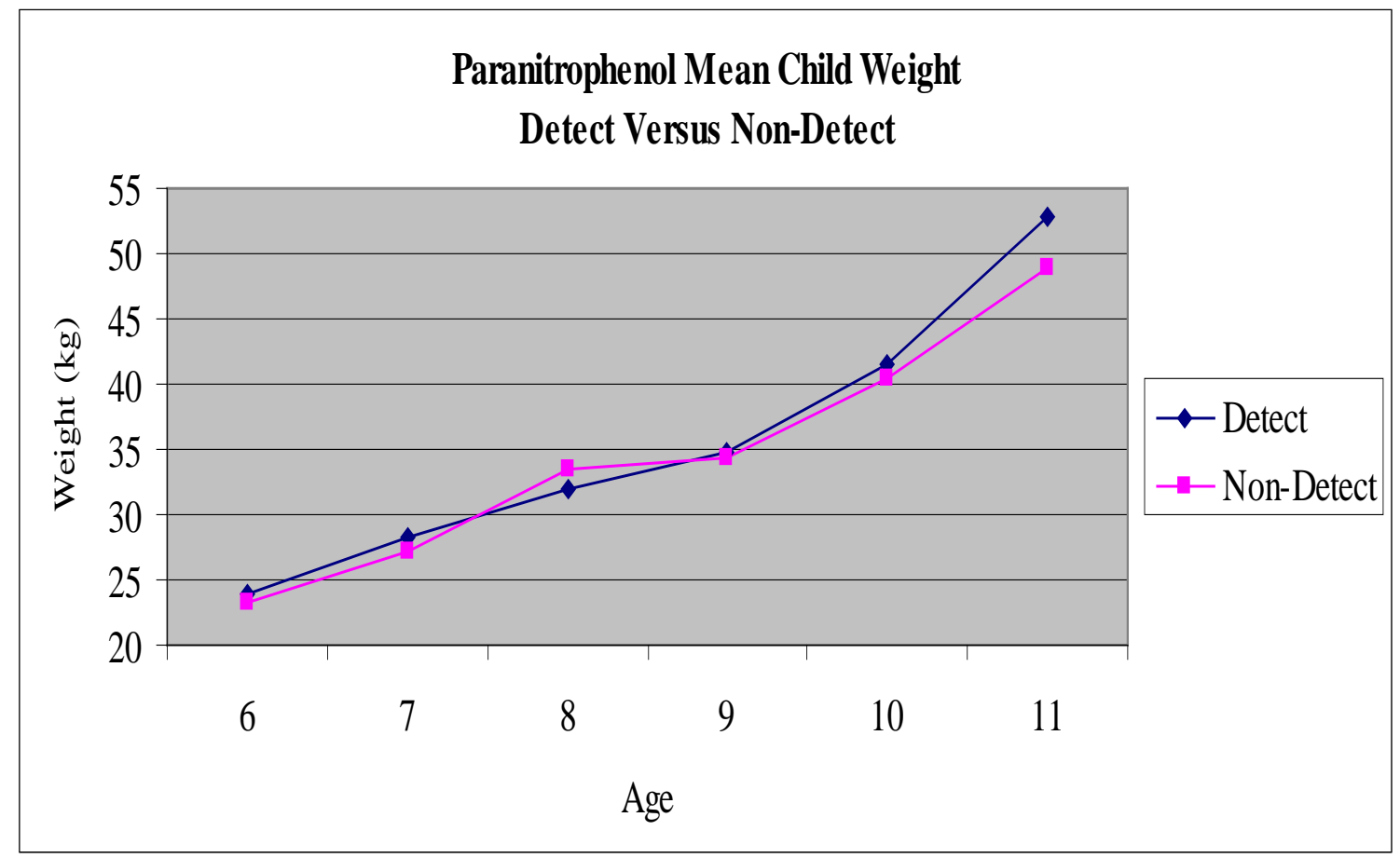

Figure 23: Graph of Arithmetic Mean Weight for Detects Versus Non-Detects for Paranitrophenol, Ages 6-11. Kg= Kilograms 
Table 27: Student's t-test Comparing Detects Versus Non-Detects for Arithmetic Mean of Weight for Paranitrophenol.

\begin{tabular}{|c|c|c|c|c|c|c|c|}
\hline Age & Detect $^{a}$ & Mean $\left(\mathrm{Kg}^{\mathrm{b}}\right)$ & $\mathrm{LCL}^{\mathrm{c}}$ & $\mathrm{UCL}^{\mathrm{d}}$ & $\mathrm{SD}^{\mathrm{e}}$ & $n^{f}$ & $\mathrm{p}^{\mathrm{g}}$ \\
\hline \multirow{2}{*}{6} & Yes & 23.86 & 22.62 & 25.11 & 4.56 & 54 & \multirow{2}{*}{0.476} \\
\hline & No & 23.20 & 21.95 & 24.45 & 3.58 & 34 & \\
\hline \multirow{2}{*}{7} & Yes & 28.19 & 26.64 & 29.75 & 6.11 & 62 & \multirow{2}{*}{0.470} \\
\hline & No & 27.23 & 24.93 & 29.53 & 7.09 & 39 & \\
\hline \multirow{2}{*}{8} & Yes & 31.96 & 28.92 & 34.99 & 10.46 & 48 & \multirow{2}{*}{0.491} \\
\hline & No & 33.48 & 30.30 & 36.66 & 9.54 & 37 & \\
\hline \multirow{2}{*}{9} & Yes & 34.70 & 31.94 & 37.45 & 10.68 & 60 & \multirow{2}{*}{0.864} \\
\hline & No & 34.37 & 31.79 & 36.94 & 8.86 & 48 & \\
\hline \multirow{2}{*}{10} & Yes & 41.56 & 37.73 & 45.38 & 13.03 & 47 & \multirow{2}{*}{0.711} \\
\hline & No & 40.41 & 35.41 & 45.41 & 13.14 & 29 & \\
\hline \multirow{2}{*}{11} & Yes & 52.89 & 47.76 & 58.02 & 20.02 & 61 & \multirow{2}{*}{0.319} \\
\hline & No & 48.93 & 43.31 & 54.54 & 16.60 & 36 & \\
\hline
\end{tabular}

${ }^{\mathrm{a}}($ Detect $)=$ Detectable Level of Biomarker in the Urine Sample; ${ }^{\mathrm{b}}(\mathrm{Kg})=$ Kilograms;

${ }^{\mathrm{c}}(\mathrm{LCL})=$ Lower Confidence Limit; ${ }^{\mathrm{d}}(\mathrm{UCL})=$ Upper Confidence Limit; ${ }^{\mathrm{e}}(\mathrm{SD})$ = Standard Deviation; ${ }^{\mathrm{f}}(\mathrm{n})=$ Number in Sample; ${ }^{\mathrm{g}}(\mathrm{p})=$ Level of Significance at $\mathrm{p}=0.05$ Level

There are no significant differences at the $\mathrm{p}<0.05$ level between detect and nondetect urinary concentrations of paranitrophenol when evaluating variations in children's weight. 
Table 28: Paranitrophenol Female Biochemical t-test Comparisons.

\begin{tabular}{|c|c|c|c|c|c|c|c|c|c|}
\hline Biochemical & Detect $^{\mathrm{a}}$ & Mean & $\mathrm{LCL}^{\mathrm{b}}$ & $\mathrm{UCL}^{\mathrm{c}}$ & $\mathrm{SD}^{\mathrm{d}}$ & $\mathrm{n}^{\mathrm{e}}$ & $\operatorname{Min}^{f}$ & $\operatorname{Max}^{\mathrm{g}}$ & $\mathrm{p}^{\mathrm{h}}$ \\
\hline \multirow{2}{*}{ Alanine Transaminase $(\mathrm{U} / \mathrm{L})^{\mathrm{i}}$} & Yes & 18.70 & 17.87 & 19.53 & 9.78 & 538 & 7 & 102 & \multirow{2}{*}{0.375} \\
\hline & No & 19.18 & 18.51 & 19.86 & 8.87 & 666 & 5 & 83 & \\
\hline \multirow{2}{*}{ Albumin $(\mathrm{g} / \mathrm{dL})^{\mathrm{j}}$} & Yes & 4.15 & 4.12 & 4.18 & 0.33 & 538 & 2.6 & 5 & \multirow{2}{*}{0.196} \\
\hline & No & 4.18 & 4.15 & 4.20 & 0.36 & 666 & 2.6 & 5 & \\
\hline \multirow{2}{*}{ Alkaline Phosphatase (U/L) } & Yes & 83.90 & 80.06 & 87.75 & 45.43 & 538 & 30 & 424 & \multirow{2}{*}{0.084} \\
\hline & No & 79.63 & 76.69 & 82.57 & 38.64 & 666 & 24 & 341 & \\
\hline \multirow{2}{*}{ Aspartate Transaminase (U/L) } & Yes & 21.48 & 20.83 & 22.13 & 7.70 & 538 & 9 & 114 & \multirow{2}{*}{0.399} \\
\hline & No & 21.84 & 21.31 & 22.37 & 6.93 & 666 & 7 & 84 & \\
\hline \multirow{2}{*}{ Bicarbonate $(\mathrm{mmol} / \mathrm{L})^{\mathrm{k}}$} & Yes & 23.01 & 22.83 & 23.19 & 2.16 & 538 & 16 & 29 & \multirow{2}{*}{0.083} \\
\hline & No & 22.79 & 22.61 & 22.96 & 2.27 & 666 & 16 & 29 & \\
\hline \multirow{2}{*}{ Bilirubin (mg/dL) ${ }^{1}$} & Yes & 0.65 & 0.63 & 0.66 & 0.20 & 538 & 0.2 & 2.1 & \multirow{2}{*}{0.083} \\
\hline & No & 0.67 & 0.65 & 0.68 & 0.22 & 666 & 0.2 & 1.9 & \\
\hline \multirow{2}{*}{ Blood Urea Nitrogen (mg/dL) } & Yes & 11.99 & 11.57 & 12.41 & 4.96 & 538 & 2 & 45 & \multirow{2}{*}{0.973} \\
\hline & No & 11.98 & 11.46 & 12.49 & 6.79 & 666 & 2 & 122 & \\
\hline \multirow{2}{*}{ Total Calcium (mg/dL) } & Yes & 9.43 & 9.40 & 9.46 & 0.38 & 538 & 8.1 & 10.7 & \multirow{2}{*}{0.516} \\
\hline & No & 9.45 & 9.42 & 9.48 & 0.40 & 666 & 8.3 & 11 & \\
\hline \multirow{2}{*}{ Chloride (mmol/L) } & Yes & 103.20 & 102.90 & 103.40 & 2.60 & 538 & 93 & 111 & \multirow{2}{*}{0.375} \\
\hline & No & 103.00 & 102.80 & 103.20 & 2.76 & 665 & 89 & 113 & \\
\hline \multirow{2}{*}{ Cholesterol (mg/dL) } & Yes & 187.10 & 183.60 & 190.50 & 41.28 & 538 & 91 & 334 & \multirow{2}{*}{0.003} \\
\hline & No & 194.60 & 191.10 & 198.10 & 46.08 & 666 & 90 & 476 & \\
\hline \multirow{2}{*}{ Creatinine (mg/dL) } & Yes & 0.73 & 0.72 & 0.75 & 0.19 & 538 & 0.3 & 2.3 & 0.820 \\
\hline & No & 0.73 & 0.71 & 0.75 & 0.25 & 666 & 0.3 & 4.4 & $0.8<0$ \\
\hline & Yes & 20.59 & 18.82 & 22.36 & 20.94 & 538 & 5 & 266 & \\
\hline$\gamma$ Glutamyı I ransferase (U/L) & No & 20.12 & 18.44 & 21.80 & 22.08 & 666 & 4 & 369 & 0.105 \\
\hline & Yes & 3.17 & 3.14 & 3.21 & 0.40 & 538 & 2.2 & 5.4 & 0.478 \\
\hline GloDumn (mg/aL) & No & 3.16 & 3.13 & 3.19 & 0.39 & 666 & 2.2 & 4.8 & $0.4 / 8$ \\
\hline & Yes & 92.03 & 89.15 & 94.91 & 33.99 & 538 & 50 & 521 & \\
\hline Glucose (mg/dL) & No & 88.48 & 86.56 & 90.40 & 25.23 & 666 & 30 & 453 & 0.044 \\
\hline & Yes & 81.59 & 78.38 & 84.81 & 37.99 & 538 & 8 & 249 & \\
\hline Iron (mg/dL) & No & 83.07 & 80.29 & 85.85 & 36.54 & 666 & 7 & 268 & 0.493 \\
\hline Lactate Debydrooenase (U/L) & Yes & 129.40 & 127.10 & 131.70 & 26.96 & 538 & 51 & 277 & \\
\hline Lactate Dehydrogenase (U/L) & No & 131.40 & 129.10 & 133.60 & 29.49 & 665 & 58 & 470 & 0.230 \\
\hline Ocmolality $(\mathrm{mmol} / \mathrm{K} \sigma)^{\mathrm{m}}$ & Yes & 275.80 & 275.30 & 276.20 & 5.37 & 538 & 250 & 297 & 0100 \\
\hline Usmoramty (IIIIIOI/Rg) & No & 275.30 & 274.80 & 275.70 & 5.67 & 666 & 248 & 310 & 0.100 \\
\hline & Yes & 4.02 & 3.97 & 4.07 & 0.59 & 538 & 2.3 & 5.7 & \\
\hline Phosphorus (mg/dL) & No & 3.95 & 3.91 & 3.99 & 0.55 & 666 & 2.3 & 6.1 & 0.053 \\
\hline Potassium (mmol/L) & Yes & 3.99 & 3.96 & 4.02 & 0.33 & 538 & 3.1 & 5.5 & \\
\hline Potassium (mmol/L) & No & 3.99 & 3.96 & 4.01 & 0.35 & 666 & 2.6 & 6 & 0.924 \\
\hline & Yes & 7.32 & 7.28 & 7.37 & 0.49 & 538 & 5.5 & 9.5 & \\
\hline Total Protein (g/dL) & No & 7.33 & 7.30 & 7.37 & 0.48 & 666 & 5.9 & 9.1 & 0.737 \\
\hline & Yes & 138.40 & 138.20 & 138.60 & 2.42 & 538 & 125 & 145 & 020 \\
\hline soaium (mmol/L) & No & 138.20 & 138.00 & 138.40 & 2.60 & 666 & 124 & 147 & 0.229 \\
\hline & Yes & 121.90 & 114.20 & 129.50 & 90.47 & 538 & 23 & 742 & \\
\hline Triglycerıdes (mg/dL) & No & 119.50 & 113.20 & 125.90 & 83.24 & 666 & 28 & 1077 & 0.644 \\
\hline & Yes & 4.57 & 4.46 & 4.67 & 1.26 & 538 & 0.4 & 10.9 & \\
\hline UrIC Acia (mg/aL) & No & 4.55 & 4.46 & 4.64 & 1.25 & 666 & 1.8 & 13.9 & 0.820 \\
\hline
\end{tabular}

${ }^{\mathrm{a}}$ (Detect) $=$ Detectable Level of Biomarker in the Urine Sample; ${ }^{\mathrm{b}}(\mathrm{LCL})=$ Lower Confidence Limit; ' $($ UCL $)=$ Upper Confidence Limit; ${ }^{\mathrm{d}}(\mathrm{SD})=$ Standard Deviation; ${ }^{\mathrm{e}}(\mathrm{n})=$ Number in Sample; ${ }^{\mathrm{f}}(\mathrm{Min})=$ Minimum; ${ }^{\mathrm{g}}(\mathrm{Max})=$ Maximum; ${ }^{\mathrm{h}}(\mathrm{p})=$ Level of Significance at $\mathrm{p}=0.05$ Level (highlighted in Bold); ${ }^{\mathrm{i}}(\mathrm{U} / \mathrm{L})=$ Units per Liter; ${ }^{\mathrm{j}}(\mathrm{g} / \mathrm{dL})=$ Grams per Deciliter; ${ }^{\mathrm{k}}(\mathrm{mmol} / \mathrm{L})=$ Millimole per Liter; ${ }^{\mathrm{l}}(\mathrm{mg} / \mathrm{dL})=$ Milligram per Deciliter; ${ }^{\mathrm{m}}(\mathrm{mmol} / \mathrm{Kg})=$ Millimole per Kilogram 
Table 29: Paranitrophenol Male Biochemical t-test Comparisons.

\begin{tabular}{|c|c|c|c|c|c|c|c|c|c|}
\hline Biochemical & Detect $^{\mathrm{a}}$ & Mean & $\mathrm{LCL}^{\mathrm{b}}$ & $\mathrm{UCL}^{\mathrm{C}}$ & $\mathrm{SD}^{\mathrm{d}}$ & $\mathrm{n}^{\mathrm{e}}$ & $\operatorname{Min}^{f}$ & $\operatorname{Max}^{\mathrm{g}}$ & $p^{h}$ \\
\hline \multirow{2}{*}{ Alanine Transaminase $(\mathrm{U} / \mathrm{L})^{\mathrm{i}}$} & Yes & 26.54 & 25.04 & 28.04 & 18.97 & 620 & 8 & 243 & \multirow{2}{*}{0.954} \\
\hline & No & 26.61 & 24.97 & 28.24 & 17.40 & 436 & 7 & 165 & \\
\hline \multirow{2}{*}{ Albumin (g/dL) $)^{\mathrm{j}}$} & Yes & 4.38 & 4.35 & 4.40 & 0.30 & 620 & 2.1 & 5.3 & \multirow{2}{*}{0.200} \\
\hline & No & 4.40 & 4.37 & 4.43 & 0.31 & 436 & 2.6 & 5.3 & \\
\hline \multirow{2}{*}{ Alkaline Phosphatase (U/L) } & Yes & 102.10 & 96.44 & 107.70 & 71.20 & 620 & 19 & 617 & \multirow{2}{*}{0.872} \\
\hline & No & 102.80 & 95.69 & 109.90 & 75.50 & 436 & 33 & 515 & \\
\hline \multirow{2}{*}{ Aspartate Transaminase (U/L) } & Yes & 26.55 & 25.50 & 27.59 & 13.28 & 620 & 9 & 187 & \multirow{2}{*}{0.950} \\
\hline & No & 26.50 & 25.36 & 27.63 & 12.05 & 436 & 12 & 118 & \\
\hline \multirow{2}{*}{ Bicarbonate $(\mathrm{mmol} / \mathrm{L})^{\mathrm{k}}$} & Yes & 24.00 & 23.82 & 24.17 & 2.16 & 620 & 15 & 29 & \multirow{2}{*}{0.903} \\
\hline & No & 24.01 & 23.81 & 24.21 & 2.10 & 436 & 17 & 30 & \\
\hline \multirow{2}{*}{ Bilirubin $(\mathrm{mg} / \mathrm{dL})^{\mathrm{l}}$} & Yes & 0.82 & 0.79 & 0.84 & 0.30 & 620 & 0.3 & 2.9 & \multirow{2}{*}{0.518} \\
\hline & No & 0.83 & 0.80 & 0.86 & 0.32 & 436 & 0.3 & 3.5 & \\
\hline \multirow{2}{*}{ Blood Urea Nitrogen (mg/dL) } & Yes & 14.25 & 13.84 & 14.67 & 5.28 & 620 & 3 & 48 & \multirow{2}{*}{0.103} \\
\hline & No & 13.72 & 13.24 & 14.20 & 5.10 & 436 & 3 & 41 & \\
\hline \multirow{2}{*}{ Total Calcium (mg/dL) } & Yes & 9.53 & 9.50 & 9.56 & 0.38 & 620 & 7.2 & 10.6 & \multirow{2}{*}{0.022} \\
\hline & No & 9.59 & 9.55 & 9.63 & 0.42 & 436 & 7.6 & 11.3 & \\
\hline \multirow{2}{*}{ Chloride (mmol/L) } & Yes & 102.60 & 102.40 & 102.80 & 2.63 & 620 & 83 & 111 & \multirow{2}{*}{0.003} \\
\hline & No & 102.20 & 101.90 & 102.40 & 2.55 & 436 & 93 & 112 & \\
\hline \multirow{2}{*}{ Cholesterol (mg/dL) } & Yes & 183.60 & 180.00 & 187.20 & 45.40 & 620 & 71 & 566 & \multirow{2}{*}{0.078} \\
\hline & No & 188.40 & 184.50 & 192.40 & 41.69 & 436 & 86 & 402 & \\
\hline \multirow{2}{*}{ Creatinine (mg/dL) } & Yes & 0.97 & 0.95 & 0.99 & 0.26 & 620 & 0.4 & 4.4 & \\
\hline & No & 0.97 & 0.94 & 0.99 & 0.24 & 436 & 0.4 & 2.5 & $0.8 / 1$ \\
\hline Glutamyl Trancferace (LU/L) & Yes & 30.34 & 27.74 & 32.93 & 32.89 & 620 & 6 & 482 & 0788 \\
\hline$\gamma$ Glutamyl I ransterase (U/L) & No & 30.88 & 27.90 & 33.87 & 31.73 & 436 & 6 & 394 & 0.788 \\
\hline Clobulin (matdI ) & Yes & 3.08 & 3.04 & 3.11 & 0.47 & 620 & 1.6 & 5.9 & 0765 \\
\hline Globulin (mg/dL) & No & 3.07 & 3.03 & 3.10 & 0.39 & 435 & 2 & 4.4 & 0.765 \\
\hline & Yes & 94.51 & 92.73 & 96.29 & 22.60 & 620 & 65 & 295 & \\
\hline Glucose (mg/dL) & No & 96.65 & 92.89 & 100.40 & 39.97 & 436 & 68 & 707 & 0.312 \\
\hline & Yes & 95.80 & 92.76 & 98.84 & 38.58 & 620 & 12 & 276 & 100 \\
\hline Iron (mg/dL) & No & 99.07 & 95.34 & 102.80 & 39.60 & 436 & 18 & 333 & 0.180 \\
\hline I & Yes & 136.30 & 133.80 & 138.80 & 31.70 & 620 & 52 & 355 & זم: \\
\hline Lactate Dehydrogenase (U/L) & No & 139.00 & 135.60 & 142.40 & 35.74 & 436 & 75 & 399 & 0.205 \\
\hline & Yes & 278.00 & 277.60 & 278.40 & 5.51 & 620 & 218 & 299 & \\
\hline Osmolality $(\mathrm{mmol} / \mathrm{Kg})^{\mathrm{m}}$ & No & 277.50 & 277.00 & 278.00 & 4.99 & 436 & 261 & 298 & 0.126 \\
\hline & Yes & 3.93 & 3.88 & 3.99 & 0.69 & 620 & 2.5 & 6.6 & \\
\hline Phosphorus (mg/dL) & No & 3.88 & 3.81 & 3.95 & 0.70 & 436 & 2.4 & 6.6 & 0.234 \\
\hline & Yes & 4.12 & 4.09 & 4.15 & 0.36 & 620 & 3.1 & 5.5 & \\
\hline Potassium (mmol/L) & No & 4.12 & 4.09 & 4.15 & 0.34 & 436 & 3.2 & 5.3 & 0.937 \\
\hline Totol Dmatoin (oldI ) & Yes & 7.45 & 7.42 & 7.49 & 0.48 & 620 & 5.3 & 9.8 & $0,0<0$ \\
\hline 1 otal Protein (g/aL) & No & 7.47 & 7.43 & 7.51 & 0.44 & 435 & 5.9 & 8.7 & 0.569 \\
\hline Sodium (mmol/I) & Yes & 139.10 & 138.90 & 139.30 & 2.72 & 620 & 108 & 147 & 0146 \\
\hline Sodium (mmol/L) & No & 138.90 & 138.60 & 139.10 & 2.28 & 436 & 131 & 146 & 0.146 \\
\hline Triglycerides (mo/dI) & Yes & 140.90 & 127.00 & 154.70 & 175.90 & 620 & 21 & 2677 & 0550 \\
\hline Triglycerides (mg/dL) & No & 148.30 & 128.00 & 168.60 & 215.60 & 436 & 27 & 3854 & 0.550 \\
\hline & Yes & 5.98 & 5.88 & 6.08 & 1.26 & 620 & 1.5 & 13.4 & \\
\hline Uric Acid (mg/dL) & No & 6.02 & 5.89 & 6.15 & 1.40 & 436 & 2.6 & 11 & 0.643 \\
\hline
\end{tabular}

${ }^{\mathrm{a}}($ Detect $)=$ Detectable Level of Biomarker in the Urine Sample; ${ }^{\mathrm{b}}(\mathrm{LCL})=$ Lower Confidence Limit; ${ }^{\mathrm{C}}(\mathrm{UCL})=$ Upper Confidence Limit; ${ }^{\mathrm{d}}(\mathrm{SD})=$ Standard Deviation; ${ }^{\mathrm{e}}(\mathrm{n})=$ Number in Sample; ${ }^{\mathrm{f}}(\mathrm{Min})=$ Minimum; ${ }^{\mathrm{g}}(\mathrm{Max})=$ Maximum; ${ }^{\mathrm{h}}(\mathrm{p})=$ Level of Significance at $\mathrm{p}=0.05$ Level (highlighted in Bold); ${ }^{\mathrm{i}}(\mathrm{U} / \mathrm{L})=$ Units per Liter; ${ }^{\mathrm{j}}(\mathrm{g} / \mathrm{dL})=$ Grams per Deciliter; ${ }^{\mathrm{k}}(\mathrm{mmol} / \mathrm{L})=$ Millimole per Liter; ${ }^{\mathrm{l}}(\mathrm{mg} / \mathrm{dL})=$ Milligram per Deciliter; ${ }^{\mathrm{m}}(\mathrm{mmol} / \mathrm{Kg})=$ Millimole per Kilogram 
Table 30: Paranitrophenol Overall Biochemical t-test Comparisons.

\begin{tabular}{|c|c|c|c|c|c|c|c|c|c|}
\hline Biochemical & Detect $^{\mathrm{a}}$ & Mean & $\mathrm{LCL}^{\mathrm{b}}$ & $\mathrm{UCL}^{\mathrm{c}}$ & $\mathrm{SD}^{\mathrm{d}}$ & $\mathrm{n}^{\mathrm{e}}$ & $\operatorname{Min}^{f}$ & $\operatorname{Max}^{\mathrm{g}}$ & $\mathrm{p}^{\mathrm{h}}$ \\
\hline \multirow{2}{*}{ Alanine Transaminase $(\mathrm{U} / \mathrm{L})^{\mathrm{i}}$} & Yes & 22.90 & 21.98 & 23.81 & 15.88 & 1158 & 7 & 243 & \multirow{2}{*}{0.208} \\
\hline & No & 22.12 & 21.33 & 22.91 & 13.43 & 1102 & 5 & 165 & \\
\hline \multirow{2}{*}{ Albumin $(\mathrm{g} / \mathrm{dL})^{\mathrm{j}}$} & Yes & 4.27 & 4.25 & 4.29 & 0.33 & 1158 & 2.1 & 5.3 & \multirow{2}{*}{0.646} \\
\hline & No & 4.27 & 4.24 & 4.29 & 0.36 & 1102 & 2.6 & 5.3 & \\
\hline \multirow{2}{*}{ Alkaline Phosphatase (U/L) } & Yes & 93.62 & 90.09 & 97.16 & 61.26 & 1158 & 19 & 617 & \multirow{2}{*}{0.053} \\
\hline & No & 88.80 & 85.41 & 92.18 & 57.29 & 1102 & 24 & 515 & \\
\hline \multirow{2}{*}{ Aspartate Transaminase (U/L) } & Yes & 24.19 & 23.54 & 24.84 & 11.32 & 1158 & 9 & 187 & \multirow{2}{*}{0.247} \\
\hline & No & 23.68 & 23.12 & 24.25 & 9.57 & 1102 & 7 & 118 & \\
\hline \multirow{2}{*}{ Bicarbonate $(\mathrm{mmol} / \mathrm{L})^{\mathrm{k}}$} & Yes & 23.54 & 23.41 & 23.66 & 2.22 & 1158 & 15 & 29 & \multirow{2}{*}{0.005} \\
\hline & No & 23.27 & 23.14 & 23.41 & 2.29 & 1102 & 16 & 30 & \\
\hline \multirow{2}{*}{ Bilirubin (mg/dL) $)^{1}$} & Yes & 0.74 & 0.72 & 0.75 & 0.27 & 1158 & 0.2 & 2.9 & \multirow{2}{*}{0.612} \\
\hline & No & 0.73 & 0.72 & 0.75 & 0.28 & 1102 & 0.2 & 3.5 & \\
\hline \multirow{2}{*}{ Blood Urea Nitrogen (mg/dL) } & Yes & 13.20 & 12.90 & 13.50 & 5.25 & 1158 & 2 & 48 & \multirow{2}{*}{0.028} \\
\hline & No & 12.67 & 12.30 & 13.04 & 6.23 & 1102 & 2 & 122 & \\
\hline \multirow{2}{*}{ Total Calcium (mg/dL) } & Yes & 9.48 & 9.46 & 9.51 & 0.38 & 1158 & 7.2 & 10.7 & \multirow{2}{*}{0.287} \\
\hline & No & 9.50 & 9.48 & 9.53 & 0.41 & 1102 & 7.6 & 11.3 & \\
\hline \multirow{2}{*}{ Chloride (mmol/L) } & Yes & 102.90 & 102.70 & 103.00 & 2.63 & 1158 & 83 & 111 & \multirow{2}{*}{0.073} \\
\hline & No & 102.70 & 102.50 & 102.80 & 2.71 & 1101 & 89 & 113 & \\
\hline \multirow{2}{*}{ Cholesterol (mg/dL) } & Yes & 185.20 & 182.70 & 187.70 & 43.55 & 1158 & 71 & 566 & \multirow{2}{*}{0.0002} \\
\hline & No & 192.20 & 189.50 & 194.80 & 44.48 & 1102 & 86 & 476 & \\
\hline \multirow{2}{*}{ Creatinine (mg/dL) } & Yes & 0.86 & 0.84 & 0.87 & 0.26 & 1158 & 0.3 & 4.4 & \\
\hline & No & 0.82 & 0.81 & 0.84 & 0.27 & 1102 & 0.3 & 4.4 & 0.002 \\
\hline & Yes & 25.81 & 24.17 & 27.45 & 28.39 & 1158 & 5 & 482 & \\
\hline$\gamma$ Glutamyl Transferase (U/L) & No & 24.38 & 22.79 & 25.96 & 26.83 & 1102 & 4 & 394 & 0.218 \\
\hline & Yes & 3.12 & 3.10 & 3.15 & 0.44 & 1158 & 1.6 & 5.9 & \\
\hline Globulin (mg/dL) & No & 3.12 & 3.10 & 3.14 & 0.39 & 1101 & 2 & 4.8 & 0.967 \\
\hline & Yes & 93.36 & 91.72 & 95.00 & 28.48 & 1158 & 50 & 521 & \\
\hline Glucose (mg/dL) & No & 91.71 & 89.81 & 93.61 & 32.12 & 1102 & 30 & 707 & 0.198 \\
\hline & Yes & 89.20 & 86.95 & 91.44 & 38.94 & 1158 & 8 & 276 & 0007 \\
\hline Iron (mg/dL) & No & 89.40 & 87.12 & 91.68 & 38.57 & 1102 & 7 & 333 & 0.902 \\
\hline I setate Dobudroxonoct & Yes & 133.10 & 131.40 & 134.80 & 29.78 & 1158 & 51 & 355 & \\
\hline Lactate Dehydrogenase (U/L) & No & 134.40 & 132.50 & 136.30 & 32.31 & 1101 & 58 & 470 & \\
\hline Ocmolality $\left(\mathrm{mmol} / \mathrm{Kq}^{\mathrm{m}}\right.$ & Yes & 277.00 & 276.60 & 277.30 & 5.56 & 1158 & 218 & 299 & 00004 \\
\hline & No & 276.10 & 275.80 & 276.50 & 5.52 & 1102 & 248 & 310 & 0.0004 \\
\hline & Yes & 3.97 & 3.93 & 4.01 & 0.64 & 1158 & 2.3 & 6.6 & \\
\hline Phosphorus (mg/dL) & No & 3.92 & 3.89 & 3.96 & 0.62 & 1102 & 2.3 & 6.6 & 0.075 \\
\hline & Yes & 4.06 & 4.04 & 4.08 & 0.36 & 1158 & 3.1 & 5.5 & \\
\hline Potassium $(\mathrm{mmol} / \mathrm{L})$ & No & 4.04 & 4.02 & 4.06 & 0.35 & 1102 & 2.6 & 6 & 0.170 \\
\hline Totol Dmotoin ( & Yes & 7.39 & 7.36 & 7.42 & 0.49 & 1158 & 5.3 & 9.8 & \\
\hline Total Protein (g/dL) & No & 7.39 & 7.36 & 7.42 & 0.47 & 1101 & 5.9 & 9.1 & \\
\hline & Yes & 138.80 & 138.60 & 138.90 & 2.60 & 1158 & 108 & 147 & \\
\hline Sodium (mmol/L) & No & 138.50 & 138.30 & 138.60 & 2.49 & 1102 & 124 & 147 & 0.008 \\
\hline Trialmonidor (moldI ) & Yes & 132.00 & 123.80 & 140.30 & 143.00 & 1158 & 21 & 2677 & \\
\hline Triglycerides (mg/dL) & No & 130.90 & 122.00 & 139.80 & 150.80 & 1102 & 27 & 3854 & 0.858 \\
\hline & Yes & 5.32 & 5.24 & 5.41 & 1.45 & 1158 & 0.4 & 13.4 & \\
\hline Uric Acid (mg/dL) & No & 5.13 & 5.04 & 5.22 & 1.49 & 1102 & 1.8 & 13.9 & 002 \\
\hline
\end{tabular}

${ }^{\mathrm{a}}($ Detect $)=$ Detectable Level of Biomarker in the Urine Sample; ${ }^{\mathrm{b}}(\mathrm{LCL})=$ Lower Confidence Limit; ${ }^{\mathrm{C}}(\mathrm{UCL})=$ Upper Confidence Limit; ${ }^{\mathrm{d}}(\mathrm{SD})=$ Standard Deviation; ${ }^{\mathrm{e}}(\mathrm{n})=$ Number in Sample; ${ }^{\mathrm{f}}(\mathrm{Min})=$ Minimum; ${ }^{\mathrm{g}}(\mathrm{Max})=$ Maximum; ${ }^{\mathrm{h}}(\mathrm{p})=$ Level of Significance at $\mathrm{p}=0.05$ Level (highlighted in Bold); ${ }^{\mathrm{i}}(\mathrm{U} / \mathrm{L})=$ Units per Liter; ${ }^{\mathrm{j}}(\mathrm{g} / \mathrm{dL})=$ Grams per Deciliter; ${ }^{\mathrm{k}}(\mathrm{mmol} / \mathrm{L})=$ Millimole per Liter; ${ }^{\mathrm{l}}(\mathrm{mg} / \mathrm{dL})=$ Milligram per Deciliter; ${ }^{\mathrm{m}}(\mathrm{mmol} / \mathrm{Kg})=$ Millimole per Kilogram 


\subsubsection{Logistic Regression}

Table 31: Logistic Regression for Paranitrophenol.

\begin{tabular}{|c|c|c|c|}
\hline & $\begin{array}{c}\text { Detect }^{\mathrm{a}} \\
\left(\mathrm{DF}^{\mathrm{b}}=1\right)\end{array}$ & $\begin{array}{l}\text { Detect, Non-Hispanic White } \\
(\mathrm{DF}=1)\end{array}$ & $\begin{array}{l}\text { Detect, Female } \\
\quad(\mathrm{DF}=1)\end{array}$ \\
\hline Age & $\begin{array}{c}\beta=-0.005 \\
\text { Wald } \chi 2=8.78 \\
p=0.003 \\
\text { OR=0.995 }\end{array}$ & & \\
\hline Mexican American & & $\begin{array}{c}\beta=-0.0239 \\
\text { Wald } \chi 2=0.0863 \\
p=0.77 \\
\text { OR }=1.18\end{array}$ & \\
\hline $\begin{array}{l}\text { Non-Hispanic } \\
\text { Black }\end{array}$ & & $\begin{array}{c}\beta=-0.213 \\
\text { Wald } \chi 2=2.00 \\
p=0.158 \\
\text { OR=0.976 }\end{array}$ & \\
\hline Other Hispanic & & $\begin{array}{c}\beta=0.183 \\
\text { Wald } \chi 2=4.96 \\
p=0.026 \\
\text { OR=1.45 }\end{array}$ & \\
\hline Other & & $\begin{array}{c}\beta=0.242 \\
\text { Wald } \chi 2=2.39 \\
p=0.122 \\
\text { OR-1.54 }\end{array}$ & \\
\hline Male & & & $\begin{array}{c}\beta=0.227 \\
\text { Wald } \chi 2=36.82 \\
p<0.0001 \\
O R=1.57\end{array}$ \\
\hline
\end{tabular}

${ }^{\mathrm{a}}($ Detect $)=$ Detectable Level of Biomarker in the Urine Sample, used as a reference category in the Model; ${ }^{b}(\mathrm{DF})=$ Degree of Freedom. Significant differences are highlight in Bold.

The overall model fit was significant, with Likelihood $\chi 2=71.3, \mathrm{p}<0.0001$ and the $\mathrm{R}_{\text {Max }}^{2}=0.0316$. The Hosmer and Lemeshow goodness-of-fit test resulted in a $\chi^{2}=$ 16.01, $\mathrm{p}=0.0414$, indicating that the data from the independent variables did not fit the model well. The listed detects at the row headers are the reference groups for each subcategory. When stratifying for individual groups, age does not seem to have an effect on the detection of a biomarker $(\beta=-0.005$ and $\mathrm{OR}=0.995, \mathrm{p}=0.003)$. Other Hispanics $(\beta=0.183$ and $\mathrm{OR}=1.45, \mathrm{p}=0.026)$ had a slightly higher change in the regression coefficient and a higher odds of having a detectable level of biomarker than NonHispanic Whites (reference group). Males had a higher change in the regression 
coefficient and a higher odds of having a detectable level of biomarker than females $(\beta=0.227$ and $\mathrm{OR}=1.57, \mathrm{p}<0.0001)$

\subsection{Pyrethroid}

\subsubsection{Pyrethroid Biomarker: 3-Phenoxybenzoic Acid (3-PBA)}

\subsubsection{Descriptive Statistics}

The information covered in the following figures and tables characterizes the exposures to pyrethroids in the overall sample and in various subgroups.

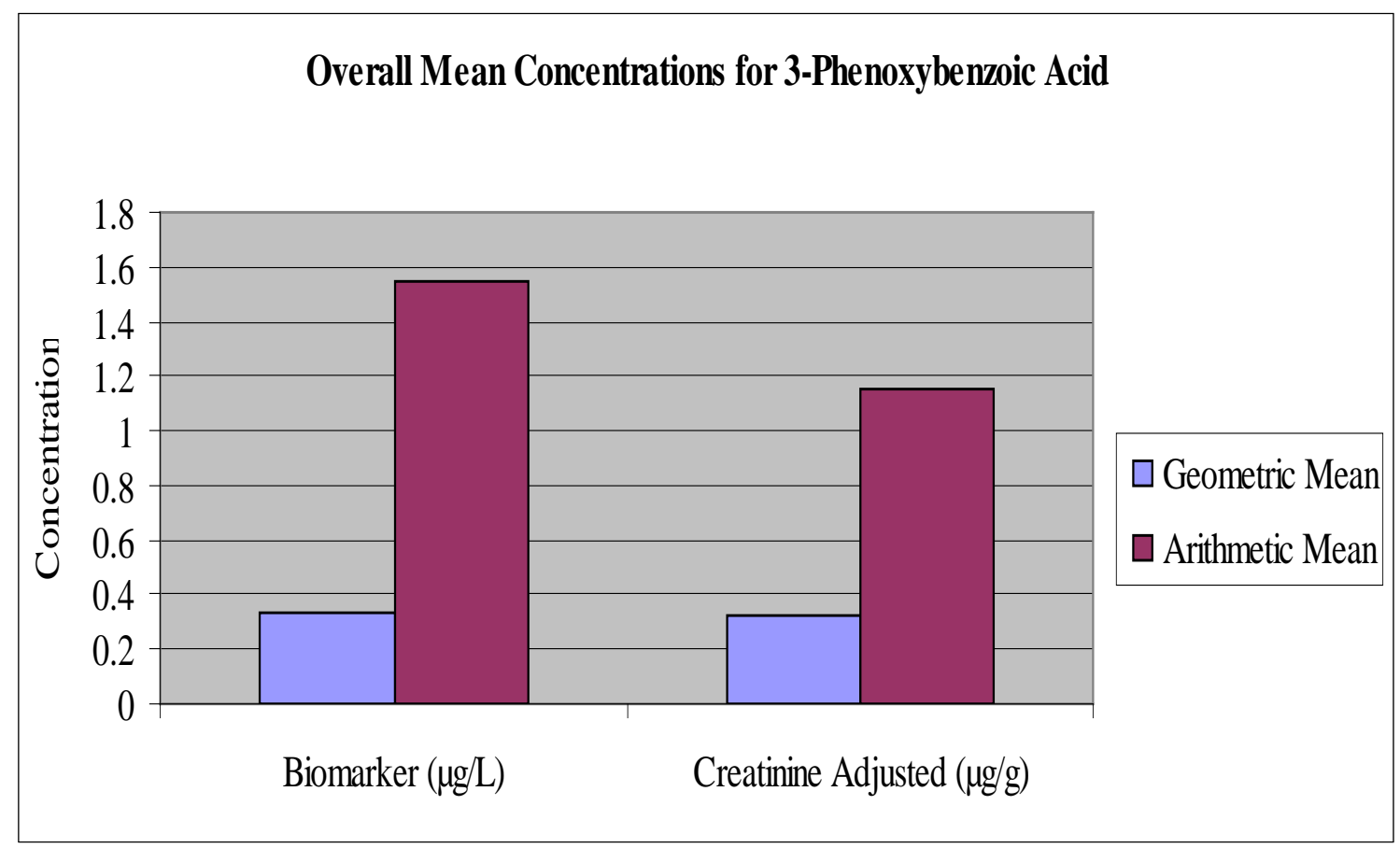

Figure24: Comparison of Means for 3-Phenoxybenzoic Acid. $\mu \mathrm{g} / \mathrm{l}=$ Micrograms per Liter; $\mu \mathrm{g} / \mathrm{g}=$ Micrograms per Gram. Adjusting for creatinine results in means (both geometric and arithmetic) that are lower than if using the concentration of the 3-PBA biomarker in urine $(\mu \mathrm{g} / \mathrm{L})$ alone. Limit of Detection (LOD) for 3-PBA in sample was 0.1 $\mu \mathrm{g} / \mathrm{L}$. 
Table 32: Descriptive Statistics for 3-Phenoxybenzoic Acid.

\begin{tabular}{|c|c|c|c|c|c|}
\hline \multicolumn{3}{|c|}{ Biomarker $(\mu g / L)^{a}$} & \multicolumn{3}{|c|}{ Creatinine Adjusted $(\mu \mathrm{g} / \mathrm{g})^{\mathrm{b}}$} \\
\hline & $\begin{array}{l}\text { Geometric } \\
\text { Mean }\end{array}$ & $\begin{array}{l}\text { Arithmetic } \\
\text { Mean }\end{array}$ & & $\begin{array}{c}\text { Geometric } \\
\text { Mean }\end{array}$ & $\begin{array}{c}\text { Arithmetic } \\
\text { Mean }\end{array}$ \\
\hline $\mathrm{n}^{\mathrm{c}}$ & 3048 & 3048 & $\mathrm{~N}$ & 3046 & 3046 \\
\hline Mean & 0.336 & 1.55 & Mean & 0.323 & 1.15 \\
\hline $\mathrm{LCL}^{\mathrm{d}}$ & 0.320 & 0.864 & LCL & 0.310 & 0.819 \\
\hline $\mathrm{UCL}^{\mathrm{e}}$ & 0.352 & 2.24 & UCL & 0.338 & 1.48 \\
\hline $\mathrm{SD}^{\mathrm{f}}$ & 3.70 & 19.31 & SD & 3.37 & 9.27 \\
\hline $\mathrm{P} 25^{\mathrm{g}}$ & 0.110 & 0.110 & P25 & 0.143 & 0.143 \\
\hline $\mathrm{P} 50^{\mathrm{h}}$ & 0.300 & 0.300 & P50 & 0.292 & 0.292 \\
\hline $\mathrm{P}^{2} 5^{\mathrm{i}}$ & 0.740 & 0.740 & P75 & 0.612 & 0.612 \\
\hline${\mathrm{P} 90^{\mathrm{j}}}$ & 1.73 & 1.73 & P90 & 1.46 & 1.46 \\
\hline $\mathrm{P} 95^{\mathrm{k}}$ & 3.38 & 3.38 & P95 & 2.82 & 2.82 \\
\hline $\operatorname{Min}^{1}$ & 0.07 & 0.07 & Min & 0.0201 & 0.0201 \\
\hline $\operatorname{Max}^{\mathrm{m}}$ & 999.6 & 999.6 & Max & 421.8 & 421.8 \\
\hline
\end{tabular}

${ }^{\mathrm{a}}(\mu \mathrm{g} / \mathrm{L})=$ Micrograms per Liter; ${ }^{\mathrm{b}}(\mu \mathrm{g} / \mathrm{g})=$ Micrograms per Gram; ${ }^{\mathrm{C}}(\mathrm{n})=$ Number in Sample; ${ }^{\mathrm{d}}(\mathrm{LCL})=$ Lower Confidence Limit; ${ }^{\mathrm{e}}(\mathrm{UCL})=$ Upper Confidence Limit; ${ }^{\mathrm{f}}(\mathrm{SD})=$ Standard Deviation; ${ }^{\mathrm{g}}(\mathrm{P} 25)=$ Lower Quartile; ${ }^{\mathrm{h}}(\mathrm{P} 50)=$ Median; ${ }^{\mathrm{i}}(\mathrm{P} 75)=$ Upper Quartile; ${ }^{\mathrm{j}}($ P90 $)=90^{\text {th }}$ Percentile; ${ }^{\mathrm{k}}($ P95 $)=95^{\text {th }}$ Percentile; ${ }^{\mathrm{l}}(\mathrm{Min})=$ Minimum ${ }^{\mathrm{m}}($ Max $)=$ Maximum

Like the organophosphates, adjusting for creatinine results in means (both geometric and arithmetic) that are lower than if using the concentration of the biomarker in urine $(\mu \mathrm{g} / \mathrm{L})$. While the maximum urinary biomarker concentration was $999.6 \mu \mathrm{g} / \mathrm{L}$, the next two highest values in the dataset were 253.8 and $160 \mu \mathrm{g} / \mathrm{L}$. 


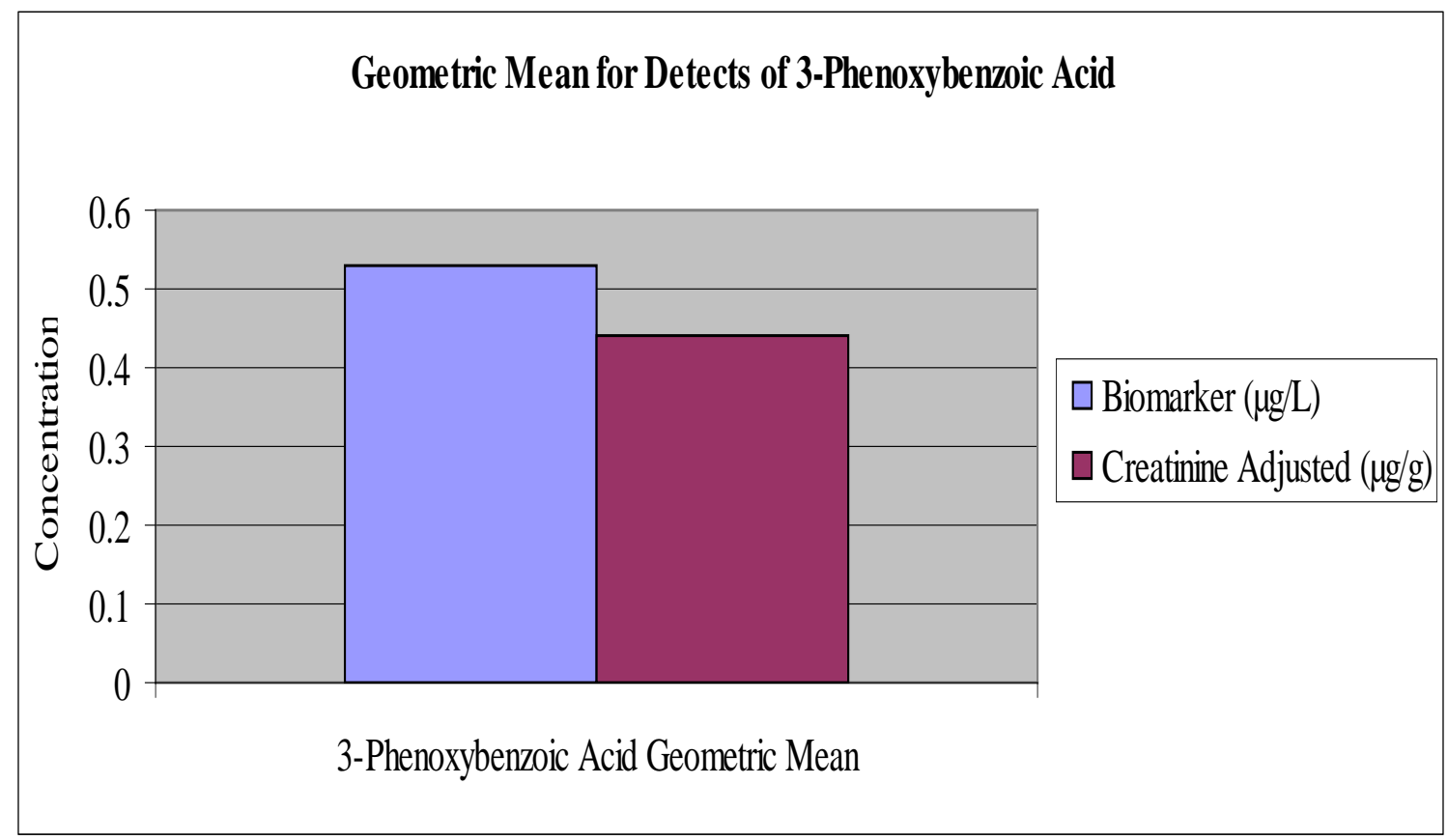

Figure 25: Comparison of Detectable Geometric Mean Concentrations for 3-Phenoxybenzoic Acid. $\mu \mathrm{g} / \mathrm{l}=$ Micrograms per Liter; $\mu \mathrm{g} / \mathrm{g}=$ Micrograms per Gram.

Table 33: Descriptive Statistics for Detectable Levels of 3-Phenoxybenzoic Acid.

\begin{tabular}{|l|c|c|c|c|c|c|}
\hline & $\mathrm{GM}^{\mathrm{c}}$ & $\mathrm{LCL}^{\mathrm{d}}$ & $\mathrm{UCL}^{\mathrm{e}}$ & $\mathrm{SD}^{\mathrm{f}}$ & Median & $\mathrm{n}^{\mathrm{g}}$ \\
\hline Biomarker $(\mu \mathrm{g} / \mathrm{L})^{\mathrm{a}}$ & 0.531 & 0.507 & 0.556 & 3.10 & 0.450 & 2359 \\
\hline${\text { Creatinine Adjusted }(\mu \mathrm{g} / \mathrm{g})^{\mathrm{b}}}^{\mathrm{a}}$ & 0.442 & 0.422 & 0.463 & 3.12 & 0.375 & 2359 \\
\hline
\end{tabular}

${ }^{\mathrm{a}}(\mu \mathrm{g} / \mathrm{L})=$ Micrograms per Liter; ${ }^{\mathrm{b}}(\mu \mathrm{g} / \mathrm{g})=$ Micrograms per Gram; ${ }^{\mathrm{C}}(\mathrm{GM})=$ Geometric Mean; ${ }^{\mathrm{d}}(\mathrm{LCL})=$ Lower Confidence Limit; ${ }^{\mathrm{e}}(\mathrm{UCL})=$ Upper Confidence Limit; ${ }^{\mathrm{f}}(\mathrm{SD})=$ Standard Deviation; ${ }^{\mathrm{g}}(\mathrm{n})=$ Number in Sample

The geometric mean was determined for $77.4 \%$ of the individuals that had a detectable level of biomarker in their urine sample. Based on this analysis, the geometric mean for only detectable levels of the biomarker was $\sim 0.2 \mu \mathrm{g} / \mathrm{L}$ higher that the overall geometric mean. 


\subsubsection{Comparative Statistics}

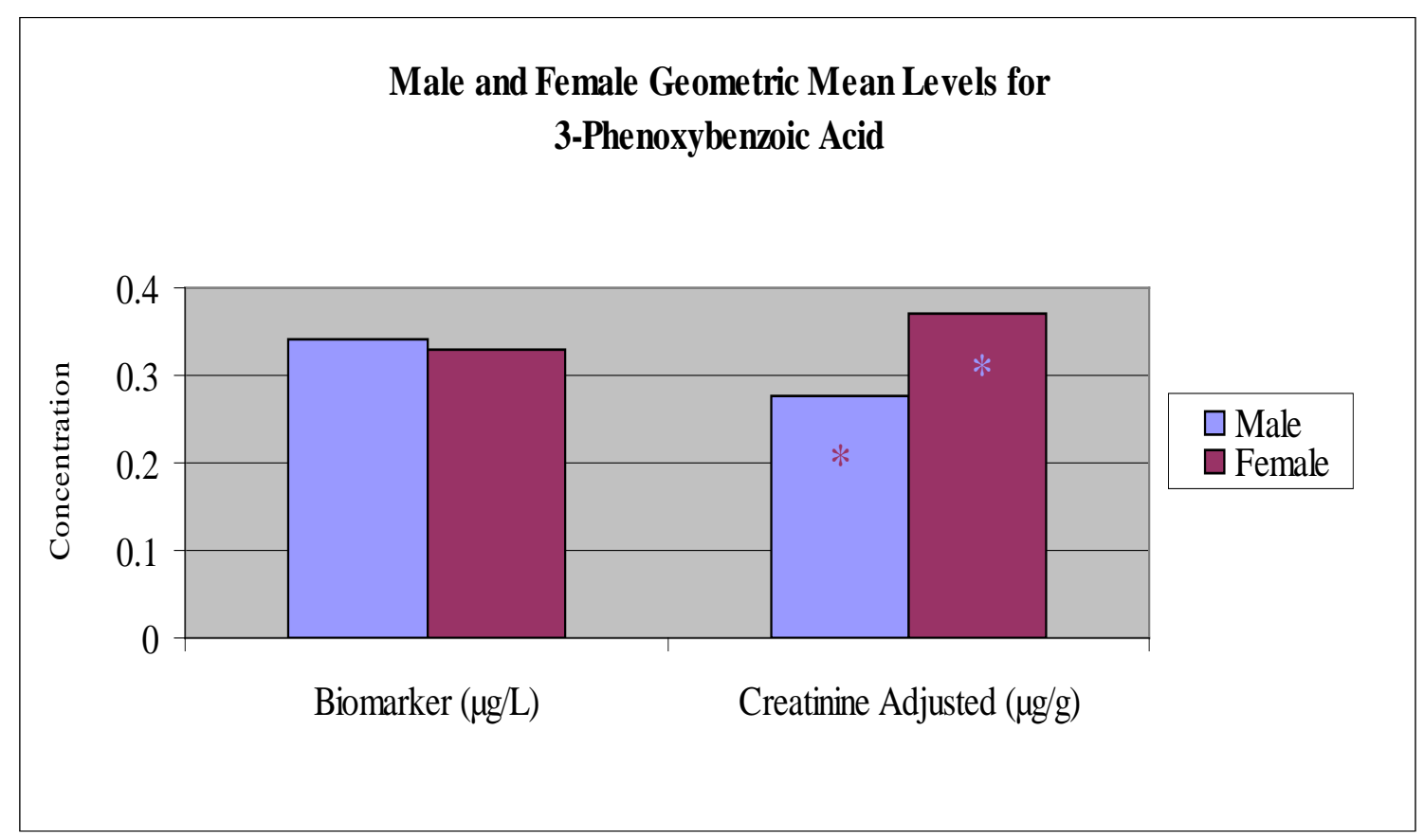

Figure 26: Comparison of Geometric Mean Values of Males Versus Females for 3-Phenoxybenzoic Acid. $\mu \mathrm{g} / \mathrm{l}=$ Micrograms per Liter; $\mu \mathrm{g} / \mathrm{g}=$ Micrograms per Gram. Color-coded “*” indicates females are significantly different from males. 
Table 34: Student's t-test Comparing Geometric Means of Males Versus Females for 3Phenoxybenzoic Acid.

\begin{tabular}{|c|c|c|c|c|c|c|c|}
\hline \multicolumn{8}{|c|}{ Biomarker $(\mu \mathrm{g} / \mathrm{L})^{\mathrm{a}}$} \\
\hline & $\mathrm{GM}^{\mathrm{b}}$ & $\mathrm{LCL}^{\mathrm{C}}$ & $\mathrm{UCL}^{\mathrm{d}}$ & $\mathrm{SD}^{\mathrm{e}}$ & Median & $\mathrm{n}^{\mathrm{f}}(\mathrm{D} / \mathrm{ND})^{\mathrm{g}}$ & $\mathrm{P}^{\mathrm{h}}$ \\
\hline Male & 0.341 & 0.319 & 0.365 & 3.58 & 0.320 & $1429(1131 / 298)$ & \multirow{3}{*}{0.514} \\
\hline Female & 0.331 & 0.310 & 0.353 & 3.81 & 0.290 & $1619(1228 / 391)$ & \\
\hline \multicolumn{7}{|r|}{3048} & \\
\hline \multicolumn{8}{|c|}{ Creatinine Adjusted $(\mu \mathrm{g} / \mathrm{g})^{\mathrm{i}}$} \\
\hline & GM & LCL & UCL & $\mathrm{SD}$ & Median & $\mathrm{n}$ & $\mathrm{p}$ \\
\hline Male & 0.278 & 0.261 & 0.296 & 3.38 & 0.250 & 1429 & \multirow{3}{*}{$<0.0001$} \\
\hline Female & 0.370 & 0.349 & 0.392 & 3.31 & 0.325 & 1617 & \\
\hline \multicolumn{6}{|l|}{ Total } & 3046 & \\
\hline
\end{tabular}

${ }^{\mathrm{a}}(\mu \mathrm{g} / \mathrm{L})=$ Micrograms per Liter; ${ }^{\mathrm{b}}(\mathrm{GM})=$ Geometric Mean; ${ }^{\mathrm{C}}(\mathrm{LCL})=$ Lower Confidence Limit; ${ }^{\mathrm{d}}(\mathrm{UCL})=$ Upper Confidence Limit; ${ }^{\mathrm{e}}(\mathrm{SD})=$ Standard Deviation; ${ }^{\mathrm{f}}(\mathrm{n})=$ Number in Sample; ${ }^{g}(\mathrm{D} / \mathrm{ND})=$ Number of Detects/Number of Non-Detects; ${ }^{\mathrm{h}}(\mathrm{p})=$ Level of Significance at $\mathrm{p}=0.05$ Level (Highlighted in Bold); ${ }^{\mathrm{i}}(\mu \mathrm{g} / \mathrm{g})=$ Micrograms per Gram

Females had a significantly higher geometric mean when compared to males when adjusting for creatinine $(\mu \mathrm{g} / \mathrm{g})$. However, the significance is not present when using the unadjusted urinary concentration of the biomarker. 


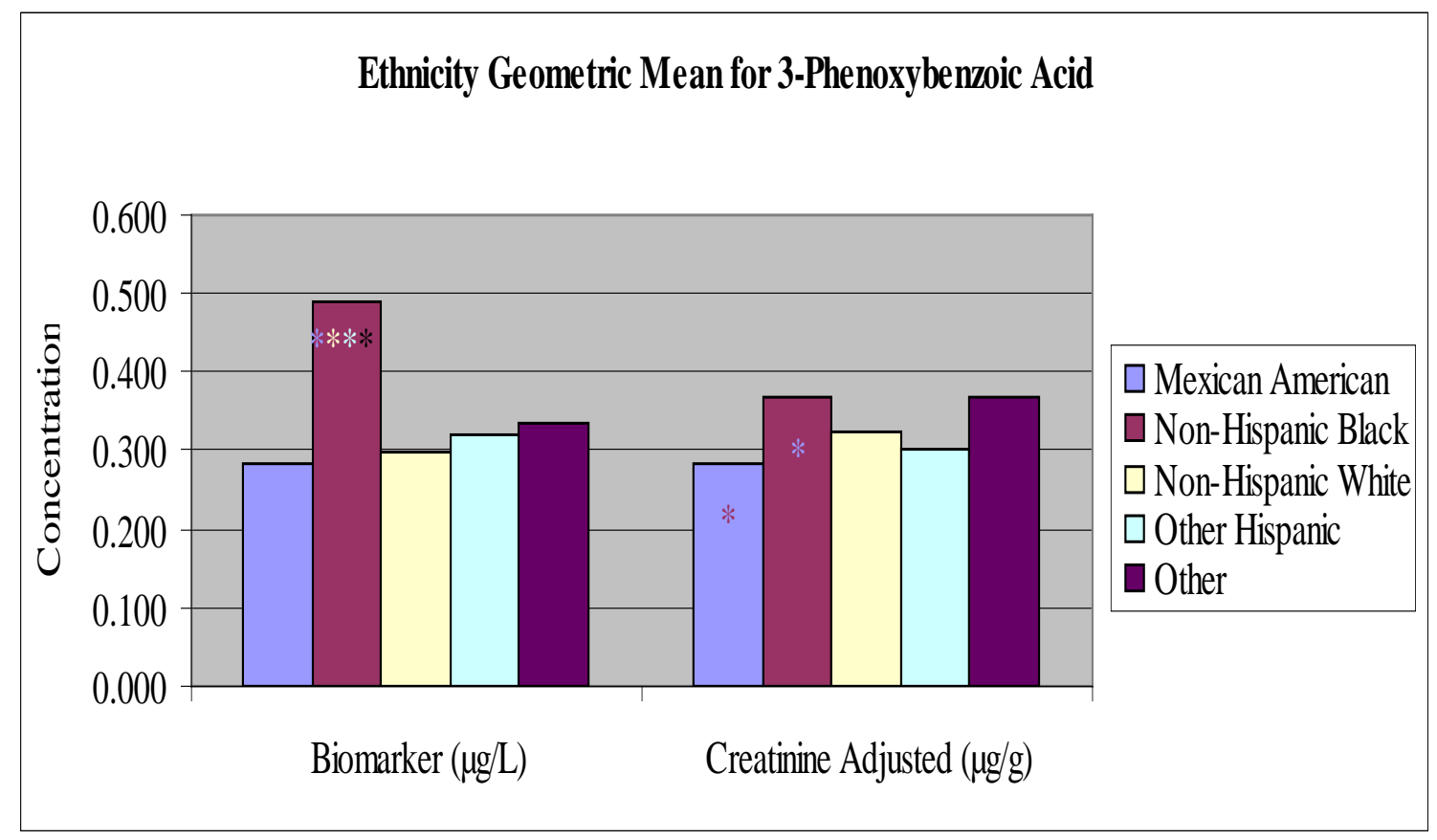

Figure 27: Comparison of Geometric Mean Values of Ethnic Groups for 3-Phenoxybenzoic Acid. $\mu \mathrm{g} / \mathrm{l}=$ Micrograms per Liter; $\mu \mathrm{g} / \mathrm{g}=$ Micrograms per Gram. Color-coded “****” indicates this groups is significantly different from all other groups. Color-coded “*” indicates these groups are significantly different from each other. 
Table 35: One-Way ANOVA and Tukey Analysis Comparing Geometric Means of Ethnic Groups for 3-Phenoxybenzoic Acid.

\begin{tabular}{|c|c|c|c|c|c|c|}
\hline Biomarker $(\mu \mathrm{g} / \mathrm{L})^{\mathrm{a}}$ & & & & & & \\
\hline & $\mathrm{GM}^{\mathrm{b}}$ & $\mathrm{LCL}^{\mathrm{C}}$ & $\mathrm{UCL}^{\mathrm{d}}$ & $\mathrm{SD}^{\mathrm{e}}$ & $n^{f}(D / N D)^{g}$ & $\mathrm{P}^{\mathrm{h}}$ \\
\hline Mexican American & 0.284 & 0.047 & 0.520 & 3.34 & $767(580 / 187)$ & \multirow{6}{*}{$<0.0001$} \\
\hline Non-Hispanic Black*all & 0.489 & 0.251 & 0.727 & 3.35 & $762(667 / 95)$ & \\
\hline Non-Hispanic White & 0.298 & 0.083 & 0.513 & 3.91 & $1269(920 / 349)$ & \\
\hline Other Hispanic & 0.320 & -0.339 & 0.980 & 3.82 & $129(103 / 26)$ & \\
\hline Other & 0.335 & -0.434 & 1.10 & 4.32 & $121(89 / 32)$ & \\
\hline \multicolumn{5}{|l|}{ Total } & 3048 & \\
\hline \multicolumn{7}{|c|}{ Creatinine Adjusted $(\mu \mathrm{g} / \mathrm{g})^{\mathrm{i}}$} \\
\hline & GM & $\mathrm{LCL}$ & UCL & SD & $\mathrm{n}$ & $\mathrm{p}$ \\
\hline Mexican American* & 0.283 & 0.068 & 0.497 & 3.03 & 767 & \multirow{6}{*}{0.0007} \\
\hline Non-Hispanic Black* & 0.367 & 0.148 & 0.585 & 3.08 & 761 & \\
\hline Non-Hispanic White & 0.323 & 0.123 & 0.524 & 3.64 & 1268 & \\
\hline Other Hispanic & 0.301 & -0.339 & 0.942 & 3.71 & 129 & \\
\hline Other & 0.367 & -0.341 & 1.08 & 3.98 & 121 & \\
\hline \multicolumn{5}{|l|}{ Total } & 3046 & \\
\hline
\end{tabular}

${ }^{\mathrm{a}}(\mu \mathrm{g} / \mathrm{L})=$ Micrograms per Liter; ${ }^{\mathrm{b}}(\mathrm{GM})=$ Geometric Mean; ${ }^{\mathrm{C}}(\mathrm{LCL})=$ Lower Confidence Limit; ${ }^{\mathrm{d}}(\mathrm{UCL})=$ Upper Confidence Limit; ${ }^{\mathrm{e}}(\mathrm{SD})=$ Standard Deviation; ${ }^{\mathrm{f}}(\mathrm{n})=$ Number in Sample; ${ }^{g}(\mathrm{D} / \mathrm{ND})=$ Number of Detects/Number of Non-Detects; ${ }^{\mathrm{h}}(\mathrm{p})=$ Level of Significance at $\mathrm{p}=0.05$ Level (Highlighted in Bold); $(\mu \mathrm{g} / \mathrm{g})=$ Micrograms per Gram. *all Indicates that group is significantly different than all other groups.

* Indicates that groups are significantly different from each other.

Non-Hispanic blacks have a significantly elevated geometric mean when compared to the other ethnic groups when evaluating the unadjusted urinary concentration of the biomarker $(\mu \mathrm{g} / \mathrm{L})$. When adjusting for creatinine $(\mu \mathrm{g} / \mathrm{g})$, only Mexican American and Non-Hispanic Blacks were significantly different. 


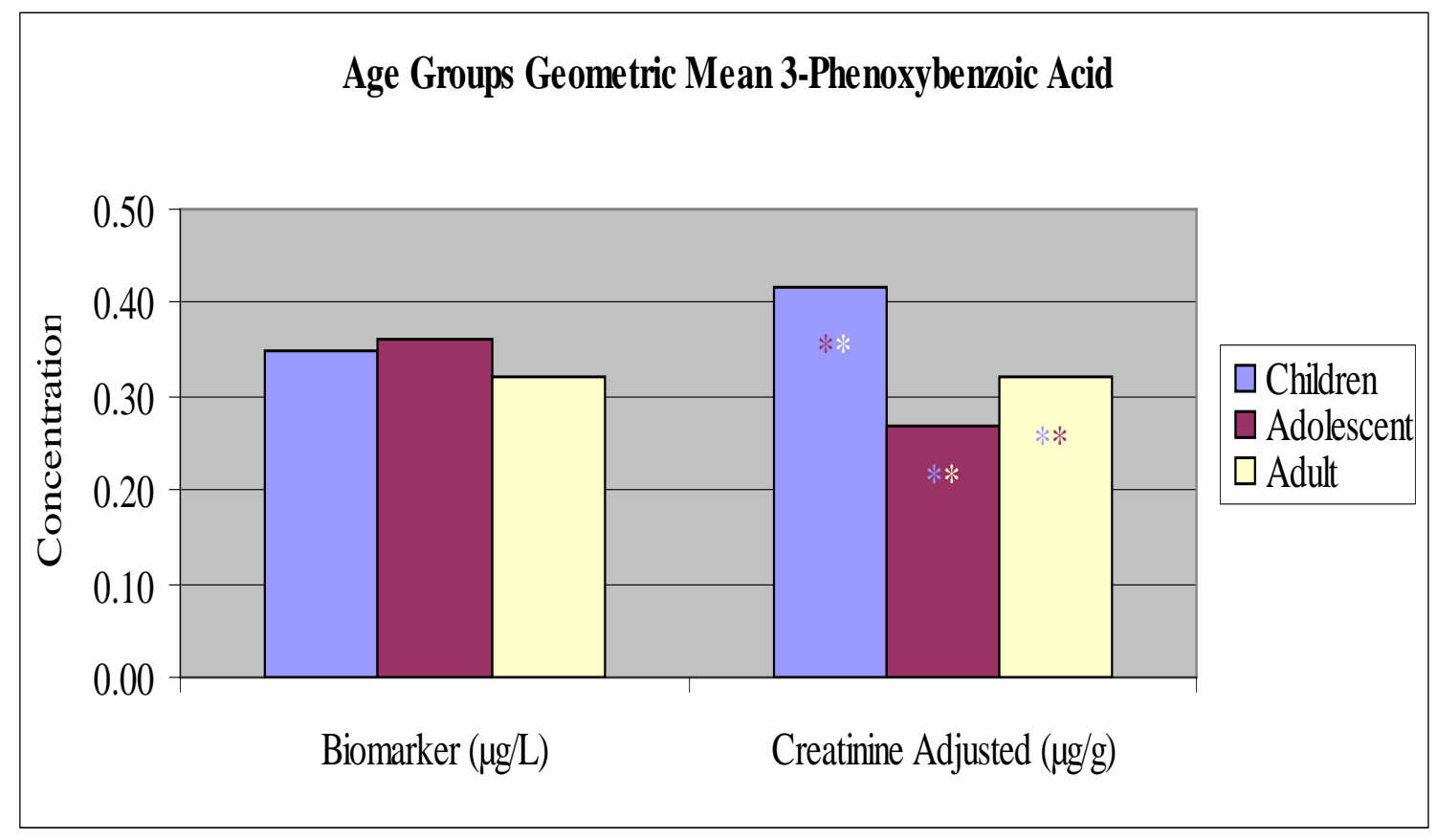

Figure 28: Comparison of Geometric Mean Values of Age Groups for 3-Phenoxybenzoic Acid. $\mu \mathrm{g} / \mathrm{l}=$ Micrograms per Liter; $\mu \mathrm{g} / \mathrm{g}=$ Micrograms per Gram. Color-coded “*” indicates which groups are significantly different from each other. 
Table 36: One-Way ANOVA and Tukey Analysis Comparing Geometric Means of Age Groups for 3-Phenoxybenzoic Acid.

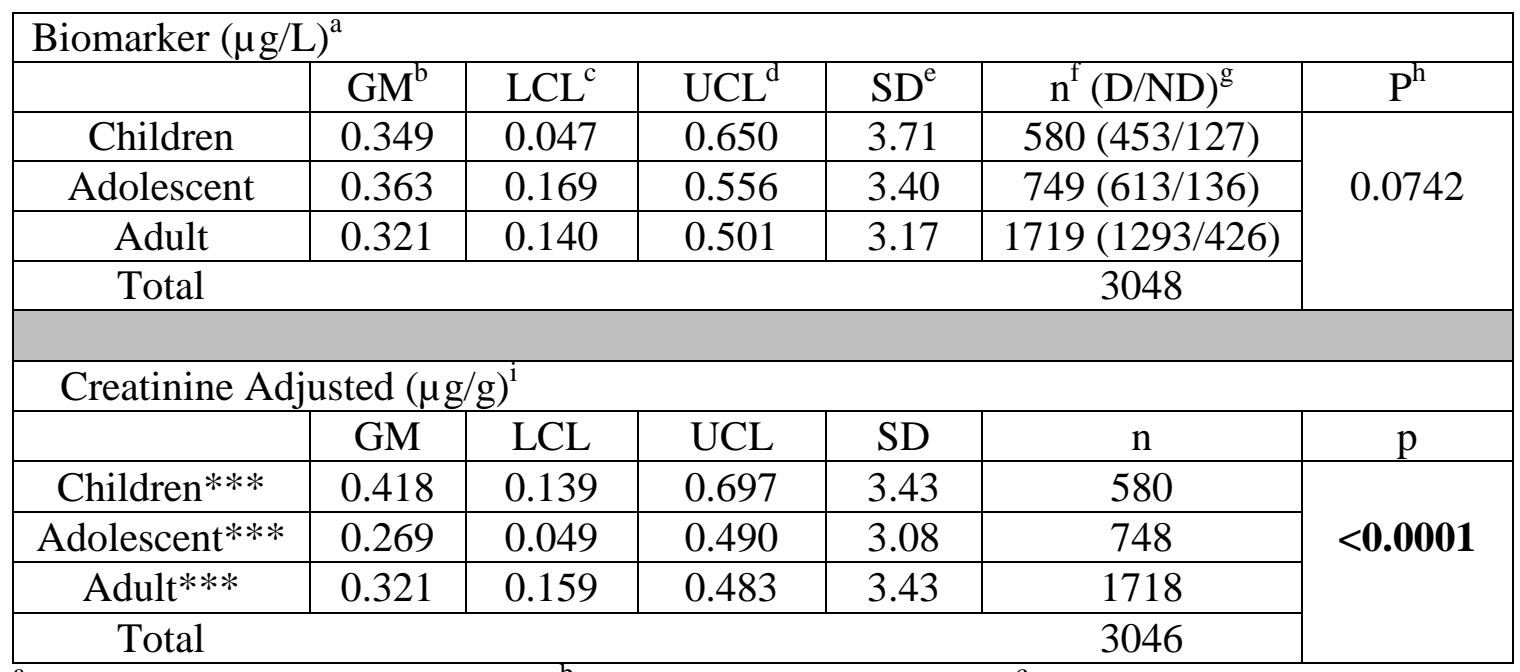

${ }^{\mathrm{a}}(\mu \mathrm{g} / \mathrm{L})=$ Micrograms per Liter; ${ }^{\mathrm{b}}(\mathrm{GM})=$ Geometric Mean; ${ }^{\mathrm{C}}(\mathrm{LCL})=$ Lower Confidence Limit; ${ }^{\mathrm{d}}(\mathrm{UCL})=$ Upper Confidence Limit; ${ }^{\mathrm{e}}(\mathrm{SD})=$ Standard Deviation; ${ }^{\mathrm{f}}(\mathrm{n})=$ Number in Sample; ${ }^{g}(\mathrm{D} / \mathrm{ND})=$ Number of Detects/Number of Non-Detects; ${ }^{\mathrm{h}}(\mathrm{p})=$ Level of Significance at $\mathrm{p}=0.05$ Level (Highlighted in Bold); ${ }^{\mathrm{i}}(\mu \mathrm{g} / \mathrm{g})=$ Micrograms per Gram. *** Indicates that all three groups are significantly different from each other.

Significant differences were present between all three age groups when adjusting for creatinine $(\mu \mathrm{g} / \mathrm{g})$; however there is no significance when evaluating the unadjusted urinary concentration of the biomarker $(\mu \mathrm{g} / \mathrm{L})$. 


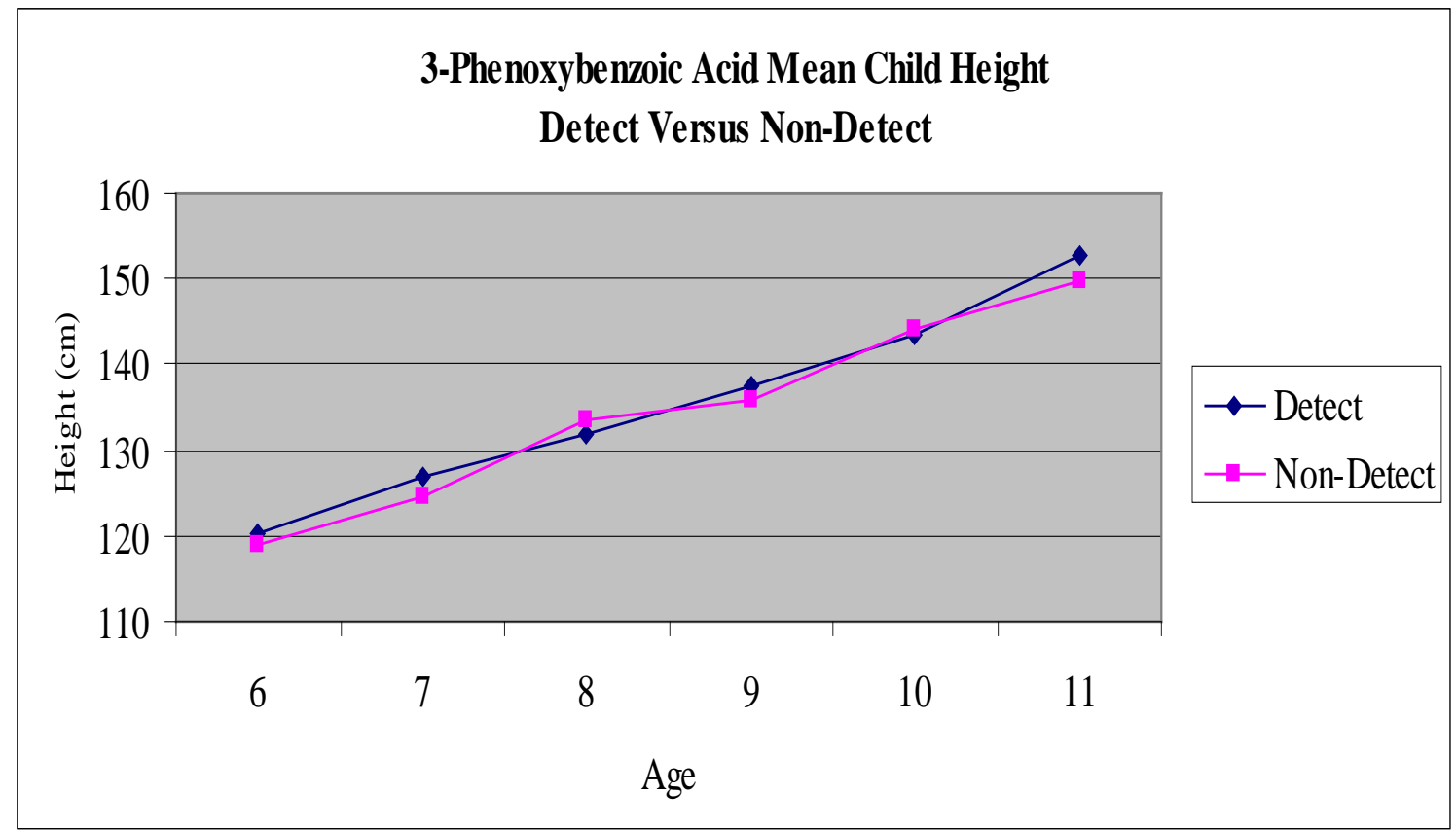

Figure 29: Graph of Arithmetic Mean Height for Detects Versus Non-Detects for 3-Phenoxybenzoic Acid, Ages 6-11. cm= Centimeter. 
Table 37: Student's t-test Comparing Detects Versus Non-Detects for Arithmetic Mean of Height for 3-Phenoxybenzoic Acid.

\begin{tabular}{|c|c|c|c|c|c|c|c|}
\hline Age & Detect $^{a}$ & Mean $\left(\mathrm{cm}^{\mathrm{b}}\right)$ & $\mathrm{LCL}^{\mathrm{C}}$ & $\mathrm{UCL}^{\mathrm{d}}$ & $\mathrm{SD}^{\mathrm{e}}$ & $n^{f}$ & $p^{g}$ \\
\hline \multirow{2}{*}{6} & Yes & 120.2 & 118.7 & 121.7 & 6.14 & 66 & \multirow{2}{*}{0.415} \\
\hline & No & 119 & 116.9 & 121.2 & 4.84 & 22 & \\
\hline \multirow{2}{*}{7} & Yes & 127 & 125.5 & 128.4 & 6.36 & 77 & \multirow{2}{*}{0.081} \\
\hline & No & 124.6 & 122.8 & 126.5 & 4.60 & 27 & \\
\hline \multirow{2}{*}{8} & Yes & 132 & 130.2 & 133.9 & 7.85 & 69 & \multirow{2}{*}{0.441} \\
\hline & No & 133.6 & 129.8 & 137.5 & 7.79 & 18 & \\
\hline \multirow{2}{*}{9} & Yes & 137.4 & 135.9 & 138.9 & 7.30 & 91 & \multirow{2}{*}{0.346} \\
\hline & No & 135.8 & 133 & 138.7 & 6.59 & 23 & \\
\hline \multirow{2}{*}{10} & Yes & 143.6 & 141.8 & 145.5 & 7.19 & 60 & \multirow{2}{*}{0.809} \\
\hline & No & 144.2 & 139.3 & 149 & 10.04 & 19 & \\
\hline \multirow{2}{*}{11} & Yes & 152.7 & 151 & 154.4 & 8.11 & 89 & \multirow{2}{*}{0.154} \\
\hline & No & 149.7 & 146.1 & 153.3 & 6.91 & 17 & \\
\hline
\end{tabular}

a $($ Detect $)=$ Detectable Level of Biomarker in the Urine Sample; ${ }^{b}(\mathrm{~cm})=$ Centimeters; ${ }^{\mathrm{c}}(\mathrm{LCL})=$ Lower Confidence Limit; ${ }^{\mathrm{d}}(\mathrm{UCL})=$ Upper Confidence Limit; ${ }^{\mathrm{e}}(\mathrm{SD})=$ Standard Deviation; ${ }^{\mathrm{f}}(\mathrm{n})=$ Number in Sample; ${ }^{\mathrm{g}}(\mathrm{p})=$ Level of Significance at $\mathrm{p}=0.05$ Level

There are no significant differences at the $\mathrm{p}<0.05$ level between detect and nondetect urinary concentrations of 3-phenoxybenzoic acid when evaluating variations in children’s height. 


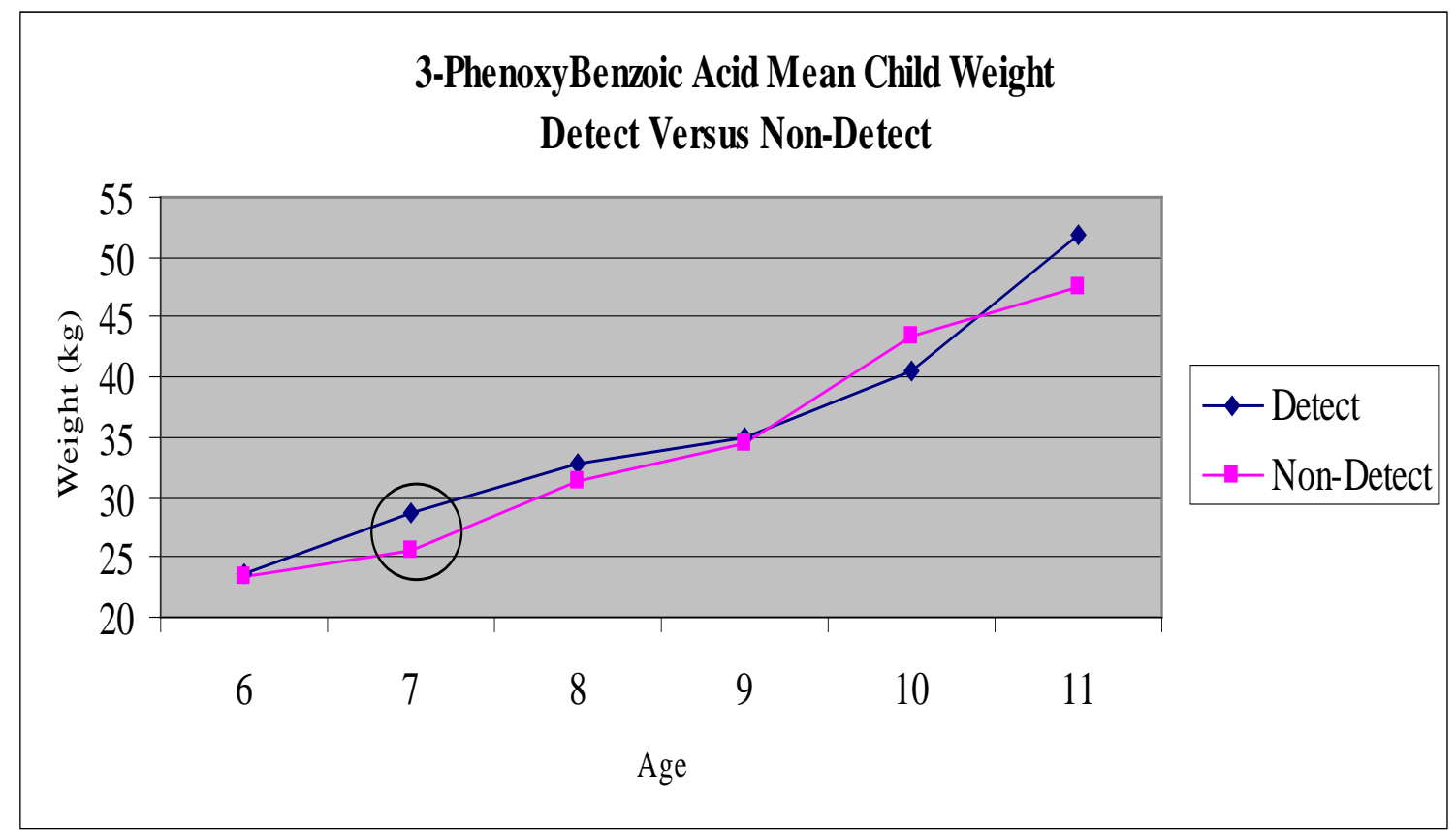

Figure 30: Graph of Arithmetic Mean Height for Detects Versus Non-Detects for 3-Phenoxybenzoic Acid, Ages 6-11. Kg= Kilograms. $\bigcirc$ = Significantly different means. 
Table 38: Student's t-test Comparing Detects Versus Non-Detects for Arithmetic Mean of Weight for 3-Phenoxybenzoic Acid.

\begin{tabular}{|c|c|c|c|c|c|c|c|}
\hline Age & Detect $^{\mathrm{a}}$ & Mean $\left(\mathrm{Kg}^{\mathrm{b}}\right)$ & $\mathrm{LCL}^{\mathrm{C}}$ & $\mathrm{UCL}^{\mathrm{d}}$ & $\mathrm{SD}^{\mathrm{e}}$ & $n^{f}$ & $\mathrm{p}^{\mathrm{g}}$ \\
\hline \multirow{2}{*}{6} & Yes & 23.72 & 22.62 & 24.81 & 4.45 & 66 & \multirow{2}{*}{0.672} \\
\hline & No & 23.28 & 21.76 & 24.80 & 3.43 & 22 & \\
\hline \multirow{2}{*}{7} & Yes & 28.61 & 27.03 & 30.18 & 6.90 & 76 & \multirow{2}{*}{0.009} \\
\hline & No & 25.56 & 23.89 & 27.22 & 4.22 & 27 & \\
\hline \multirow{2}{*}{8} & Yes & 32.91 & 30.35 & 35.46 & 10.56 & 68 & \multirow{2}{*}{0.597} \\
\hline & No & 31.46 & 27.47 & 35.45 & 7.76 & 17 & \\
\hline \multirow{2}{*}{9} & Yes & 34.88 & 32.85 & 36.91 & 9.64 & 89 & \multirow{2}{*}{0.867} \\
\hline & No & 34.49 & 29.74 & 39.25 & 11.00 & 23 & \\
\hline \multirow{2}{*}{10} & Yes & 40.56 & 37.32 & 43.80 & 12.54 & 60 & \multirow{2}{*}{0.412} \\
\hline & No & 43.35 & 36.64 & 50.06 & 13.92 & 19 & \\
\hline \multirow{2}{*}{11} & Yes & 51.79 & 47.73 & 55.84 & 19.03 & 87 & \multirow{2}{*}{0.408} \\
\hline & No & 47.64 & 40.26 & 55.02 & 13.85 & 16 & \\
\hline
\end{tabular}

${ }^{\mathrm{a}}$ (Detect) $=$ Detectable Level of Biomarker in the Urine Sample; ${ }^{\mathrm{b}}(\mathrm{Kg})=$ Kilograms;

${ }^{\mathrm{c}}(\mathrm{LCL})=$ Lower Confidence Limit; ${ }^{\mathrm{d}}(\mathrm{UCL})=$ Upper Confidence Limit; ${ }^{\mathrm{e}}(\mathrm{SD})$ = Standard Deviation; ${ }^{\mathrm{f}}(\mathrm{n})=$ Number in Sample; ${ }^{\mathrm{g}}(\mathrm{p})=$ Level of Significance at $\mathrm{p}=0.05$ Level (highlighted in Bold)

There is a significantly higher arithmetic mean height for the age 7 group that recorded a detect for the biomarker in urine as compared to those with a non-detect for the biomarker. 
Table 39: 3-Phenoxybenzoic Acid Female Biochemical t-test Comparisons.

\begin{tabular}{|c|c|c|c|c|c|c|c|c|c|}
\hline Biochemical & Detect $^{\mathrm{a}}$ & Mean & $\mathrm{LCL}^{\mathrm{b}}$ & $\mathrm{UCL}^{\mathrm{C}}$ & $\mathrm{SD}^{\mathrm{d}}$ & $\mathrm{n}^{\mathrm{e}}$ & $\operatorname{Min}^{f}$ & $\operatorname{Max}^{\mathrm{g}}$ & $\mathrm{p}^{\mathrm{h}}$ \\
\hline \multirow{2}{*}{ Alanine Transaminase $(\mathrm{U} / \mathrm{L})^{\mathrm{i}}$} & Yes & 18.95 & 18.32 & 19.58 & 9.69 & 924 & 5 & 102 & \multirow{2}{*}{0.993} \\
\hline & No & 18.95 & 17.98 & 19.91 & 8.62 & 309 & 5 & 102 & \\
\hline \multirow{2}{*}{ Albumin $(\mathrm{g} / \mathrm{dL})^{\mathrm{j}}$} & Yes & 4.16 & 4.14 & 4.19 & 0.34 & 924 & 2.6 & 5 & \multirow{2}{*}{0.671} \\
\hline & No & 4.17 & 4.13 & 4.21 & 0.36 & 309 & 2.6 & 5 & \\
\hline \multirow{2}{*}{ Alkaline Phosphatase (U/L) } & Yes & 82.87 & 80.07 & 85.66 & 43.33 & 924 & 30 & 424 & \multirow{2}{*}{0.036} \\
\hline & No & 77.54 & 73.40 & 81.67 & 36.92 & 309 & 24 & 330 & \\
\hline \multirow{2}{*}{ Aspartate Transaminase (U/L) } & Yes & 21.62 & 21.12 & 22.12 & 7.80 & 924 & 7 & 114 & \multirow{2}{*}{0.442} \\
\hline & No & 21.94 & 21.30 & 22.57 & 5.64 & 309 & 9 & 57 & \\
\hline \multirow{2}{*}{ Bicarbonate $(\mathrm{mmol} / \mathrm{L})^{\mathrm{k}}$} & Yes & 22.84 & 22.70 & 22.97 & 2.14 & 924 & 16 & 29 & \multirow{2}{*}{0.104} \\
\hline & No & 23.08 & 22.82 & 23.35 & 2.38 & 309 & 17 & 29 & \\
\hline \multirow{2}{*}{ Bilirubin $(\mathrm{mg} / \mathrm{dL})^{\mathrm{l}}$} & Yes & 0.65 & 0.64 & 0.67 & 0.21 & 924 & 0.2 & 1.9 & \multirow{2}{*}{0.119} \\
\hline & No & 0.68 & 0.65 & 0.70 & 0.22 & 309 & 0.2 & 2.1 & \\
\hline \multirow{2}{*}{ Blood Urea Nitrogen (mg/dL) } & Yes & 11.76 & 11.39 & 12.14 & 5.82 & 924 & 2 & 122 & \multirow{2}{*}{0.015} \\
\hline & No & 12.78 & 12.05 & 13.50 & 6.50 & 309 & 2 & 53 & \\
\hline \multirow{2}{*}{ Total Calcium (mg/dL) } & Yes & 9.44 & 9.41 & 9.46 & 0.39 & 924 & 8.3 & 11 & \multirow{2}{*}{0.897} \\
\hline & No & 9.44 & 9.40 & 9.48 & 0.39 & 309 & 8.1 & 10.8 & \\
\hline \multirow{2}{*}{ Chloride (mmol/L) } & Yes & 103.10 & 102.90 & 103.30 & 2.63 & 924 & 90 & 111 & \multirow{2}{*}{0.065} \\
\hline & No & 102.80 & 102.40 & 103.10 & 2.95 & 308 & 89 & 113 & \\
\hline \multirow{2}{*}{ Cholesterol (mg/dL) } & Yes & 188.60 & 185.80 & 191.40 & 42.99 & 924 & 90 & 476 & \multirow{2}{*}{$<.0001$} \\
\hline & No & 200.20 & 195.00 & 205.40 & 46.65 & 309 & 91 & 348 & \\
\hline \multirow{2}{*}{ Creatinine (mg/dL) } & Yes & 0.72 & 0.71 & 0.73 & 0.18 & 924 & 0.3 & 2.8 & 0.008 \\
\hline & No & 0.77 & 0.74 & 0.81 & 0.32 & 309 & 0.4 & 4.4 & 0.008 \\
\hline$\gamma$ Glutamyl Transferase (U/L) & Yes & 20.19 & 18.76 & 21.61 & 22.11 & 924 & 4 & 369 & \\
\hline$\gamma$ Glutamyl I ransterase (U/L) & No & 20.60 & 18.45 & 22.76 & 19.26 & 309 & 5 & 190 & 0.152 \\
\hline Globulin (mo/dI ) & Yes & 3.18 & 3.16 & 3.21 & 0.40 & 924 & 2.3 & 5.4 & 0006 \\
\hline Giovum (III)/CL) & No & 3.11 & 3.07 & 3.15 & 0.37 & 309 & 2.2 & 4.4 & 0.000 \\
\hline Clucose $(\mathrm{mg} / \mathrm{dI})$ & Yes & 90.27 & 88.25 & 92.29 & 31.29 & 924 & 34 & 521 & 0761 \\
\hline Glucose (mg/aL) & No & 89.75 & 87.07 & 92.42 & 23.91 & 309 & 30 & 284 & 0.101 \\
\hline & Yes & 81.67 & 79.28 & 84.06 & 37.04 & 924 & 8 & 268 & \\
\hline Iron (mg/dL) & No & 85.35 & 81.05 & 89.64 & 38.37 & 309 & 7 & 249 & 0.135 \\
\hline I actate Dehydrooenase (U/I ) & Yes & 129.60 & 127.90 & 131.30 & 26.73 & 923 & 51 & 329 & \\
\hline Lactate Denyarogenase (U/L) & No & 134.00 & 130.30 & 137.60 & 32.68 & 309 & 58 & 470 & 0.035 \\
\hline Ocmolality $(\mathrm{mmol} / \mathrm{K} \sigma)^{\mathrm{m}}$ & Yes & 275.40 & 275.10 & 275.80 & 5.26 & 924 & 248 & 310 & 0881 \\
\hline Usmoramty (1111101/ng) & No & 275.50 & 274.80 & 276.20 & 6.23 & 309 & 252 & 305 & 0.001 \\
\hline Phosnhorus (mo/dL) & Yes & 3.99 & 3.95 & 4.02 & 0.58 & 924 & 2.3 & 6.1 & 0.401 \\
\hline Phosphorus (mg/dL) & No & 3.95 & 3.90 & 4.01 & 0.53 & 309 & 2.3 & 5.6 & 0.401 \\
\hline Potassium (mmol/L) & Yes & 3.99 & 3.97 & 4.01 & 0.33 & 924 & 2.6 & 6 & \\
\hline Potassium (mmol/L) & No & 3.98 & 3.94 & 4.02 & 0.36 & 309 & 2.9 & 5.3 & 0.133 \\
\hline Total Protein (g/dL) & Yes & 7.35 & 7.32 & 7.38 & 0.49 & 924 & 5.9 & 9.5 & \\
\hline rotal proteln (g/aL) & No & 7.29 & 7.23 & 7.34 & 0.48 & 309 & 5.5 & 9.1 & 0.056 \\
\hline & Yes & 138.30 & 138.20 & 138.50 & 2.44 & 924 & 124 & 145 & \\
\hline soalum (mmol/L) & No & 138.20 & 137.90 & 138.50 & 2.74 & 309 & 125 & 147 & 0.329 \\
\hline & Yes & 116.10 & 110.50 & 121.70 & 86.44 & 924 & 23 & 1077 & \\
\hline Triglycerides (mg/dL) & No & 134.30 & 124.50 & 144.10 & 87.41 & 309 & 34 & 628 & 0.001 \\
\hline & Yes & 4.50 & 4.42 & 4.58 & 1.19 & 924 & 1.8 & 10.8 & 0.027 \\
\hline Uric Acid (mg/aL) & No & 4.70 & 4.54 & 4.86 & 1.40 & 309 & 0.4 & 13.9 & 0.021 \\
\hline
\end{tabular}

${ }^{\mathrm{a}}$ (Detect) $=$ Detectable Level of Biomarker in the Urine Sample; ${ }^{\mathrm{b}}(\mathrm{LCL})=$ Lower Confidence Limit; ${ }^{\mathrm{C}}(\mathrm{UCL})=$ Upper Confidence Limit; ${ }^{\mathrm{d}}(\mathrm{SD})=$ Standard Deviation; ${ }^{\mathrm{e}}(\mathrm{n})=$ Number in Sample; ${ }^{\mathrm{f}}(\mathrm{Min})=$ Minimum; ${ }^{\mathrm{g}}(\mathrm{Max})=$ Maximum; ${ }^{\mathrm{h}}(\mathrm{p})=$ Level of Significance at $\mathrm{p}=0.05$ Level (highlighted in Bold); ${ }^{\mathrm{i}}(\mathrm{U} / \mathrm{L})=$ Units per Liter; ${ }^{\mathrm{j}}(\mathrm{g} / \mathrm{dL})=$ Grams per Deciliter; ${ }^{\mathrm{k}}(\mathrm{mmol} / \mathrm{L})=$ Millimole per Liter; ${ }^{\mathrm{l}}(\mathrm{mg} / \mathrm{dL})=$ Milligram per Deciliter; ${ }^{\mathrm{m}}(\mathrm{mmol} / \mathrm{Kg})=$ Millimole per Kilogram 
Table 40: 3-Phenoxybenzoic Acid Male Biochemical t-test Comparisons.

\begin{tabular}{|c|c|c|c|c|c|c|c|c|c|}
\hline Biochemical & Detect $^{\mathrm{a}}$ & Mean & $\mathrm{LCL}^{\mathrm{b}}$ & $\mathrm{UCL}^{\mathrm{C}}$ & $\mathrm{SD}^{\mathrm{d}}$ & $\mathrm{n}^{\mathrm{e}}$ & $\operatorname{Min}^{f}$ & $\operatorname{Max}^{\mathrm{g}}$ & $\mathrm{p}^{\mathrm{h}}$ \\
\hline \multirow{2}{*}{ Alanine Transaminase $(\mathrm{U} / \mathrm{L})^{\mathrm{i}}$} & Yes & 27.44 & 26.12 & 28.75 & 19.56 & 857 & 7 & 243 & \multirow{2}{*}{0.0004} \\
\hline & No & 23.78 & 22.23 & 25.32 & 11.82 & 227 & 8 & 102 & \\
\hline \multirow{2}{*}{ Albumin $(\mathrm{g} / \mathrm{dL})^{\mathrm{j}}$} & Yes & 4.38 & 4.36 & 4.40 & 0.30 & 857 & 2.1 & 5.3 & \multirow{2}{*}{0.772} \\
\hline & No & 4.39 & 4.35 & 4.43 & 0.33 & 227 & 3 & 5.1 & \\
\hline \multirow{2}{*}{ Alkaline Phosphatase (U/L) } & Yes & 102.10 & 97.32 & 106.90 & 71.59 & 857 & 19 & 589 & \multirow{2}{*}{0.675} \\
\hline & No & 104.70 & 93.58 & 115.80 & 85.04 & 227 & 37 & 617 & \\
\hline \multirow{2}{*}{ Aspartate Transaminase (U/L) } & Yes & 27.07 & 26.14 & 27.99 & 13.80 & 857 & 9 & 187 & \multirow{2}{*}{0.0003} \\
\hline & No & 24.71 & 23.83 & 25.59 & 6.71 & 227 & 12 & 61 & \\
\hline \multirow{2}{*}{ Bicarbonate $(\mathrm{mmol} / \mathrm{L})^{\mathrm{k}}$} & Yes & 23.98 & 23.84 & 24.12 & 2.06 & 857 & 15 & 29 & \multirow{2}{*}{0.255} \\
\hline & No & 24.17 & 23.87 & 24.48 & 2.33 & 227 & 17 & 30 & \\
\hline \multirow{2}{*}{ Bilirubin (mg/dL) ${ }^{l}$} & Yes & 0.82 & 0.80 & 0.84 & 0.32 & 857 & 0.3 & 3.5 & \multirow{2}{*}{0.436} \\
\hline & No & 0.81 & 0.77 & 0.84 & 0.26 & 227 & 0.3 & 2 & \\
\hline \multirow{2}{*}{ Blood Urea Nitrogen (mg/dL) } & Yes & 14.02 & 13.67 & 14.37 & 5.24 & 857 & 3 & 48 & \multirow{2}{*}{0.407} \\
\hline & No & 14.35 & 13.62 & 15.07 & 5.54 & 227 & 3 & 40 & \\
\hline \multirow{2}{*}{ Total Calcium (mg/dL) } & Yes & 9.55 & 9.53 & 9.58 & 0.39 & 857 & 7.2 & 11.3 & \multirow{2}{*}{0.658} \\
\hline & No & 9.54 & 9.49 & 9.60 & 0.42 & 227 & 7.8 & 10.8 & \\
\hline \multirow{2}{*}{ Chloride (mmol/L) } & Yes & 102.50 & 102.40 & 102.70 & 2.43 & 857 & 92 & 112 & \multirow{2}{*}{0.020} \\
\hline & No & 102.00 & 101.60 & 102.40 & 3.13 & 227 & 83 & 109 & \\
\hline \multirow{2}{*}{ Cholesterol (mg/dL) } & Yes & 185.90 & 182.90 & 188.90 & 44.47 & 857 & 71 & 566 & \multirow{2}{*}{0.931} \\
\hline & No & 186.20 & 180.80 & 191.70 & 41.72 & 227 & 84 & 407 & \\
\hline \multirow{2}{*}{ Creatinine (mg/dL) } & Yes & 0.96 & 0.94 & 0.98 & 0.26 & 857 & 0.4 & 4.4 & \\
\hline & No & 0.98 & 0.95 & 1.01 & 0.26 & 227 & 0.5 & 2.5 & 0.317 \\
\hline$\gamma$ Glutamvl Transferase (U/L) & Yes & 31.21 & 28.93 & 33.49 & 34.03 & 857 & 6 & 482 & \\
\hline$\gamma$ Glutamyı I ransterase (U/L) & No & 27.79 & 24.77 & 30.81 & 23.11 & 227 & 6 & 183 & $0.0 / 6$ \\
\hline & Yes & 3.09 & 3.06 & 3.12 & 0.43 & 856 & 2 & 5.9 & \\
\hline GlobuIIn (mg/aL) & No & 3.01 & 2.95 & 3.07 & 0.46 & 227 & 1.6 & 4.5 & 0.009 \\
\hline & Yes & 95.09 & 93.53 & 96.65 & 23.30 & 857 & 58 & 317 & 0641 \\
\hline Glucose (mg/dL) & No & 96.70 & 90.09 & 103.30 & 50.55 & 227 & 67 & 707 & 0.041 \\
\hline & Yes & 97.36 & 94.71 & 100.00 & 39.50 & 857 & 12 & 333 & \\
\hline Iron (mg/dL) & No & 96.49 & 91.54 & 101.40 & 37.86 & 227 & 18 & 223 & 0.767 \\
\hline Lactate Dehydrogenase (U/L) & Yes & 138.90 & 136.60 & 141.30 & 34.90 & 857 & 52 & 399 & 0.004 \\
\hline Lactate Denyarogenase (U/L) & No & 132.90 & 129.40 & 136.30 & 26.43 & 227 & 72 & 220 & 0.004 \\
\hline Ocmolality $(\mathrm{mmol} / \mathrm{K} \sigma)^{\mathrm{m}}$ & Yes & 278.00 & 277.70 & 278.30 & 4.67 & 857 & 264 & 299 & 0105 \\
\hline Usmorallty (1IIIIOI/ng) & No & 277.20 & 276.20 & 278.10 & 7.20 & 227 & 218 & 298 & 0.100 \\
\hline Phosnhorus (mo/dI) & Yes & 3.91 & 3.86 & 3.96 & 0.70 & 857 & 2.4 & 6.6 & 0946 \\
\hline Phosphorus (mg/dL) & No & 3.91 & 3.82 & 4.00 & 0.68 & 227 & 2.4 & 6.6 & \\
\hline Potassiun $>2$ > & Yes & 4.14 & 4.12 & 4.16 & 0.35 & 857 & 3.1 & 5.5 & \\
\hline Potassium (mmol/L) & No & 4.06 & 4.02 & 4.11 & 0.36 & 227 & 3.1 & 5.3 & 0.003 \\
\hline & Yes & 7.47 & 7.44 & 7.50 & 0.45 & 856 & 5.9 & 9.8 & \\
\hline Total Protein (g/dL) & No & 7.40 & 7.33 & 7.46 & 0.50 & 227 & 5.3 & 9 & 0.025 \\
\hline Sodium (mmol/I ) & Yes & 139.10 & 139.00 & 139.30 & 2.22 & 857 & 131 & 147 & \\
\hline Sodum (IIII01/L) & No & 138.60 & 138.10 & 139.00 & 3.44 & 227 & 108 & 144 & 0.022 \\
\hline & Yes & 141.30 & 128.40 & 154.30 & 192.70 & 857 & 21 & 3854 & 0.372 \\
\hline Triglycerıdes (mg/dL) & No & 154.10 & 129.70 & 178.50 & 186.40 & 227 & 28 & 2337 & $0.3 / 2$ \\
\hline & Yes & 6.00 & 5.92 & 6.09 & 1.28 & 857 & 1.5 & 10.8 & \\
\hline Uric Acid (mg/aL) & No & 5.99 & 5.79 & 6.18 & 1.50 & 227 & 2.6 & 13.4 & 0.880 \\
\hline
\end{tabular}

${ }^{\mathrm{a}}$ (Detect) $=$ Detectable Level of Biomarker in the Urine Sample; ${ }^{\mathrm{b}}(\mathrm{LCL})=$ Lower Confidence Limit; ' $($ UCL $)=$ Upper Confidence Limit; ${ }^{\mathrm{d}}(\mathrm{SD})=$ Standard Deviation; ${ }^{\mathrm{e}}(\mathrm{n})=$ Number in Sample; ${ }^{\mathrm{f}}(\mathrm{Min})=$ Minimum; ${ }^{\mathrm{g}}(\mathrm{Max})=$ Maximum; ${ }^{\mathrm{h}}(\mathrm{p})=$ Level of Significance at $\mathrm{p}=0.05$ Level (highlighted in Bold); ${ }^{\mathrm{i}}(\mathrm{U} / \mathrm{L})=$ Units per Liter; ${ }^{\mathrm{j}}(\mathrm{g} / \mathrm{dL})=$ Grams per Deciliter; ${ }^{\mathrm{k}}(\mathrm{mmol} / \mathrm{L})=$ Millimole per Liter; ${ }^{\mathrm{l}}(\mathrm{mg} / \mathrm{dL})=$ Milligram per Deciliter; ${ }^{\mathrm{m}}(\mathrm{mmol} / \mathrm{Kg})=$ Millimole per Kilogram 
Table 41: 3-Phenoxybenzoic Acid Overall Biochemical t-test Comparisons.

\begin{tabular}{|c|c|c|c|c|c|c|c|c|c|}
\hline Biochemical & Detect $^{\mathrm{a}}$ & Mean & $\mathrm{LCL}^{\mathrm{b}}$ & $\mathrm{UCL}^{\mathrm{c}}$ & $\mathrm{SD}^{\mathrm{d}}$ & $\mathrm{n}^{\mathrm{e}}$ & $\operatorname{Min}^{f}$ & $\operatorname{Max}^{\mathrm{g}}$ & $\mathrm{p}^{\mathrm{h}}$ \\
\hline \multirow{2}{*}{ Alanine Transaminase $(\mathrm{U} / \mathrm{L})^{\mathrm{i}}$} & Yes & 23.03 & 22.30 & 23.77 & 15.83 & 1781 & 5 & 243 & \multirow{2}{*}{0.001} \\
\hline & No & 20.99 & 20.11 & 21.87 & 10.37 & 536 & 5 & 102 & \\
\hline \multirow{2}{*}{ Albumin $(g / d L)^{j}$} & Yes & 4.27 & 4.25 & 4.29 & 0.34 & 1781 & 2.1 & 5.3 & \multirow{2}{*}{0.803} \\
\hline & No & 4.27 & 4.23 & 4.30 & 0.36 & 536 & 2.6 & 5.1 & \\
\hline \multirow{2}{*}{ Alkaline Phosphatase (U/L) } & Yes & 92.13 & 89.37 & 94.89 & 59.42 & 1781 & 19 & 589 & \multirow{2}{*}{0.299} \\
\hline & No & 89.04 & 83.66 & 94.42 & 63.40 & 536 & 24 & 617 & \\
\hline \multirow{2}{*}{ Aspartate Transaminase (U/L) } & Yes & 24.24 & 23.71 & 24.77 & 11.42 & 1781 & 7 & 187 & \multirow{2}{*}{0.003} \\
\hline & No & 23.11 & 22.58 & 23.64 & 6.26 & 536 & 9 & 61 & \\
\hline \multirow{2}{*}{ Bicarbonate $(\mathrm{mmol} / \mathrm{L})^{\mathrm{k}}$} & Yes & 23.39 & 23.28 & 23.49 & 2.18 & 1781 & 15 & 29 & \multirow{2}{*}{0.171} \\
\hline & No & 23.54 & 23.34 & 23.75 & 2.42 & 536 & 17 & 30 & \\
\hline \multirow{2}{*}{ Bilirubin (mg/dL) $)^{1}$} & Yes & 0.74 & 0.72 & 0.75 & 0.28 & 1781 & 0.2 & 3.5 & \multirow{2}{*}{0.755} \\
\hline & No & 0.73 & 0.71 & 0.75 & 0.25 & 536 & 0.2 & 2.1 & \\
\hline \multirow{2}{*}{ Blood Urea Nitrogen (mg/dL) } & Yes & 12.85 & 12.59 & 13.11 & 5.66 & 1781 & 2 & 122 & \multirow{2}{*}{0.047} \\
\hline & No & 13.44 & 12.92 & 13.96 & 6.16 & 536 & 2 & 53 & \\
\hline \multirow{2}{*}{ Total Calcium (mg/dL) } & Yes & 9.49 & 9.48 & 9.51 & 0.39 & 1781 & 7.2 & 11.3 & \multirow{2}{*}{0.596} \\
\hline & No & 9.48 & 9.45 & 9.52 & 0.41 & 536 & 7.8 & 10.8 & \\
\hline \multirow{2}{*}{ Chloride (mmol/L) } & Yes & 102.80 & 102.70 & 102.90 & 2.55 & 1781 & 90 & 112 & \multirow{2}{*}{0.007} \\
\hline & No & 102.40 & 102.20 & 102.70 & 3.05 & 535 & 83 & 113 & \\
\hline \multirow{2}{*}{ Cholesterol (mg/dL) } & Yes & 187.30 & 185.30 & 189.30 & 43.72 & 1781 & 71 & 566 & \multirow{2}{*}{0.001} \\
\hline & No & 194.30 & 190.40 & 198.10 & 45.12 & 536 & 84 & 407 & \\
\hline \multirow{2}{*}{ Creatinine (mg/dL) } & Yes & 0.84 & 0.82 & 0.85 & 0.25 & 1781 & 0.3 & 4.4 & \\
\hline & No & 0.86 & 0.83 & 0.89 & 0.31 & 536 & 0.4 & 4.4 & 0.112 \\
\hline$\gamma$ Glutamvl Transferase (U/L) & Yes & 25.49 & 24.14 & 26.84 & 29.00 & 1781 & 4 & 482 & \\
\hline$\gamma$ Glutamyı I ransterase (U/L) & No & 23.65 & 21.84 & 25.45 & 21.26 & 536 & 5 & 190 & 0.108 \\
\hline & Yes & 3.14 & 3.12 & 3.16 & 0.42 & 1780 & 2 & 5.9 & 0.001 \\
\hline GlobulIn (mg/aL) & No & 3.07 & 3.03 & 3.10 & 0.41 & 536 & 1.6 & 4.5 & 0.001 \\
\hline & Yes & 92.59 & 91.30 & 93.88 & 27.83 & 1781 & 34 & 521 & 0953 \\
\hline Glucose (mg/dL) & No & 92.69 & 89.49 & 95.89 & 37.69 & 536 & 30 & 707 & 0.953 \\
\hline & Yes & 89.22 & 87.40 & 91.03 & 39.03 & 1781 & 8 & 333 & \\
\hline Iron (mg/dL) & No & 90.07 & 86.80 & 93.34 & 38.52 & 536 & 7 & 249 & 0.658 \\
\hline Lactate Debydrogenace (LU/L) & Yes & 134.10 & 132.70 & 135.60 & 31.28 & 1780 & 51 & 399 & 0692 \\
\hline Lactate Denyarogenase (U/L) & No & 133.50 & 130.90 & 136.10 & 30.17 & 536 & 58 & 470 & 0.092 \\
\hline Osmolalitv $(\mathrm{mmol} / \mathrm{K} \sigma)^{\mathrm{m}}$ & Yes & 3.95 & 3.92 & 3.98 & 0.64 & 1781 & 2.3 & 6.6 & 0613 \\
\hline Usmorallty (1IIIIOI/Rg) & No & 3.93 & 3.88 & 3.99 & 0.60 & 536 & 2.3 & 6.6 & 0.013 \\
\hline & Yes & 4.06 & 4.05 & 4.08 & 0.35 & 1781 & 2.6 & 6 & 008 \\
\hline Phosphorus (mg/dL) & No & 4.02 & 3.99 & 4.05 & 0.36 & 536 & 2.9 & 5.3 & 0.008 \\
\hline & Yes & 7.41 & 7.39 & 7.43 & 0.47 & 1780 & 5.9 & 9.8 & \\
\hline Potassium (mmol/L) & No & 7.33 & 7.29 & 7.37 & 0.49 & 536 & 5.3 & 9.1 & 0.001 \\
\hline & Yes & 276.70 & 276.40 & 276.90 & 5.14 & 1781 & 248 & 310 & \\
\hline Total Protein (g/dL) & No & 276.20 & 275.60 & 276.80 & 6.70 & 536 & 218 & 305 & 0.144 \\
\hline Sodium (mmol/I ) & Yes & 138.70 & 138.60 & 138.80 & 2.37 & 1781 & 124 & 147 & \\
\hline Sodum (IIIm01/L) & No & 138.30 & 138.10 & 138.60 & 3.06 & 536 & 108 & 147 & 0.009 \\
\hline & Yes & 128.20 & 121.40 & 135.10 & 148.00 & 1781 & 21 & 3854 & \\
\hline Triglycerides (mg/dL) & No & 142.70 & 130.90 & 154.40 & 138.50 & 536 & 28 & 2337 & 0.045 \\
\hline & Yes & 5.22 & 5.16 & 5.29 & 1.44 & 1781 & 1.5 & 10.8 & \\
\hline Uric Acid (mg/aL) & No & 5.24 & 5.11 & 5.38 & 1.58 & 536 & 0.4 & 13.9 & 0.192 \\
\hline
\end{tabular}

${ }^{\mathrm{a}}$ (Detect) $=$ Detectable Level of Biomarker in the Urine Sample; ${ }^{\mathrm{b}}(\mathrm{LCL})=$ Lower Confidence Limit; ' $($ UCL $)=$ Upper Confidence Limit; ${ }^{\mathrm{d}}(\mathrm{SD})=$ Standard Deviation; ${ }^{\mathrm{e}}(\mathrm{n})=$ Number in Sample; ${ }^{\mathrm{f}}(\mathrm{Min})=$ Minimum; ${ }^{\mathrm{g}}(\mathrm{Max})=$ Maximum; ${ }^{\mathrm{h}}(\mathrm{p})=$ Level of Significance at $\mathrm{p}=0.05$ Level (highlighted in Bold); ${ }^{\mathrm{i}}(\mathrm{U} / \mathrm{L})=$ Units per Liter; ${ }^{\mathrm{j}}(\mathrm{g} / \mathrm{dL})=$ Grams per Deciliter; ${ }^{\mathrm{k}}(\mathrm{mmol} / \mathrm{L})=$ Millimole per Liter; ${ }^{\mathrm{l}}(\mathrm{mg} / \mathrm{dL})=$ Milligram per Deciliter;

${ }^{\mathrm{m}}(\mathrm{mmol} / \mathrm{Kg})=$ Millimole per Kilogram 


\subsubsection{Logistic Regression}

Table 42: Logistic Regression for 3-Phenoxybenzoic Acid.

\begin{tabular}{|c|c|c|c|}
\hline & $\begin{array}{l}\text { Detect }^{\mathrm{a}} \\
\left(\mathrm{DF}{ }^{\mathrm{b}}=1\right)\end{array}$ & $\begin{array}{l}\text { Detect, Non-Hispanic White } \\
(\mathrm{DF}=1)\end{array}$ & $\begin{array}{c}\text { Detect, Female } \\
(\mathrm{DF}=1)\end{array}$ \\
\hline Age & $\begin{array}{c}\beta=-0.006 \\
\text { Wald } \chi 2=10.2 \\
p=0.001 \\
\text { OR }=0.994\end{array}$ & & \\
\hline Mexican American & & $\begin{array}{c}\beta=-0.175 \\
\text { Wald } \chi 2=3.44 \\
p=0.064 \\
O R=1.09\end{array}$ & \\
\hline $\begin{array}{l}\text { Non-Hispanic } \\
\text { Black }\end{array}$ & & $\begin{array}{c}\beta=0.076 \\
\text { Wald } \chi 2=0.171 \\
p=0.679 \\
O R=1.4\end{array}$ & \\
\hline Other Hispanic & & $\begin{array}{c}\beta=0.630 \\
\text { Wald } \chi 2=33.5 \\
p<0.0001 \\
\text { OR=2.43 }\end{array}$ & \\
\hline Other & & $\begin{array}{c}\beta=-0.273 \\
\text { Wald } \chi 2=2.46 \\
p=0.117 \\
O R=0.986\end{array}$ & \\
\hline Male & & & $\begin{array}{c}\beta=0.0927 \\
\text { Wald } \chi 2=4.40 \\
p=0.036 \\
\text { OR=1.2 }\end{array}$ \\
\hline
\end{tabular}

${ }^{\mathrm{a}}($ Detect $)=$ Detectable Level of Biomarker in the Urine Sample, used as a reference category in the Model; ${ }^{b}(D F)=$ Degree of Freedom. Significant differences are highlight in Bold.

The overall model fit was significant, with Likelihood $\chi 2=84.8, \mathrm{p}<0.0001$ and the $\mathrm{R}_{\text {Max }}^{2}=0.0418$. The Hosmer and Lemeshow goodness-of-fit test resulted in a $\chi 2=$ 7.59, $\mathrm{p}=0.475$, indicating that the data from the independent variables fit the model well. The listed detects at the row headers are the reference groups for each sub-category. When stratifying for individual groups, age does not seem to have an effect on the detection of a biomarker $(\beta=-0.006$ and $\mathrm{OR}=0.994, \mathrm{p}=0.001)$. Other Hispanics $(\beta=0.630$ and $\mathrm{OR}=2.43, \mathrm{p}<0.0001$ ) had a higher change in the regression coefficient and a higher odds of having a detectable level of biomarker than Non-Hispanic Whites (reference 
group). Males had a change in the regression coefficient and a higher odds of having a detectable level of biomarker than females $(\beta=0.0927$ and $\mathrm{OR}=1.2, \mathrm{p}=0.036)$.

\subsection{Summary of Mean Biomarker Concentrations}

The summary of biomarker concentrations from this research are listed in Table 43.

Table 43: Summary of Means for All Three Biomarkers.

\begin{tabular}{|c|c|c|c|c|c|}
\hline & \multicolumn{2}{|c|}{ Biomarker $(\mu \mathrm{g} / \mathrm{L})^{\mathrm{a}}$} & \multicolumn{3}{|c|}{ Creatinine Adjusted $(\mu \mathrm{g} / \mathrm{g})^{\mathrm{b}}$} \\
\hline & $\begin{array}{l}\text { Geometric } \\
\text { Mean }\end{array}$ & $\begin{array}{c}\text { Arithmetic } \\
\text { Mean }\end{array}$ & $\begin{array}{l}\text { Geometric } \\
\text { Mean }\end{array}$ & $\begin{array}{l}\text { Arithmetic } \\
\text { Mean }\end{array}$ & $\mathrm{DF}^{\mathrm{c}}$ \\
\hline $\mathrm{TCPy}^{\mathrm{d}}$ & 2.07 & 4.28 & 1.98 & 3.42 & $78.6 \%$ \\
\hline $\mathrm{PNP}^{\mathrm{e}}$ & 0.37 & 1.16 & 0.35 & 0.90 & $53.1 \%$ \\
\hline $3-\mathrm{PBA}^{\mathrm{f}}$ & 0.34 & 1.55 & 0.32 & 1.15 & $77.4 \%$ \\
\hline
\end{tabular}

${ }^{\mathrm{a}}(\mu \mathrm{g} / \mathrm{L})=$ Micrograms per Liter; ${ }^{\mathrm{b}}(\mu \mathrm{g} / \mathrm{g})=$ Micrograms per Gram; ${ }^{\mathrm{C}}(\mathrm{DF})=$ Detection

Frequency; ${ }^{\mathrm{d}}(\mathrm{TCP} y)=3,5,6$-Trichloropyridinol; ${ }^{\mathrm{e}}(\mathrm{PNP})=$ Paranitrophenol; ${ }^{\mathrm{f}}(3-\mathrm{PBA})=3$ Phenoxybenzoic Acid

The unweighted sample results from this study can be compared to the concentrations determined in other studies. Those studies are listed in Table 44. 
Table 44: Summary of Results from Epidemiological Biomarker Studies.

\begin{tabular}{|c|c|c|c|c|c|}
\hline Author & $\mathrm{n}^{\mathrm{a}}$ & Sample Source & Metabolite & $\mathrm{DF}^{\mathrm{b}}$ & Central Tendency \\
\hline Adgate (2001) [61] & 102 & Minnesota Child & TCPy & $93 \%$ & $\mathrm{GM}^{\mathrm{c}}=6.4 \mu \mathrm{g} / \mathrm{L}^{\mathrm{d}} ; \mathrm{AM}^{\mathrm{e}}=9.2 \mu \mathrm{g} / \mathrm{L}$ \\
\hline Aprea (1999) [143] & 42 & $\begin{array}{c}\text { General } \\
\text { Population Italy }\end{array}$ & TCPy & $88 \%$ & $\mathrm{CAM}^{\mathrm{f}}=3.5 \mu \mathrm{g} / \mathrm{g}^{\mathrm{g}}$ \\
\hline \multirow{3}{*}{ Arcury (2007) [144] } & \multirow{3}{*}{60} & \multirow{3}{*}{ Latino Age 1-6 } & TCPy & $83.3 \%$ & $\mathrm{GM}=1.92 \mu \mathrm{g} / \mathrm{L} ; \mathrm{CAGM}^{\mathrm{h}}=2.38 \mu \mathrm{g} / \mathrm{g}$ \\
\hline & & & PNP & $90 \%$ & $\mathrm{GM}=1.0 \mu \mathrm{g} / \mathrm{L} ; \mathrm{CAGM}=1.25 \mu \mathrm{g} / \mathrm{g}$ \\
\hline & & & 3-PBA & $40 \%$ & $\mathrm{NA}^{\mathrm{i}}$ \\
\hline Barr (2005) [145] & 1994 & All & TCPy & 91\% (weighted) & $\mathrm{GM}=1.77 \mu \mathrm{g} / \mathrm{L} ; \mathrm{CAGM}=1.58 \mu \mathrm{g} / \mathrm{g}$ \\
\hline Barr (2010) [64] & $\begin{array}{c}3048 \\
\text { (3046 for } \\
\text { CA) }\end{array}$ & $\begin{array}{l}\text { NHANES 1999- } \\
2002\end{array}$ & 3-PBA & $\begin{array}{c}75.4 \% \\
\text { (weighted) }\end{array}$ & $\begin{array}{c}\mathrm{GM}=0.318 \mu \mathrm{g} / \mathrm{L} ; \mathrm{CAGM}=0.324 \\
\mu \mathrm{g} / \mathrm{g}\end{array}$ \\
\hline $\begin{array}{c}\text { Berger-Preiss } \\
\text { (2002) [147] } \\
\end{array}$ & 145 & $\begin{array}{c}\text { Adults and } \\
\text { Children } \\
\end{array}$ & 3-PBA & $28 \%$ & Mean $=0.25 \mu \mathrm{g} / \mathrm{L}$ \\
\hline $\begin{array}{c}\text { Berkowitz (2004) } \\
{[108]}\end{array}$ & 404 & Pregnant Females & TCPy & NA & $\begin{array}{c}\text { Median=7.6 } \mu \mathrm{g} / \mathrm{L} ; \mathrm{CA} \text { Median= } 11.5 \\
\mu \mathrm{g} / \mathrm{g}\end{array}$ \\
\hline \multirow{2}{*}{$\begin{array}{c}\text { Eskenazi (2004) } \\
\text { [107] }\end{array}$} & \multirow{2}{*}{488} & \multirow{2}{*}{$\begin{array}{c}\text { Pregnant Females } \\
\text { in Agricultural } \\
\text { Community }\end{array}$} & TCPy & $76.3 \%$ & Median=3.3 $\mu \mathrm{g} / \mathrm{L}$ \\
\hline & & & PNP & $54.4 \%$ & Median $=0.5 \mu \mathrm{g} / \mathrm{L}$ \\
\hline \multirow{2}{*}{ Hill (1995) [147] } & 993 & \multirow{2}{*}{ USA NHANES III } & TCPy & $82 \%$ & Mean=4.5 $\mu \mathrm{g} / \mathrm{L} ; \mathrm{CAM}=3.1 \mu \mathrm{g} / \mathrm{g}$ \\
\hline & 980 & & PNP & $41 \%$ & Mean=1.6 $\mu \mathrm{g} / \mathrm{L}, \mathrm{CAM}=1.2 \mathrm{ug} / \mathrm{g}$ \\
\hline $\begin{array}{c}\text { Macintosh (2001) } \\
{[148]} \\
\end{array}$ & 80 & $\begin{array}{l}\text { NHEXAS- } \\
\text { Maryland }\end{array}$ & TCPy & $96 \%$ & $\mathrm{GM}=5.1 \mu \mathrm{g} / \mathrm{L} ; \mathrm{CAGM}=4.5 \mathrm{ug} / \mathrm{g}$ \\
\hline \multirow[b]{2}{*}{ Morgan 2005 [149] } & 128 & \multirow[b]{2}{*}{ Children } & TCP & NA & $\mathrm{GM}=5.2 \mathrm{ng} / \mathrm{ml} ;$ Mean=7.3 ng/ml \\
\hline & $\begin{array}{c}110 \\
\text { (Creatinine) } \\
\end{array}$ & & & & CAGM 8 ng/mg; CAM= 10.5 ng/mg \\
\hline $\begin{array}{c}\text { Naeher (2010) } \\
{[150]} \\
\end{array}$ & 203 & $\begin{array}{l}\text { Children } \\
\text { Age 4-6 } \\
\end{array}$ & 3-PBA & $99.5 \%$ & Mean=5.0 ug/L \\
\hline \multirow[t]{2}{*}{ Olsson (2003) [151] } & \multirow{2}{*}{140} & \multirow{2}{*}{ NA } & TCPy & $56 \%$ & $\mathrm{GM}=9.7 \mu \mathrm{g} / \mathrm{L}$ \\
\hline & & & PNP & $99 \%$ & $\mathrm{GM}=2.1 \mu \mathrm{g} / \mathrm{L}$ \\
\hline \multirow{3}{*}{$\begin{array}{l}\text { Panuwet (2008) } \\
\text { [51] }\end{array}$} & 136 & \multirow{3}{*}{$\begin{array}{l}\text { Thailand General } \\
\text { Population }\end{array}$} & PNP & $99.3 \%$ & $\mathrm{GM}=2.8 \mu \mathrm{g} / \mathrm{L} ; \mathrm{CAGM}=2.1 \mu \mathrm{g} / \mathrm{g}$ \\
\hline & 104 & & TCPy & $76.5 \%$ & $\mathrm{GM}=1.7 \mu \mathrm{g} / \mathrm{L} ; \mathrm{CAGM}=1.3 \mu \mathrm{g} / \mathrm{g}$ \\
\hline & 118 & & 3-PBA & $86.8 \%$ & $\mathrm{GM}=1.1 \mu \mathrm{g} / \mathrm{L} ; \mathrm{CAGM}=0.86 \mu \mathrm{g} / \mathrm{g}$ \\
\hline \multirow{6}{*}{$\begin{array}{c}\text { Panuwet (2009) } \\
\text { [114] }\end{array}$} & \multirow{6}{*}{207} & \multirow{6}{*}{$\begin{array}{l}\text { Thailand Age 12- } \\
13\end{array}$} & PNP & $98 \%$ & $\mathrm{GM}=2.68 \mathrm{ng} / \mathrm{ML} ; \mathrm{CAGM}=3.07 \mu \mathrm{g} / \mathrm{g}$ \\
\hline & & & & & $\mathrm{AM}=4.07 \mathrm{ng} / \mathrm{ml} ; \mathrm{CAAM}^{\mathrm{j}}=3.81 \mu \mathrm{g} / \mathrm{g}$ \\
\hline & & & TCPy & $92 \%$ & $\mathrm{GM}=2.35 \mathrm{ng} / \mathrm{ml} ; \mathrm{CAGM}=2.7 \mathrm{mg} / \mathrm{g}$ \\
\hline & & & & & $\mathrm{AM}=4.02 \mathrm{ng} / \mathrm{ml} ; \mathrm{CAAM}=3.74 \mathrm{mg} / \mathrm{g}$ \\
\hline & & & 3-PBA & $47 \%$ & $\mathrm{GM}=0.2 \mathrm{ng} / \mathrm{ml} ; \mathrm{CAGM}=0.23 \mu \mathrm{g} / \mathrm{g}$ \\
\hline & & & & & $\mathrm{AM}=1.0 \mathrm{ng} / \mathrm{ml} ; \mathrm{CAAM}=0.95 \mu \mathrm{g} / \mathrm{g}$ \\
\hline \multirow{3}{*}{$\begin{array}{c}\text { Steenland (2000) } \\
{[102]}\end{array}$} & 65 & $\begin{array}{c}\text { Termiticide } \\
\text { Applicator } \\
\text { (Recent App) } \\
\end{array}$ & TCPy & NA & Mean=629.5 $\mu \mathrm{g} / \mathrm{L} ; \mathrm{CAM}=331 \mu \mathrm{g} / \mathrm{g}$ \\
\hline & 40 & $\begin{array}{l}\text { Termiticide } \\
\text { Applicator }\end{array}$ & TCPy & NA & Mean= $119.0 \mu \mathrm{g} / \mathrm{L} ; \mathrm{CAM}=55 \mu \mathrm{g} / \mathrm{g}$ \\
\hline & 52 & $\begin{array}{c}\text { Non-Exposed } \\
\text { Control } \\
\end{array}$ & TCPy & & Mean=6.2 $\mu \mathrm{g} / \mathrm{L} ; \mathrm{CAM}=3 \mu \mathrm{g} / \mathrm{g}$ \\
\hline \multirow{4}{*}{$\begin{array}{c}\text { Ueyama (2009) } \\
\text { [152] }\end{array}$} & \multirow{2}{*}{448} & \multirow{2}{*}{$\begin{array}{c}\text { Japanese General } \\
\text { Population }\end{array}$} & 3-PBA & & $\mathrm{GM}=0.29 \mu \mathrm{g} / \mathrm{L} ; \mathrm{CAGM}=0.4 \mu \mathrm{g} / \mathrm{g}$ \\
\hline & & & & & $\mathrm{AM}=0.63 \mu \mathrm{g} / \mathrm{L} ; \mathrm{CAAM}=0.73 \mu \mathrm{g} / \mathrm{g}$ \\
\hline & \multirow{2}{*}{87} & \multirow{2}{*}{ Japanese Farmers } & & & $\mathrm{GM}=0.38 \mu \mathrm{g} / \mathrm{L} ; \mathrm{CAGM}=0.45 \mu \mathrm{g} / \mathrm{g}$ \\
\hline & & & & & $\mathrm{AM}=0.76 \mu \mathrm{g} / \mathrm{L} ; \mathrm{CAAM}=0.81 \mu \mathrm{g} / \mathrm{g}$ \\
\hline Ye (2008) [153] & 9778 & Mothers & TCPy & $100 \%$ & $\mathrm{GM}=1.2 \mu \mathrm{g} / \mathrm{L} ; \mathrm{CAGM}=1.9 \mu \mathrm{g} / \mathrm{g}$ \\
\hline
\end{tabular}

${ }^{\mathrm{a}}(\mathrm{n})=$ Number in Sample; ${ }^{\mathrm{b}}(\mathrm{DF})=$ Detection Frequency; ${ }^{\mathrm{C}}(\mathrm{GM})=$ Geometric Mean; ${ }^{\mathrm{d}}(\mu \mathrm{g} / \mathrm{L})=$ Micrograms per Liter; ${ }^{\mathrm{e}}(\mathrm{AM})=$ Arithmetic Mean; ${ }^{\mathrm{f}}(\mathrm{CAM})=$ CreatinineAdjusted Mean; ${ }^{\mathrm{g}}(\mu \mathrm{g} / \mathrm{g})$ = Micrograms per Gram; ${ }^{\mathrm{h}}(\mathrm{CAGM})=$ Creatinine-Adjusted GM; i $(\mathrm{NA})=$ Not Available; ${ }^{\mathrm{j}}(\mathrm{CAAM})=$ Creatinine-Adjusted AM 


\subsection{Biochemical Summary}

When examining significant alterations in overall biochemical concentrations across all three biomarkers, only two were significant: cholesterol and sodium.

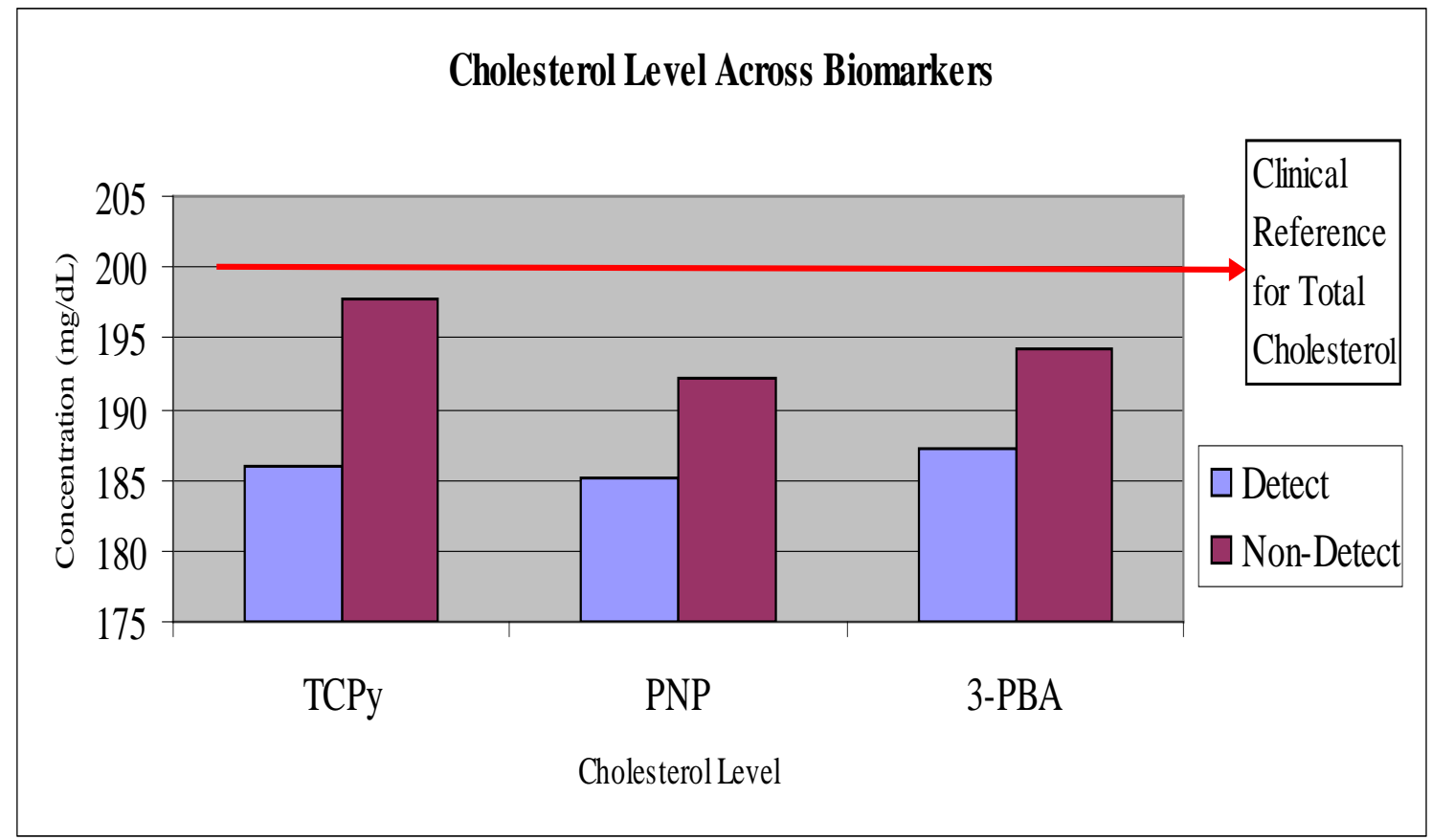

Figure 31: Overall Cholesterol Levels Across All Three Biomarkers. mg/dL= Milligram per Deciliter; TCPy= 3,5,6-Trichloropyridinol; PNP = Paranitrophenol; 3-PBA = 3Phenoxybenzoic Acid. The clinical reference for serum levels of cholesterol are $<200$ $\mathrm{mg} / \mathrm{dL}$ for desirable [154]. Borderline high is defined as $200-239 \mathrm{mg} / \mathrm{dL}$ [154]. 


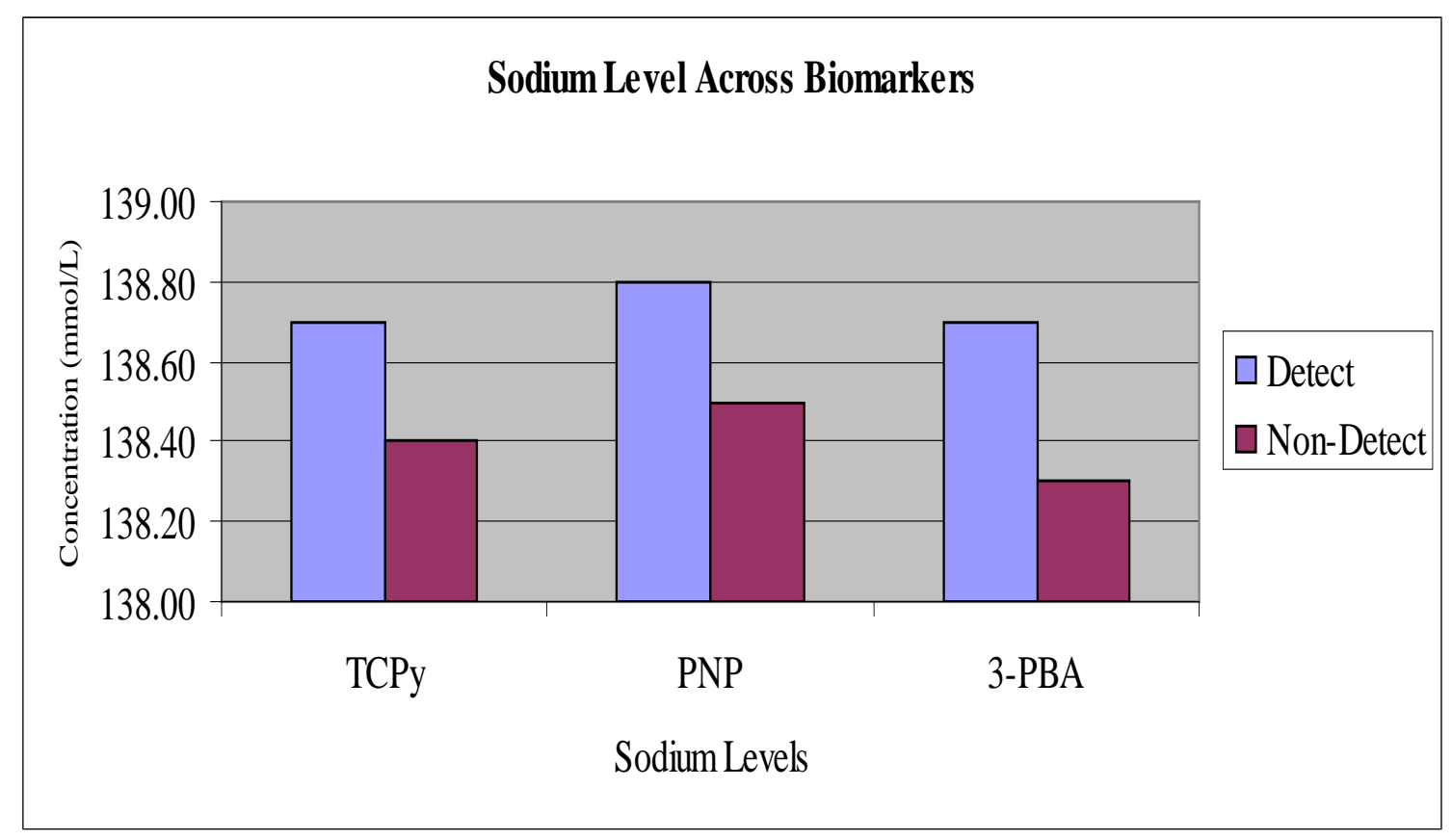

Figure 32: Overall Sodium Levels Across All Three Biomarkers. mmol/L= Millimole per Liter; TCPy= 3,5,6-Trichloropyridinol; PNP = Paranitrophenol; 3-PBA = 3-

Phenoxybenzoic Acid. The clinical reference range for serum sodium levels is 135-145 $\mathrm{mmol} / \mathrm{L}[154]$.

There were more significant findings when comparing the overall biochemical concentrations between the organophosphate pesticides: bicarbonate, cholesterol, osmolality and sodium. None of the significantly different levels were above clinical reference values [154].

Stratification for gender removes most of the consistent significant findings. The only gender specific significantly different biochemical concentrations across all three biomarkers was the cholesterol levels in females. 


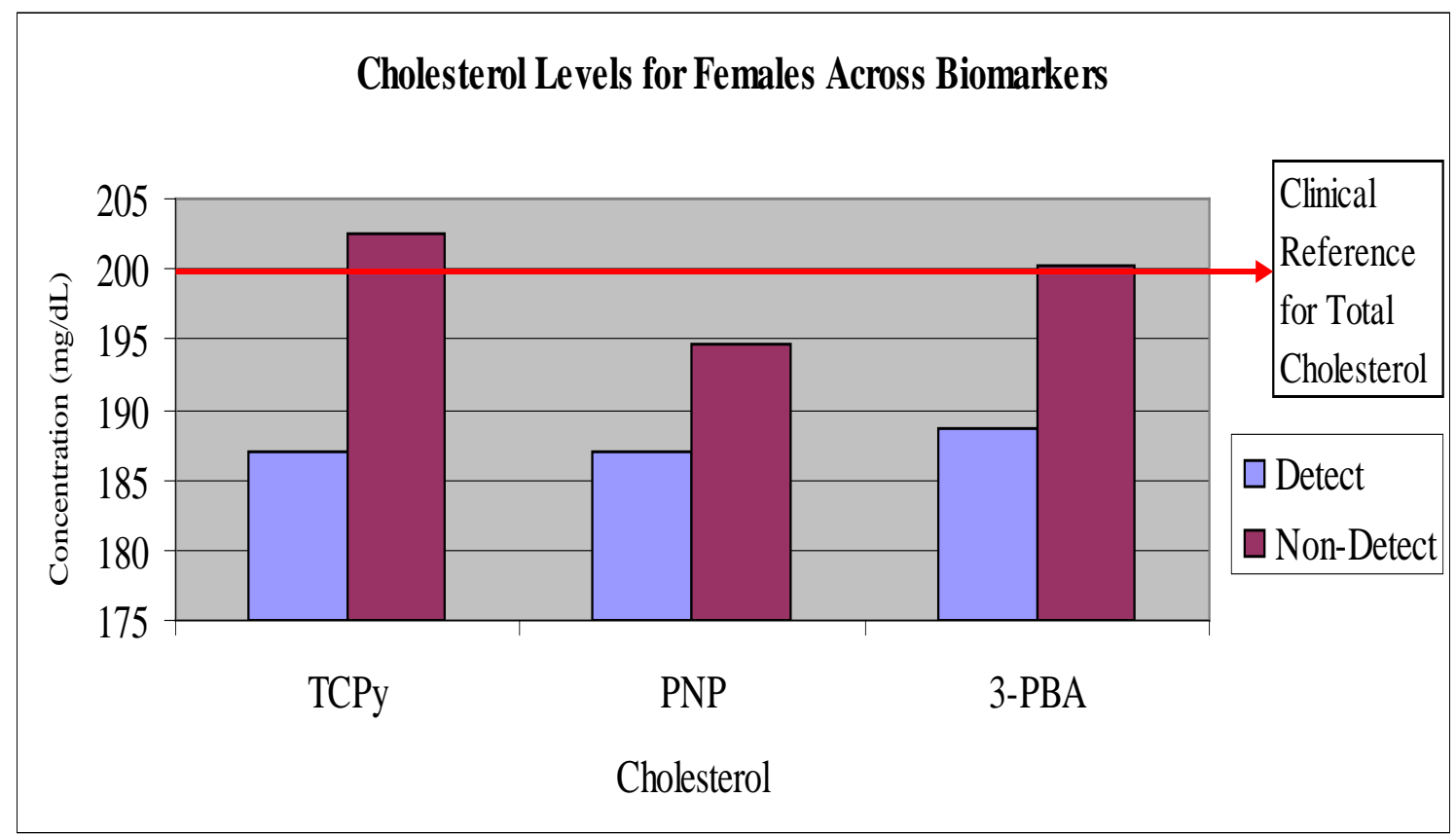

Figure 33: Female Cholesterol Levels Across All Three Biomarkers. mg/dL= Milligram per Deciliter; TCPy= 3,5,6-Trichloropyridinol; PNP = Paranitrophenol; 3-PBA = 3Phenoxybenzoic Acid. The clinical reference for serum levels of cholesterol are $<200$ $\mathrm{mg} / \mathrm{dL}$ for desirable [154]. Borderline high is defined as 200-239 mg/dL [154].

Males did not have a consistent significant alteration for biochemicals across the biomarkers. Differences were limited to a specific biochemical. 


\section{Chapter 5}

\section{Discussion}

\subsection{Evaluation of Research Hypotheses}

To determine how well the results of this study supported the overall goals of this research, the postulated hypotheses will be examined below:

Hypothesis 1: Biomonitoring data obtained from NHANES indicate the presence of background biomarkers of exposure in individuals from a sample of the general population.

Based on the analysis of the pesticide dataset, there is evidence that pesticide biomarkers are present in a sample of the US general population. However, significant findings varied when examining the biomarker in urine versus correcting for dilution with creatinine. Metabolism rates can vary among individuals [26, 128]. Dilution of urine may have an effect on the concentration of the biomarker. Creatinine adjustment has been used to normalize analyte concentrations due to the relatively constant excretion rate of creatinine, reporting the result as a weight of analyte per gram of creatinine [155]. Barr et al. (2005) suggests that there may be urine dilution variability between groups (gender, ethnicity and age) and suggests establishing and using reference ranges for creatinine concentrations for the individual being investigated, as those values may be a 
more appropriate comparison [155]. Analysis of both urinary biomarker level and creatinine-adjusted levels should be conducted to determine if significance is eliminated or elucidated due to the correction with creatinine, as observed with some groups in this study.

Hypothesis 2: Mean concentrations of biomarkers of exposure are homogeneous across the various subgroups of the sample indicating that no one subgroup is at an increased risk of an adverse health outcome.

Upon examining the mean concentrations of the biomarkers for various subgroups in the study, the mean concentrations are not homogeneous, at least on the surface. Certain groups have a significantly higher mean concentration of the biomarker than other groups. Variations in the mean concentrations for gender depended on whether or not the biomarker concentration in urine $(\mu \mathrm{g} / \mathrm{L})$ was used or whether it was corrected for dilution with creatinine $(\mu \mathrm{g} / \mathrm{g})$. Mean biomarker of exposure concentrations in ethnicity groups were consistently significantly varied. Non-Hispanic Blacks, followed by Mexican Americans, appeared to have significantly higher means than the other members of the group. Children and, in some cases, adolescents had significantly higher mean values as compared to adults. These variations could be due to the biological differences between children and adults, as children may metabolize xenobiotics at a different rate than adults [156-157]. Different rates of enzyme activity may also affect these results. Increased instances of hand-to-mouth and pica in children may also result in an increase in exposure and explain the findings in this research [108, 158-159]. 
Significant outcomes discovered in this research could be due to the oversampling of minorities by NHANES researchers in the sample. NHANES oversampled certain subgroups that were the target of a specific health interest [160]. In this study period, NHANES researchers oversampled "low-income persons, adolescents 12-19 years, persons 60+ years of age, African Americans and Mexican Americans” [131]. The survey oversampled to increase reliability and precision in the target population [160]. The NHANES documentation does not give a specific reason for not oversampling other subgroups (citing "cost prohibitive" or "operationally not feasible" as reasons) [160]. This oversampling of certain minority or at-risk groups can overestimate the true exposure. Significant means discovered in this data may be negated if the groups had not been given special focus.

If oversampling had not occurred, and/or if the unused weight supplied by the NHANES documentation for population-based analysis could accurately control for the oversampling, this significance may disappear and the groups may actually be homogenous for mean concentrations of biomarkers. When assessing the population, the results are viewed as non-random and over sampled. As the documentation for the NHANES data suggests, not using appropriate weights may lead to an over-estimate of actual exposure. If this is the case, these data may be viewed as overestimating the actual concentration of the biomarker when comparing to a population. The population levels may actually be lower. 
Hypothesis 3: Urine sample data from NHANES reveal that biomarker levels in the sample are not correlated with an increased risk of a negative health outcome.

Based on the overall results of this study, there were no consistent results to suggest that exposed individuals had an increased risk of a negative health outcome. When comparing the weight and height of study participants ages 6-11, those with a recorded biomarker detect versus non-detect, many of the comparisons were not significant, indicating that there was no appreciable difference between the exposed versus non-exposed. No significant results were found when evaluating these differences for 3,5,6-trichloropyridinol exposure. Paranitrophenol associated with shorter children at age 8 [Non-Detect $=134.3 \mathrm{~cm}$ and Detect: $130.9 \mathrm{~cm}(\mathrm{p}=0.046)$ ] and taller children at age 11 [Detect $=153.7 \mathrm{~cm}$ and Non-Detect $=149.9 \mathrm{~cm}(\mathrm{p}=0.022)]$. Heavier children associated with 3-Phenoxybenzoic Acid at age 7: [Detect=28.61 kg and Non-Detect=25.26 kg $(\mathrm{p}=0.009)]$. The significant findings are not consistent between all of the exposed groups. Out of the 36 height and weight comparisons made between detectable levels of biomarker and non-detectable levels, 33 did not have significant findings at the $\mathrm{p}<0.05$ level. It appears that exposure in this group of children does not have an overall negative association with childhood development. Similar comparisons have been made when evaluating biomarker levels in newborns with negative associations with birth outcomes [104, 107-108].

The biochemical concentrations evaluated in this research can be used to evaluate health status at the time of the sampling. Many of the comparisons were not statistically 
significant. For those levels that were significantly different, those groups with a detect for the biomarker were within the normal range. While stratification for gender further elucidated any statistical significance between those with a detectable level of the biomarker versus those without a detectable level, few alterations were consistent across all three biomarkers, or among the biomarkers themselves. The overall biochemical concentrations that had significant findings were cholesterol and sodium. In females, the only consistently significantly different biochemical concentration was cholesterol.

Overall, individuals that recorded a detect for the biomarker had a significantly lower cholesterol level than those without a detect. While establishing a causal relationship is difficult without further investigation, it is possible that those individuals that ate more agricultural commodities had a healthier diet than those that did not have a detect for the biomarker. If a major pathway of exposure to the general population is through the ingestion of residues on fruits and vegetables, then this conclusion may be plausible. However, like the assessment of the biomarkers, the biochemical concentrations are one point in time and do not give a trend to evaluate variations in the levels. Many factors can influence the status of biochemical levels on a physiological level and further research would be necessary to determine if there is a causal relationship [77].

The logistic regression performed in this study allowed for modeling to determine how the independent variables (age, ethnicity and gender) had an effect on the detection of the biomarkers in the sample. This was then used to determine, based on the detection, 
which groups had a higher correlation/odds of having a detect for a biomarker when related to a reference group. Unlike linear regression, logistic regression does not fully explain the variance of the data. Some groups within each biomarker had a significantly higher correlation and higher odds of having a detect. All models were significant; however, only 3,5,6-trichloropyridinol and 3-phenoxybenzoic acid were the regressions where the independent variables fit the model well. The independent variables did not fit well within the paranitrophenol model. The independent variables for ethnicity and gender in the 3,5,6-trichloropyridinol model reflected the actual odds ratios well. Gender consistency reflected the actual odds ratios for all models.

\subsection{Evaluation of Results}

Based on the information in Tables 43 and 44, the mean biomarker levels from this study are consistent with measurements of central tendency in other population and sample based research studies. Comparison to other studies can be difficult depending on the statistical test performed or the sample media used, and, as previously noted, creatinine concentrations can vary for a variety of biological reasons. The presentation of the data using multiple forms of descriptive and comparative statistics can make comparison to other studies more plausible.

Data from this NHANES dataset has been partially analyzed previously by Barr et al. in 2010 [64]. The study focused on 3-PBA and used data from both the 1999-2000 and 2001-2001 NHANES data. The study divided participants into only three ethnic groups (Non-Hispanic White, Non-Hispanic Black and Hispanic Americans). The Barr 
et al. study used the sample weights found in the NHANES dataset. Weighted geometric mean for the biomarker in urine was determined to be $0.318 \mu \mathrm{g} / \mathrm{L}$ and the creatinine adjusted geometric mean concentration was $0.324 \mu \mathrm{g} / \mathrm{g}$ [64]. Unweighted geometric means from the current research were $0.336 \mu \mathrm{g} / \mathrm{L}$ for the biomarker and $0.323 \mu \mathrm{g} / \mathrm{g}$ when correcting for creatinine. When comparing the data in this research to the Barr et al. study in which the various weights and unequal probabilities of selection as supplied in the NHANES data files were integrated into the analysis, the unadjusted results only overestimate the means by $0.018 \mu \mathrm{g} / \mathrm{L}$ for the biomarker in urine and $0.001 \mu \mathrm{g} / \mathrm{g}$ when adjusted for creatinine, suggesting that the results of the unadjusted data reflect the results of the complex study-designed data rather well.

Based on occupational studies, individuals working with pesticides had a chronic exposure and measurable levels of biomarker in their urine. The mean TCPy levels in the Albers et al. (2004) study were 100 times higher than the mean TCPy concentration found in the current research [101]. The overall lack of significant findings in the Albers et al. study suggest that the individuals in this sample are at less risk of a negative neurological outcome. In addition, the lack of consistency in the studies evaluating exposures and negative birth outcomes gives further support to the final hypothesis of this research. There does not appear to be a consistent correlation between the low-levels observed in this research and an increased risk of an adverse health effect. 


\subsection{Biomarker of Exposure Research}

As mentioned earlier in the literature review, epidemiological studies by Whyatt et al. (Columbia Study), Eskenazi et al. (CHAMACOS) and Berkowitz et al. (Mount Sinai Study) evaluated prenatal exposures to pesticides and negative birth outcomes [104, 107-108]. Results across these studies were not consistent. The Columbia Study indicated an association between chlorpyrifos exposure and reductions in birth weight and length [104]. Further analysis of the Columbia data by Rauh et al. suggested delays in neurodevelopment [105-106]. The studies by Eskenazi et al. and Berkowitz et al. did not find overall significant associations, and in some instances, some associations appeared to be protective [107-108].

Eaton et al., in a review of these studies, observed that other environmental factors, including tobacco and alcohol consumption, have been associated with negative birth outcomes in other studies and could have resulted in the negative outcomes discovered in the Columbia study [77]. While the cotinine levels of participants in the study were evaluated, the short half-life of the biomarker and the time of sample collection (after admission to the hospital) could have resulted in cotinine levels that underestimated actual exposure [77]. Additionally, alcohol consumption was self reported at the time of the interview and, while they were used as a covariate in the analysis in some part, underreporting of alcohol use could introduce bias into the evaluations. Another limitation of these studies is the use of TCPy as the specific biomarker for chlorpyrifos. It has been determined that chlorpyrifos-methyl is also a parent of this biomarker [77]. Degradation of the parent compound in the environment 
can also lead to TCPy exposure [148]. Because of the multiple sources of TCPy, the exposure to AChE inhibiting chlorpyrifos may be overestimated in certain instances. With regard to adverse health effects from prenatal exposure, Eaton et al. point out that scientific evidence does not suggest adverse neurodevelopment effects in infants from in utero dietary exposures to chlorpyrifos, if the neurodevelopment effects are from inhibition of AChE [77]. The article does point out that the results from studies finding associations cannot be ignored and further epidemiological investigation is warranted to fully elucidate the associations [77].

The studies evaluating developmental effects from prenatal pesticide exposure attempted to associate low-level exposures with the risk of a negative health outcome. The results are determined by a cross-sectional examination with simultaneous evaluation of both exposure and outcome. While this method may elucidate associations, these associations cannot be viewed as causal. No studies were identified that attempted to characterize exposure over a period of time (none more than a few days or multiple sampling events over a period of time) with negative health effects. A longitudinal prospective study may allow urinary biomarker concentrations to be better characterized. However, because other chemicals are capable of causing teratogenic and neurotoxic outcomes, controlling for the many covariates that are involved in everyday life may be difficult.

In recent evaluations of exposures to pesticides, an increased amount of consideration has been placed on the small number of human studies that found 
associations between prenatal pesticide exposures and negative birth outcomes, including those studies associating chlorpyrifos exposure and reductions in birth outcomes and cognitive abilities later in life. While chlorpyrifos is still applied on a limited number of agricultural commodities, no recent studies were identified that attempted to re-evaluate current chlorpyrifos exposures and negative health effects. Recently published articles appear to be based on original, decade-old cross-sectional data and use various analytical techniques and different covariates to determine if any associations can be found. Because chlorpyrifos is no longer registered for residential application, the current primary exposure route of exposure is oral. Previous studies included evaluation of cumulative exposures. If inhalation is no longer a viable exposure route for residential application (except for certain populations residing in close proximity to applications in agricultural scenarios), it would be expected that the current exposure is lower than those previously documented.

Many of the reviewed cross-sectional studies did not evaluate the dose that lead to the detection of the biomarkers in urine. A small sample of studies were identified that attempted to estimate dose based on urinary concentrations of pesticide biomarkers. Fenske et al. (2000) used a deterministic steady state model to estimate doses from urinary concentrations of non-specific OP biomarkers [162]. The spray season creatinine-adjusted dose estimated means were 2.4 to $3.8 \mu \mathrm{g} / \mathrm{kg} /$ day for children with a household relation working in the agricultural field and the single day dose estimated creatinine-adjusted means ranged from 2.5-4.0 $\mu \mathrm{g} / \mathrm{kg} /$ day [162]. A second study by Curwin et al. (2007) used a farming community and reference community in Iowa to 
estimate a maximum-likelihood geometric mean chlorpyrifos dose of $0.67 \mu \mathrm{g} / \mathrm{kg} / \mathrm{day}$ and a maximum dose estimate of $1.96 \mu \mathrm{g} / \mathrm{kg} /$ day [163]. The ATSDR exposure levels from Table 4 for chlorpyrifos put the acute and intermediate threshold dose at $3 \mu \mathrm{g} / \mathrm{kg} / \mathrm{day}$ and the chronic dose at $1 \mu \mathrm{g} / \mathrm{kg} /$ day. The average estimate of $0.67 \mu \mathrm{g} / \mathrm{kg} / \mathrm{day}$ from the Curwin et al. study is below the chronic threshold dose and the estimated maximum is lower than the acute and intermediate threshold. Because these are estimates, the actual exposed amount may be lower.

Biological Exposure Indices published by the ACGIH established thresholds for biomarkers in occupational settings [55]. However, there are no regulatory health-related thresholds for pesticide biomarkers of exposure in the general population. An attempt has been made by the German Human Biomonitoring Commission to establish a reference value $\left(\mathrm{RV}_{95}\right)$ from biomonitoring data [164]. Heudorf et al. (2006) reports on the use of biomonitoring data from a sample of the German population for non-specific OP biomarkers and biomarkers for pyrethroids [165]. A threshold value was established for 3-PBA and was set at $2 \mu \mathrm{g} / \mathrm{L}$ (for children age 3-14). The $\mathrm{RV}_{95}$ were statistically derived from the $95 \%$ percentile within the $95 \% \mathrm{CI}$, are not based on toxicological data and are not related to risk assessment [165]. Because these levels are statistically derived, they should not be used to evaluate adverse health effects from biomonitoring data [164-165]. The $R V_{95}$ is suggested to be used to determine if any one group or population is exposed to a higher degree than another population and to highlight populations for further evaluations where the biomarker levels are elevated. The mean value for children age 6-11 in this study fall below this value. 
Based on a Pubmed/Medline literature search, it appears research co-authored by Perera at the Columbia Center for Children's Environmental Health has focused on children's prenatal and postnatal exposure to various chemicals and the associated negative developmental outcomes. In addition to pesticides, research at the Columbia Center has associated negative birth outcomes with prenatal exposures to polychlorinated biphenyl ethers (PCBEs) and polycyclic aromatic hydrocarbons (PAHs) [166-167]. The research findings from the Columbia center suggest two possibilities: 1) that the researchers suffer from investigator bias, because they continue to find negative associations between exposure to a variety of chemicals and birth outcomes, or 2) that their research is supporting the fact that there are multiple confounding chemicals that should be considered when investigating negative outcomes and that attributing negative outcomes to pesticides alone is not warranted. It is the unknown exposures that hamper the establishment of causation in biomonitoring exposures scenarios.

\subsection{Evaluation of Risk}

The FQPA of 1996 required all routes of exposure to be taken into consideration when evaluating risk from a non-occupational exposure to pesticides [68]. This has resulted in the EPA publishing a guidance document on cumulative risk assessment for pesticides. The cumulative risk assessment makes the assumption that the pesticides included in the assessment have a common mechanism of toxicity [168]. Because biomonitoring is an assessment based on all routes of exposure, the cumulative risk assessment is the most appropriate assessment for the current studies researching cumulative exposure data. In 2006, the EPA published an updated cumulative risk 
assessment for OP pesticides (an update to the original CRA published in 2002) [169]. This assessment uses a relative potency factor (RPF) to determine joint risk associated with the exposure by using a reference chemical for comparing the toxicity of other OP pesticides [169]. The RPF is the ratio of the toxic potency of an OP to its index chemical (for the EPA CRA, the reference chemical is Methamidophos) [169]. This index pesticide is used to determine toxic potencies and used an exponential dose-response model to determine points of departure (POD) to extrapolate risk from an exposure in human populations [168]. The point of evaluation is the Benchmark Dose $\left(\mathrm{BMD}_{10}\right)$ in which $10 \%$ AChE inhibition takes place in the female rat brain from an oral exposure [169]. This leads to the determination of a Margin of Exposure (MOE). The target MOE is 100 for both one day acute exposure and for a 21 day rolling chronic exposure. The findings from the CRA conclude that:

"Taking all of these factors into account, EPA finds that there is a reasonable certainty of no harm to all major, identifiable population subgroups from cumulative exposure to the OPs" [169].

A recently published CRA for pyrethroids and pyrethrins finds that there are no cumulative estimated risks of concern [169]. These CRA are based on traditional outcomes from exposure to pesticides. For the pyrethroid CRA, deltametrhin was used as the index chemical [169]. The findings from these CRA are designed to be conservative estimates of risk. This conservative approach adds additional levels of safety into the findings of the assessments.

When reviewing the EPA Integrated Risk Information System (IRIS) database, it was observed that the previous Reference Dose (RfD) of $0.3 \mu \mathrm{g} / \mathrm{kg} /$ day for chlorpyrifos had been removed on March 24, 2011 [170]. The RfD remains for both MP and 
parathion. It was not clear why the RfD was removed. It may be because the RfD for chlorpyrifos is undergoing re-assessment based on the most recent risk assessment and Interim Registration Eligibility Decision (IRED). The Oral RfD for permethrin remains at $5.0 \times 10^{-2} \mathrm{mg} / \mathrm{kg} /$ day [171].

The data obtained from biomonitoring is difficult to relate to risk due to the lack of information on exposure pathway and source of exposure [30]. Information on dose, duration of the exposure, phenotypic and genotypic differences between individuals and the time of the exposure in relation to the biomarker's half-life are important to know when assessing toxicity [29]. However, this information is usually not available for large-scale biomonitoring programs and lack of such information can confound the results. The detection of a biomarker from a biomonitoring event does not mean that the exposed are at an increased risk [29]. There is a dose for a particular chemical at which there will not be an appreciable risk of an adverse health effect.

While various biomonitoring studies have evaluated the presence of biomarkers in biological media, many shy away from assessing risk and suggest that the results serve as a reference range and can be used to evaluate trends in public health [29, 145, 147]. However, previously mentioned studies have used biomonitoring data to form associations between low-level pesticides and negative birth outcomes. Statistically significant associations were observed in the reviewed epidemiological studies as well as in the current research. While associations may warrant further investigation, there are no known exposure factors in the current epidemiological biomonitoring studies that may 
allow the elucidation of causality. This research, like other cross-sectional research studies, evaluated the exposure and the outcome simultaneously. Without knowing all of the covariates involved in the exposure, it remains difficult to relate the biomarker concentration to a risk factor.

\subsection{Limitations of the Research}

It is unknown if the associations found in this research are causal based on the supplied information. A more accurate way to identify health risk would be a longitudinal study [29]. This would assist in establishing a temporal relationship. However, this design also has limitation beyond normal bias. The mechanism for the purported adverse health effects from chronic, low-level exposure, if it exists, is unknown and thus makes evaluating the dose-response relationship difficult.

Statistical comparisons were made in this research between detectable and nondetectable levels of biomarkers of exposure in urine. It is plausible that the individuals with a recorded non-detect were actually exposed, but those exposures were not detected due to the half-life of the biomarker and the laboratory limit of detection. This could have introduced misclassification bias into the research. However, this bias would be

expected in other epidemiological studies using the same criteria. The oversampling of certain subgroups may have introduced sampling bias into the analysis as well. 


\section{Chapter 6}

\section{Conclusion}

This research study used urinary biomarker of exposure levels from the 20012002 National Health and Nutrition Examination Survey (NHANES) national sampling event to determine if chronic, low-level exposure to pesticides can be associated with an appreciable increase in risk of an adverse health event. The research determined that there were detectable levels of pesticide biomarkers in the urine of individuals that participated in the study, and, depending on the dilution of the analyte concentration in

urine, certain subgroups had significantly higher means than others. Analysis of phenotypic variations in children and adolescents and biochemical concentrations across individuals in the study revealed significant differences, but the differences were not consistent across the biomarkers. Out of the 36 height and weight comparisons made between detectable levels of biomarker and non-detectable levels, 33 did not have significant findings, and two of the associations indicated that detection of a biomarker in urine was positively associated with the height and weight of children. Mean overall biomarker levels were consistent with other studies evaluating background levels of pesticides and the mean levels were lower than those in research that associated negative outcomes from exposure. In instances where significant differences between biochemical concentrations where found, the group with detectable levels of a biomarker did not exceed established clinical reference values. In fact, cholesterol levels for overall 
biomarker concentration and females were consistently and significantly lower than those with a non-detect for the biomarker.

As previously noted, based on the weight of evidence from the studies investigating low levels of biomarkers of exposure in biological media, there are not enough significant findings to conclude that these exposures would result in adverse health effects or increase the risk of such outcomes. While young individuals may be more sensitive to AChE inhibition from acute exposures, there is little evidence to suggest that the pesticides examined in this research bioaccumulate in any body compartment [75]. Metabolism and elimination of the parent compound and intermediates appears to occur quickly $[75,120]$.

Biomarker of exposure concentrations from national sampling events can be useful for establishing ranges of background exposures, but only if the data is unbiased. Oversampling of certain subpopulations can skew the results and give an inaccurate baseline for evaluation. Additionally, the physical sampling locations for the national sampling should be made available to determine if one area has an elevated exposure level as compared to another.

Any further studies investigating low-level pesticide exposures and neurodevelopment impairment should seek to further limit investigator bias that skews the research results. Conducting research with a pre-conceived notion that exposures to pesticides, and other chemicals, will be associated with negative outcomes can have an 
effect on results and can negatively influence any regulatory decisions based on those results.

Conclusions from this study are:

1. Biomarkers of exposure are present in a sample of the US population and certain subgroups have significantly higher geometric means than others.

2. Due to the cross-sectional nature of the data, there is no clear way of establishing causation based on the associations found.

3. Oversampling of certain at-risk groups may have skewed the findings in the research.

4. Evaluation of health status of the individuals in the sample does not indicate that there is an overall negative health impact associated with exposures. 


\section{References}

1) Delaplane, K. S., Pesticide usage in the United States: history, benefits, risks, and trends. Athens, GA: Cooperative Extension Service, The University of Georgia College of Agriculture and Environmental Sciences, 2000.

2) Unsworth, J., History of Pesticide Use.

http://agrochemicals.iupac.org/index.php?option=com_sobi2\&sobi2Task =sobi2Details\&catid=3\&sobi2Id=31, May 10, 2010.

3) Sachs, C. E., Growing Public Concern Over Pesticides in Food and Water. In The Pesticide Question: Environemnt, Economics and Ethics, Lehman, D. P. a. H., Ed. Chapmann and Hall: Ney York and London, 1993

4) Damalas, C. A., Understanding benefits and risks of pesticide use. Sci. Res. Essays 2009, 4, 945-949.

5) Boffey, P., 20 YEARS AFTER: 'SILENT SPRING': A Troubled Landscape. The New York Times, May 25, 1982.

6) Cowen, R. C., Tightening the lid on unproven chemicals. Christian Science Monitor, March 8, 1984.

7) Cox News Service, Criticism greets Bush’s pesticide plan. St. Petersburg Times (Florida), October 27, 1989.

8) Gold, A. R., Bush Would Change Rules On Regulation of Pesticides. The New York Times, October 26, 1989.

9) Mackerron C., C. B., EPA Zeros in on Pesticide Suspension. Chemical Week, August 3, 1989.

10) Hornblower, M., Pesticide Spraying on Nearby Farmlands Sickens Their Families, Housewives Say. The Washington Post, June 28, 1979.

11) AP, Albany Plan for Pesticide Warnings Is Criticized. The New York Times, November 15, 1987. 
12) Burros, M., U.S. Will Focus on Reducing Pesticides in Food Production. The New York Times, June 27, 1993.

13) Costa, L., Toxic Effects of Pesticides. In Casarett and Doull's toxicology: the basic science of poisons, Klaassen, C. D., Ed. McGraw-Hill: 2008.

14) Hillman, J., Insecticides. In Hamilton and Hardy's Industrial Toxicology, Harbison, R. D., Ed. Mosby: 1998.

15) EPA, Pesticide Industry Sales and Usage: 2006 and 2007 Market Estimates. http://www.epa.gov/pesticides/pestsales/07pestsales/market_estimates2007.pdf., 2011.

16) NPIRS, National Pesticide Information Retrieval System, Purdue University. http://ppis.ceris.purdue.edu/ , 2011.

17) Miller, M. L., Pesticides. In Environmental Law Handbook, 20th ed. / Thomas F.P. Sullivan, editor emeritus ; authors, Christopher L. Bell ... [et al.]. ed.; Bell, C. L.; Sullivan, T. F. P., Eds. Government Institutes: Lanham, Md, 2009

18) Toth, S.J., Federal Pesticide Laws and Regulations. North Carolina: North Carolina Cooperative Extension Service, North Carolina State University Extension Integrated Pest Management Program, 2000

19) Miller, T. A., Federal and state pesticide regulations and legislation. Annu Rev Entomol 1975, 20, 119-31.

20) USEPA, Summary of the Federal Food, Drug and Cosmetic Act. http://www.epa.gov/lawsregs/laws/ffdca.html, 2002.

21) Chaffey, C.; Dobozy, V., Regulation Under NAFTA. In Current toxicology series, Ballantyne, B.; Marrs, T. C., Eds. J. Wiley: Chichester, West Sussex, England ; Hoboken, N.J, 2004.

22) USEPA. FIFRA Statute, Regulations \& Enforcement http://www.epa.gov/oecaerth/civil/fifra/fifraenfstatreq.html, 2011.

23) USEPA. Federal Insecticide, Fungicide and Rodenticide Act (FIFRA) Enforcement. http://www.epa.gov/compliance/civil/fifra/index.html, 2011.

24) USEPA Implementation of Requirements undertThe Food Quality Protection Act (FQPA). http://www.epa.gov/pesticides/regulating/laws/fqpa/fqpa_implementation. htm, 2011. 
25) Harper, M., Assessing workplace chemical exposures: the role of exposure Journal of Environmental Monitoring 2004, 6 (5), 404-412.

26) Manno, M.; Viau, C.; Cocker, J.; Colosio, C.; Lowry, L.; Mutti, A.; Nordberg, M.; Wang, S., Biomonitoring for occupational health risk assessment (BOHRA). Toxicology Letters 2010, 192 (1), 3-16.

27) Cocker, J.; Mason, H. J.; Garfitt, S. J.; Jones, K., Biological monitoring of exposure to organophosphate pesticides. Toxicol Lett 2002, 134 (1-3), 97-103.

28) DeCaprio, A. P., Biomarkers: Coming of Age for Environmental Health and Risk Assessment. Environmental Science \& Technology 1997, 31 (7), 1837-1848.

29) Paustenbach, D.; Galbraith, D., Biomonitoring and biomarkers: exposure assessment will never be the same. Environmental Health Perspectives 2006, 114 (8), 1143-1149.

30) Albertini, R.; Bird, M.; Doerrer, N.; Needham, L.; Robison, S.; Sheldon, L.; Zenick, $\mathrm{H}$., The use of biomonitoring data in exposure and human health risk assessments. Environ Health Perspect 2006, 114 (11), 1755-62.

31) Biological markers in environmental health research. Committee on Biological Markers of the National Research Council. Environ Health Perspect 1987, 74, 39.

32) Paustenbach, D., Galbraith, D., Biomonitoring: Is body burden relevant to public health? Regulatory Toxicology and Pharmacology 2006, 44 (3), 249-261.

33) Angerer, J.; Aylward, L. L.; Hays, S. M.; Heinzow, B.; Wilhelm, M., Human biomonitoring assessment values: approaches and data requirements. Int J Hyg Environ Health 2011, 214 (5), 348-60.

34) Egeghy, P. P.; Cohen Hubal, E. A.; Tulve, N. S.; Melnyk, L. J.; Morgan, M. K.; Fortmann, R. C.; Sheldon, L. S., Review of Pesticide Urinary Biomarker Measurements from Selected US EPA Children's Observational Exposure Studies. International Journal of Environmental Research and Public Health 2011, 8 (5), 1727-1754.

35) Calafat, A. M.; Ye, X.; Silva, M. J.; Kuklenyik, Z.; Needham, L. L., Human exposure assessment to environmental chemicals using biomonitoring. Int $J$ Androl 2006, 29 (1), 166-71; discussion 181-5.

36) Hee, S. Q., Biological Monitoring: An Introduction. John Wiley \& Sons, Inc.: USA, 1993; $\mathrm{p} 653$. 
37) Castorina, R.; Bradman, A.; Fenster, L.; Barr, D. B.; Bravo, R.; Vedar, M. G.; Harnly, M. E.; McKone, T. E.; Eisen, E. A.; Eskenazi, B., Comparison of currentuse pesticide and other toxicant urinary metabolite levels among pregnant women in the CHAMACOS cohort and NHANES. Environ Health Perspect 2010, 118 (6), 856-63.

38) Mage, D. T.; Allen, R. H.; Gondy, G.; Smith, W.; Barr, D. B.; Needham, L. L., Estimating pesticide dose from urinary pesticide concentration data by creatinine correction in the Third National Health and Nutrition Examination Survey (NHANES-III). Journal of Exposure Analysis and Environmental Epidemiology 2004, 14 (6), 457-465.

39) Schulz, C.; Conrad, A.; Becker, K.; Kolossa-Gehring, M.; Seiwert, M.; Seifert, B., Twenty years of the German Environmental Survey (GerES): human biomonitoring--temporal and spatial (West Germany/East Germany) differences in population exposure. Int J Hyg Environ Health 2007, 210 (3-4), 271-97.

40) Lu, C.; Schenck, F. J.; Pearson, M. A.; Wong, J. W., Assessing Children’s Dietary Pesticide Exposure: Direct Measurement of Pesticide Residues in 24-Hr Duplicate Food Samples. Environmental Health Perspectives 2010, 118 (11), 1625-1630.

41) Ye, X.; Pierik, F. H.; Hauser, R.; Duty, S.; Angerer, J.; Park, M. M.; Burdorf, A.; Hofman, A.; Jaddoe, V. W.; Mackenbach, J. P.; Steegers, E. A.; Tiemeier, H.; Longnecker, M. P., Urinary metabolite concentrations of organophosphorous pesticides, bisphenol A, and phthalates among pregnant women in Rotterdam, the Netherlands: the Generation R study. Environ Res 2008, 108 (2), 260-7.

42) Curwin, B. D.; Hein, M. J.; Sanderson, W. T.; Barr, D. B.; Heederik, D.; Reynolds, S. J.; Ward, E. M.; Alavanja, M. C., Urinary and hand wipe pesticide levels among farmers and nonfarmers in Iowa. Journal of Exposure Analysis and Environmental Epidemiology 2005, 15 (6), 500-508.

43) Jaga, K.; Dharmani, C., Sources of exposure to and public health implications of organophosphate pesticides. Rev Panam Salud Publica 2003, 14 (3), 171-85.

44) Calvert, G. M.; Karnik, J.; Mehler, L.; Beckman, J.; Morrissey, B.; Sievert, J.; Barrett, R.; Lackovic, M.; Mabee, L.; Schwartz, A., Acute pesticide poisoning among agricultural workers in the United States, 1998-2005. American journal of industrial medicine 2008, 51 (12), 883-898.

45) USEPA Worker Safety and Training, http://www.epa.gov/pesticides/health/worker.htm, 2011.

46) NIOSH Pesticide Illness and Injury Surveillance, http://www.cdc.gov/niosh/topics/pesticides/, 2011. 
47) BOUCHARD, M., Biological Monitoring of Exposure to Organophosphorus Insecticides in a Group of Horticultural Greenhouse Workers. Annals of Occupational Hygiene 2006, 50 (5), 505-515.

48) NIOSH SENSOR- Pesticide Database, http://wwwn.cdc.gov/nioshsurvapps/sensor/. No Date Listed.

49) Geer, L.; Cardello, N.; Dellarco, M.; Leighton, T.; Zendzian, R.; Roberts, J.; Buckley, T., Comparative analysis of passive dosimetry and biomonitoring for assessing chlorpyrifos exposure in pesticide workers. Annals of Occupational Hygiene 2004, 48 (8), 683.

50) Damalas, C.A., I. G. E., Pesticide Exposure, Safety Issues, and Risk Assessment Indicators. International Journal of Environmental Research and Public Health 2011, 8 (5), 1402.

51) Panuwet, P.; Prapamontol, T.; Chantara, S.; Thavornyuthikarn, P.; Montesano, M. A.; Whitehead, R. D., Jr.; Barr, D. B., Concentrations of urinary pesticide metabolites in small-scale farmers in Chiang Mai Province, Thailand. Sci Total Environ 2008, 407 (1), 655-68.

52) DiNardi, S. R.; Association, A. I. H., The occupational environment: its evaluation, control, and management. AIHA Press (American Industrial Hygiene Association): 2003.

53) OSHA PEL, http://www.osha.gov/SLTC/pel/, 2006.

54) NIOSH Pocket Guide, http://www.cdc.gov/niosh/npg/pgintrod.html, 2010.

55) ACGIH 2011 TLVs and BEIs Resources. ACGIH (Cincinnati, Oh.): 2008.

56) Bouvier, G.; Seta, N.; Vigouroux-Villard, A.; Blanchard, O.; Momas, I., Insecticide Urinary Metabolites in Nonoccupationally Exposed Populations. Journal of Toxicology and Environmental Health Part B: Critical Reviews 2005, 8 (6), 485-512.

57) Bronstein M.D., A. C.; Spyker PH.D., D. A.; Cantilena JR, L. R.; Green PH.D., J. L.; Rumack M.D., B. H.; Giffin RN, S. L., 2008 Annual Report of the American Association of Poison Control Centers' National Poison Data System (NPDS): 26th Annual Report. Clinical Toxicology 2009, 47 (10), 911-1084.

58) Beamer, P. I.; Canales, R. A.; Bradman, A.; Leckie, J. O., Farmworker children\&apos;s residential non-dietary exposure estimates from micro-level activity time series. Environment International 2009, 35 (8), 1202-1209. 
59) Doherty, J. D., Screening Pesticides for Neuropathogenicity. Journal of Biomedicine and Biotechnology 2006, 2006.

60) Needham, L. L., Assessing Exposure to Organophosphorus Pesticides by Biomonitoring in Epidemiologic Studies of Birth Outcomes. Environmental Health Perspectives 2005, 113 (4), 494.

61) Adgate, J.L., et. al., Measurement of children's exposure to pesticides: analysis of urinary metabolite levels in a probability-based sample. Environmental Health Perspectives 2001, 109 (6), 583-590.

62) Lu, C.; Toepel, K.; Irish, R.; Fenske, R. A.; Barr, D. B.; Bravo, R., Organic diets significantly lower children's dietary exposure to organophosphorus pesticides. Environ Health Perspect 2006, 114 (2), 260-3.

63) Kimata, A.; Kondo, T.; Ueyama, J.; Yamamoto, K.; Yoshitake, J.; Takagi, K.; Suzuki, K.; Inoue, T.; Ito, Y.; Hamajima, N.; Kamijima, M.; Gotoh, M.; Shibata, E., Comparison of urinary concentrations of 3-phenoxybenzoic acid among general residents in rural and suburban areas and employees of pest control firms. International Archives of Occupational and Environmental Health 2009, 82 (10), 1173-1178.

64) Barr, D. B.; Olsson, A. O.; Wong, L.-Y.; Udunka, S.; Baker, S. E.; Whitehead, R. D.; Magsumbol, M. S.; Williams, B. L.; Needham, L. L., Urinary Concentrations of Metabolites of Pyrethroid Insecticides in the General U.S. Population: National Health and Nutrition Examination Survey 1999-2002. Environmental Health Perspectives 2010, 118 (6), 742-748.

65) Meeker, J. D.; Barr, D. B.; Hauser, R., Pyrethroid insecticide metabolites are associated with serum hormone levels in adult men. Reproductive Toxicology 2009, 27 (2), 155-160.

66) Marrs, T. C.; Ballantyne, B., Pesticides: An Overview of Fundamentals. Marrs, T. C.; Ballantyne, B., Eds. John Wiley \& Sons, Ltd. (UK): 2004; pp 1-26.

67) Morgan, M.; Sheldon, L.; Croghan, C., An observational study of 127 preschool children at their homes and daycare centers in Ohio: Environmental pathways to cis-and trans-permethrin exposure. Environmental ... 2007, 104 (2), 266-274.

68) USEPA, Food Quality Protection Act (FQPA), http://www.epa.gov/agriculture/lqpa.html, 2010. 
69) Hore, P.; Zartarian, V.; Xue, J.; Özkaynak, H.; Wang, S.-W.; Yang, Y.-C.; Chu, P.-L.; Sheldon, L.; Robson, M.; Needham, L.; Barr, D.; Freeman, N.;

Georgopoulos, P.; Lioy, P. J., Children's residential exposure to chlorpyrifos: Application of CPPAES field measurements of chlorpyrifos and TCPy within MENTOR/SHEDS-Pesticides model. Science of The Total Environment 2006, 366 (2-3), 525-537.

70) USPEA, Pesticides and Food: What the Pesticide Residue Limits are on Food, http://www.epa.gov/pesticides/food/viewtols.htm, 2011.

71) ATSDR, Minimal Risk Levels (MRLs), http://www.atsdr.cdc.gov/mrls/index.html, 2011.

72) COSTA, L., Current issues in organophosphate toxicology. Clinica Chimica Acta 2006, 366 (1-2), 1-13.

73) ATSDR Toxicological Profile: Chlorpyrifos, http://www.atsdr.cdc.gov/ToxProfiles/tp84.pdf, 1997.

74) ATSDR Toxicological Profile: Methyl Parathion, http://www.atsdr.cdc.gov/ToxProfiles/tp48.pdf, 2001.

75) Whyatt R. M., et. al.,Contemporary-use pesticides in personal air samples during pregnancy and blood samples at delivery among urban minority mothers and newborns. Environmental Health Perspectives 2003, 111 (5), 749.

76) Thompson, C.; Richardson, R., Pesticide Toxicology and International Regulation. Marrs, T. C.; Ballantyne, B., Eds. John Wiley \& Sons, Ltd. (UK): 2004; pp 89-128.

77) $\quad$ Eaton, D. L.; Daroff, R. B.; Autrup, H.; Bridges, J.; Buffler, P.; Costa, L. G.; Coyle, J.; McKhann, G.; Mobley, W. C.; Nadel, L.; Neubert, D.; SchulteHermann, R.; Spencer, P. S., Review of the toxicology of chlorpyrifos with an emphasis on human exposure and neurodevelopment. Crit Rev Toxicol 2008, 38 Suppl 2, 1-125.

78) Farahat, F. M.; Ellison, C. A.; Bonner, M. R.; McGarrigle, B. P.; Crane, A. L.; Fenske, R. A.; Lasarev, M. R.; Rohlman, D. S.; Anger, W. K.; Lein, P. J.; Olson, J. R., Biomarkers of chlorpyrifos exposure and effect in Egyptian cotton field workers. Environ Health Perspect 2011, 119 (6), 801-6.

79) Rubin, C.; Esteban, E.; Hill, R. H., Jr.; Pearce, K., Introduction--the methyl parathion story: a chronicle of misuse and preventable human exposure. Environ Health Perspect 2002, 110 Suppl 6, 1037-40. 
80) Jokanovic, M.; Stukalov, P. V.; Kosanovic, M., Organophosphate induced delayed polyneuropathy. Current Drug Targets-CNS \&amp;\# 38; Neurological Disorders 2002, 1 (6), 593-602.

81) Jokanovic, M.; Kosanovic, M.; Brkic, D.; Vukomanovic, P., Organophosphate induced delayed polyneuropathy in man: an overview. Clin Neurol Neurosurg 2011, 113 (1), 7-10.

82) Kamanyire, R., Organophosphate toxicity and occupational exposure. Occupational Medicine 2004.

83) Jokanović, M.; Kosanović, M., Neurotoxic effects in patients poisoned with organophosphorus pesticides. Environmental Toxicology and Pharmacology 2010, 29 (3), 195-201.

84) Yang, C.; Deng, J., Intermediate Syndrome Following Organophosphate Insecticide Poisoning. Journal of the Chinese Medical Association 2007, 70 (11), 467-472.

85) Doherty, J. D., Screening Pesticides for Neuropathogenicity. Journal of Biomedicine and Biotechnology, 2006.

86) Lotti, M., Low-level exposures to organophosphorus esters and peripheral nerve function. Muscle \&amp; Nerve 2002, 25 (4), 492-504.

87) Ray, D. E., Chronic effects of low level exposure to anticholinesterases--a mechanistic review. Toxicol Lett 1998, 102-103, 527-33.

88) Colosio, C.; Tiramani, M.; Maroni, M., Neurobehavioral effects of pesticides: state of the art. NeuroToxicology 2003, 24 (4-5), 577-591.

89) Alexander, B. H.; Burns, C. J.; Bartels, M. J.; Acquavella, J. F.; Mandel, J. S.; Gustin, C.; Baker, B. A., Chlorpyrifos exposure in farm families: Results from the farm family exposure study. Journal of Exposure Science and Environmental Epidemiology 2006, 16 (5), 447-456.

90) Chambers, J. E.; Boone, J. S.; Davis, M. K.; Moran, J. E.; Tyler, J. W., Assessing transferable residues from intermittent exposure to flea control collars containing the organophosphate insecticide chlorpyrifos. J Expo Sci Environ Epidemiol 2007, 17 (7), 656-66.

91) USEPA Office of Pesticides and Toxic Substances. Chlprpyrifos Interim Registration Eligibility Decision (IRED), http://www.epa.gov/oppsrrd1/REDs/chlorpyrifos_ired.pdf, 2006. 
92) Nolan, R. J.; Rick, D. L.; Freshour, N. L.; Saunders, J. H., Chlorpyrifos: pharmacokinetics in human volunteers. Toxicol Appl Pharmacol 1984, 73 (1), 815.

93) Timchalk, C.; Nolan, R.; Mendrala, A.; Dittenber, D.; Brzak, K.; Mattsson, J., A physiologically based pharmacokinetic and pharmacodynamic (PBPK/PD) model for the organophosphate insecticide chlorpyrifos in rats and humans.

Toxicological Sciences 2002, 66 (1), 34.

94) Smith, G.; Watson, B.; Fischer, F., Investigations of Dursban Insecticide. Metabolism of O, O-Diethyl O-3, 5, 6-Trichloro-2-pyridyl Phosphorothioate and 3, 5, 6-Trichloro-2-pyridinol in Plants. Journal of Agricultural and Food Chemistry 1967, 15 (5), 870-877.

95) Abdel-Rahman, A. A.; Blumenthal, G. M.; Abou-Donia, S. A.; Ali, F. A.; AbdelMonem, A.; Abou-Donia, M. B., Pharmacokinetic profile and placental transfer of a single intravenous injection of [14 C] chlorpyrifos in pregnant rats. Archives of Toxicology 2002, 76 (8), 452-459.

96) Timchalk, C.; Busby, A.; Campbell, J. A.; Needham, L. L.; Barr, D. B., Comparative pharmacokinetics of the organophosphorus insecticide chlorpyrifos and its major metabolites diethylphosphate, diethylthiophosphate and 3, 5, 6trichloro-2-pyridinol in the rat. Toxicology 2007, 237 (1-3), 145-157.

97) Corley, R. A.; Calhoun, L. L.; Dittenber, D. A.; Lomax, L. G.; Landry, T. D., Chlorpyrifos: a 13-week nose-only vapor inhalation study in Fischer 344 rats. Fundam Appl Toxicol 1989, 13 (3), 616-8.

98) Moser, V. C., Comparisons of the acute effects of cholinesterase inhibitors using a neurobehavioral screening battery in rats. Neurotoxicology and Teratology 1995, 17 (6), 617-625.

99) Breslin, W.; Liberacki, A.; Dittenber, D.; Quast, J., Evaluation of the developmental and reproductive toxicity of chlorpyrifos in the rat. Toxicological Sciences 1996, 29 (1), 119.

100) Capodicasa, E.; Scapellato, M. L.; Moretto, A.; Caroldi, S.; Lotti, M., Chlorpyrifos-induced delayed polyneuropathy. Arch Toxicol 1991, 65 (2), 150-5.

101) Albers, J. W.; Garabrant, D. H.; Schweitzer, S. J.; Garrison, R. P.; Richardson, R. J.; Berent, S., The effects of occupational exposure to chlorpyrifos on the peripheral nervous system: a prospective cohort study. Occup Environ Med 2004, 61 (3), 201-11. 
102) Steenland, K.; Dick, R. B.; Howell, R. J.; Chrislip, D. W.; Hines, C. J.; Reid, T. M.; Lehman, E.; Laber, P.; Krieg Jr, E. F.; Knott, C., Neurologic function among termiticide applicators exposed to chlorpyrifos. Environmental Health Perspectives 2000, 108 (4), 293.

103) Deacon, M. M.; Murray, J. S.; Pilny, M. K.; Rao, K. S.; Dittenber, D. A.; Hanley, T. R., Jr.; John, J. A., Embryotoxicity and fetotoxicity of orally administered chlorpyrifos in mice. Toxicol Appl Pharmacol 1980, 54 (1), 31-40.

104) Whyatt, R. M.; Rauh, V.; Barr, D. B.; Camann, D. E.; Andrews, H. F.; Garfinkel, R.; Hoepner, L. A.; Diaz, D.; Dietrich, J.; Reyes, A.; Tang, D.; Kinney, P. L.; Perera, F. P., Prenatal insecticide exposures and birth weight and length among an urban minority cohort. Environ Health Perspect 2004, 112 (10), 1125-32.

105) Rauh, V. A.; Garfinkel, R.; Perera, F. P.; Andrews, H. F.; Hoepner, L.; Barr, D. B.; Whitehead, R.; Tang, D.; Whyatt, R. W., Impact of Prenatal Chlorpyrifos Exposure on Neurodevelopment in the First 3 Years of Life Among Inner-City Children. PEDIATRICS 2006, 118 (6), e1845-e1859.

106) Rauh, V.; Arunajadai, S.; Horton, M.; Perera, F.; Hoepner, L.; Barr, D. B.; Whyatt, R., Seven-year neurodevelopmental scores and prenatal exposure to chlorpyrifos, a common agricultural pesticide. Environ Health Perspect 2011, 119 (8), 1196-201.

107) Eskenazi, B.; Harley, K.; Bradman, A.; Weltzien, E.; Jewell, N. P.; Barr, D. B.; Furlong, C. E.; Holland, N. T., Association of in utero organophosphate pesticide exposure and fetal growth and length of gestation in an agricultural population. Environ Health Perspect 2004, 112 (10), 1116-24.

108) Berkowitz, G. S.; Wetmur, J. G.; Birman-Deych, E.; Obel, J.; Lapinski, R. H.; Godbold, J. H.; Holzman, I. R.; Wolff, M. S., In utero pesticide exposure, maternal paraoxonase activity, and head circumference. Environ Health Perspect 2004, 112 (3), 388-91.

109) Garcia, S. J.; Abu-Qare, A. W.; Meeker-O'Connell, W. A.; Borton, A. J.; AbouDonia, M. B., Methyl parathion: a review of health effects. J Toxicol Environ Health B Crit Rev 2003, 6 (2), 185-210.

110) USEPA, Methyl Parathion Risk Management Decision, http://www.epa.gov/pesticides/factsheets/chemicals/mpfactsheet.htm, 2011.

111) Morgan, D. P.; Hetzler, H. L.; Slach, E. F.; Lin, L. I., Urinary excretion of paranitrophenol and alkyl phosphates following ingestion of methyl or ethyl parathion by human subjects. Archives of Environmental Contamination and Toxicology 1977, 6 (1), 159-173. 
112) Garcia-Repetto, R.; Martinez, D.; Repetto, M., Biodisposition study of the organophosphorus pesticide, methyl-parathion. Bulletin of Environmental Contamination and Toxicology 1997, 59 (6), 901-908.

113) Abu-Qare, A. W.; Abou-Donia, M. B., Urinary excretion of metabolites following a single dermal dose of [14C] methyl parathion in pregnant rats. Toxicology 2000, 150 (1-3), 119-127.

114) Panuwet, P.; Prapamontol, T.; Chantara, S.; Thavornyuthikarn, P.; Bravo, R.; Restrepo, P.; Walker, R. D.; Williams, B. L.; Needham, L. L.; Barr, D. B., Urinary Paranitrophenol, a Metabolite of Methyl Parathion, in Thai Farmer and Child Populations. Archives of Environmental Contamination and Toxicology 2009, 57 (3), 623-629.

115) Tian Y, Piao F, Xie X, et al..Dose-related effect of methyl-parathion on T cell subpopulations. Environ Sci 1997,5:169-175.

116) Rodnitzky, R. L.; Levin, H. S.; Morgan, D. P., Effects of ingested parathion on neurobehavioral functions. Clin Toxicol 1978, 13 (3), 347-59.

117) Crittenden, P. L.; Carr, R.; Pruett, S. B., Immunotoxicological assessment of methyl parathion in female B6C3F1 mice. J Toxicol Environ Health A 1998, 54 (1), 1-20.

118) Ruckart, P. Z.; Kakolewski, K.; Bove, F. J.; Kaye, W. E., Long-term neurobehavioral health effects of methyl parathion exposure in children in Mississippi and Ohio. Environ Health Perspect 2004, 112 (1), 46-51.

119) Gupta, R. C.; Rech, R. H.; Lovell, K. L.; Welsch, F.; Thornburg, J. E., Brain cholinergic, behavioral, and morphological development in rats exposed in utero to methylparathion. Toxicol Appl Pharmacol 1985, 77 (3), 405-13.

120) ATSDR Toxicological Profile: Pyrethrins and Pyrethroids, http://www.atsdr.cdc.gov/toxprofiles/tp155.pdf, 2003.

121) Ray, D., Toxicology of Pyrethroids and Synethitic Pyrethroids. Marrs, T. C.; Ballantyne, B., Eds. John Wiley \& Sons, Ltd. (UK): 2004; pp 129-158.

122) Heudorf, U.; Butte, W.; Schulz, C.; Angerer, J., Reference values for metabolites of pyrethroid and organophosphorous insecticides in urine for human biomonitoring in environmental medicine. Int J Hyg Environ Health 2006, 209 (3), 293-9.

123) Leng, G.; Gries, W.; Selim, S., Biomarker of pyrethrum exposure. Toxicology Letters 2006, 162 (2-3), 195-201. 
124) Nasuti, C.; Cantalamessa, F.; Falcioni, G.; Gabbianelli, R., Different effects of Type I and Type II pyrethroids on erythrocyte plasma membrane properties and enzymatic activity in rats. Toxicology 2003, 191 (2-3), 233-244.

125) Schettgen, T.; Heudorf, U.; Drexler, H., Pyrethroid exposure of the general population--is this due to diet. Toxicology Letters 2002, 134 (1-3), 141-145.

126) Fortin, M.-C.; Carrier, G.; Bouchard, M., Concentrations versus amounts of biomarkers in urine: a comparison of approaches to assess pyrethroid exposure. Environmental Health 2008, 7 (1), 55.

127) Xia, Y.; Han, Y.; Wu, B.; Wang, S.; Gu, A.; Lu, N.; Bo, J., The relation between urinary metabolite of pyrethroid insecticides and semen quality in humans. Fertility and sterility 2008.

128) Egeghy, P. P.; Cohen Hubal, E. A.; Tulve, N. S.; Melnyk, L. J.; Morgan, M. K.; Fortmann, R. C.; Sheldon, L. S., Review of Pesticide Urinary Biomarker Measurements from Selected US EPA Children's Observational Exposure Studies. International Journal of Environmental Research and Public Health 2011, 8 (5), 1727-1754.

129) Leng, G.; Leng, A.; Kuhn, K. H.; Lewalter, J.; Pauluhn, J., Human dose-excretion studies with the pyrethroid insecticide cyfluthrin: urinary metabolite profile following inhalation. Xenobiotica 1997, 27 (12), 1273-83.

130) Quiros-Alcala, L.; Bradman, A.; Nishioka, M.; Harnly, M. E.; Hubbard, A.; McKone, T. E.; Ferber, J.; Eskenazi, B., Pesticides in house dust from urban and farmworker households in California: an observational measurement study. Environ Health 2011, 10, 19.

131) Hardt, J.; Angerer, J., Biological monitoring of workers after the application of insecticidal pyrethroids. Int Arch Occup Environ Health 2003, 76 (7), 492-8.

132) Parker, C. M.; Piccirillo, V. J.; Kurtz, S. L.; Garner, F. M.; Gardiner, T. H.; Van Gelder, G. A., Six-month feeding study of fenvalerate in dogs. Fundam Appl Toxicol 1984, 4 (4), 577-86.

133) Crofton, K. M.; Reiter, L. W., The effects of type I and II pyrethroids on motor activity and the acoustic startle response in the rat. Fundam Appl Toxicol 1988, 10 (4), 624-34.

134) Schoenig, G., Mamallian Toxicity of Pyrethrim Extract In Pyrethrum flowers : production, chemistry, toxicology, and uses, Casida, J. E.; Quistad, G. B., Eds. Oxford University Press: Oxford [England] ; New York, 1995; pp 249-257. 
135) Gupta, P. K., Tertaogenic Effects of Cypermethrin in Rats. Journal of

Environmental Biology 1990, 11 (2), 121-126.

136) CDC, National Health and Nutrition Examination Survey: History, http://www.cdc.gov/nchs/nhanes/history.htm, 2011.

137) Analytical Reporting Guidelines: NHANES, http://www.cdc.gov/nchs/data/nhanes/nhanes_03_04/nhanes_analytic_guidelines dec_2005.pdf, 2005.

138) NHANES 2001-2002 Frequently Asked Questions, http://www.cdc.gov/nchs/nhanes/nhanes2001-2002/nhanes01_02faqs.htm, 2011.

139) NHANES 2001-2002 Documentation, Codebook and Frequencies: Urinary Priority pesticides, http://www.cdc.gov/nchs/nhanes/nhanes20012002/l26PP_B.htm, 2012.

140) Kieszak, S. M.; Naeher, L. P.; Rubin, C. S.; Needham, L. L.; Backer, L.; Barr, D.; McGeehin, M., Investigation of the relation between self-reported food consumption and household chemical exposures with urinary levels of selected nonpersistent pesticides. J Expo Anal Environ Epidemiol 2002, 12 (6), 404-8.

141) Whyatt, R. M.; Garfinkel, R.; Hoepner, L. A.; Andrews, H.; Holmes, D.; Williams, M. K.; Reyes, A.; Diaz, D.; Perera, F. P.; Camann, D. E.; Barr, D. B., A biomarker validation study of prenatal chlorpyrifos exposure within an inner-city cohort during pregnancy. Environ Health Perspect 2009, 117 (4), 559-67.

142) Elfman, L.; Hogstedt, C.; Engvall, K.; Lampa, E.; Lindh, C. H., Acute Health Effects on Planters of Conifer Seedlings Treated with Insecticides. Annals of Occupational Hygiene 2009, 53 (4), 383-390.

143) Aprea, C.; Sciarra, G.; Sartorelli, P.; Ceccarelli, F.; Centi, L., Multiroute exposure assessment and excretion of urinary metabolites of fenitrothion during manual operations on treated ornamental plants in greenhouses. Archives of Environmental Contamination and Toxicology 1999, 36 (4), 490-497.

144) Arcury, T. A.; Grzywacz, J. G.; Barr, D. B.; Tapia, J.; Chen, H.; Quandt, S. A., Pesticide Urinary Metabolite Levels of Children in Eastern North Carolina Farmworker Households. Environmental Health Perspectives 2007, 115 (8), 1254-1260.

145) Barr, D. B.; Allen, R.; Olsson, A. O.; Bravo, R.; Caltabiano, L. M.; Montesano, A.; Nguyen, J.; Udunka, S.; Walden, D.; Walker, R. D.; Weerasekera, G.; Whitehead Jr., R. D.; Schober, S. E.; Needham, L. L., Concentrations of selective metabolites of organophosphorus pesticides in the United States population. Environmental Research 2005, 99 (3), 314-326. 
146) Berger-Preiss, E.; Levsen, K.; Leng, G.; Idel, H.; Sugiri, D.; Ranft, U., Indoor pyrethroid exposure in homes with woollen textile floor coverings. International Journal of Hygiene and Environmental Health 2002, 205 (6), 459-472.

147) Hill, R., Pesticide Residues in Urine of Adults Living in the United States: Reference Range Concentrations. Environmental Research 1995, 71 (2), 99-108.

148) MacIntosh, D. L.; Kabiru, C. W.; Ryan, P. B., Longitudinal investigation of dietary exposure to selected pesticides. Environ Health Perspect 2001, 109 (2), 145-50.

149) Morgan, M. K.; Sheldon, L. S.; Croghan, C. W.; Jones, P. A.; Robertson, G. L.; Chuang, J. C.; Wilson, N. K.; Lyu, C. W., Exposures of preschool children to chlorpyrifos and its degradation product 3,5,6-trichloro-2-pyridinol in their everyday environments. J Expo Anal Environ Epidemiol 2005, 15 (4), 297-309.

150) Naeher, L. P.; Tulve, N. S.; Egeghy, P. P.; Barr, D. B.; Adetona, O.; Fortmann, R. C.; Needham, L. L.; Bozeman, E.; Hilliard, A.; Sheldon, L. S., Organophosphorus and pyrethroid insecticide urinary metabolite concentrations in young children living in a southeastern United States city. Science of the Total Environment, The 2010, 408 (5), 1145-1153.

151) Olsson, A. O.; Nguyen, J. V.; Sadowski, M. A.; Barr, D. B., A liquid chromatography/electrospray ionization?tandem mass spectrometry method for quantification of specific organophosphorus pesticide biomarkers in human urine. Analytical and Bioanalytical Chemistry 2003, 376 (6), 808-815.

152) Ueyama, J.; Kimata, A.; Kamijima, M.; Hamajima, N.; Ito, Y.; Suzuki, K.; Inoue, T.; Yamamoto, K.; Takagi, K.; Saito, I.; Miyamoto, K.-i.; Hasegawa, T.; Kondo, T., Urinary excretion of 3-phenoxybenzoic acid in middle-aged and elderly general population of Japan. Environmental Research 2009, 109 (2), 175-180.

153) X.; Pierik, F. H.; Hauser, R.; Duty, S.; Angerer, J.; Park, M. M.; Burdorf, A.; Hofman, A.; Jaddoe, V. W.; Mackenbach, J. P.; Steegers, E. A.; Tiemeier, H.; Longnecker, M. P., Urinary metabolite concentrations of organophosphorous pesticides, bisphenol A, and phthalates among pregnant women in Rotterdam, the Netherlands: the Generation R study. Environ Res 2008, 108 (2), 260-7.

154) Mayo Clinic: Mayo Medical laboratories Rochester 2012 Interpretative Handbook. http://www.mayomedicallaboratories.com/testcatalog/pod/MayoTestCatalog-Rochester--SortedByTestName-duplexinterpretive.pdf , 2012. 
155) Barr, D. B.; Wilder, L. C.; Caudill, S. P.; Gonzalez, A. J.; Needham, L. L.; Pirkle, J. L., Urinary creatinine concentrations in the U.S. population: implications for urinary biologic monitoring measurements. Environ Health Perspect 2005, 113 (2), 192-200.

156) Pesticides in the Diets of Infants and Children; Council, N. R., Pesticides in the Diets of Infants and Children. The National Academies Press: 1993.

157) Wasley, A.; Lepine, L. A.; Jenkins, R.; Rubin, C., An investigation of unexplained infant deaths in houses contaminated with methyl parathion. Environ Health Perspect 2002, 110 Suppl 6, 1053-6.

158) Paustenbach, D. J., The practice of exposure assessment: a state-of-the-art review. Journal of Toxicology and Environmental Health, Part B 2000, 3 (3), 179-291.

159) Morgan, M.; Sheldon, L.; Croghan, C., An observational study of 127 preschool children at their homes and daycare centers in Ohio: Environmental pathways to cis-and trans-permethrin exposure. Environmental ... 2007, 104 (2), 266-274.

160) NHANES Web Tutorial Frequently Asked Questions, http://www.cdc.gov/nchs/tutorials/nhanes/faqs.htm, 2010.

161) NHANES 2001-2002 Public Data General Release File Documentation. http://www.cdc.gov/nchs/data/nhanes/nhanes_01_02/general_data_release_doc.pd f. No Date Listed.

162） Fenske, R. A.; Kissel, J. C.; Lu, C.; Kalman, D. A.; Simcox, N. J.; Allen, E. H.; Keifer, M. C., Biologically based pesticide dose estimates for children in an agricultural community. Environ Health Perspect 2000, 108 (6), 515-20.

163) Curwin, B. D.; Hein, M. J.; Sanderson, W. T.; Striley, C.; Heederik, D.; Kromhout, H.; Reynolds, S. J.; Alavanja, M. C., Pesticide dose estimates for children of Iowa farmers and non-farmers. Environ Res 2007, 105 (3), 307-15.

164) Schulz, C.; Wilhelm, M.; Heudorf, U.; Kolossa-Gehring, M., Update of the reference and HBM values derived by the German Human Biomonitoring Commission. Int J Hyg Environ Health 2011, 215 (1), 26-35.

165) Heudorf, U.; Butte, W.; Schulz, C.; Angerer, J., Reference values for metabolites of pyrethroid and organophosphorous insecticides in urine for human biomonitoring in environmental medicine. Int J Hyg Environ Health 2006, 209 (3), 293-9.

166) Tang, D.; Li, T. Y.; Liu, J. J.; Chen, Y. H.; Qu, L.; Perera, F., PAH-DNA adducts in cord blood and fetal and child development in a Chinese cohort. Environ Health Perspect 2006, 114 (8), 1297-300. 
167) Herbstman, J. B.; Sjodin, A.; Kurzon, M.; Lederman, S. A.; Jones, R. S.; Rauh, V.; Needham, L. L.; Tang, D.; Niedzwiecki, M.; Wang, R. Y.; Perera, F., Prenatal exposure to PBDEs and neurodevelopment. Environ Health Perspect 2010, 118 (5), 712-9.

168) USEPA, Cumulative Risk Assessment Methods and Tools, http://www.epa.gov/oppsrrd1/cumulative/methods_tools.htm, 2011.

169) USEPA, Common Mechanism Groups; Cumulative Exposure and Risk Assessment, http://www.epa.gov/oppsrrd1/cumulative/common_mech_groups.htm\#op, 2012.

170) USEPA Integrated Risk Information System: Chlorpyrifos, http://www.epa.gov/iris/subst/0026.htm\#reforal, 2011.

171) USEPA Integrated Risk Information System: Permethrin, http://www.epa.gov/iris/subst/0185.htm, 2011. 


\begin{abstract}
About the Author
Mr. Alex LeBeau graduated with a Bachelors of Science in Animal Science from the University of Florida College of Agriculture and Life Sciences (2001) and a Masters of Public Health in Toxicology and Risk Assessment from the University of South Florida College of Public Health (2007). In 2008, the Department of Environmental and Occupational Health at the University of South Florida's College of Public Health accepted Mr. LeBeau into the doctoral program. His degree program focused primarily on toxicology and risk assessment. Mr. LeBeau has participated in research designed to attenuate hepatotoxicity resulting from exposures to industrial solvents and pharmacological agents. Since 2007, he has worked as an environmental consultant.
\end{abstract}

